\title{
BRINGING
}

THE GERMAN

PAVILION

BACK HOME

Jessica Wright

Supervisor: Peter Wood 


\section{BRINGING THE GERMAN PAVILION BACK HOME}

BY

JESSICA WRIGHT

A 120-point thesis

submitted to the Victoria University of Wellington in partial fulfilment of the requirements for the degree of Master of Architecture (Professional)

Victoria University of Wellington

School of Architecture 
Geometrical analysis of the implications of perspectival space in the work of Mies van der Rohe. 
My whole work started with this image -

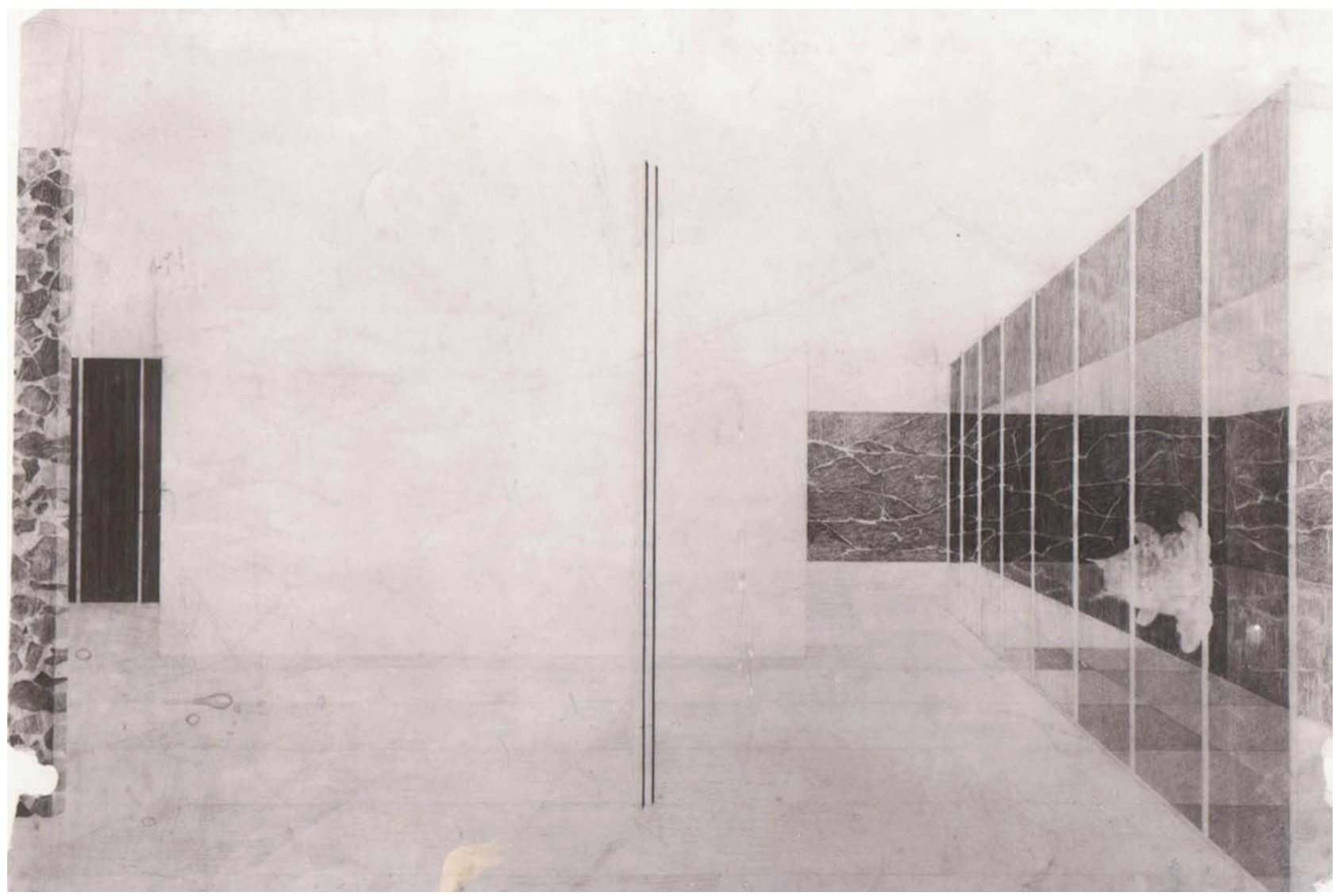

Figure 0.01 Mies van der Rohe's German Pavilion, International Exposition, Barcelona, Spain. Interior Perspective, c. 1928-29. Graphite on illustration board. MoMA Mies van der Rohe Archive. (C) 2013 Artists Rights Society (ARS), New York / VG Bild-Kunst, Bonn (Luscombe, 211 ). 


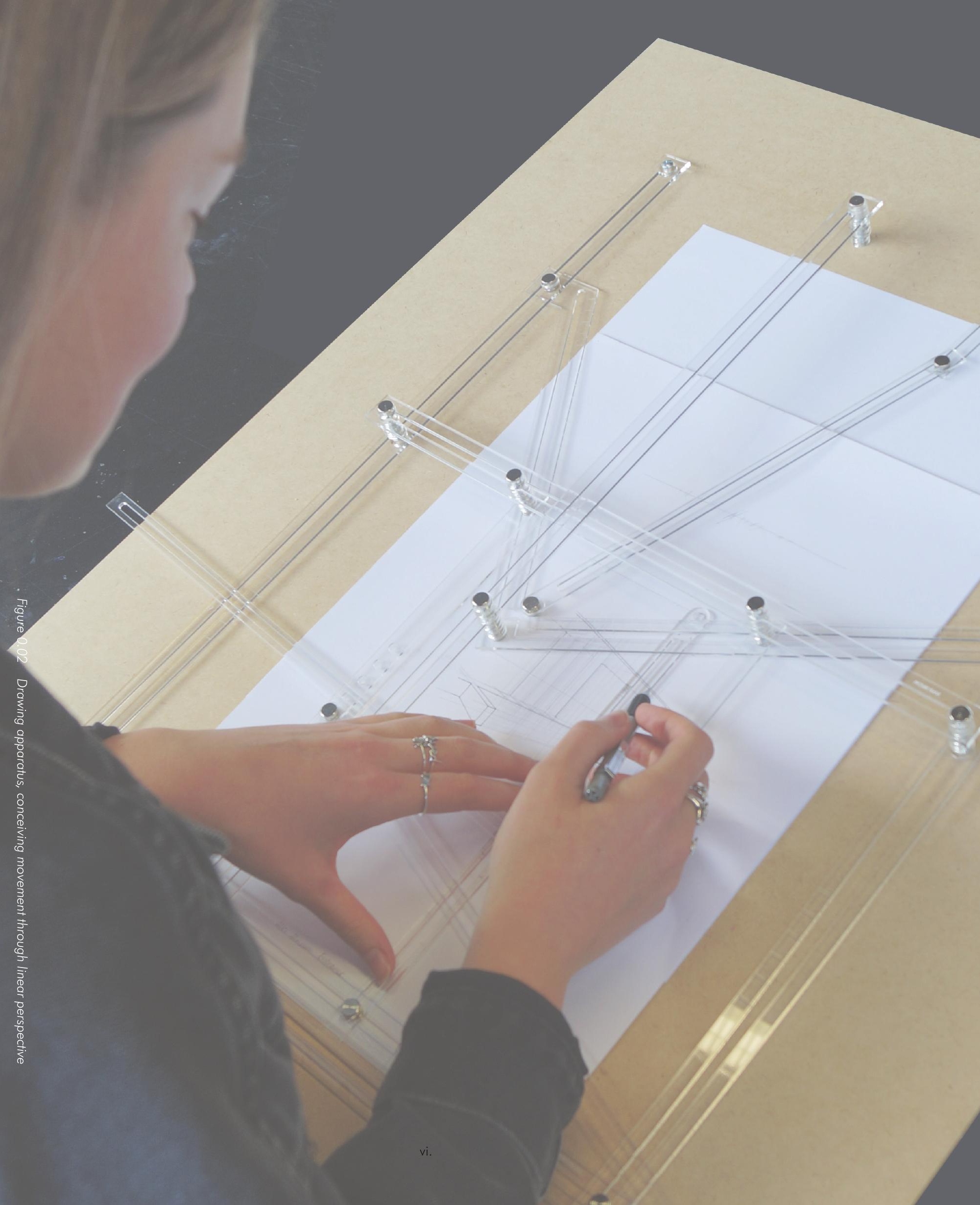


What if the representation of conventional architecture could benefit from a new way of drawing linear perspective? 


\section{ACKNOWLEDGEMENTS}

I dedicate this thesis to my Grandad.

Who called me Jessica Amy 'Archie', because of my love for architecture, and who always told me he believed in me.

Thank you to my parents Richard and Chrissie, for your endless support and words of encouragement, and to my amazing year group for making my five years at University such memorable ones.

Thank you to my supervisor Peter Wood, for your confidence, and words of wisdom and reassurance.

This year has even further solidified my passion for architecture, and has taught me to believe in myself and to trust my eye. 


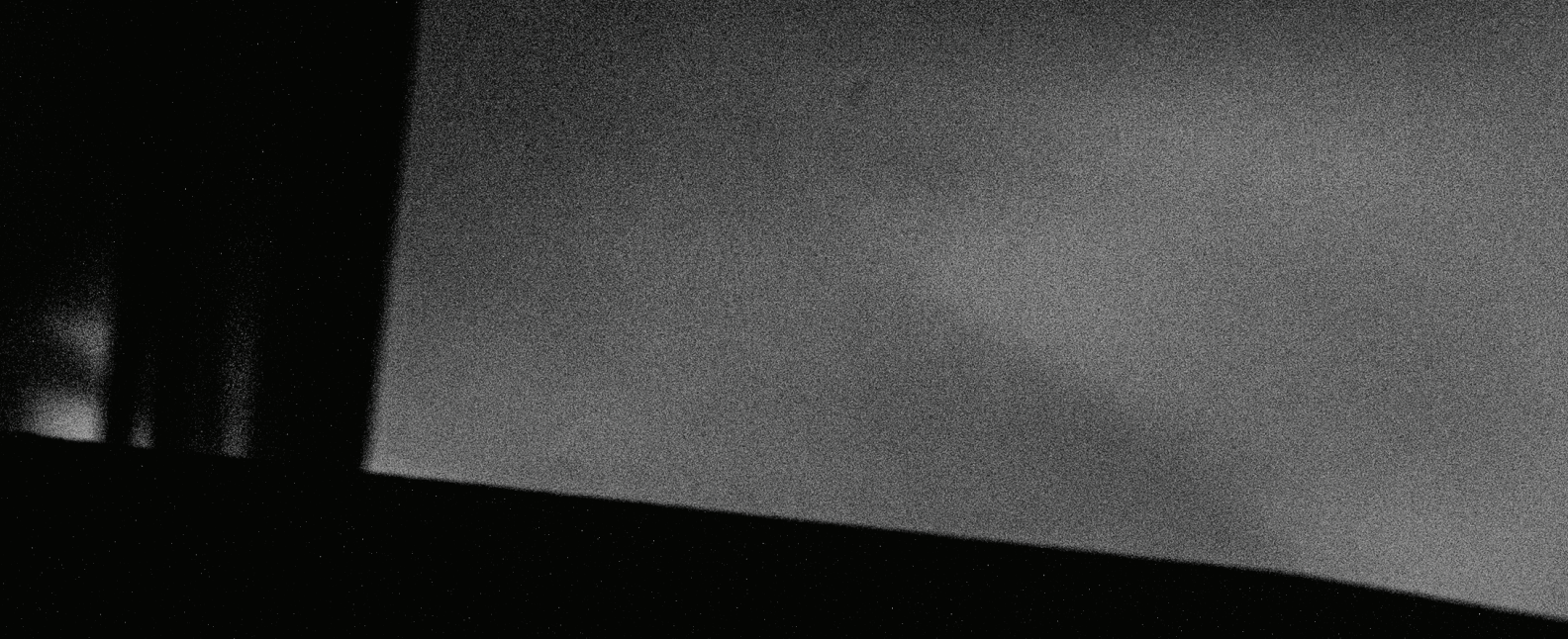

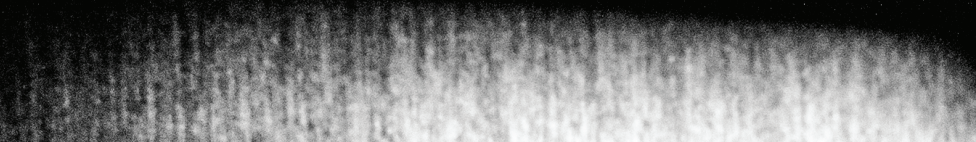

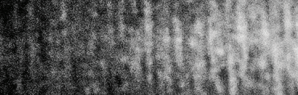

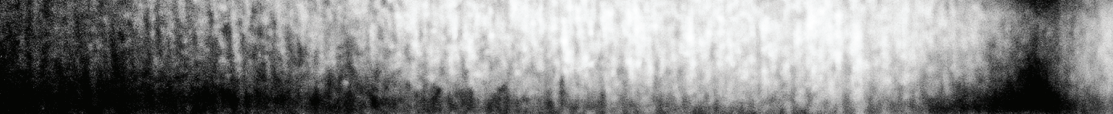

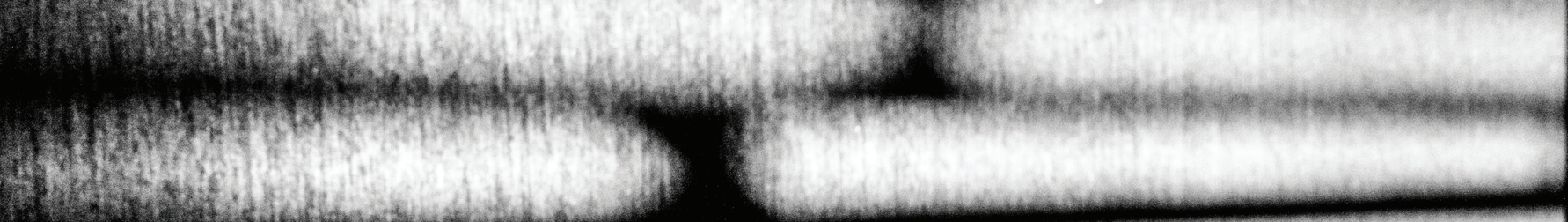

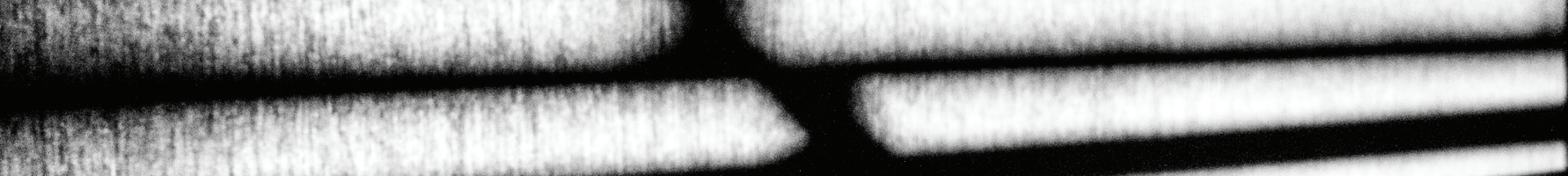

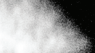

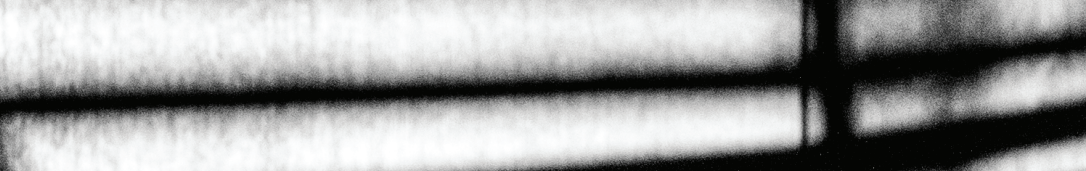
ay)

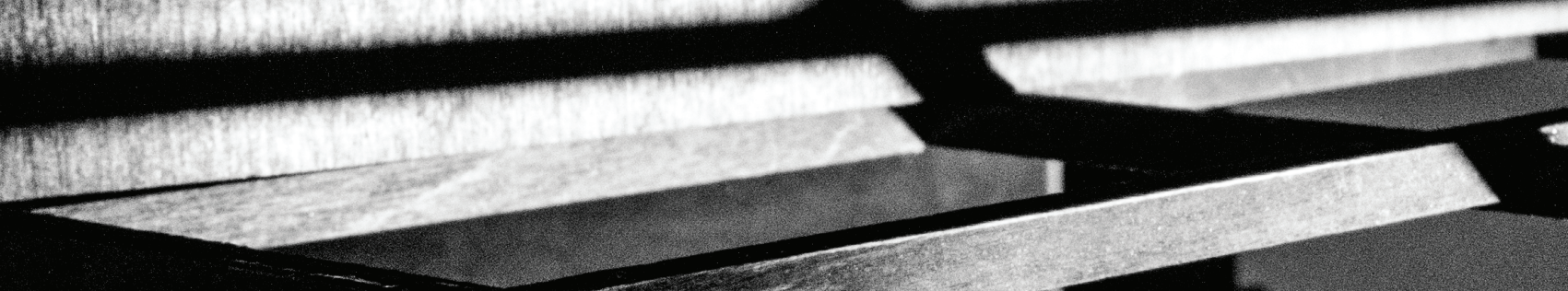

5
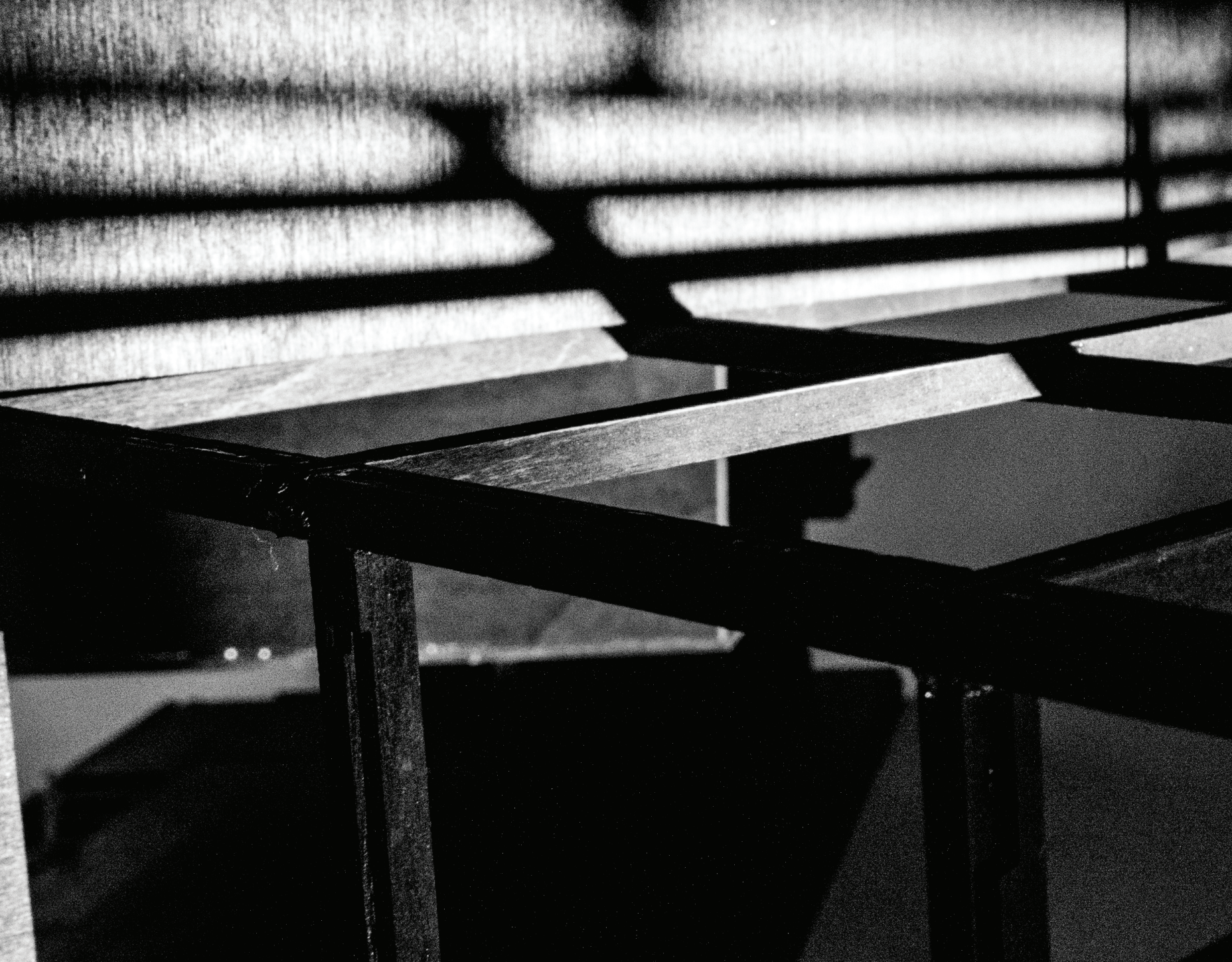
12 


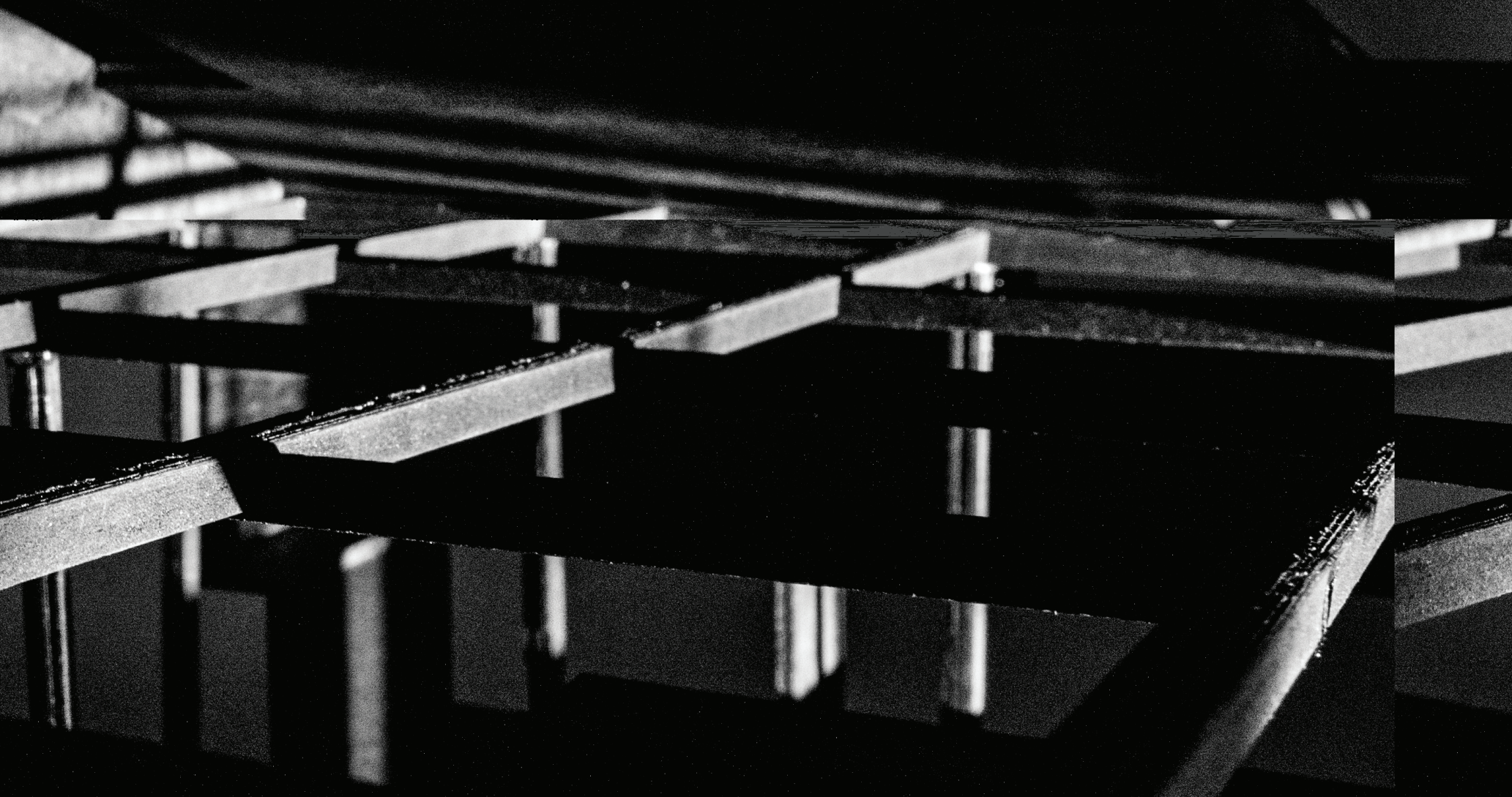

Figure 0.03 Detail of the structural frame in the circulation void of the final design outcome. Photograph of 1:50 model 


\section{TABLE OF CONTENTS}

INTRODUCTION

$02 \quad$ Abstract

03 Aims and Objectives

$04 \quad$ Positioning

10 Approach

15 CHAPTER 1

17 Perspective Drawing's Role

in the Development of Architectural Form

Theoretical Positioning

20 Reverse Construction

Literature Review - Restitution of Piranesi's Perspectives

28 Mies van der Rohe

Literature Review -

Geometric analysis of Mies' Barcelona Pavilion

\section{7 сннгікR}

110 Site Analysis

Museum Island, Berlin

123 CHAPTER 4

126 Narrative

Mies and Schinkel

134 Design Outcome

Developed Design

214 Conclusions and

Critical Reflection

\section{1 СAPTER2}

$42 \quad$ Analysis of Mies' Drawings Methodology

$70 \quad$ Case Study Analysis

223 List of References

88 Design of a Drawing Apparatus Preliminary Design 


\section{ABSTRACT}

This research investigates a correspondence between the architectural representational tool of drawing, and the translations of these into something recognised as 'built'. It is fundamentally concerned around representation in architecture driven by the principles that our entire engagement with architecture is via representation. Architects do not produce buildings but produce images of buildings, and the role of two-dimensional representation plays a principal part in architecture. Architecture is always representational, and the more we engage with representation the more we might push the envelope with what we understand architecture to be.

This thesis aims to establish within the contemporary discipline, what we understand about the responsibility of linear perspective as a representational tool. By understanding what lies behind the canon of perspective in architecture, this thesis questions whether the representation of conventional architecture could benefit from a new way of drawing linear perspective?

The discovery of perspective during the Renaissance has influenced not only our way of representing architecture but also how we view, and therefore design it. It has become integrated with our understanding of architecture at an unconscious level. Architects no longer need control of projective geometry, and due to this cannot be critical of the system of representation or control its limits. This leads to mediate a shift in perspective, with the intention to generate a representation of new form.

The motivation for this thesis was that from linear perspective, as it has done so for centuries, we can produce evocative and meaningful vocabularies that attempt to enrich architecture.

Figure 0.04

The travertine's luminous qualities

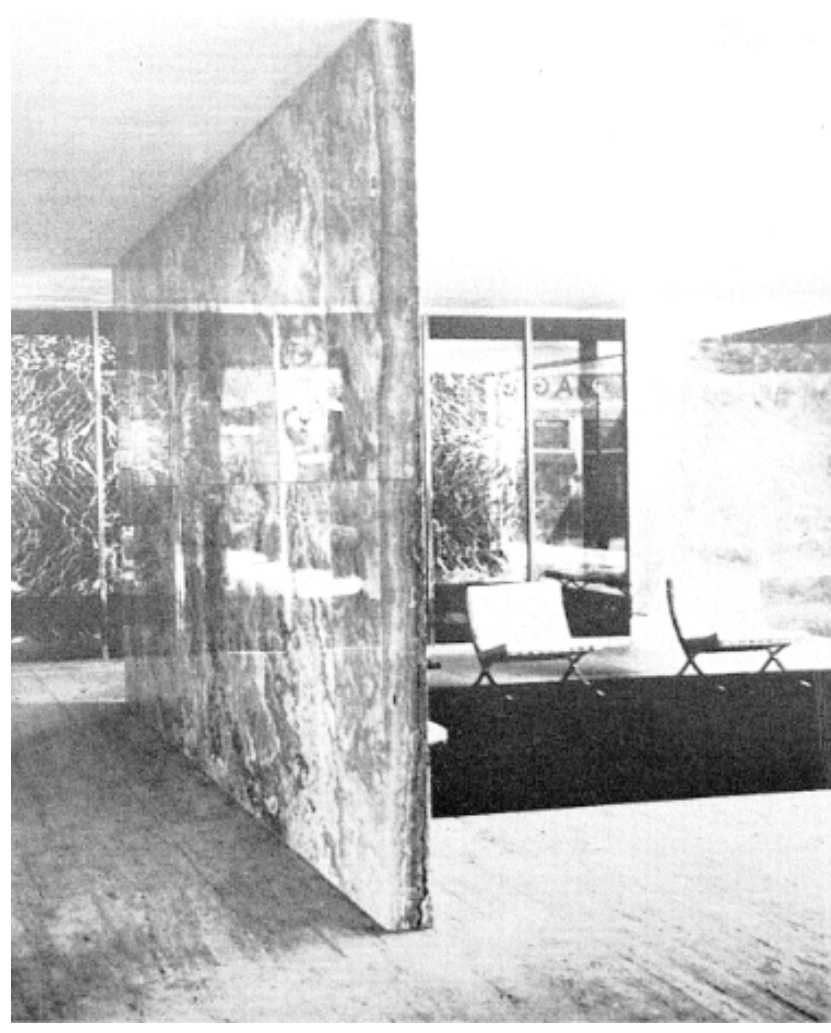

Photograph of 'the Throne Room', Barcelona Pavilion. (Quetglas, 98) 


\section{AIMS AND OBJECTIVES}

I will challenge conventional approaches to design processes by paying a closer consideration of idea to expression, and responding through representation, to what can emerge from the process of translation.

While conscious that perspective is manifest more so than ever in our 3D computer modelling programmes, the tendency today is to think only through a computer. In that sense drawing almost comes as an afterthought - once the object has been modelled in 3D, sections and plans can be cut from it. This thesis looks at architectural drawings not solely as technical devices to manipulate, but as tools to discover something original, and explicit without becoming part of a reductive systematic representation process. It proposes that a more legitimate embodiment of architectural ideas is given if one more closely conceives the associations between the intentions of architectural drawings and the built objects they describe.

Derived from an interest in Mies van der Rohe's representational drawings, and specifically his Barcelona Pavilion as representative architecture, the design methodology builds upon critical analysis of his work. With a circular rhetoric that sets up the research, analysing Mies van der Rohe and linking the Barcelona Pavilion, to Karl Friedrich Schinkel, and to Schinkel's Neoclassical Altes Museum, the design explorations intend to reinterpret both buildings, to make a connection back to Schinkel, as the inspiration to Mies. For this reason, I am proposing to implement a new Sculpture Gallery on the site of the Altes Museum; Museum Island in Berlin.

Both German Masters, Mies and Schinkel shared a common view that architecture is a frame that should accommodate human experience, and this is what is intended to be carried through the analysis. Derived from these two architects is the idea of human occupation and movement through the spaces, and in an investigation of a new representational technique, this thesis looks to consider these qualities foremost.

This thesis addresses that the tools of representation have a direct influence on the conceptual development of projects and generation of forms. If to change how one draws, it changes the outcome. This study is unpacking our use of linear perspective and changing the way we see it. Through designled research, this thesis seeks to test the boundaries of how we use linear perspective, what we expect from it, and how we might challenge such expectations. 


\section{POSITIONING}

The research firstly looks at case study writings of Giovanni Battista Piranesi, an Italian artist famous for his etchings of Rome, situating the study within the context of the 15th-century technique of perspective. Studies into Mies van der Rohe, looking in particular at Mies' Barcelona Pavilion and perspectival analysis of his interior perspective drawing of it, has set up how further analysis could be carried out. Fundamentally, in order to establish how the representation of conventional architecture could benefit further from perspective drawings. Through the different perspectives of key figures; Architectural historians Robin Evans, Erwin Panofsky, Alberto PérezGómez, Manfredo Tafuri; Professors, Juan Pablo Bonta, Detlef Mertins, Desley Luscombe; and Architects Josep Quetglas, and George Dodds; between these interpretations, specific evaluations can be made. With so much writing on these studies, it becomes relevant research as soon as interpretations of the inconsistencies are made.

The relationship between the orthogonal plan and the perspective image introduces a translation of ideasto-drawings, drawings-to-buildings. Johann Heinrich Lambert, through perspectival studies, was interested in this relationship.

Figure 0.05 Interior of a Gallery Space, final design of Sculpture Gallery

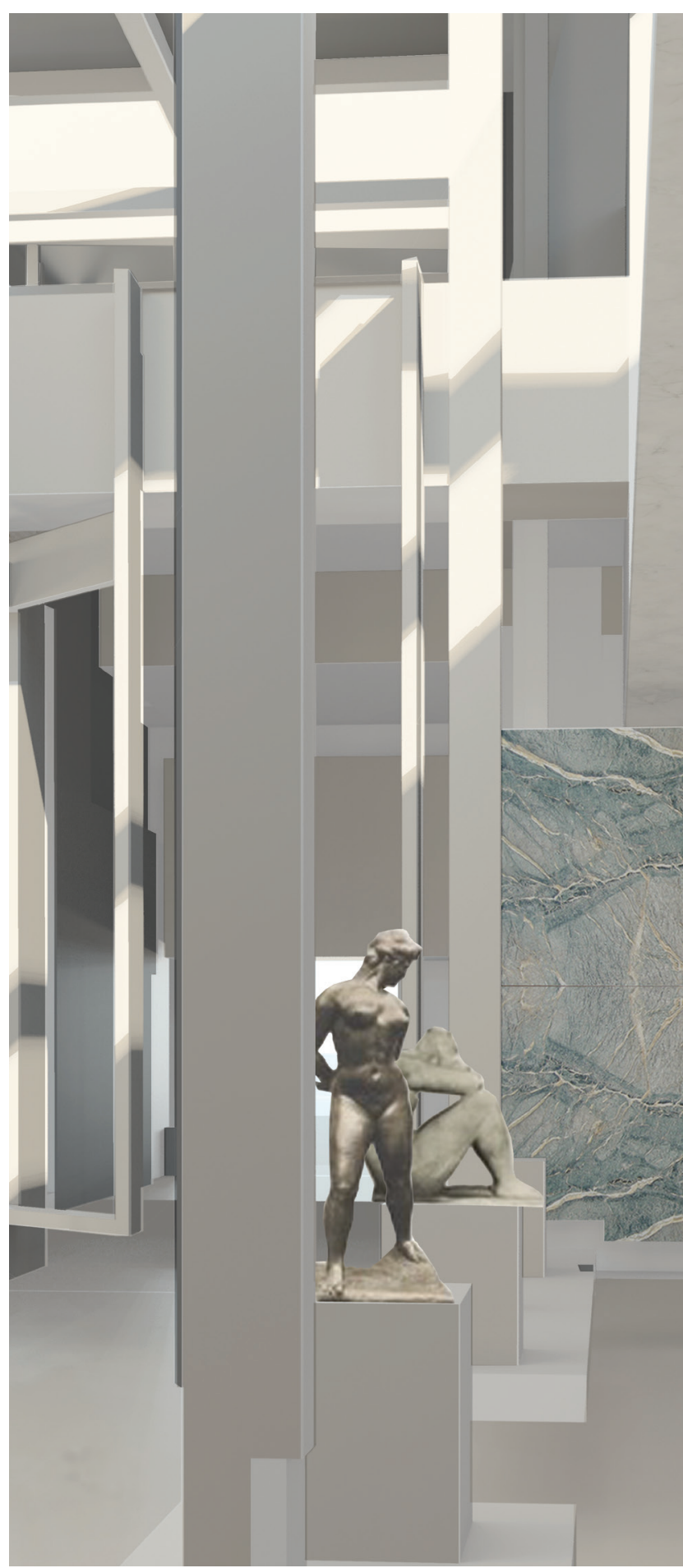


The process of geometric restitution pioneered by the eighteenth-century German mathematician Lambert, works as reverse-perspective, serving as a valuable method for investigating the geometric properties of perspective. It uses descriptive geometry to derive from its perspective image the shape, size, and position of the object as it would be in real space (Rapp, 701). Both the case studies; Joanna Rapp's PhD study into Piranesi's work, Desley Luscombe's Drawing the Barcelona Pavilion: Mies van der Rohe and the implications of perspectival space; and Robin Evans' writings, wanted to understand the geometric properties of perspective and how to deduce the viewing position of the artist from it. These case studies identified ways to carry out analysis to understand not just how the perspective image has been constructed, but what it was intending to communicate. A technique invaluable in carrying forward analysis of Mies' perspectives.

When analysing from plan to perspective, it is important that the recessional field established by the gridded plane which is consistent through Mies' work, is kept throughout the analysis of his work. The module established by the grid creates a governing rule set for position and placement.

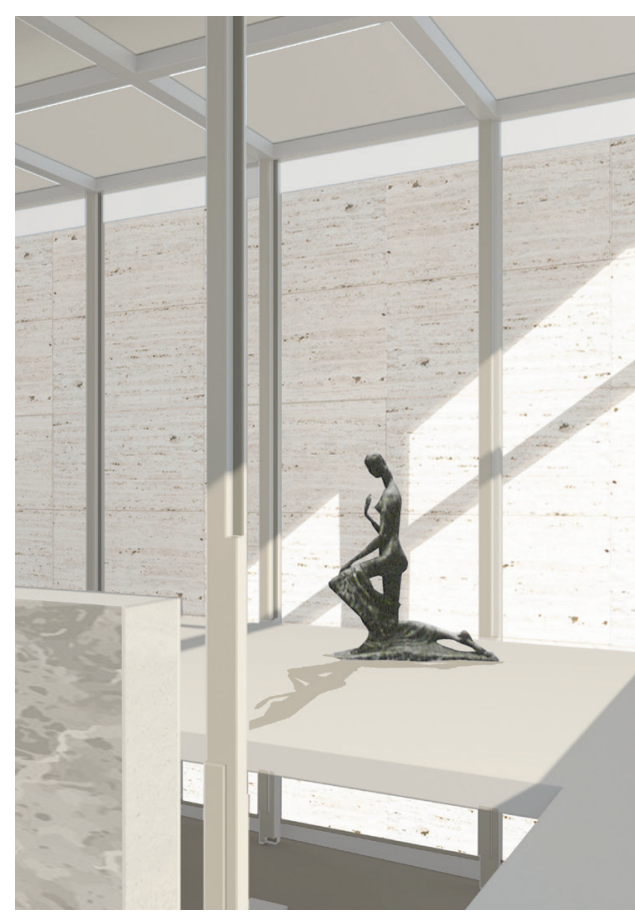


The underlying grid from the Barcelona Pavilion perspective, in wanting to understand how Mies' constructed his perspective drawings, has been applied to others of his perspectives. While it can never be known for sure exactly what Mies' intended, a series of 'What ifs' were asked, and this has carried through the analysis.

The Pavilion perspective drawing, in the deconstructing of it through geometric restitution, was used to determine the design of a drawing apparatus. This tool is designed to reapply the analysis through the work, controlling the parameters to further analyse and carry out drawings to test design. In wanting to establish parameters for design, the drawing apparatus explores a new way of drawing, making the drawings become witnesses of the performance, connecting movement and geometry. In the way it conceives in plan, the suggestion of movement, it is similar to Diller and Scoffidio's Slow House apparatus, which is discussed in Chapter 2 as a case study.

From drawing in the apparatus, the concepts are taken back into the design framework that was set up through the initial unpicking of Mies' drawings. The whole time this narrative continued, building up a 'rule set', with the intention that through the design, testing the framework would be valuable in controlling the complexity arising through the drawing apparatus. 
Site analysis was carried out so that design could be considered in parallel between the site parameters and what is happening in the drawings. Site cues have been important, but fundamentally this site is concerned with site grids and axes, and as true throughout the work, is about the setting up of rules and parameters, with knowledge behind what they achieve, then allowing to break them. The methodology has been in unpicking and testing what has been set up within these alignments.

Through a series of 'what ifs' to analyse the drawings of Schinkel alongside those of Mies (particularly where there are alignments) came direct design moves, taking partial plans into the drawing apparatus. The idea of partial planes is corresponding with the notion of 'frames', which were continuous from the first analytical drawings to the design outcomes. These frames were then distorted in the apparatus through the projection of partial plan down to perspective, and then the skewing of these perspectives through several different viewing points. The perspective frames were then projected back up to plan, using a gridded volume to place the walls back onto the orthogonal grid.

Critical to the methodology thus far has been the projections of perspective to plan, varying between the drawing board, computer and apparatus, and beyond that the testing of physical models which establishes an approach in which to take the design beyond twodimensional representation projections. 


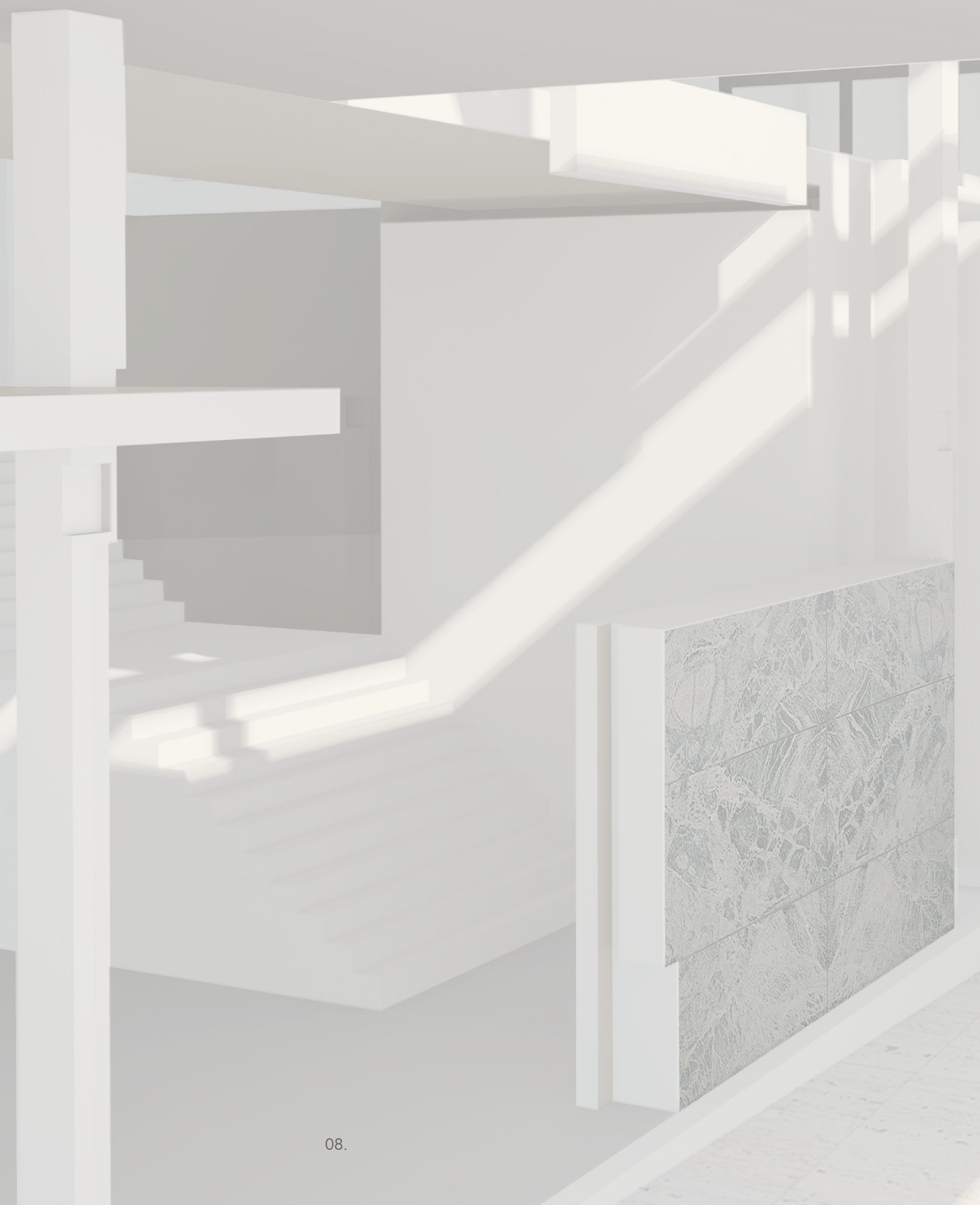


The final 'building' demonstrates a complex matrix that establishes an ordering system to piece together the partial frames arising from the distortions in the projections.

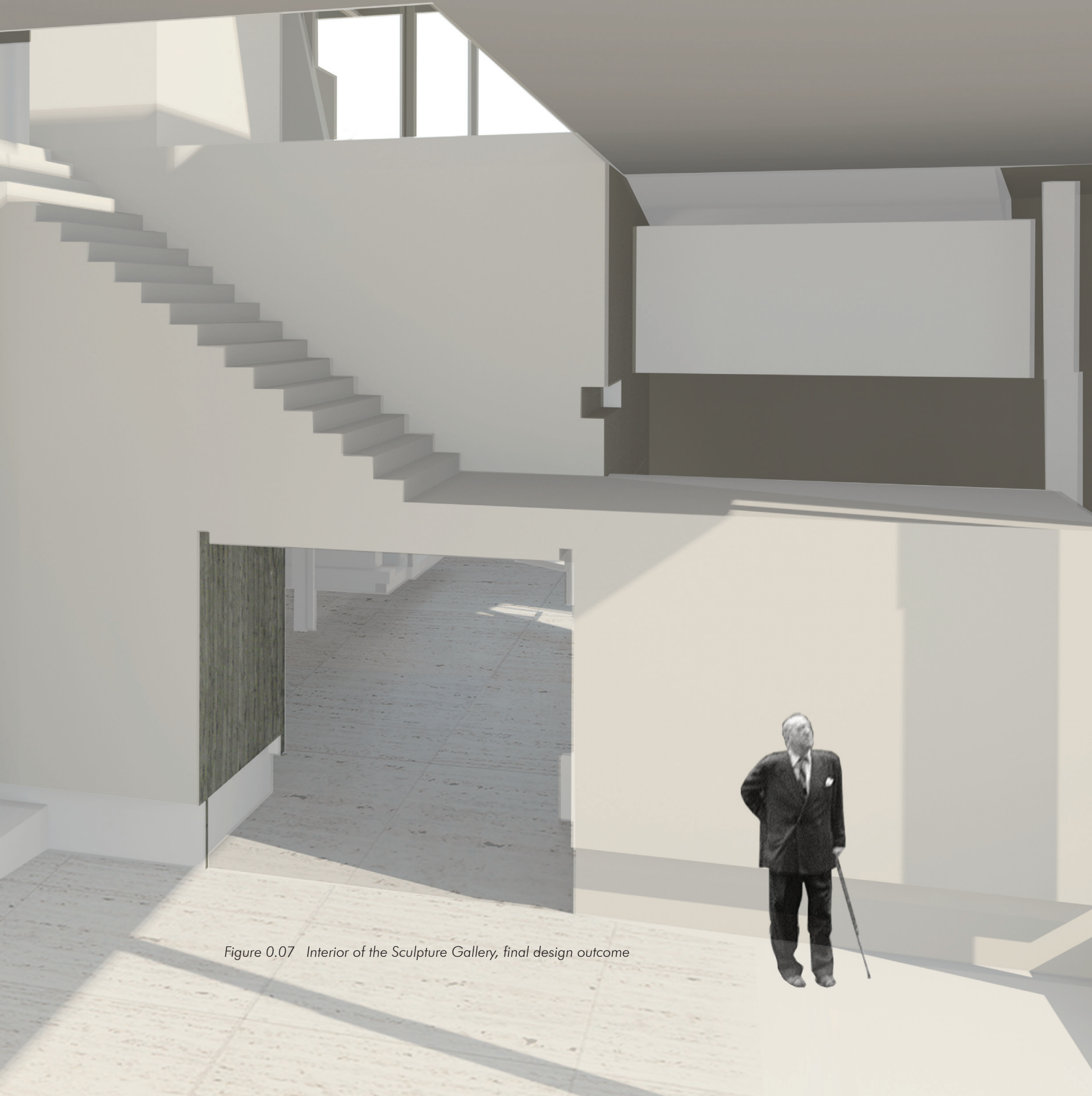




\section{APPROACH}

This thesis is very much a methodologically driven project. As such, theory strongly supports the basis of the analysis and carries through a very rigorous and justified working. Design has been used as a critical tool in testing and pursuing the framework set up through the analysis.

This project is set up in such a way that each of the phases links back to the plot as a whole; analysis which is tested back onto the site it begins with, and which could then be tested continually. It has been sequenced along this narrative through four chapters. The first of which frames this project, and situates the study within the historical context of linear perspective. Architectural theorists, and case study analysis position the project, and investigation through this chapter allows to set up chapter 2: preliminary design, and the rest of the narrative.

Chapter 2 is supported by case study reviews that specifically look to how analysis can be applied further, to test the ideas arising from chapter 1 . This chapter is set up from chapter 1 and feeds directly into chapter 4; the design outcome. The principles from testing these, those which from the first chapter have enabled to set up the preliminary design, are fed back into the framework and parameters set up from the start. These are linked to site and another main figure of the narrative.

Chapter 3 brings forward the main layer of the narrative and links the main figures from chapter 1 to chapter 4 . It adds back into the framework by establishing another layer of constraints that are then designed through and considered alongside those set up in the other 3 chapters.

Chapter 4 'tests' the framework directly into a design outcome. The research outcome will be presented as large format perspectives, juxtaposed as Mies would through presentation image, between the certainty of drawn perspectival space, and the vagueness of materiality, space and time through collage. 


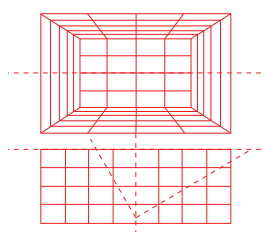

Geometric Restitution

- technique of reverse perspective

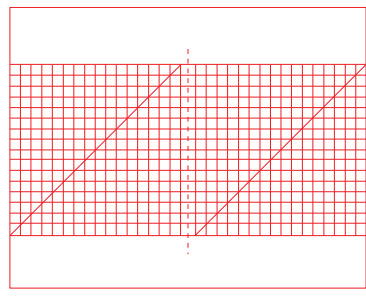

Underlying grid from the perspective

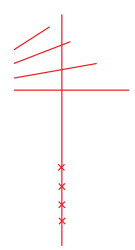

Multiple viewing points suggest movement through an otherwise static image

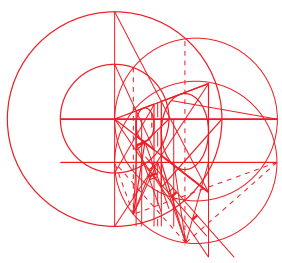

Positioning: process of restitution in the analysis of Piranesi's perspectives

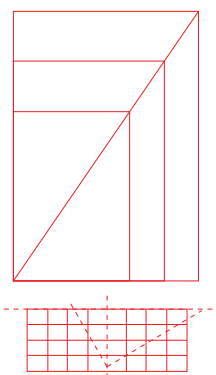

Correlation between perspective and plan grids

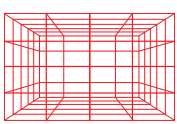

Gridded volume establishes a recessional field, a governing rule set for position and placement.

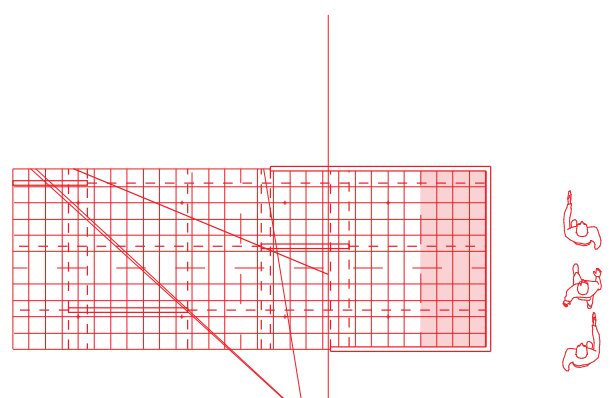

Application of restitution technique to Mies van der Rohe's Interior Perspective drawing of the Barcelona Pavilion

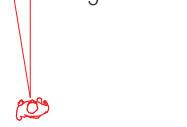

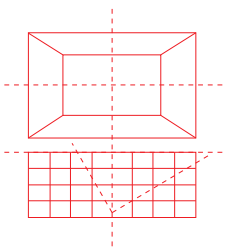

Redrawing perspective from plan, from one viewing point

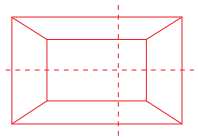

Offset centre of vision line - effecting the gridded field

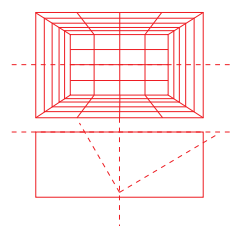

Perspective to plan, using a gridded field to position elements on the plan's grid

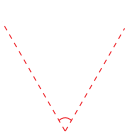

Figure 0.08 Diagram of the geometric analysis methodology 


\section{Methodology Diagram}

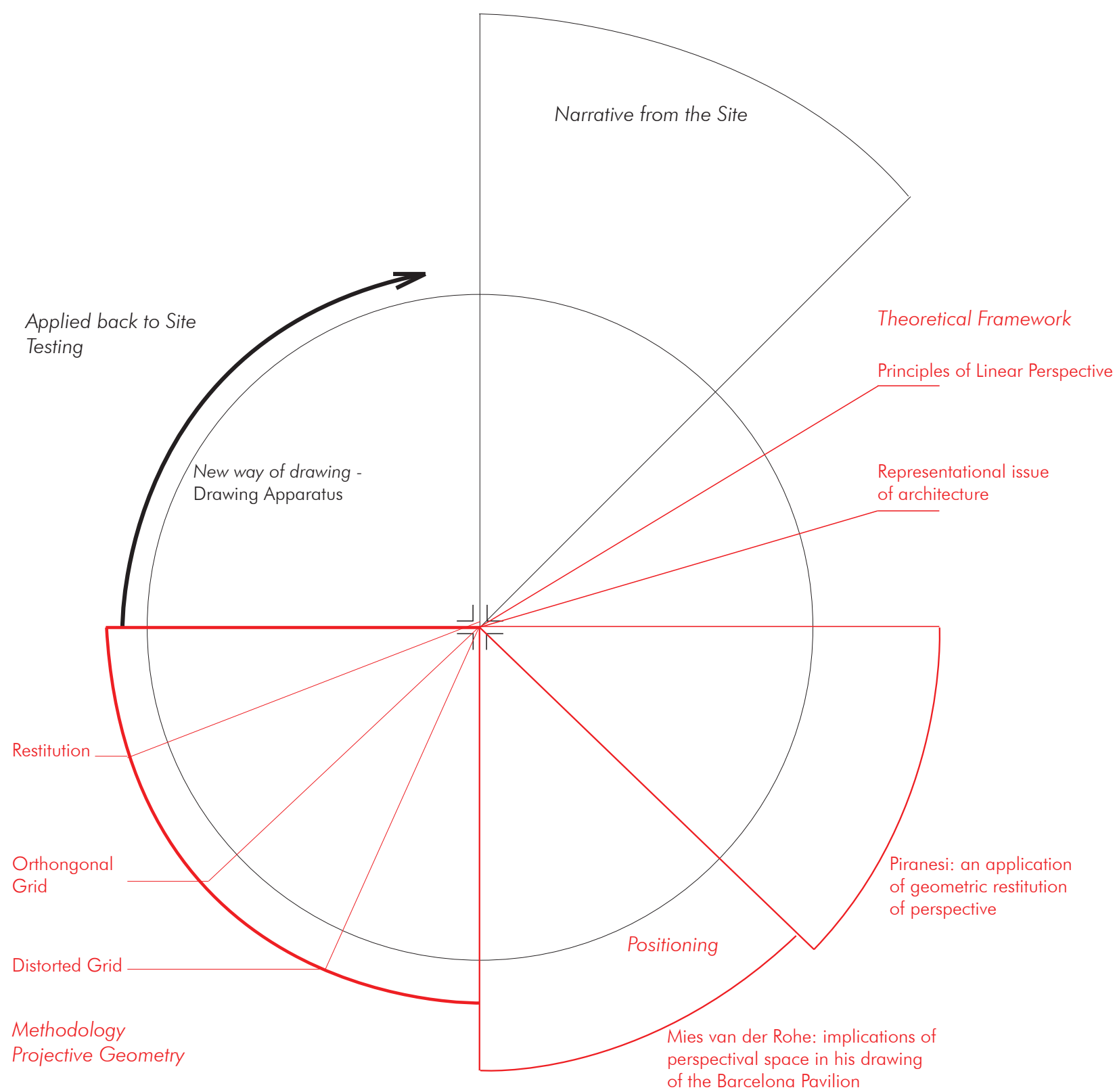

Figure 0.09 Diagram of the research methodology 


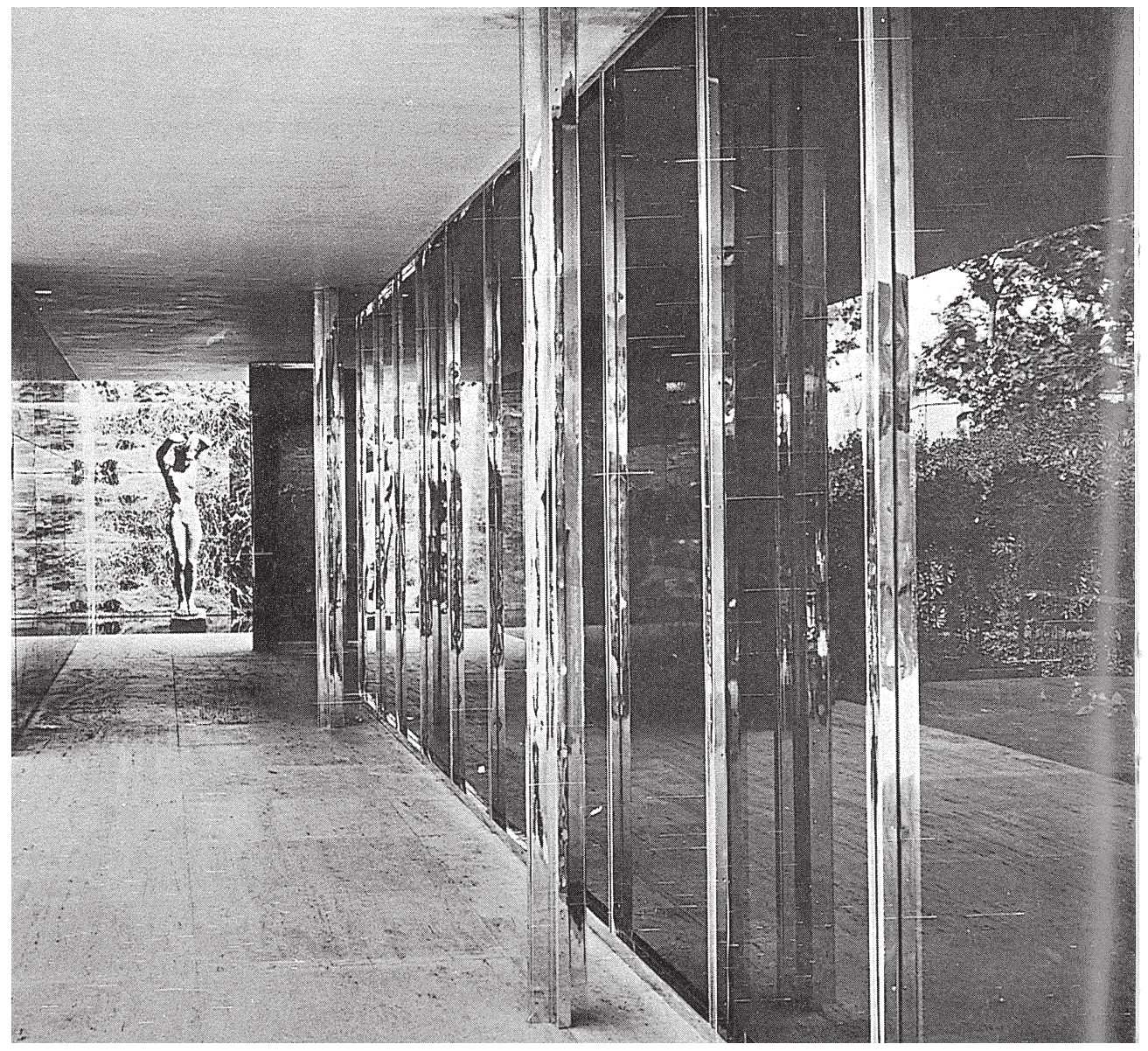

Figure 1.01 Plate 8. Barcelona Pavilion (Quetglas, 150) 

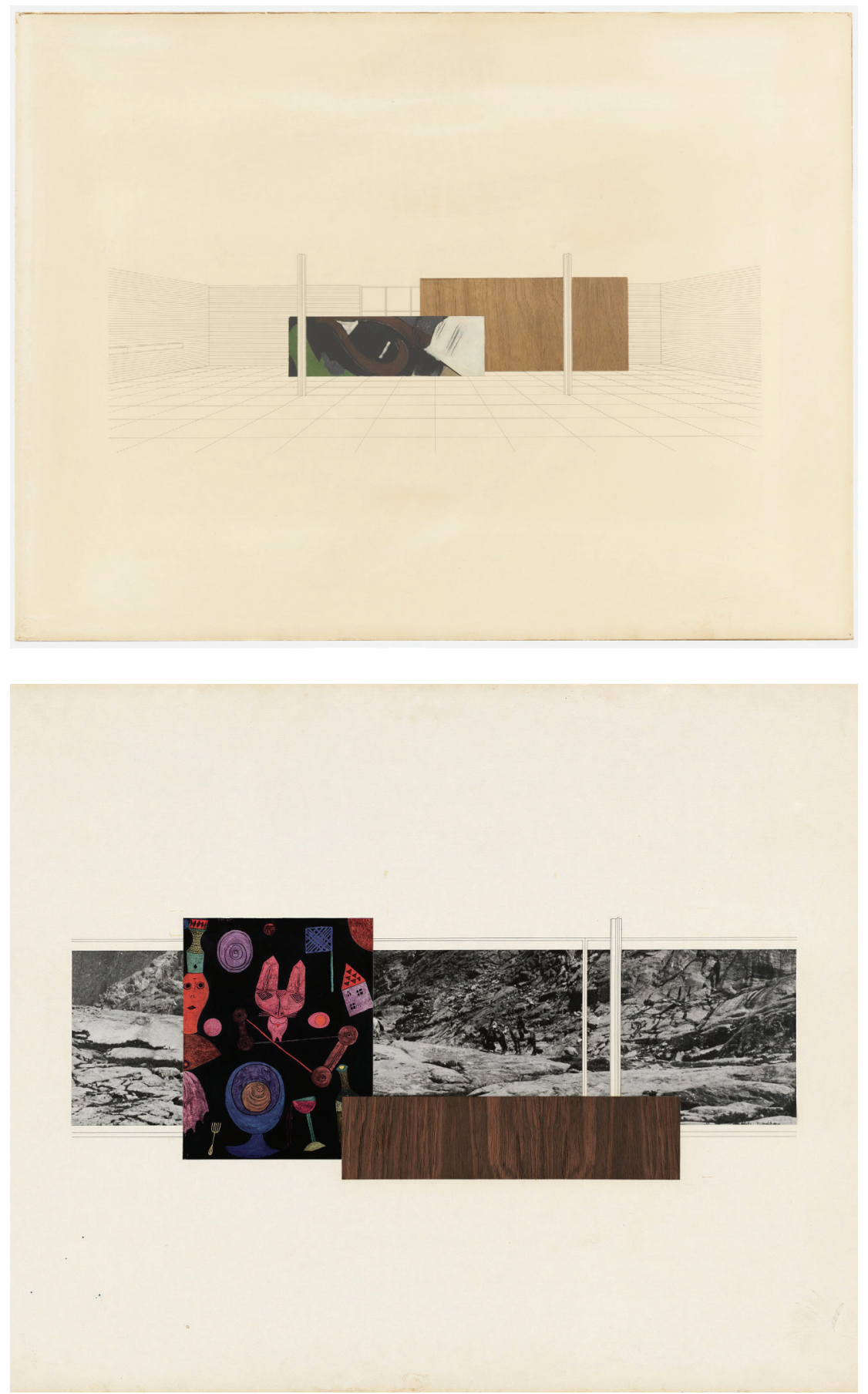

Figure 1.05 Row House with Interior Court. Interior perspective, after 1938. (Rohe, (C) 2018 Artists Rights Society (ARS), New York / VG Bild-Kunst, Bonn).

Figure 1.06 Resor House project, Jackson Hole, Wyoming. Interior perspective of living room and south glass wall, 1939. (Rohe, (c) 2018 Artists Rights Society (ARS), New York / VG Bild-Kunst, Bonn). 


\section{[PERSPECTIVE] DRAWING'S ROLE IN THE DEVELOPMENT OF ARCHITECTURAL FORM}

In his book 'Translations from Drawing to Building', Robin Evans discusses the rediscovery of the architectural drawing as making drawings more consumable; they have become more concerned with their own composition than by what they're representing.

The process of creation prevalent in architecture today assumes that a conventional set of projections, at various scales from site to detail, adds up to a complete, objective idea of a building. However it is Robin Evan's view that not all things architectural can be arrived at through drawing, so the transmutation that occurs between drawing and building remains to a large extent confusing (Evans, 159). This is predominately what has driven the research and what is to be kept at the foreground through this analysis - that 'translations' from drawing to building are not physical certainties but 'promises' of intuition.

Evans states that architects are "never working directly with the object of their thought, always working at it through some intervening medium, almost always the drawing, while painters and sculptors, who might spend some time on preliminary sketches and maquettes, all ended up working on the thing itself ... the sketch and maquette are much closer to painting and sculpture than a drawing is to a building" (Evans, 156). This process separates architecture from the other visual arts, and in order to confirm architecture as a visual art, it would insist "that only that which the architect manipulates with his own hands is his work." (Evans, 157)-divorcing the architect from the building process and thus from the design decisions made subsequent to the detailed design phase. 
If to more closely regard this process, Evans sees the redefinition of architecture as having two options; insisting on a more direct involvement by the architect after the representational phase (more work), or using the drawings to better effect. Drawings can be composed to enhance both the compositional regularities of perspective construction and the irregularities of abstract. Geometry is a rational science whereas architecture is a matter for intuitive judgment, therefore it is important that "geometry gives architecture a reasonable grounds but does not confine it to rationality. On top of this geometric rationality, the creative, intuitive and rhetorical aspects of architecture can develop." (Evans, 283). Erwin Panofsky saw perspective as the objectification of the subjective, in that the representation of spaces depends on the point of view of the observer as well as the instruments of translation (Panofsky, 66), therefore if to consider these rules, we could produce different representations.

Through this study, the discussion between art and architecture will become clearer. This thesis has looked at Piranesi's drawings and an analytical study of them, and his work is aligned with the writings of Derrida and Tafuri. In Alberto Pérez-Gómez and Louise Pelletier's 'Architectural Representation and the Perspective Hinge', they have written from the perspective of the discipline of architecture, rather than from the history of painting and philosophy which is most common and which is experienced through the studies of Piranesi's work discussed in the thesis. This helps to situate the study within the historical context of perspective of architecture, to reveal the complexity and potential contradiction inherent in any linear history of representation. Anyone reviewing the history of architectural theory, Robin Evans observes, would have to conclude that architects do not produce geometry, but rather consume it. In particular, Evans concentrates on the history of architectural projection, the geometry of vision that has become an internalized and pervasive pictorial method of construction and that, until now, has played only a small part in the development of architectural theory. 
Projection is at the foreground of Mies' work and is what the analysis engages with through the study of drawings to building. The study of the Barcelona Pavilion proves textbook for this. Evans describes the ambivalent role that pictures play in architecture and urges resistance to the idea that pictures provide all that architects need, suggesting that there is much more within the scope of the architect's vision of a project than what can be drawn. The drawing has intrinsic limitations of reference. Not all things architectural can be derived through drawing. Evans is fascinated with the idea that ordinary things contain the deepest mysteries and he is sceptical of the most obvious, seemingly transparent view of things, he searches for what is beneath the surface. Slowly, methodically, 'mysteries' are unravelled in his texts. The investigation of the ambiguities of projection is applicable both in Evans' writing, and Mies' Pavilion.

Through investigating Mies' drawings, two things need to be considered; the analytical readings into his drawings as well as a more historical approach to the theory of linear perspective. This allows to place Barcelona Pavilion in context and draw conclusions from Mies' methods of drawing. Concluding this analysis, there are complex relationships found between its two-dimensional geometric characteristics and an orthogonal relationship developed between plan and perspective image. 


\section{REVERSE CONSTRUCTION}

Perspective to Plan.

Piranesi's drawings have been analysed through this text and investigated by means of geometric restitution. Using this method it is possible to focus on his perspective images, work backward and find his notional position as an observer. A similar method has been used in the text 'Drawing the Barcelona Pavilion: Mies van der Rohe and the implications of perspectival space' to understand also the position as an observer, and draw complex analysis which gives reasoning to the abstract nature of Mies van der Rohe's drawings. Reading of Panofsky's 'Perspective as Symbolic Form' supported in developing a better understanding of the principles of perspective. Understanding into the perspectival composition of this drawing has been achieved through the reverse construction of standard drafting conventions, from perspective to plan. Evans believes that "In the representation of ideas through perspective, it is the relationship with the plan that becomes important for architecture."(Evans, 214). For architectural practice, conceptual understanding of perspective as a projective technique is modified through its engagement with the architectural plan (Luscombe). It is evident of the orthographic relationship between the plan, elevation and perspective by proving that not only is it possible to turn a plan of the object into its perspective, but also to work out a plan of the object from the perspective image he tasks of restitution. Lambert however, was intent on proving that one does not need to start with the orthogonal plan to generate perspective. Ways to understand how Piranesi and Mies constructed perspective drawings, in an attempt to find correspondent points, in both cases is not as simple as understanding the relationship between plan and perspective. Through this analytical drawing it becomes clear that in an attempt to find correspondent points, any reconstruction of the perspective is unable to be simply realised using projection from the selected plan. 
As did Mies, Piranesi exploited the conventional perspective drawings to overcome the conventional limitations of these rules to find a full expression in his art. By composing the view from different viewing positions he did not want to undermine the technique, but rather use its potential to communicate more in a single image, revealing a thorough knowledge of perspective. The critical analysis of his work that Rapp does, is through the architectural redrawing of the original work, in order to set up compositional discoveries of perspective painting. Panofsky argues that there is a hand-in-hand relationship between the cultural understanding of space, and the depiction of space.

That is, tools of representation have a direct influence on the conceptual development of projects and generation of forms.

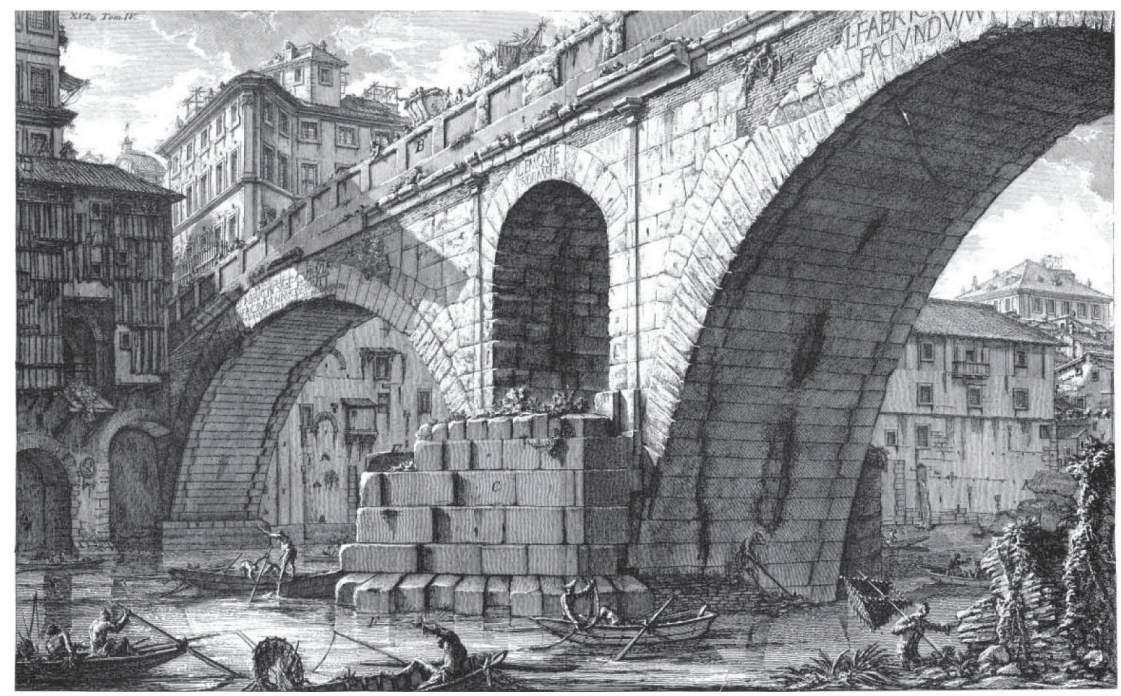

Figure 1.07 Giovanni Battista Piranesi, perspective etching of Ponte Fabrizio, c. 1756. (Rapp, 717) 


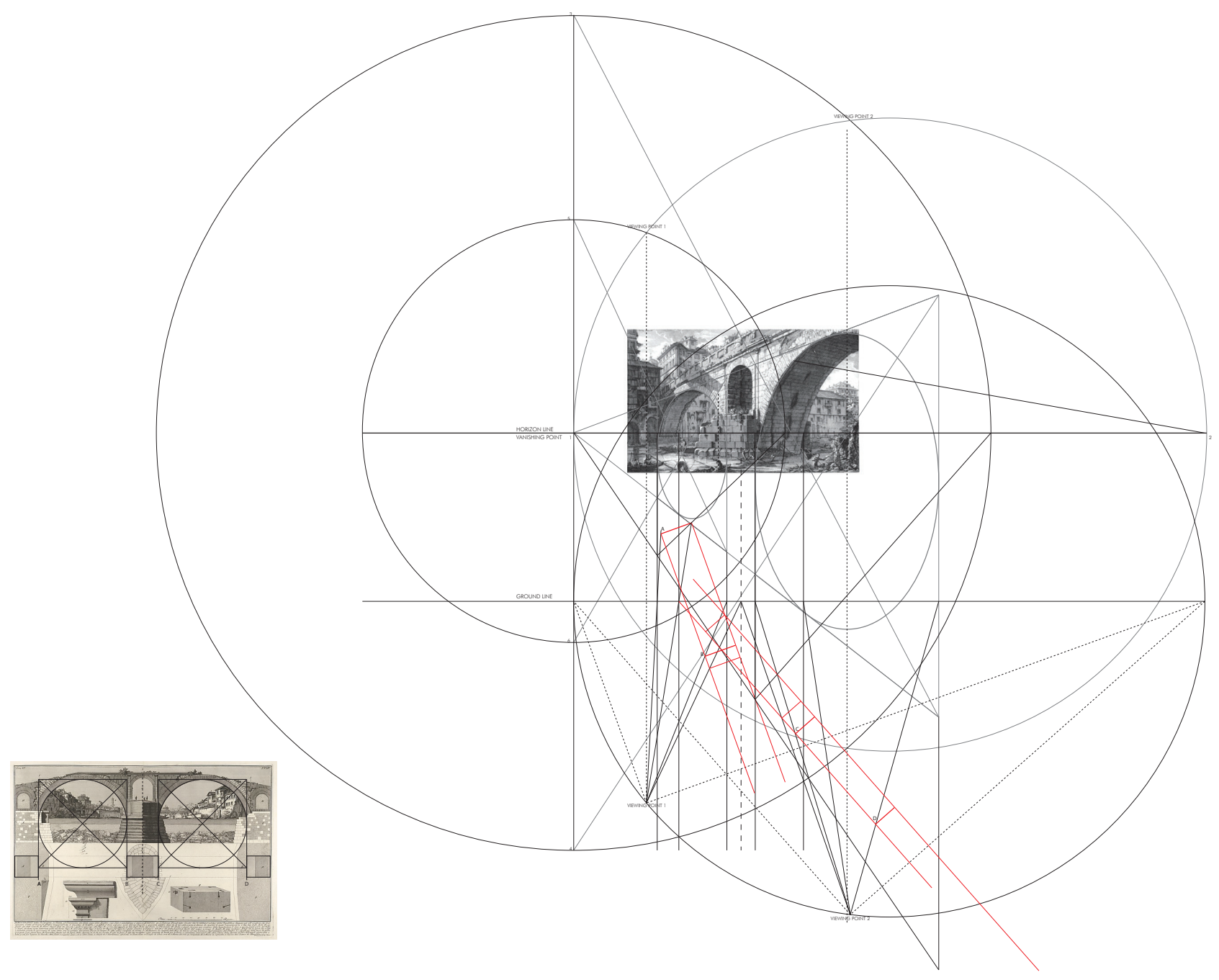

Figure 1.08 Perspective restitution of Piranesi's etching Ponte Fabrizio, from perspective to plan: author's own. 
This is the restitution analysis of a Piranesi etching achieved through the same means as Joanna Rapp, through the architectural redrawing of the original work, in order to set up compositional discoveries of his perspective painting. Firstly, establishing the horizon line and vanishing points, and deducing from it the viewing points (Figures 1.09 and 1.10). The final analysis shows how Piranesi composed the drawing of two perspectives drawn from two positions of the eye. The drawing is a symmetrical composition of the left and right side of the bridge and shows how it has been composed with incredible precision. If the perspective was to be drawn 'correctly', it would be optically wrong. 


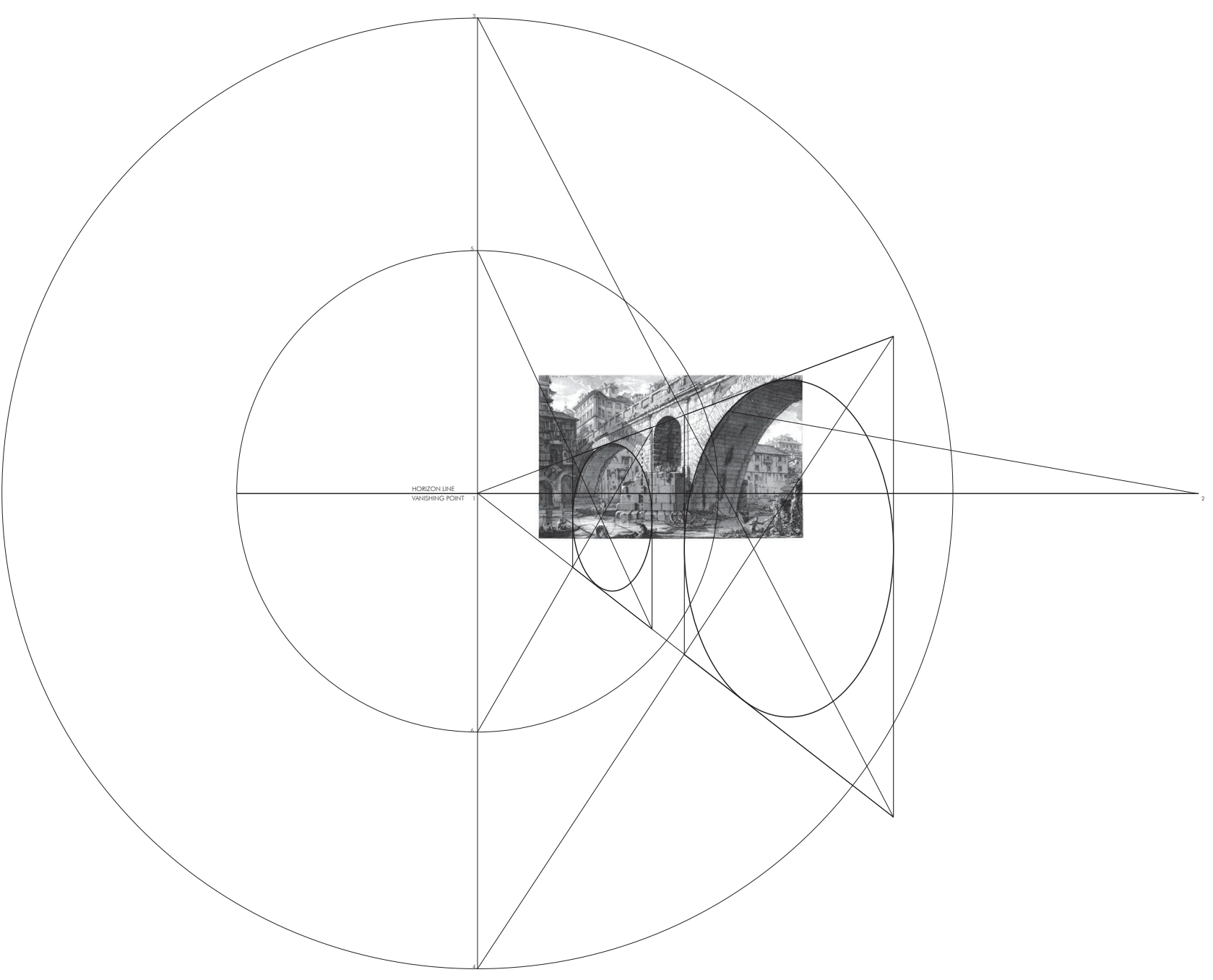

Figure 1.09 Different vanishing points of the diagonals (knowing that the Ponte Fabrizio is symmetrical and its spans are circular). 


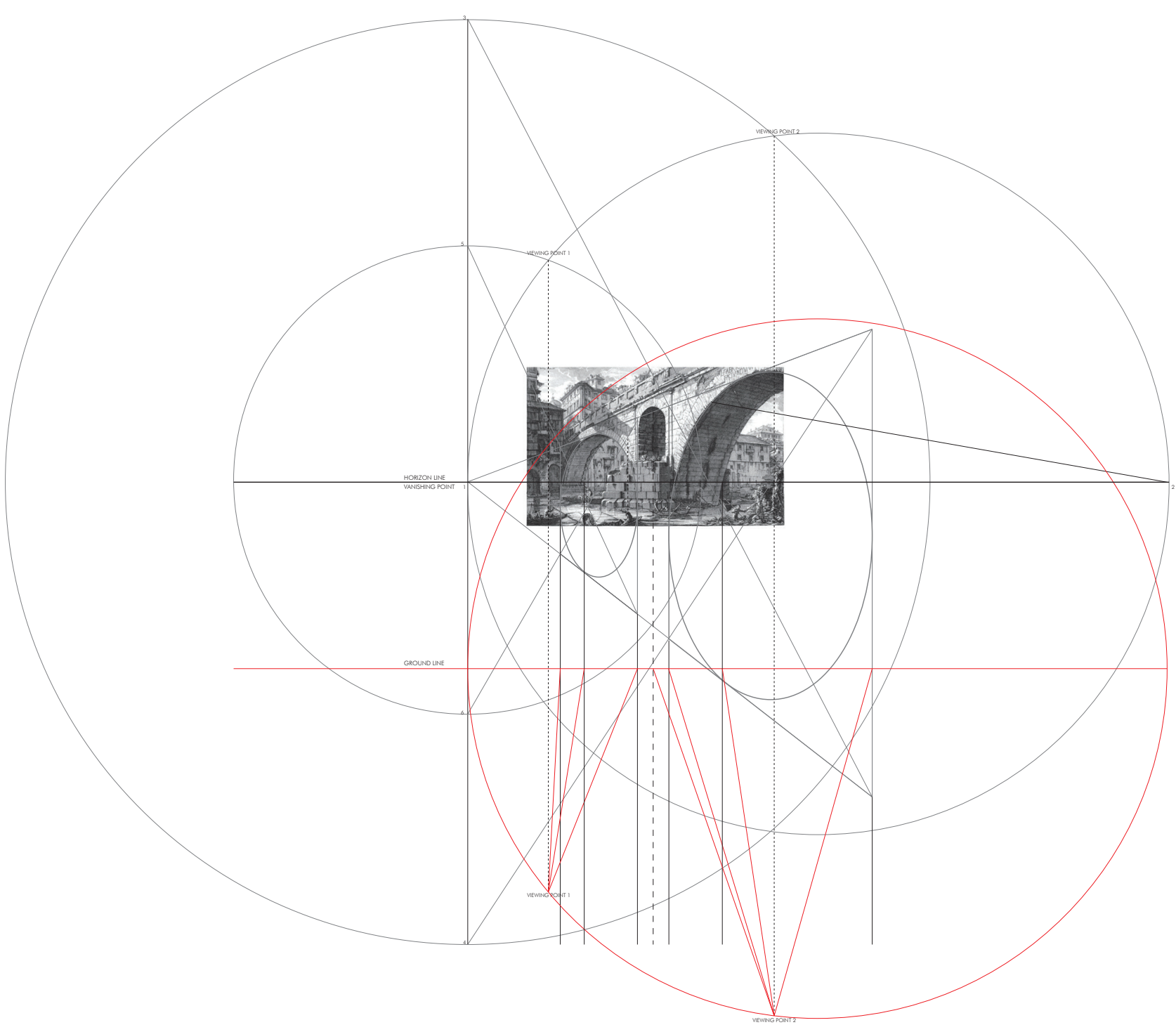

Figure 1.10 Separate positions of the eye; viewing point 1 for the left part of the bridge, and viewing point 2 for the right part. 
This drawing shows the bridge drawn completely if to continue the perspective from the same positions Piranesi drew from. By drawing from two perspectives, and through the control of the size of the drawing board, Piranesi avoided distortions across the drawing. It evidences a thorough knowledge of perspective as a potential to use the technique to communicate more in a single image. 


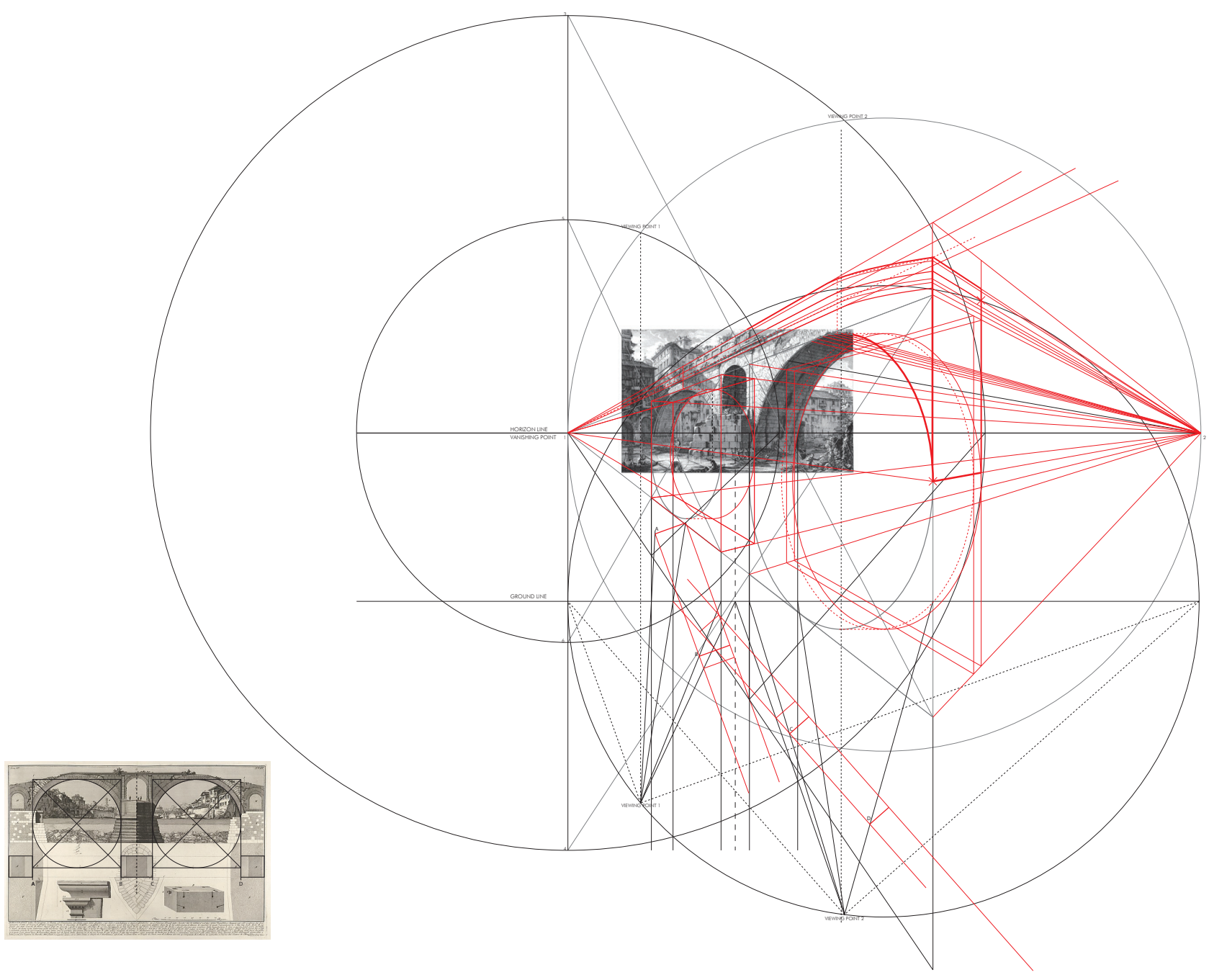

Figure 1.11 Continuation of the perspective of the Ponte Fabrizio, drawn from two positions of the eye: author's own. 


\section{MIES VAN DER ROHE}

The study started with Mies van der Rohe's interior perspective drawing of the Barcelona Pavilion, figure 1.12. It demands attention in the way which the success of the representation of both the rational and the intuitive becomes evident in Mies' perspective drawing of the Barcelona Pavilion. Initial analysis begins with the way it seems unfinished and appears to be a predetermined sheet size through the absence of construction lines from the one point perspective.

Through further investigating the drawings of Mies' it is with the intention to understand author Desley Luscombe's analytical study of Mies' perspective drawing of the Barcelona Pavilion. From this, the perspective restitution technique could be used, as Luscombe had, with the intention to establish exactly what Mies' had proposed to achieve through the complexity of them. Situating Mies' drawing in the context of the history of perspective, and amongst other examples of his work, draws further conclusions from Mies' method of drawing perspective as a tool for architectural representation. This is with the purpose to probe further into the previous conclusions drawn from Mies' work.

Luscombe suggests that Mies' drawing was intended as a tool for public engagement. That further than it being a drawing completed purely as a reflection of the architect in the process of designing a building, it becomes instrumental on many levels, namely in how it approaches spatiality with its consideration of the viewing subject. The subject-focus of representation is instrumental to Perez-Gomez and Pelletier's studies also. The inconsistencies of Mies work against that of traditional perspective, are not seen until analysis reveals the way in which he has distorted the perspective, demonstrating an intention to convey more than we would initially assume with a representational image. The drawing seems to represent a critical and selective reapplication of his ideas. Mies would insist on perspective as the principal means of representing his architecture. His spatial expression of architecture is recorded less so in his buildings plans because "in them only the vertical elements appear as sections, and in Mies' architecture the vertical does not count" (Quetglas, 102). Evans terms his walls as nonexistent, not even as vertical mirrors - in which they are, reflecting and creating illusions of space. "...vertical lines are always trapped or dissolved in the horizontal gap, in which walls are merely mist and steam." (Evans, 76). For this reason, he barely drew his designs from an axonometric perspective as this puts primary focus on the relationships among the elements and not the relationship between the spectator and the elements (Quetglas, 104,105). Linear perspective has continuously been subjective, while axonometric, as objective has influenced Avant Garde speculative projects. 


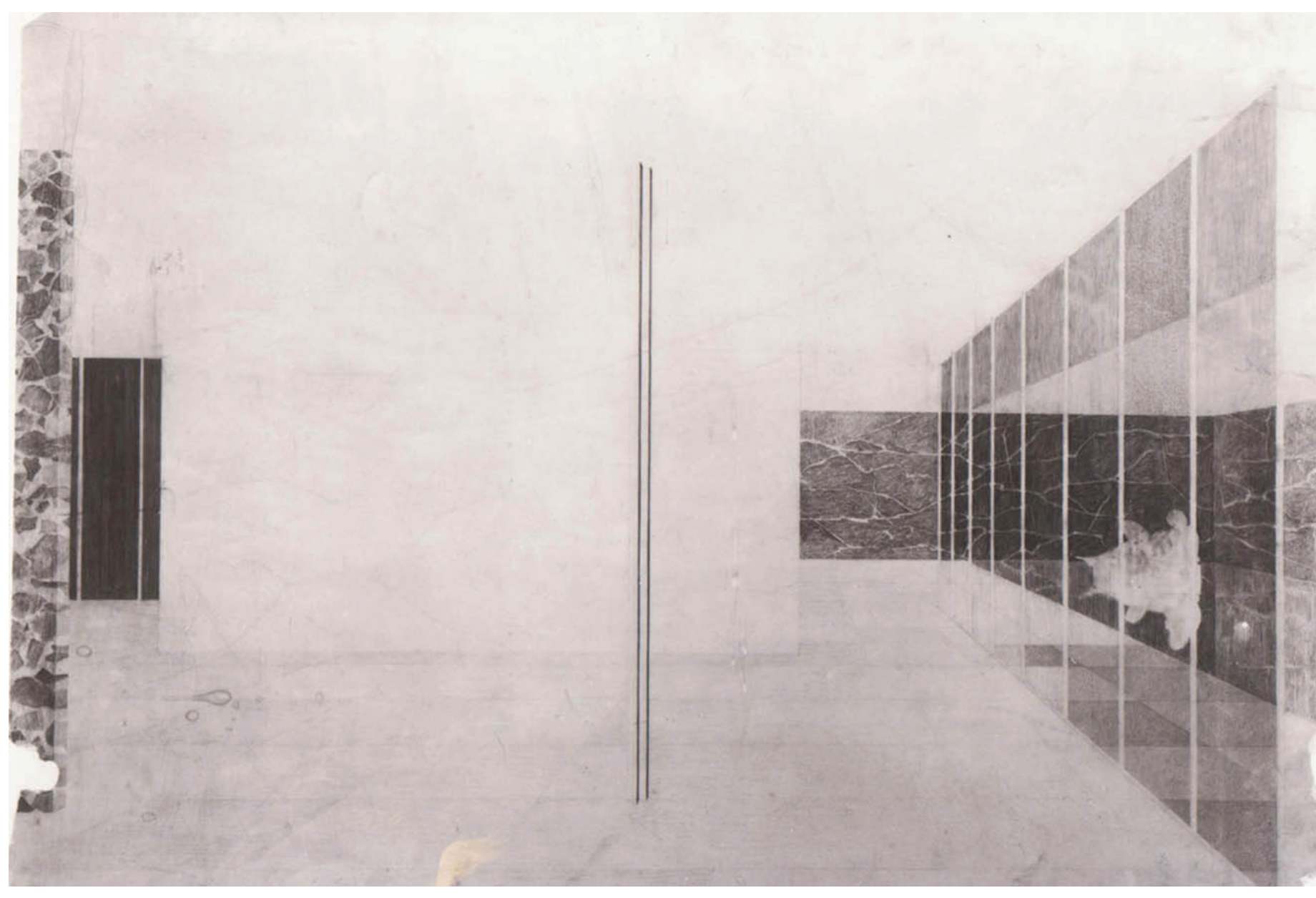

Figure 1.12 Mies van der Rohe's German Pavilion, International Exposition, Barcelona, Spain. Interior Perspective, c. 1928-29. Graphite on illustration board. Source: MoMA Mies van der Rohe Archive. (c) 2013 Artists Rights Society (ARS), New York / VG Bild-Kunst, Bonn (Luscombe, 217). 


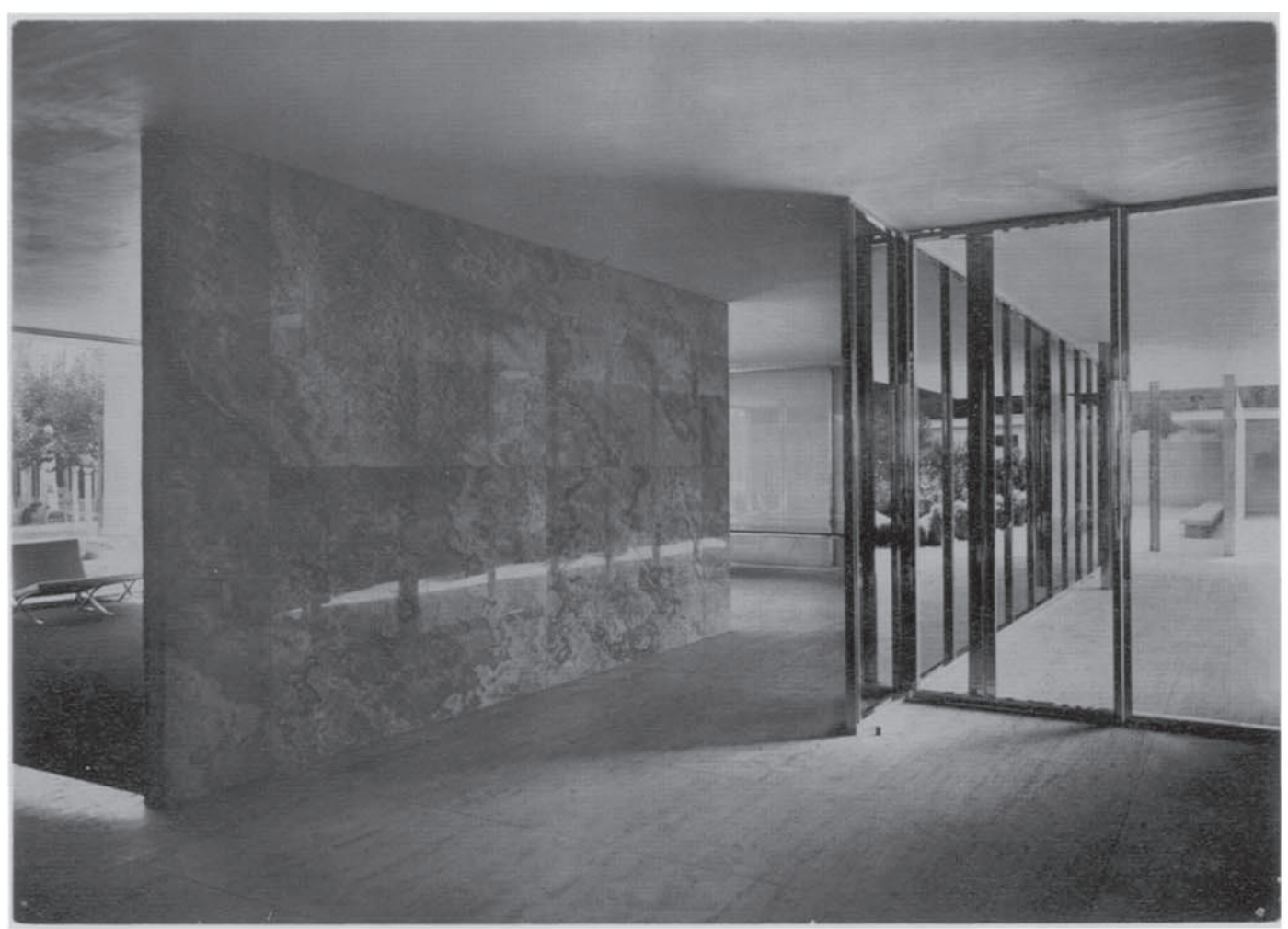

Figure 1.13 Plate 11 MMA 97, Berliner Bild-Bericht, The Museum of Modern Art/ Licensed by SCALA / Art Resources, New York (Dodds, 92) 

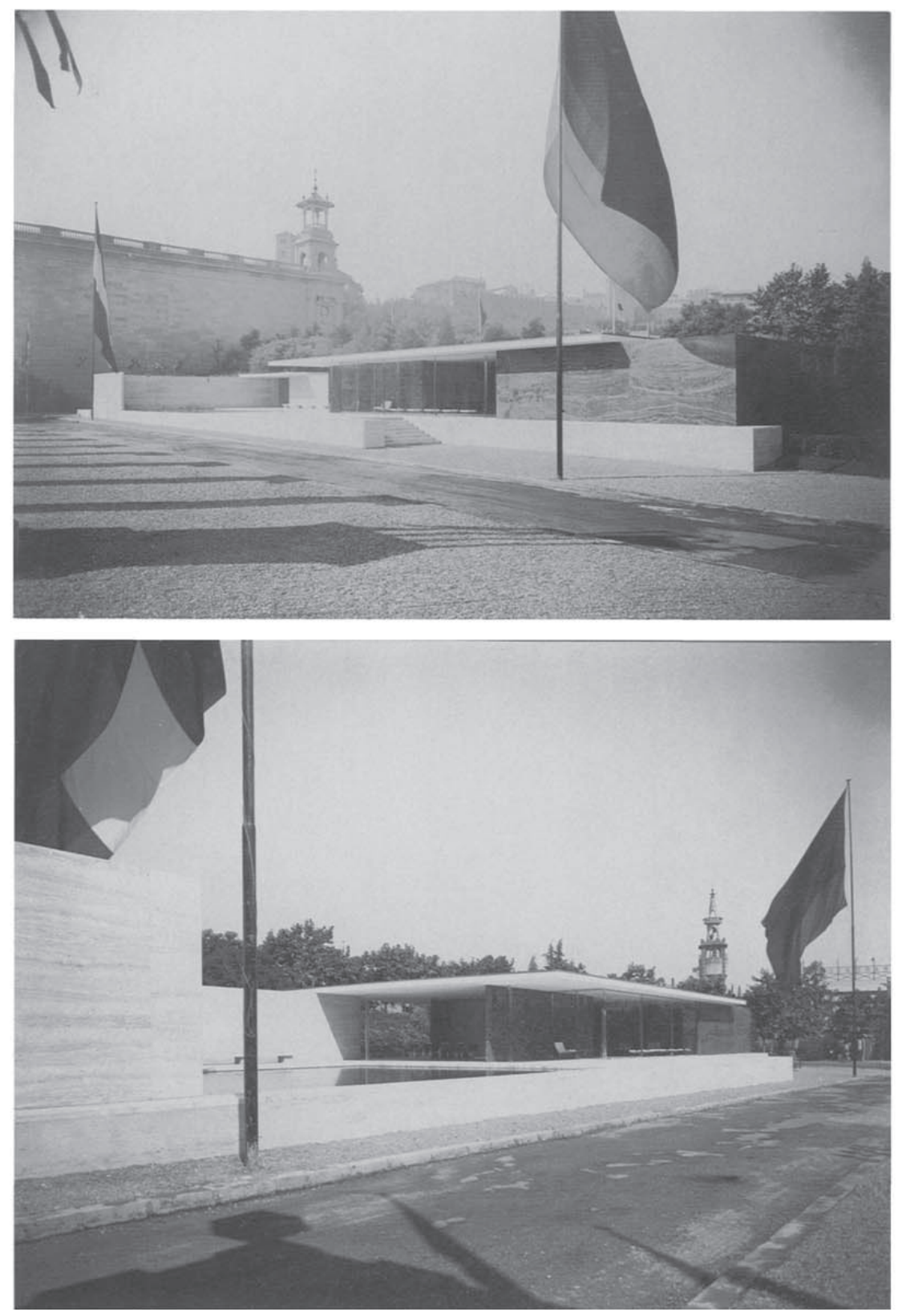

Figure 1.14 Plate 1 MMA 1554, Berliner Bild-Bericht, The Bauhaus Dessau Foundation (Dodds, 83) Figure 1.15 Plate 2 MMA 1797, Berliner Bild-Bericht, The Bauhaus Dessau Foundation (Dodds, 83) 


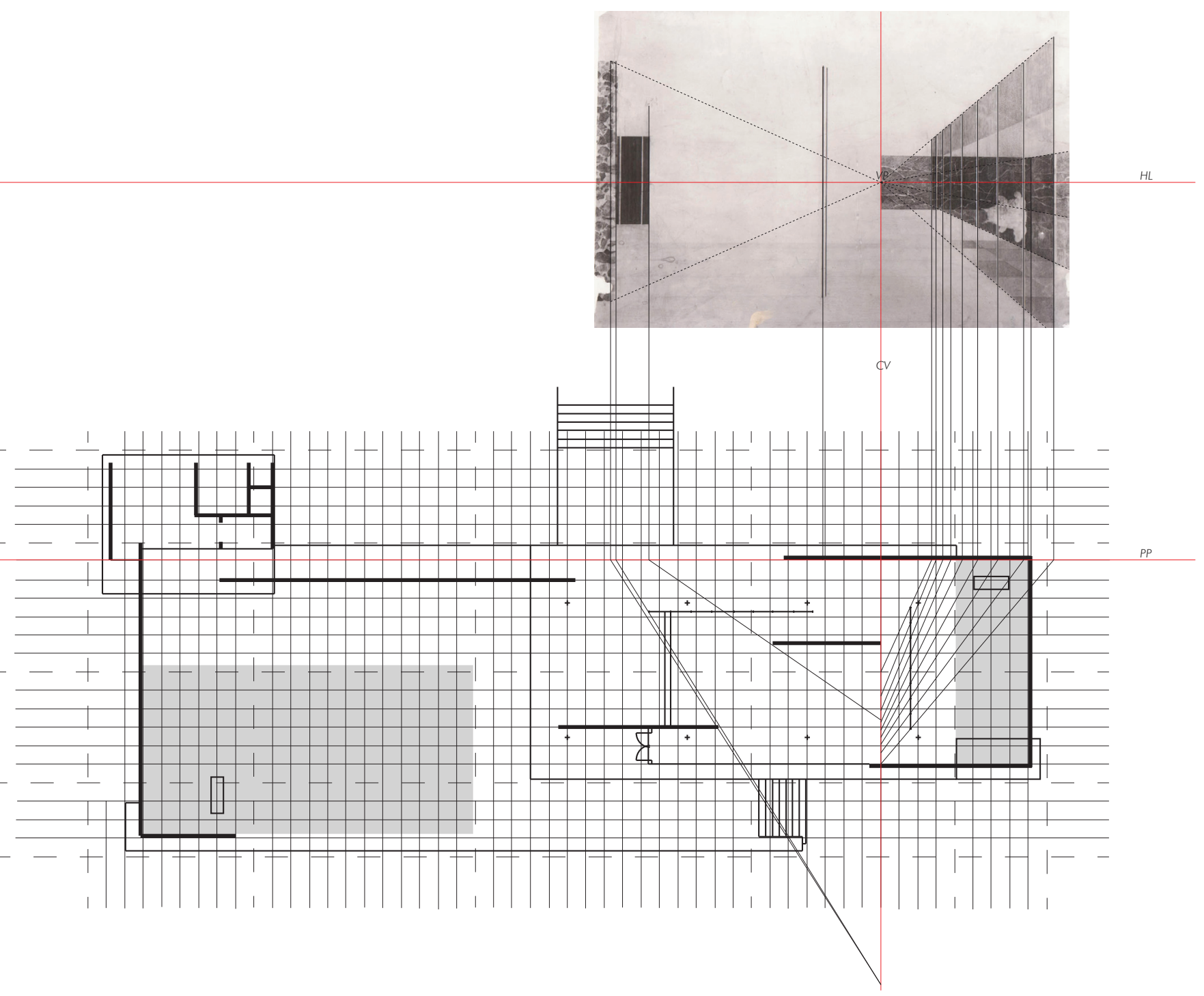

Figure 1.16 Geometric restitutiion from perspective to plan, Barcelona Pavilion: author's own. 
Through Mies' drawing are inconsistencies in the relationship between the interior perspective and the plan drawing of the Barcelona Pavilion. The correlation discovered between plan and perspective drawing is partial. The picture plane, horizon line, and ground plane remain constant, and the stationary point and vanishing point behave as independent variables. Drawing between the plan and the perspective revealed that Mies' drawing is a visual exploration of the implications of ocular 'flow', and the spatial response of an animated or moving body.

The conclusions from Mies' perspective drawing is that it was more than a representational drawing, moved beyond a perspectival proposition, it is also a depiction of an embodied ocular experience.

It is apparent that the 60-degree cone of vision (the notion of which is discussed by Panofsky), hasn't been used to define the extent of the 'view', instead, there are multiple viewing points. (This can be seen in figure 1.16). Piranesi's drawings, (figure 1.08), through the effect of changing the viewing position, can also be interpreted as if looking at the object in motion. The compositional structure of both of these drawings recognises an interpretative role of the viewer. They, therefore, are not static but have movement hidden in them. Robbers sums up the scholarly work by Paolo Amaldi, Robin Evans and Ulrich Muller as he agrees that Mies' architecture is perceived from the point of view of a moving subject, with Mies producing "paradoxical spaces that are the "properties of a changing gaze"" (Robbers, 43).

Figure 1.17 Diagram depicting movement through the plan 
The complexity in Mies' drawings was not accidental, (just as it has been said of the planned purpose of Piranesi's work). Evans writes of Mies' commitment to the excellence of the execution and to the perfection of the detail. He had a thoroughly developed intellectual - as well as spiritual - reason for everything he did as an architect. Mies reduced his buildings to the absolute platonic, pure minimum evocation of the idea, and so too, the drawing under analysis has been abstracted through geometric rigour. Author Luscombe has put that the pavilion's space is contained by geometry and not by a geometry of physical relationships, or proportions or patterns, but rather a geometry of evocations, of perceptions, of references (74). Evans is interested in this correspondence between drawings - gaps between drawing and building, plan and occupancy, projection and imagination. (Evans, 5).

Robin Evans summarises; that "Buildings are not always better than pictures show them to be, nor are they necessarily more significant than the theories that spring up around them." (Evans, 234). Mies' Barcelona Pavilion illustrates this point wholly in Evans view - shared by Juan Pablo Bonta - that "... the actual pavilion came a poor third against photographs of it and writings about it". (Evans, 234). Numerous authors including Evans and Quetglas of whom are quoted a lot throughout this research, and Tafuri, write graphical interpretations of the Pavilion, focussing on the photographs of it. When Bonta does refer to the photographs, it is indirectly focussing instead on what (and when) others have said about them. Bonta recognizes that it is difficult to make a general hypothesis out of a special case such as the Barcelona Pavilion. Further on in this chapter, I look closely at the photographs of it, still, for Bonta, any image of the pavilion is tertiary, and this is interesting to include. That is, he is more interested in the manner in which the word spread and how different interpretations related to one another than he is in attempting to render a precise reading of what the pavilion may have meant at any given time (Dodds, 35). 


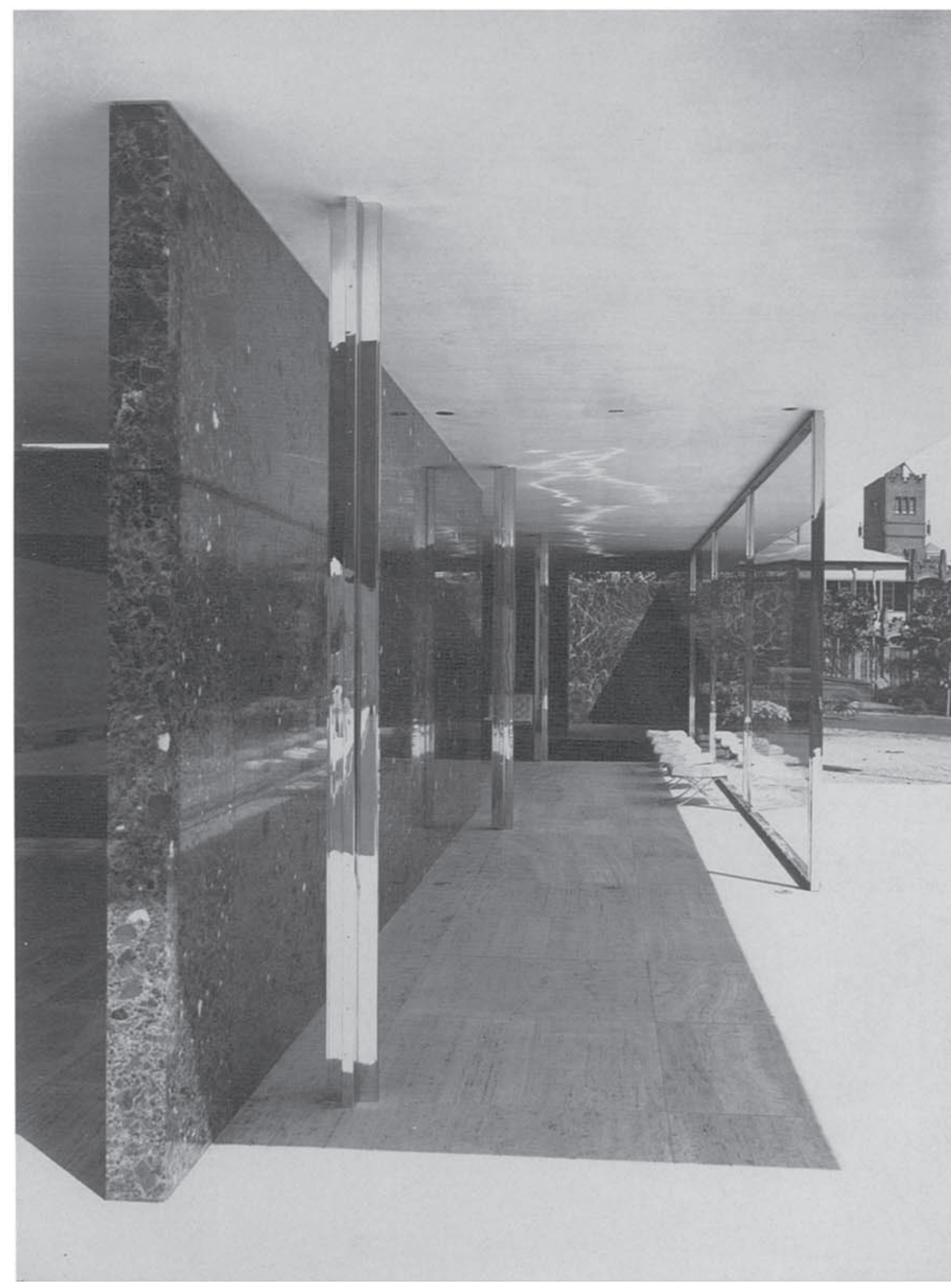


Building Desire on the Barcelona Pavilion, by George Dodds, has been an essential reading in the merging of all the writing. What initially seems contradictory of this perfectionism of Mies' work is Dodds' view that "Certainly, Mies was obsessed by certain craft-like aspects of architecture, but he was more concerned with idealizing and mediating techniques of graphic representation than with construction" (Colquhoun, 179). For Mies, interpretation and clarification are not the architect's job; but that of the critic. Part of Mies' implied working seems to have been to create ambiguous spaces in which the critic could operate. The pavilion has been designed to frame views, yet also becomes framed differently dependent on ones reading and interpretation (Dodds, 54).

It is apparent how so many interpretations have been evoked by such a means, and brings excitement that there are forever inconsistencies to be found.

Truth, in the traditional values of intellect and object, ideas and form, however, seems more consistent with Mies' oeuvre, and the Barcelona Pavilion in particular. Unlike many of his contemporaries, for instance Le Corbusier, for Mies, Truth in Architecture was not bound up in the clear and honest expression of materials, structure or function, but rather in the faithful correspondence of the image of the work with the intellect of the maker. That is, the relation of the image of construction to idea. Mies realised that the traditional relationship between the craftsman and his product had been destroyed by the machine. The Barcelona Pavilion displays the materiality of its building elements, but Mies has assembled these elements like montages; their connections are never visible (Colquhoun, 179). The construction of the pavilion was anything but pure and "rational", for example, the solid-looking marble walls were instead steel frames clad in a relatively thin layer of stone. This is referred to again in the case study chapter which discusses OMA's installation that dismisses the perception that the Pavilion is too pure and is devoid of people, time, past or tradition. 
This research looks to compare the architectural message - what is seen in the image - with the interpretation of the work. By acknowledging the importance of the process of interpretation a new consideration of architectural history arises; attention can be focussed not only on how architecture was designed but also on how it was seen. Imperative to the understanding of the historical status of the Barcelona Pavilion is the role that photographs and writings have played in the establishing of it. More than any other architect of his generation, Mies' career largely depended on reproductions of his drawings, photomontages, collages, and only occasionally modest sized buildings in periodicals, books, and exhibitions. Opposing to Bonta's views, interpretations of the images seem vital to understanding the reason for the photographs inducing the notion of perception through the space, mentioned earlier in the essay. Images create space that is able to be occupied, and it has clearly been considered in the making of the image.

Referring to figure 1.19 the photograph narrows the visitor's line of vision forcing one to adjust to the framed views. The interior consists of offset wall planes that work with the low roof plane to encourage movement, activating an architectural promenade where framed views induce movement through the narrow passage that opens into a larger volume. This cylindrical process of moving throughout the Pavilion sets in motion a process of discovery and rediscovery.
Figure 1.19

Plate 5 Seidman 249, Berliner Bild-Bericht, The Bauhaus Dessau Foundation (Dodds, 87)

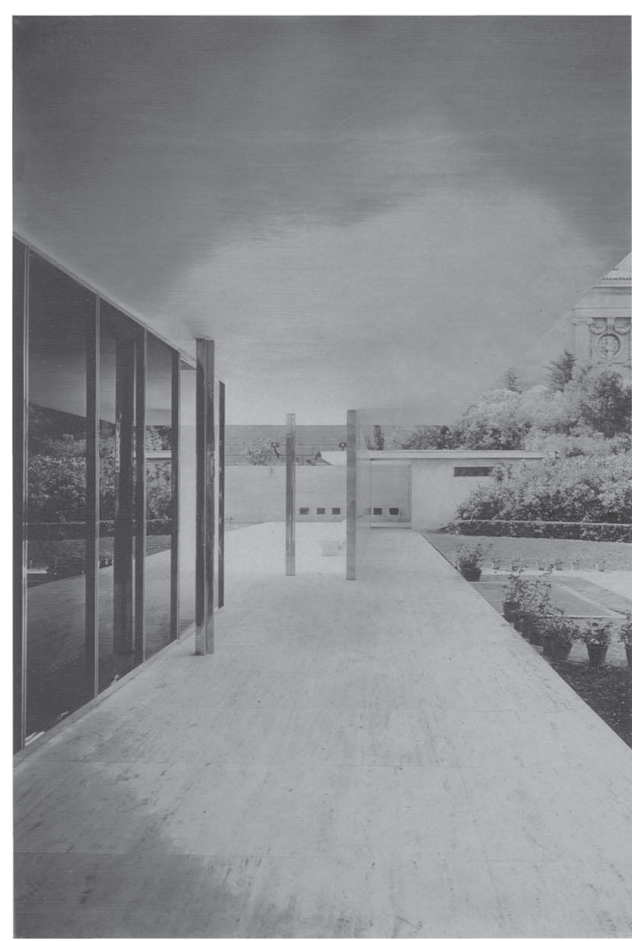


Luscombe's analytical perspective drawing study of restitution found all viewing points can be plotted along the same axis. The multiple viewing points suggest that the viewer is moving, although not smoothly, along this axis, selecting and depicting a resulting collection of controlled yet sporadic visual investigations. Building Desire on the Barcelona Pavilion bridges the discussion of perspectival drawings, and Mies subtle manipulation of them, with the translation from drawing to form, primarily through the medium of the original photos of the Pavilion. Similarly to the manipulation of the perspective drawing, the original photos of the Pavilion had been edited by painting over them.

"By covering up its roughness, the ceiling appears less, not more, like the highly textured travertine floor, suggesting that the architect wanted the photographs to highlight the difference between the two horizontal planes, not their similarity. Rather than wanting to create a horizontal symmetry that requires the optical equivalence of top and bottom, it seems more likely that Mies wanted to create a sense of horizon" (Dodds, 76)

It is important that the same emphasis on horizontality isn't reflected in the perspective, instead the freestanding centre wall has no defined top. There's much stronger emphasis on the vertical elements. Whether or not Mies was directly responsible for the alterations to the master prints of the photographs, and while there's no proof, as a group they are considered more important than any one of Mies' surviving drawings of the pavilion and far more illuminating than his published comments on the project. Mies had a lot of say in what was publicised and exhibited which makes it difficult to imagine that he did not make, or direct, the alterations to the photographic images of his most famous work to date. Through the perfectly defined spaces, Mies' architecture is seen with theatrical reference and his drawings and photographs reference the performance through the spaces. Through the play of light and shadows in them, there's identification of reflection of movement with the sensation of the body: "That is, we see in the mirror what we feel in our body" (Dodds, 43). 
Architects and critics have written about encountering similar experiences through the pavilion, catching glimpses of their own figure reflected in the glass, then others, confusing and enlivening the spatial reading of the place. Disorientation is attributed to the mirrored surfaces, labyrinthine path and the absence of an exit. "Evans's and Tegethoff's claims, on the other hand, are dependent on an absence of movement - on limiting one's vision to framed, static views as a photographic image would suggest" (Dodds, 77).

It becomes interesting then in how it was reconstructed. The Pavilion is so familiar to historians and critics that, even by those who knew it solely from photographs and drawings, through the rebuilding of the pavilion it allows fresh insights into the photographs. The canonical prints of the Barcelona Pavilion have had an influential hold on generations of interpreters, subsequently, this accompanies misstatements and inaccuracies in virtually all publications of the Barcelona Pavilion. It is realised by those who have analysed the original drawings and photographs and in turn, visited the reconstructed Pavilion that a degree of detachment consciously exists between the original and its replica. The replica is, indisputably, a reinterpretation. Any attempt at historically reconstructing the Barcelona Pavilion, (or any other building) risks a reproduction of the image of a building and, more importantly, an image of its builders.
Perhaps the most productive question raised by the reconstruction of the 1986 pavilion is not how closely the new building reflects the first one, but of the ultimate correspondence between idea and image, between truth and fact that so preoccupied Mies throughout his career.

"Not only do the photographs from 1929 not "pale" in comparison to the new building in Barcelona, they seem somehow to become more vital, more intriguing, and, if possible, more colourful than before" (Dodds, 38). It makes sense through both media that for Mies, the objective accuracy of the plan (or plan to perspective) was less important than its correspondence with his ideal of the plan and the plan-as-idea. The correspondence of truth and fact is a correspondence of idea and image. If the image of the work adequately reproduced his idea, it was, for him, true. The photographs and both Barcelona Pavilions are still isolated works, each uniquely authentic, and without thinking of their distinctiveness cannot be interpreted properly. Each an isolated work, they offer each a unique interpretation of them. An important summary to be remembered through the analytical studies of Mies' drawings. Having discussed the role of linear perspective, and its subjective nature that recognises a sensory role of the viewer, Mies acknowledged this as moving his drawings beyond representational. 


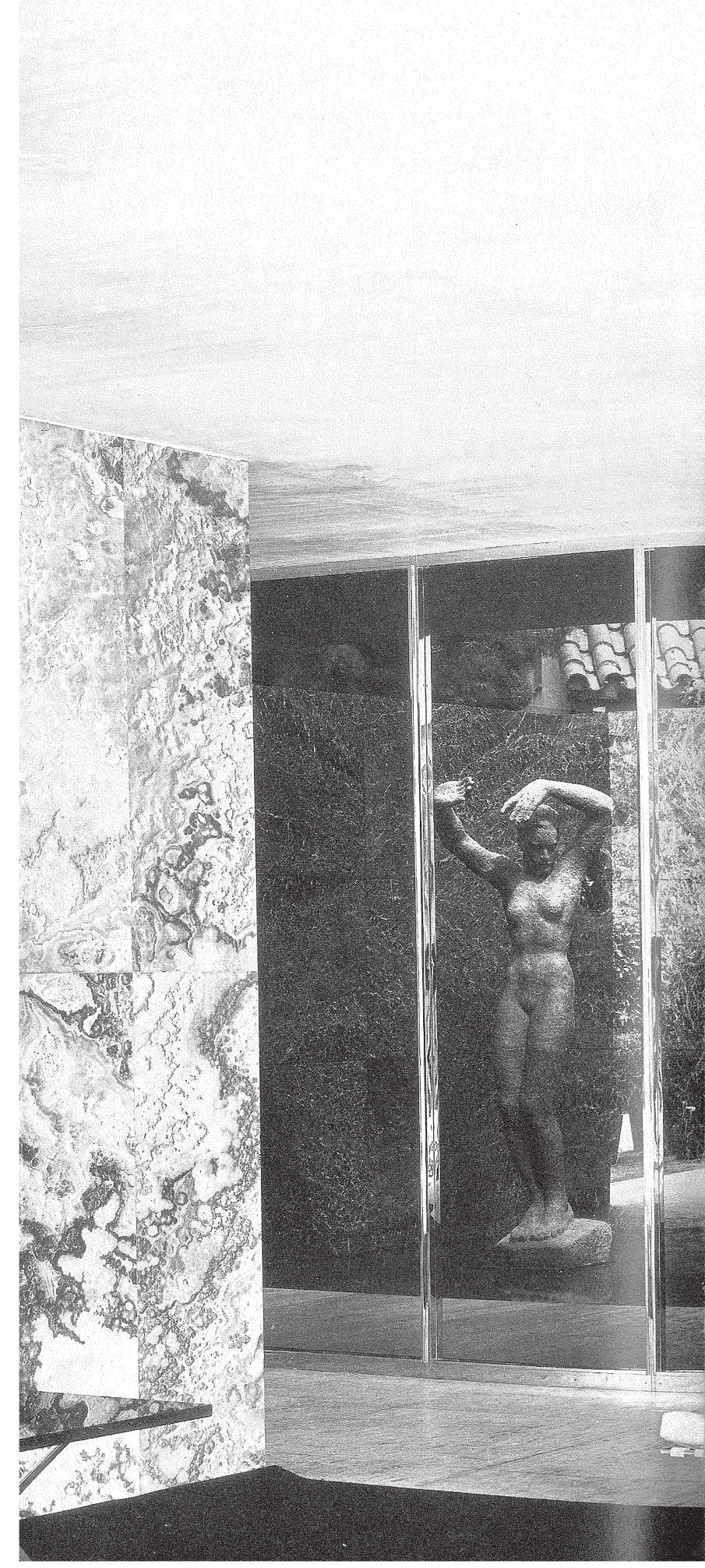

Figure 2.01 Barcelona Pavilion (Berger, Pavel and Georg-Kolbe-Museum, 90,91) 


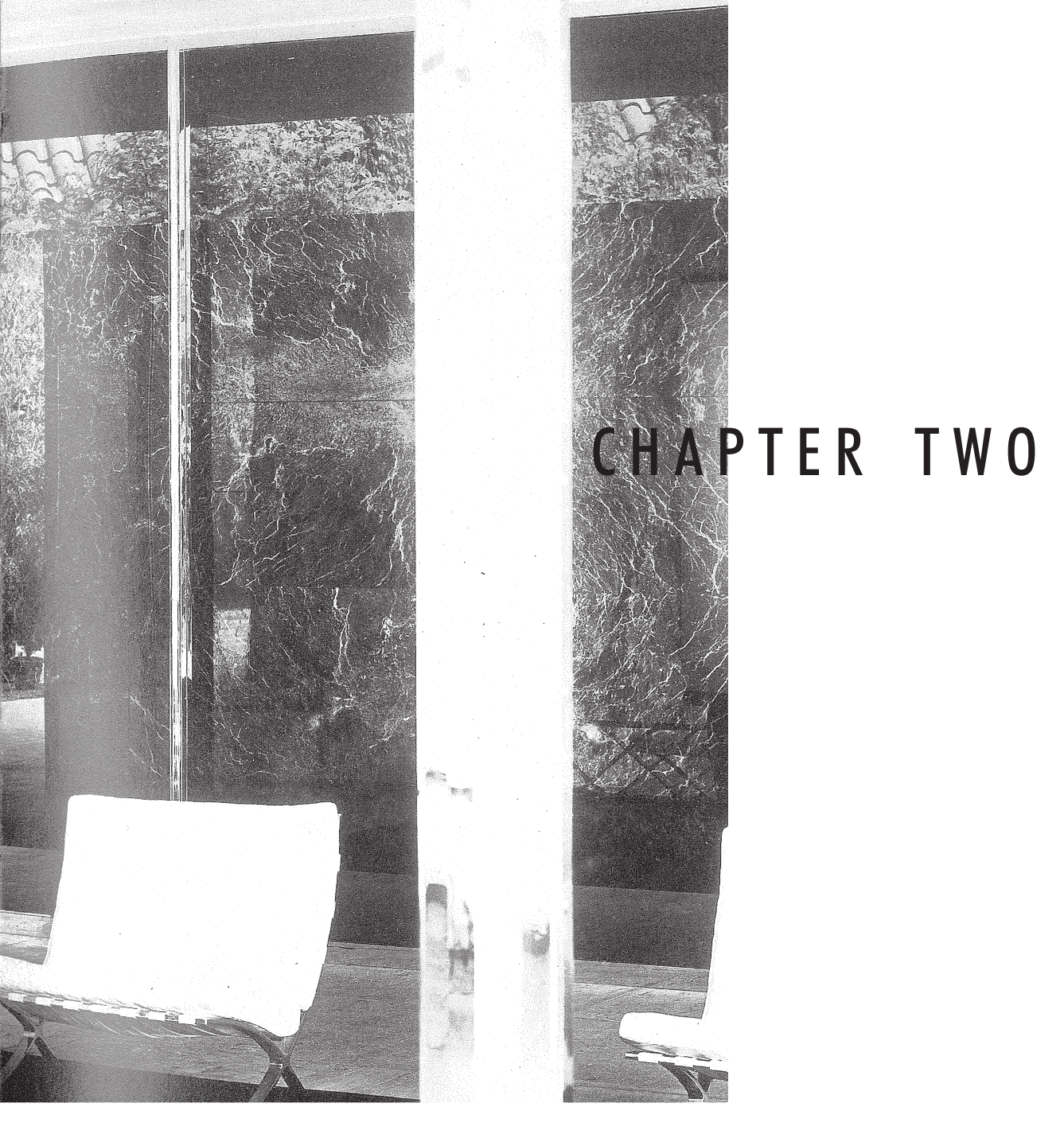




\section{PERSPECTIVAL ANALYSIS OF MIES' AND SCHINKEL'S DRAWINGS}

Correlation between plan and perspective

The universal ground grid seen in this plan is carried through the pavilion as a spatial module. Extending the ground plane grid upward as a cubic volume, it defines the base building block for the entire composition.

The module established by the grid creates a governing rule set for position and placement. This becomes important when analysing from plan to perspective. When tilted and viewed through a perspectival lens, the gridded plane establishes a recessional field. The concept of the grid has been carried out throughout the analysis of this work.

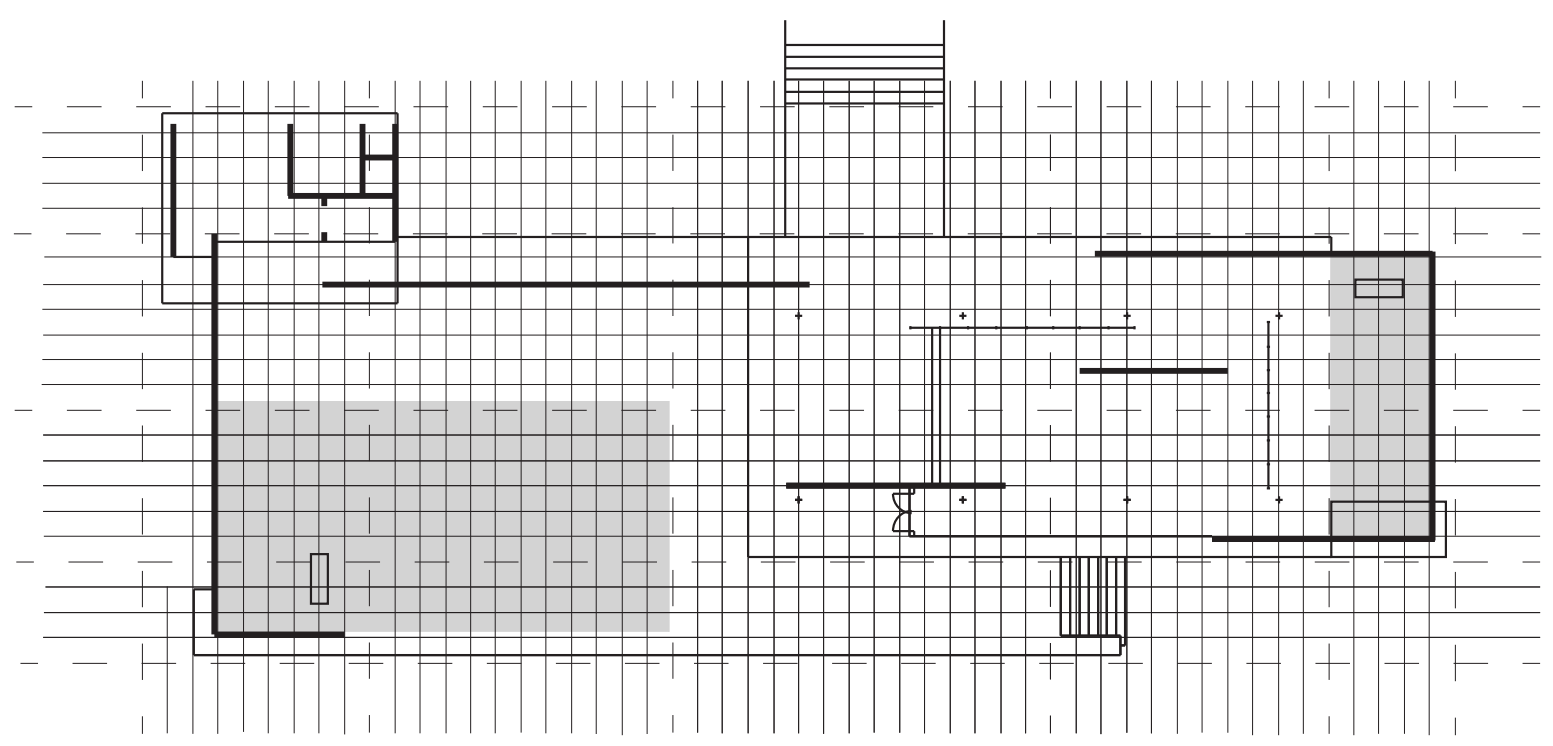

Figure 2.02 Plan of Mies van der Rohe's Barcelona Pavilion showing the Universal grid: author's own. 


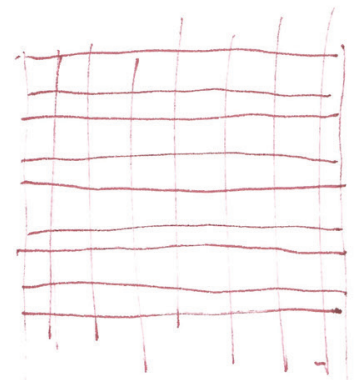

establish grid

$\rightarrow$ gridded volume

correspondence between grid in plan and grid in perspective?

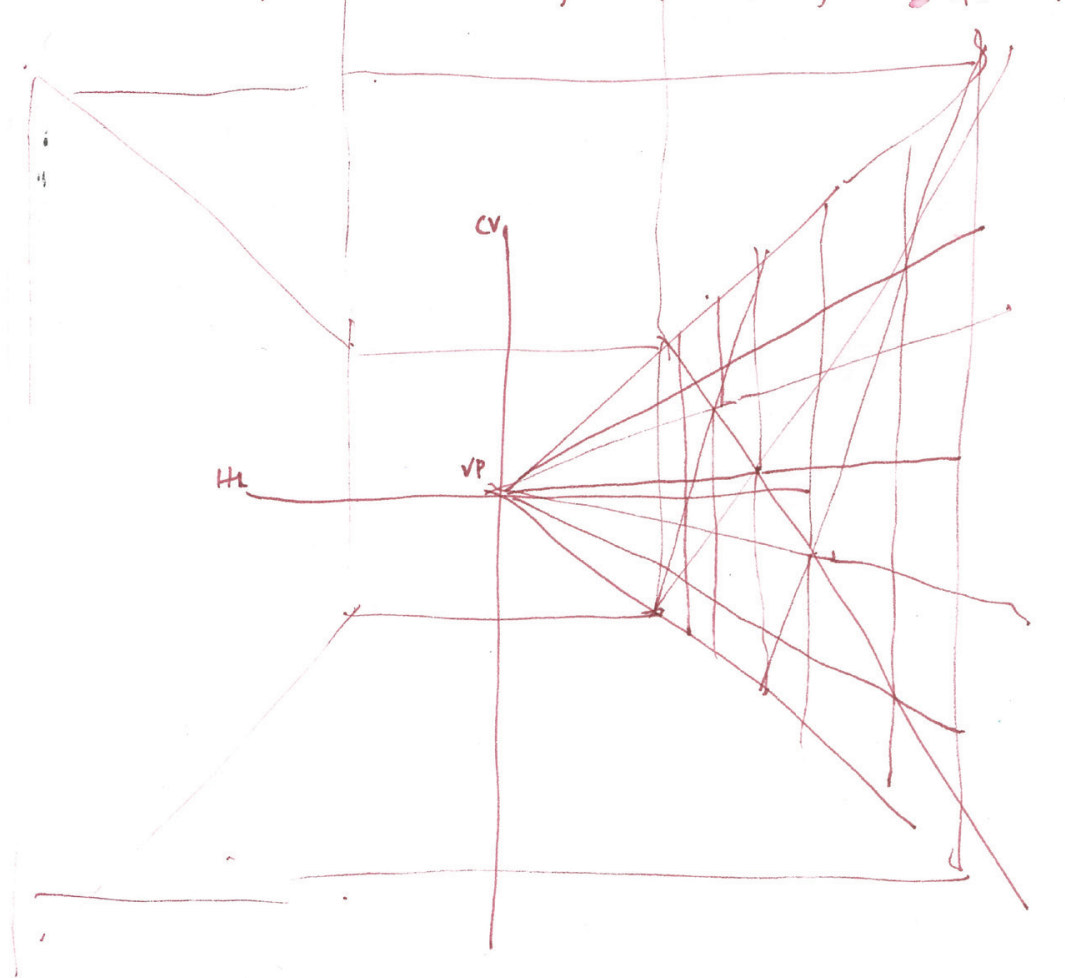

Figure 2.03 Author's sketch of establishing perspectival grids 
This is the underlying grid depicted from the drawing. It comes from a perfect square making up the dimensions of the freestanding wall, as shown in this image as well as two other squares which appear to position the column. It may be considered a pre-determined sheet size that gives the distortion of the image and forms the ambiguous and ill-defined depth of field evident in the scene, if not for the compositional accuracy of proportions. This grid has been used in wanting to understand how Mies' constructed his perspective drawings, and has been applied to others of his perspectives. In this drawing the square positions the column, and like the Barcelona Pavilion perspective also has a central vanishing point and horizon line.

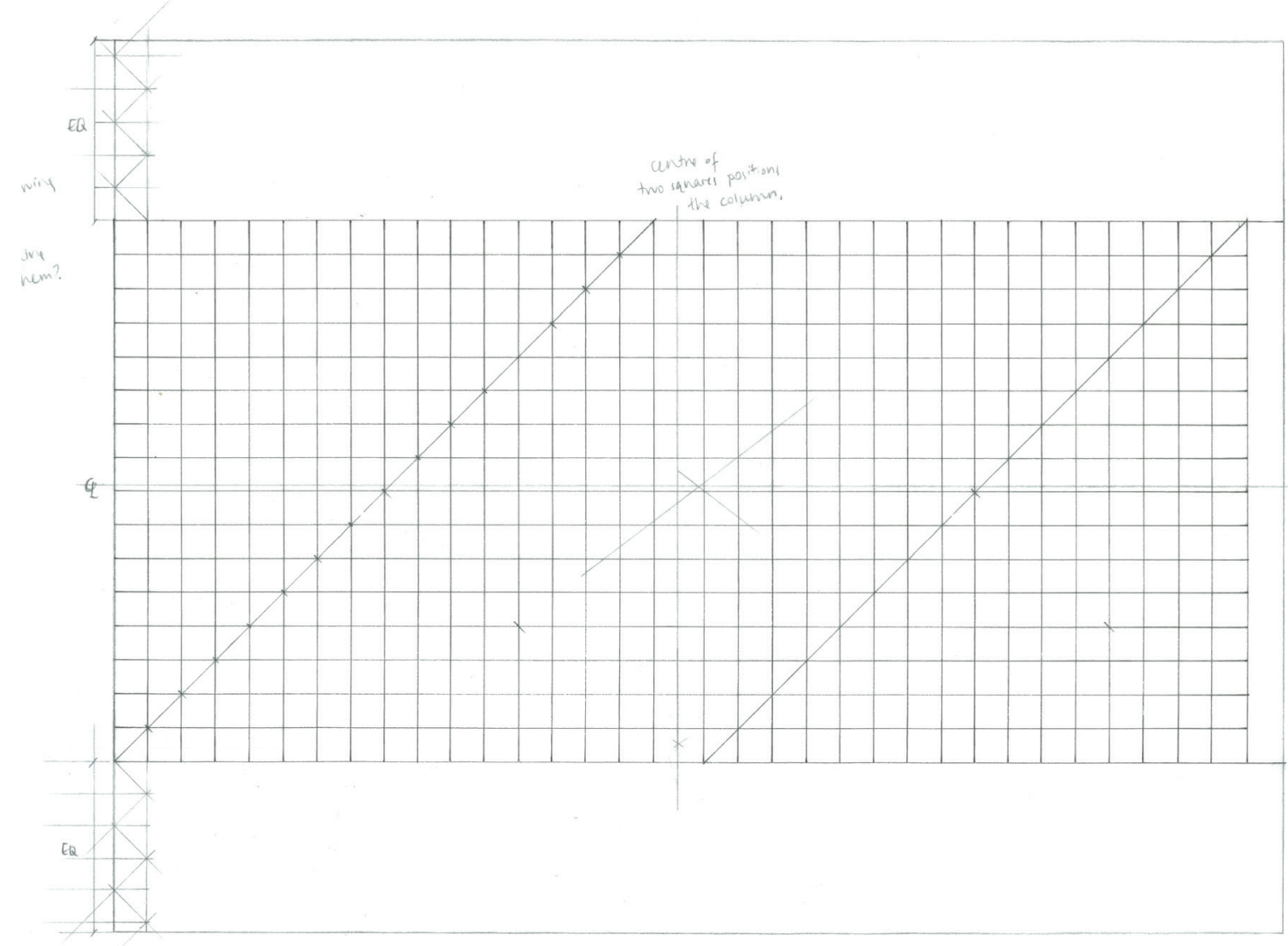

Figure 2.04 Establishing the grid: Underlying grid of the Barcelona Pavilion 
A grid was drawn over the Pavilion perspective, perfectly dividing it into $6 \times 9$ squares, and while the height of the back wall was not within the grid lines, the wall is exactly the same height as 1 gridded square.

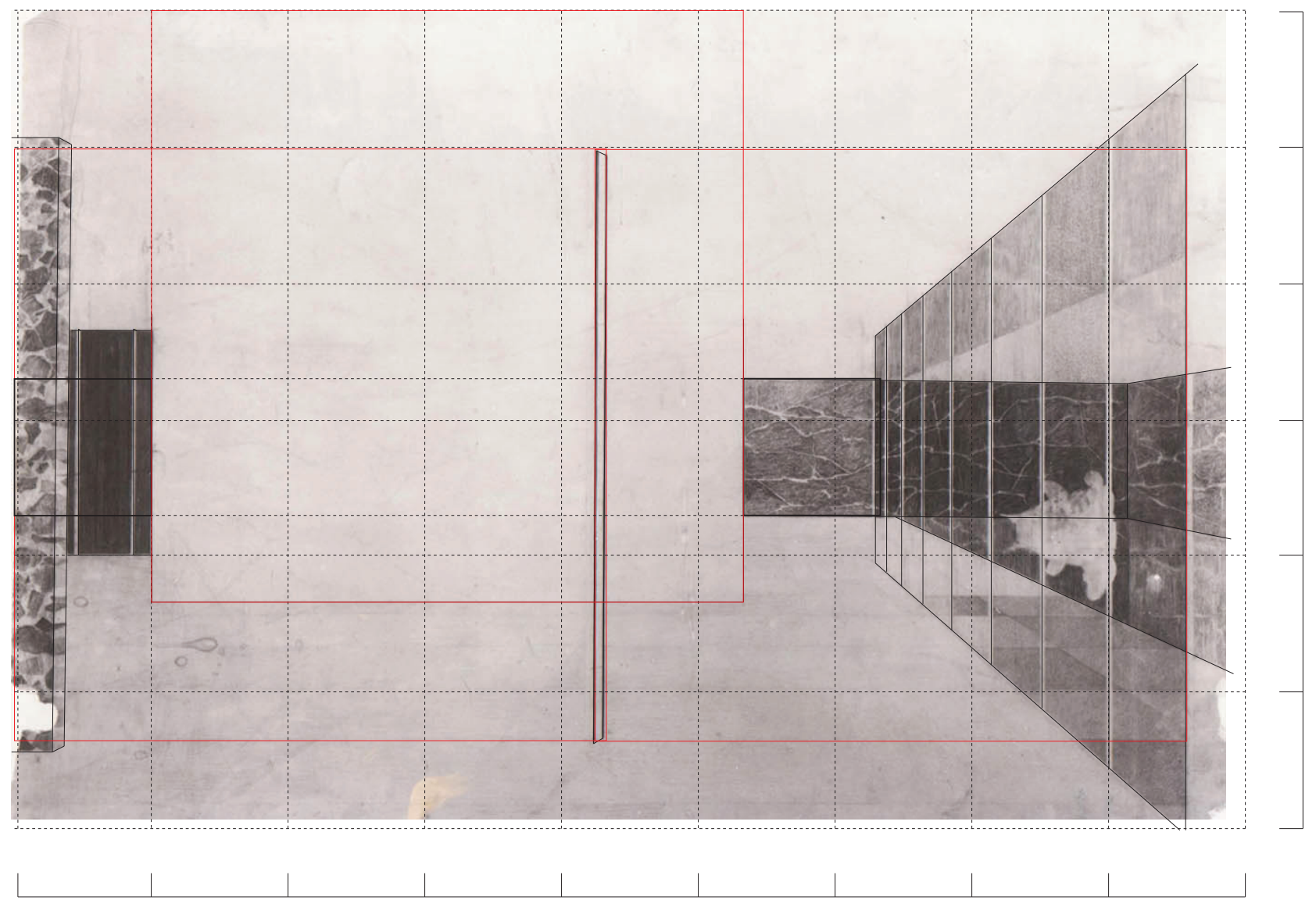

Figure 2.05 Alignments in Mies van der Rohe's Barcelona Pavilion Interior Perspective 

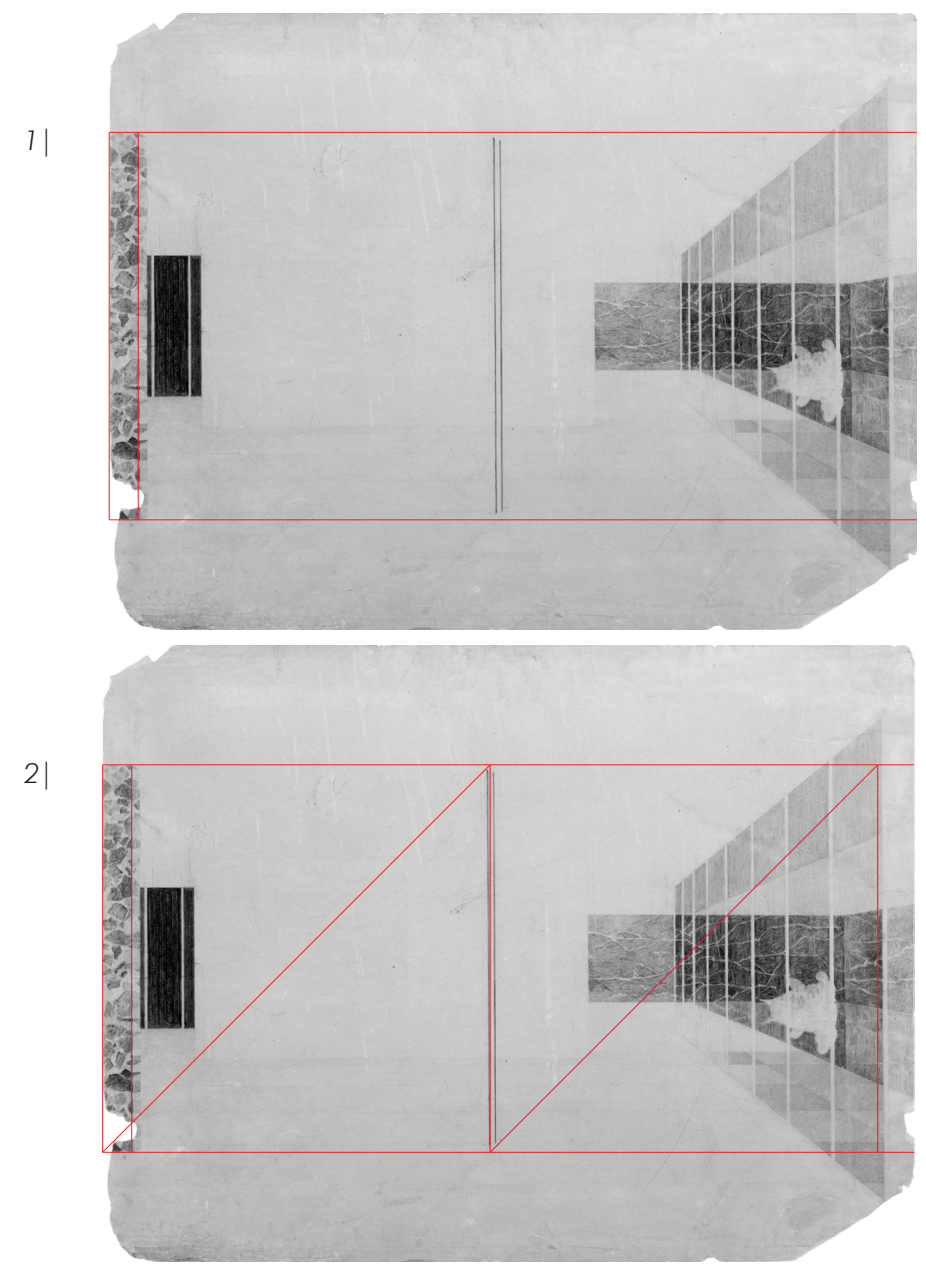

Further drawing out 45-degree angles to define squares within the perspective, and establishing the order in which each element is drawn in the perspective, establishes a method or feasible justifications to the composition of the drawing.

Carrying lines across the sheet from the top and bottom of the left wall (image 1), and creating two squares from the edge of the sheet has positioned both the centre column and the edge of the transparent wall, as noted above, and in image 2.

Dividing these squares again - into quarters- determines the height and positioning of the freestanding wall (images 3 and 4), and in splitting the primary square into $8 \times 8$ squares this seems to position the back wall (image 5). 

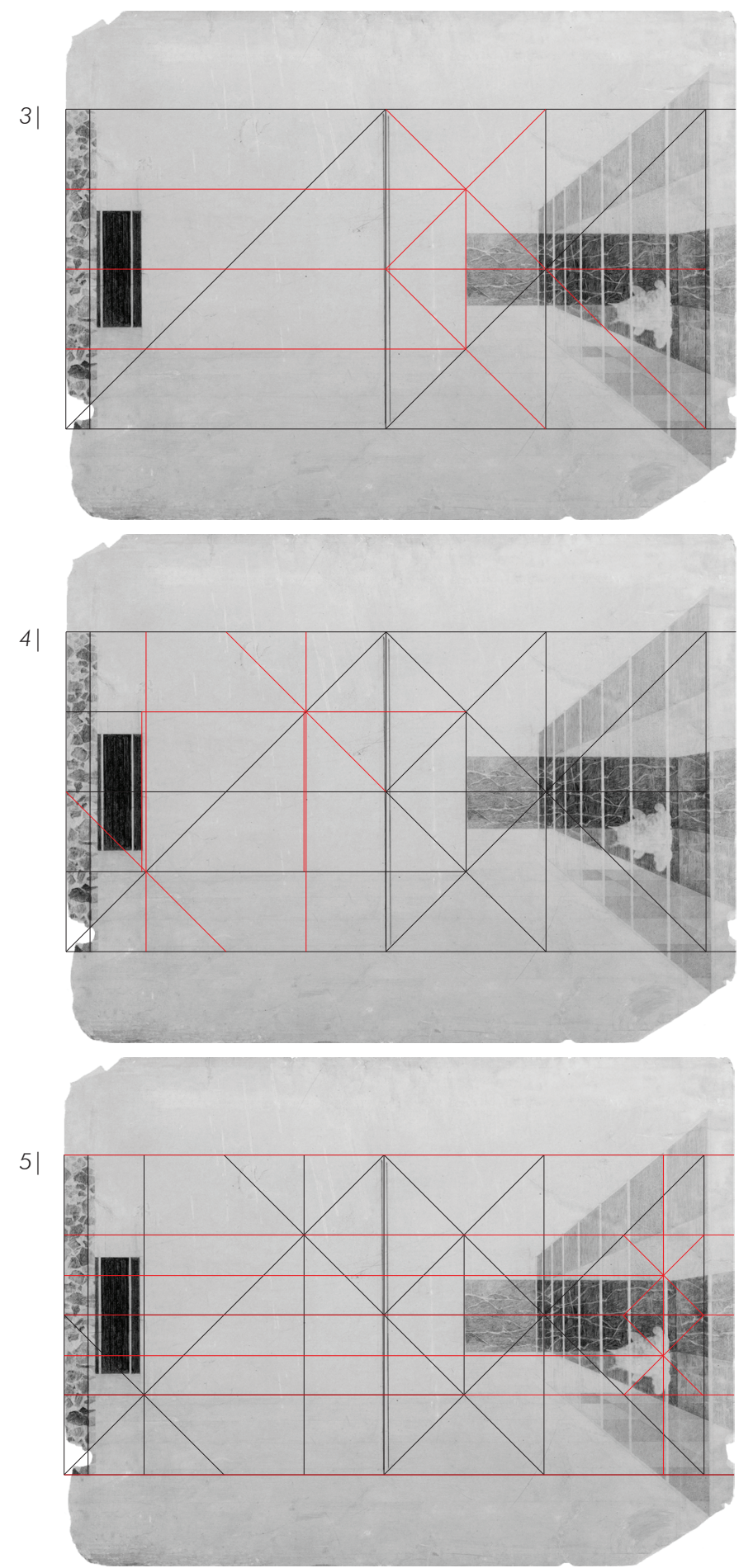

Figures 2.06 Unpicking the construction of the Barcelona Pavilion perspective 


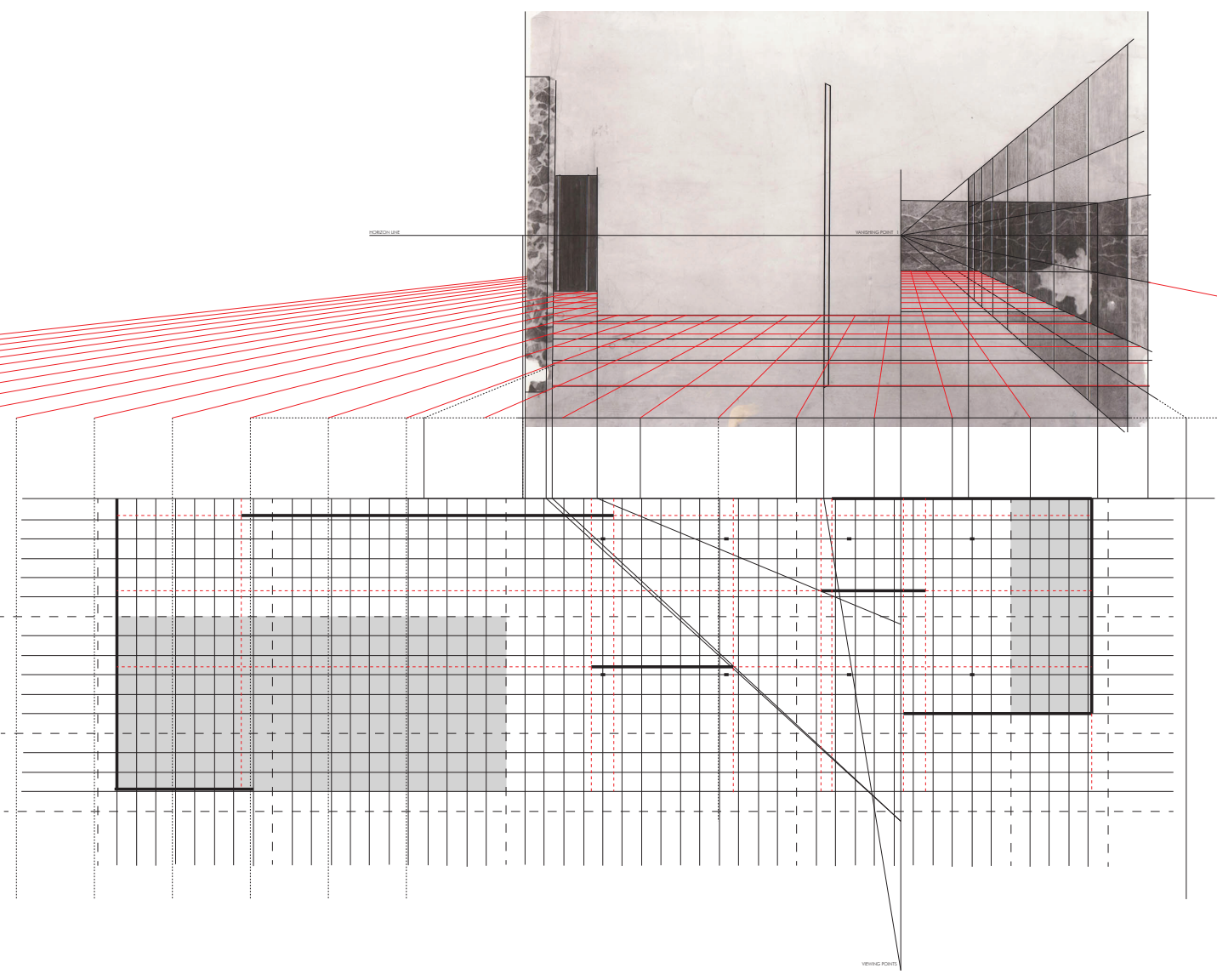

Figure 2.07 Investigation of perspectival correlation between plan and perspective 


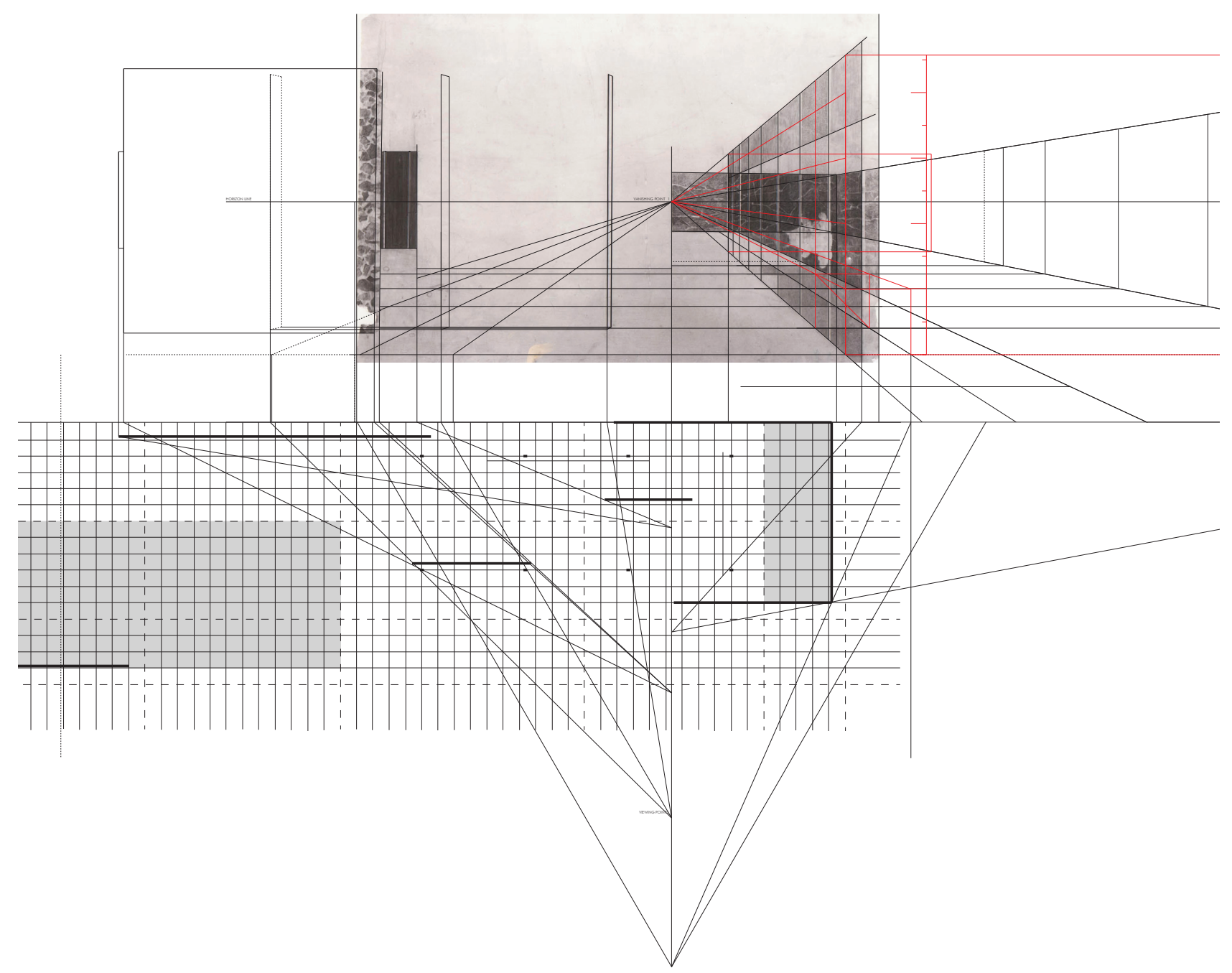

Figure 2.08 Investigation of perspectival correlation between plan and perspective, establishing a gridded field 
This thesis returns, through the process, to literature to reinforce the analysis that is happening within the drawings, and this solidifies the methodology. An instance of this was extending diagonals back to the vanishing point, as demonstrated in the sketch which placed the mullions in the drawing in the same position. The mullions had been drawn from multiple different viewing points shown in figure 2.09 .

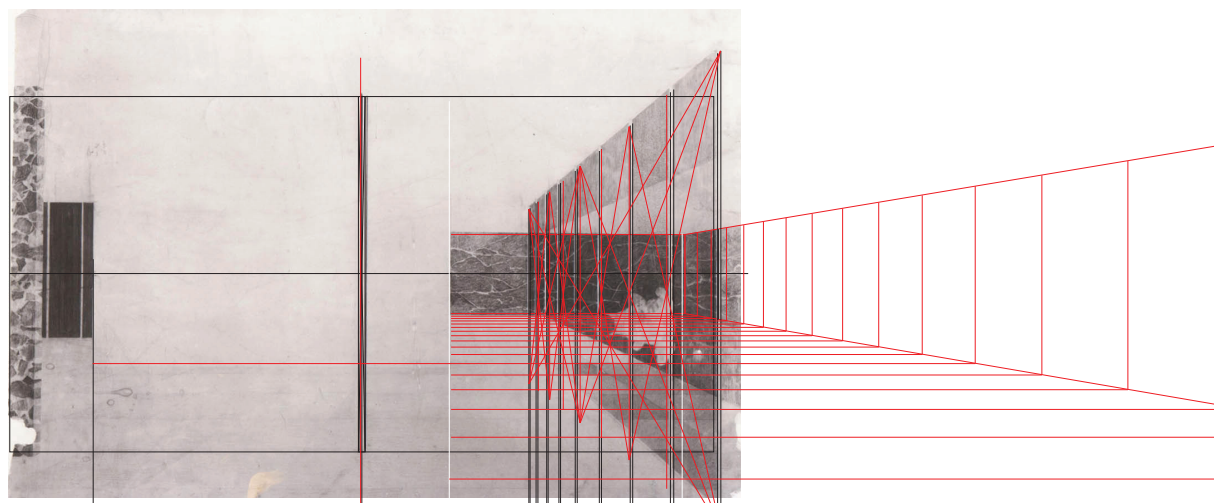


While it cannot be known for sure exactly what Mies intended, a series of 'What ifs' were queried and this has carried through the analysis. The explorations questioned, for example -

'What if Mies drew the perspective from a single viewing point?'

The restitution technique has been carried through on one set of the drawings, with no knowledge of the plan. The distortions of these are shown in the overlay of the plan generated in truth from the perspective, and the true plan.

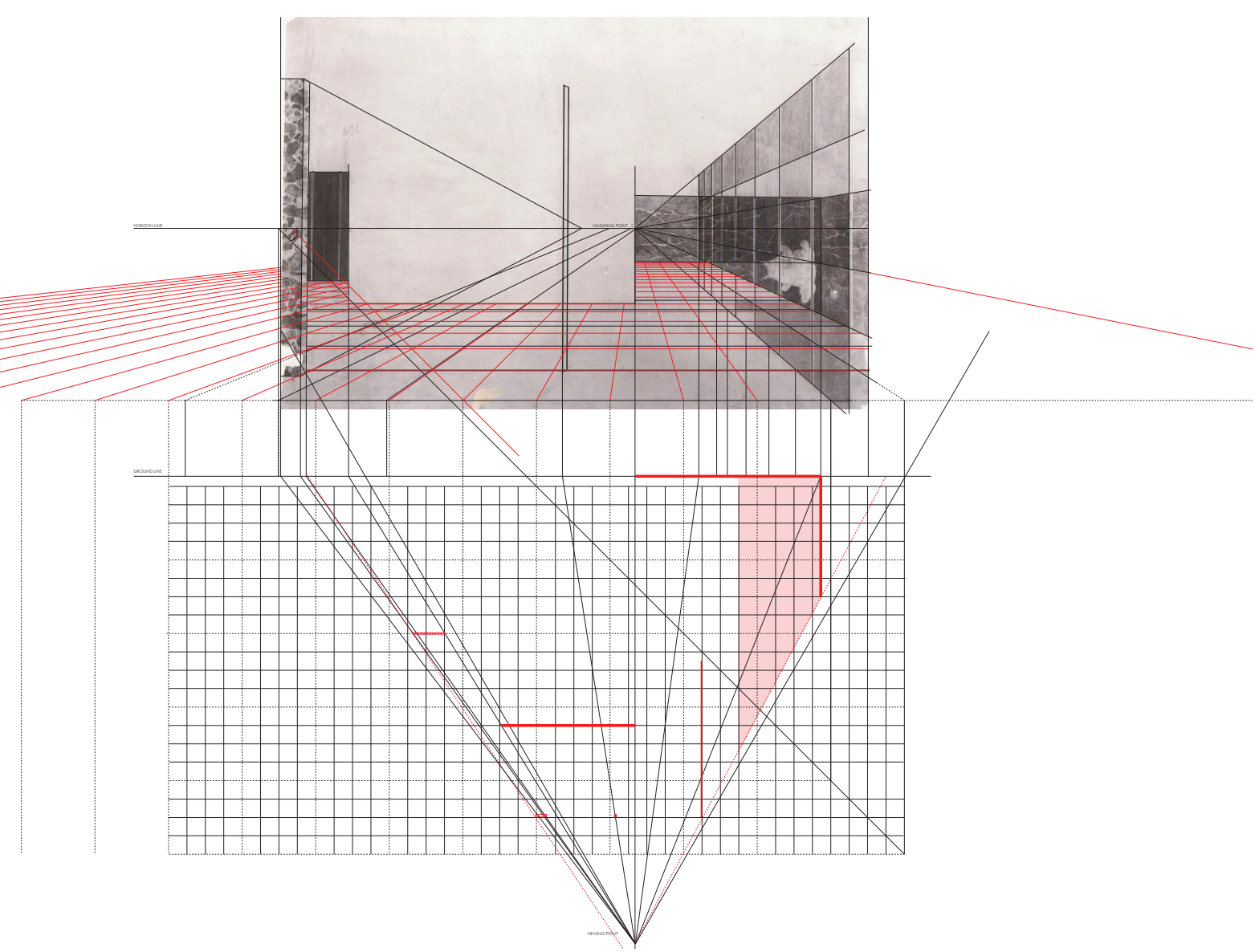


'What if the perspective was continued from outside of the framed view in order to continue to establish the correspondence of the architectural elements with the grid?'

The drawing of the rest of the image has been continued outside of the framed view in order to continue to establish the correspondence of the architectural elements with the grid.

The vanishing point is located at the precise coincidence of the edge of the main freestanding wall, and the axis drawn perpendicular to this horizon line frames the edge of the wall. The elevations of the freestanding walls in the space have been developed more in the manner of an orthographic rather than perspectival drawing.

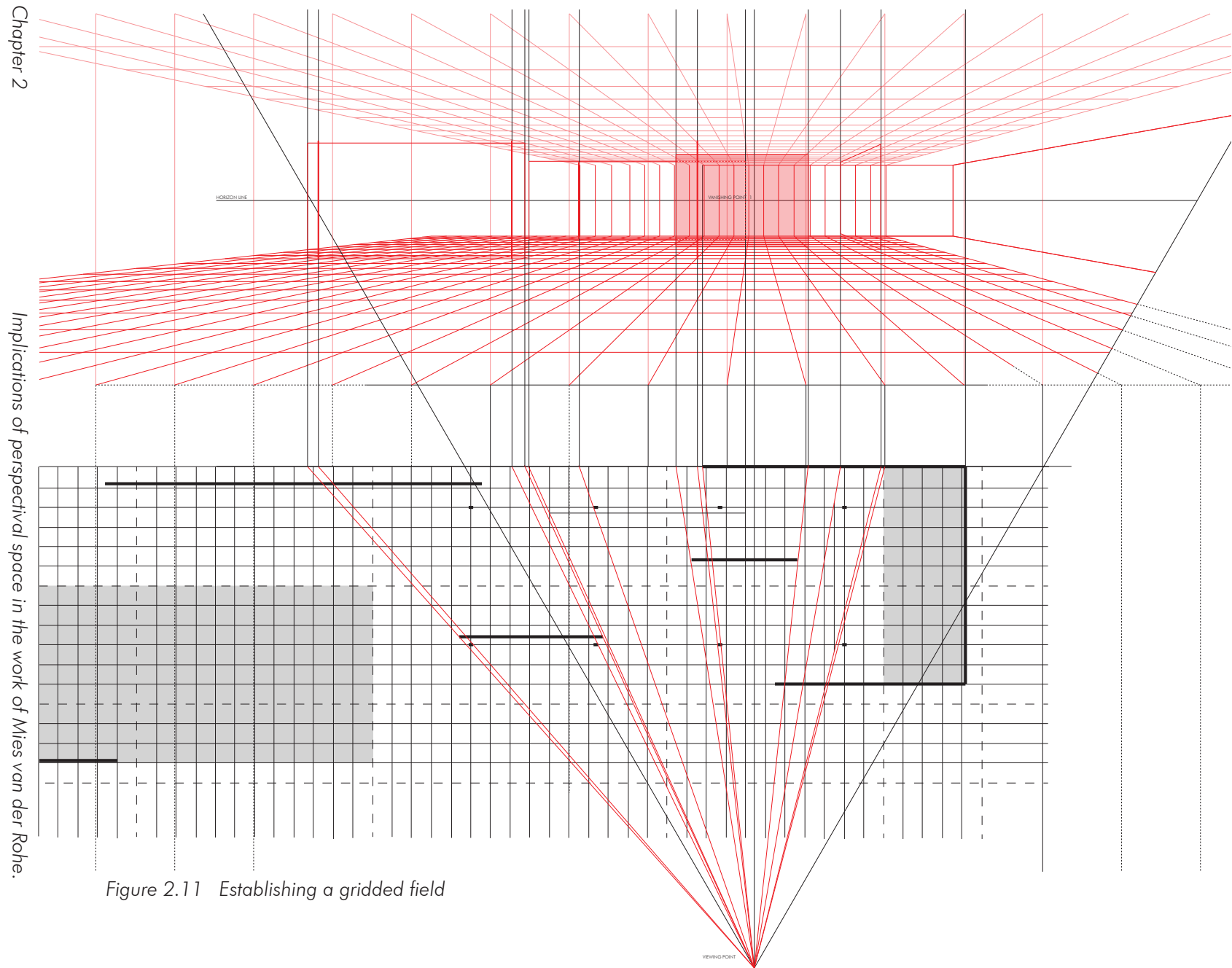


This is the space, as projected from one viewing point. If to consider this space in the same projection as his collage, it appears with such a different sense of depth to the scene. It appears more similar to others of his collages.
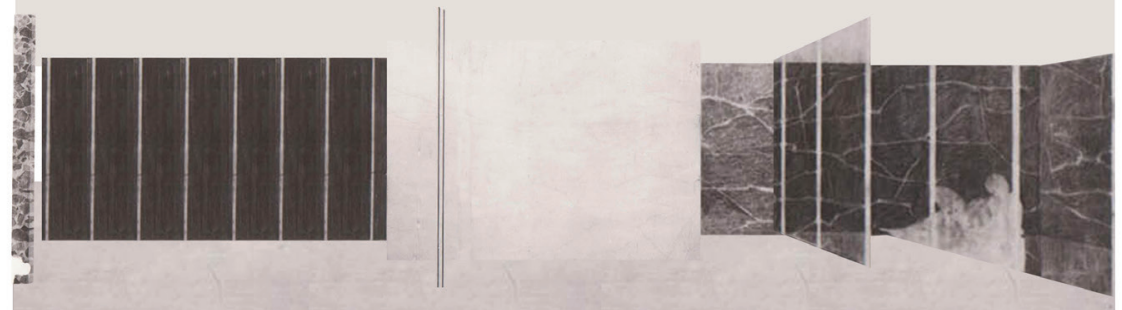

In this drawing on the following page, the plan and perspective from the initial restitution drawings have been resized so that both grids aligned - and this showed other alignments - questioning whether, unlike previously thought, the perspective grid was considered from the plan's grid. The plan's grid only aligns with the left side of the perspective, yet lining the centre of vision line with the edge of the freestanding centre wall, lines up perfectly the column in the perspective, with the line of columns in plan. This is not accidental. The column drawn in perspective is from a specific viewing point. It can't be a coincidence that the two most important elements in the perspective - the column that has been positioned by the overarching grid, and the edge of the freestanding wall that is the central visual plane for the construction of the one-point perspective drawing - align perfectly with the plan if to size the two according to their grids.

It is thought that if Mies was to have drawn from plan to perspective, he would have aligned the central visual plane with a more dominant single line on the plan. This continues the discussion there is between Mies' perspectives and plans, however, to carry through the restitution method again from plan to perspective will not be valuable as the alignments are beyond that. 


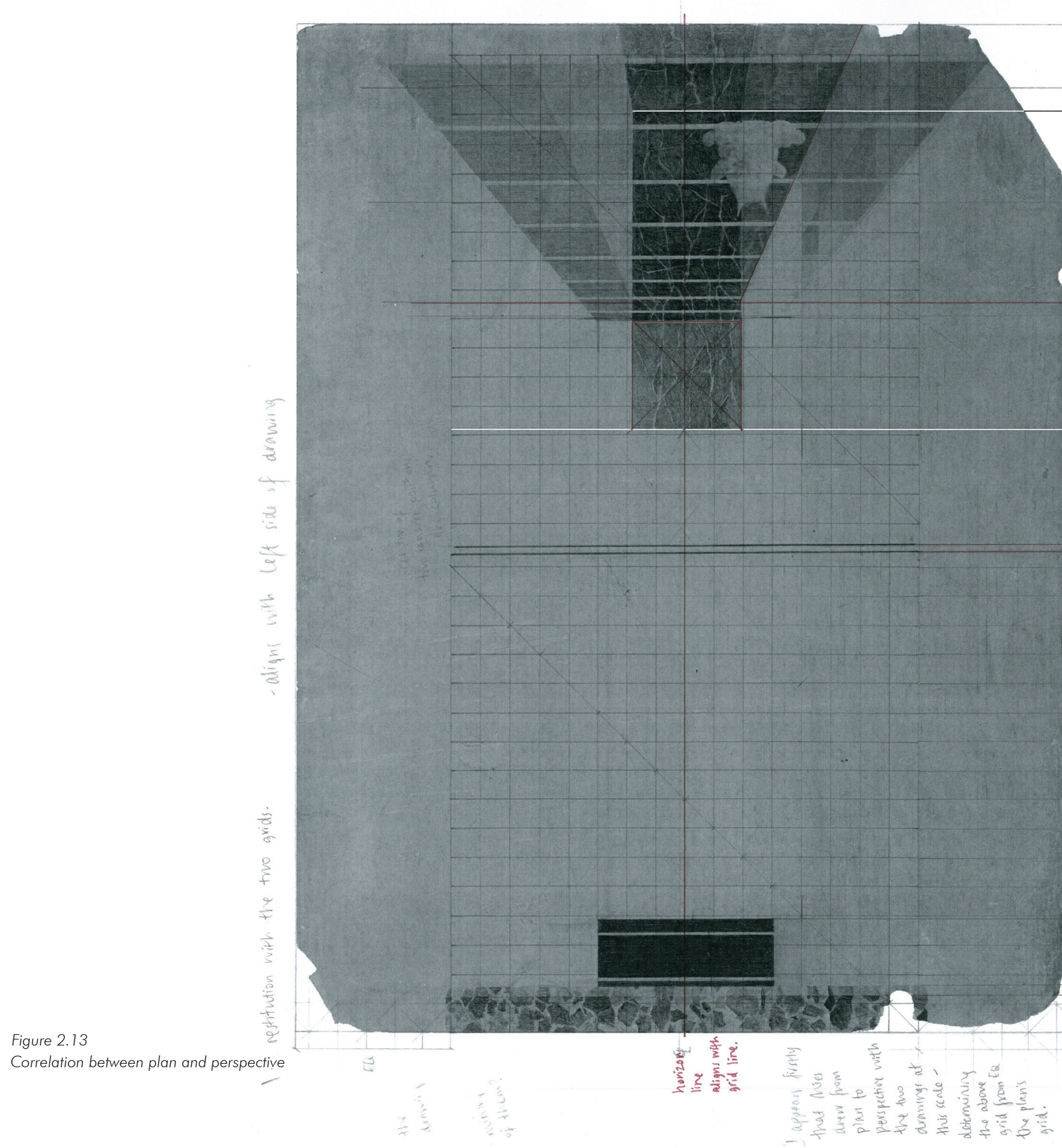


Further investigating the grid that Mies had set up, a line from the bottom of the centre column across to where it meets the transparent wall was carried downward, drawing out a 45-degree line, and at the intersection of the grid line, this was taken back to the vanishing point as a floor tile line. The centre of this, and at the same spacing as the first tile defines the edge of the pool. These tiles justified by this method, are the only ones in the original drawing that are in definition. It suggests that Mies drew this as a proportional exercise to set up placement within the grid before drawing the perspective down. Again iterating the perspective as independent of the plan.

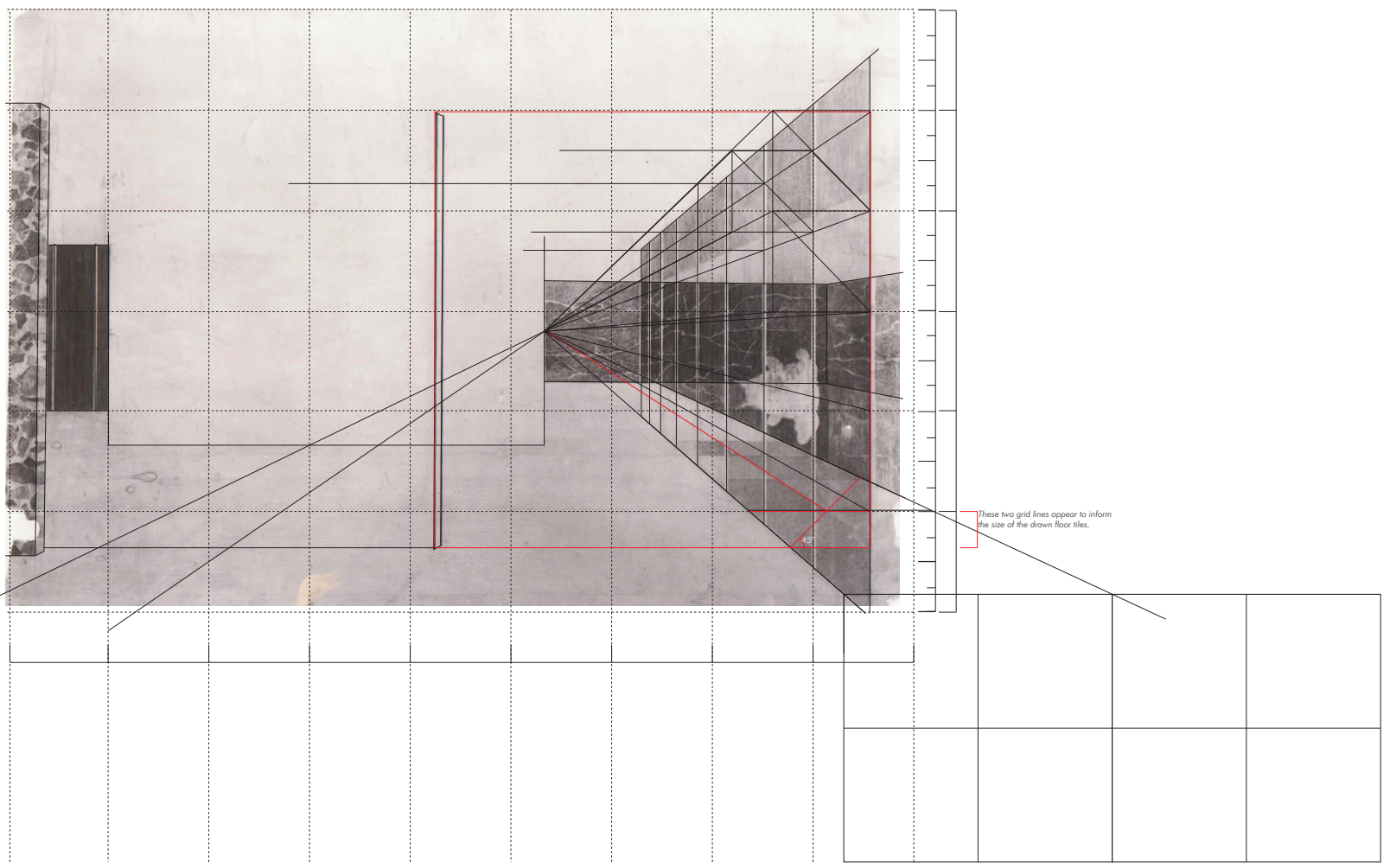

Figure 2.14 Breaking down the grid 
Measurements and further grids between the two drawings (plan and perspective) have been carried through the drawings. These show the repetition of a dimension in the drawing that corresponds with other points on the image and the division of the space into a horizontal grid that aligns with many points within the drawing. They enable justifications to specific elements of the perspective.

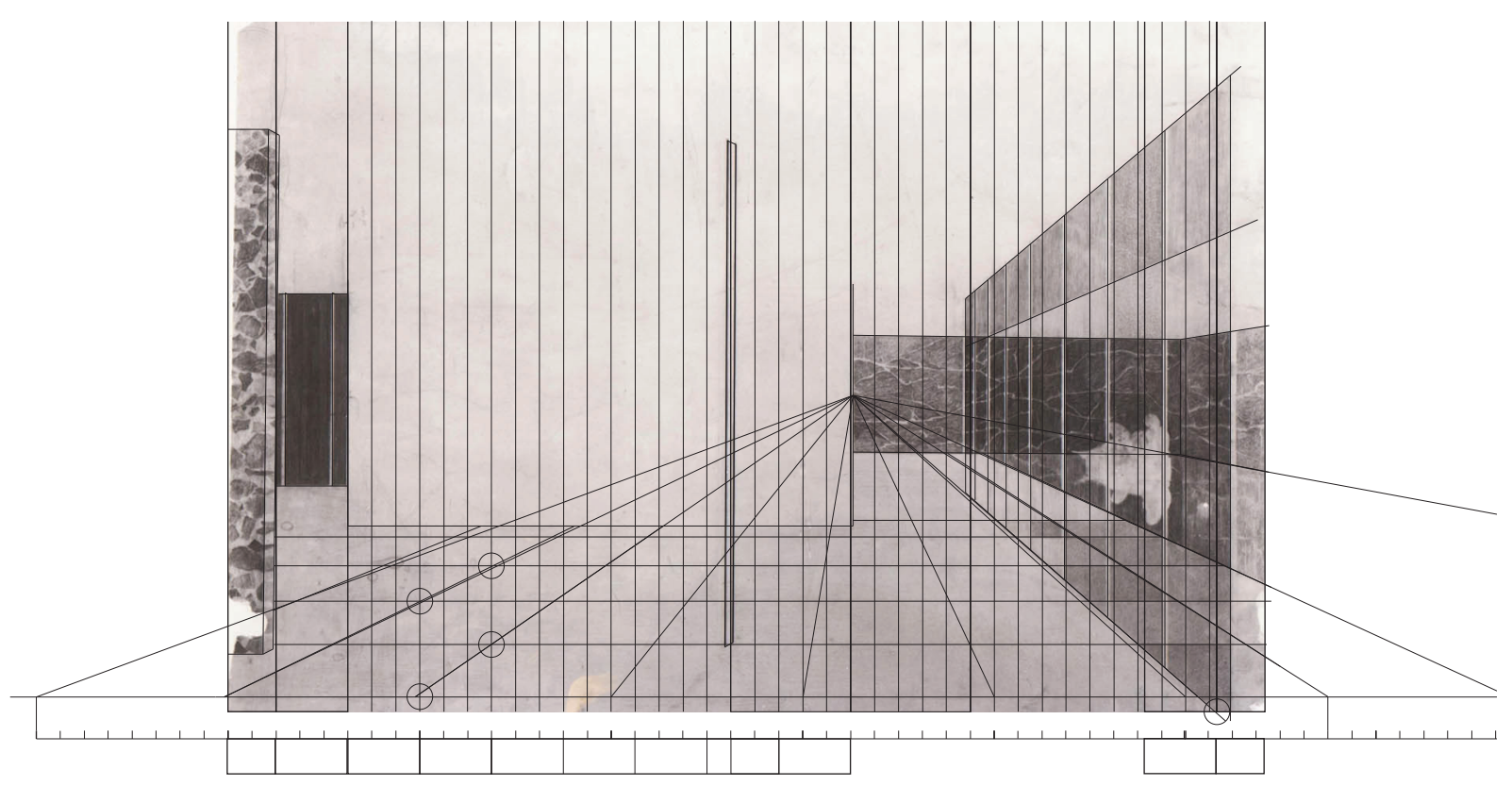


Shown by the dashed red lines each of the freestanding walls are located off the grid lines to divorce them from the static position of fitting together to make sense, and to optimise their individuation. The exterior columns fully align with the grid, they're governed in position by a standard, three-bay, square module.

In the collage, with not all of the ground plane drawn, Mies has indicated enough lines to show the fact that wall planes don't align with the floor grid, and that the columns, while not corresponding with the plan, align with the floor grid.

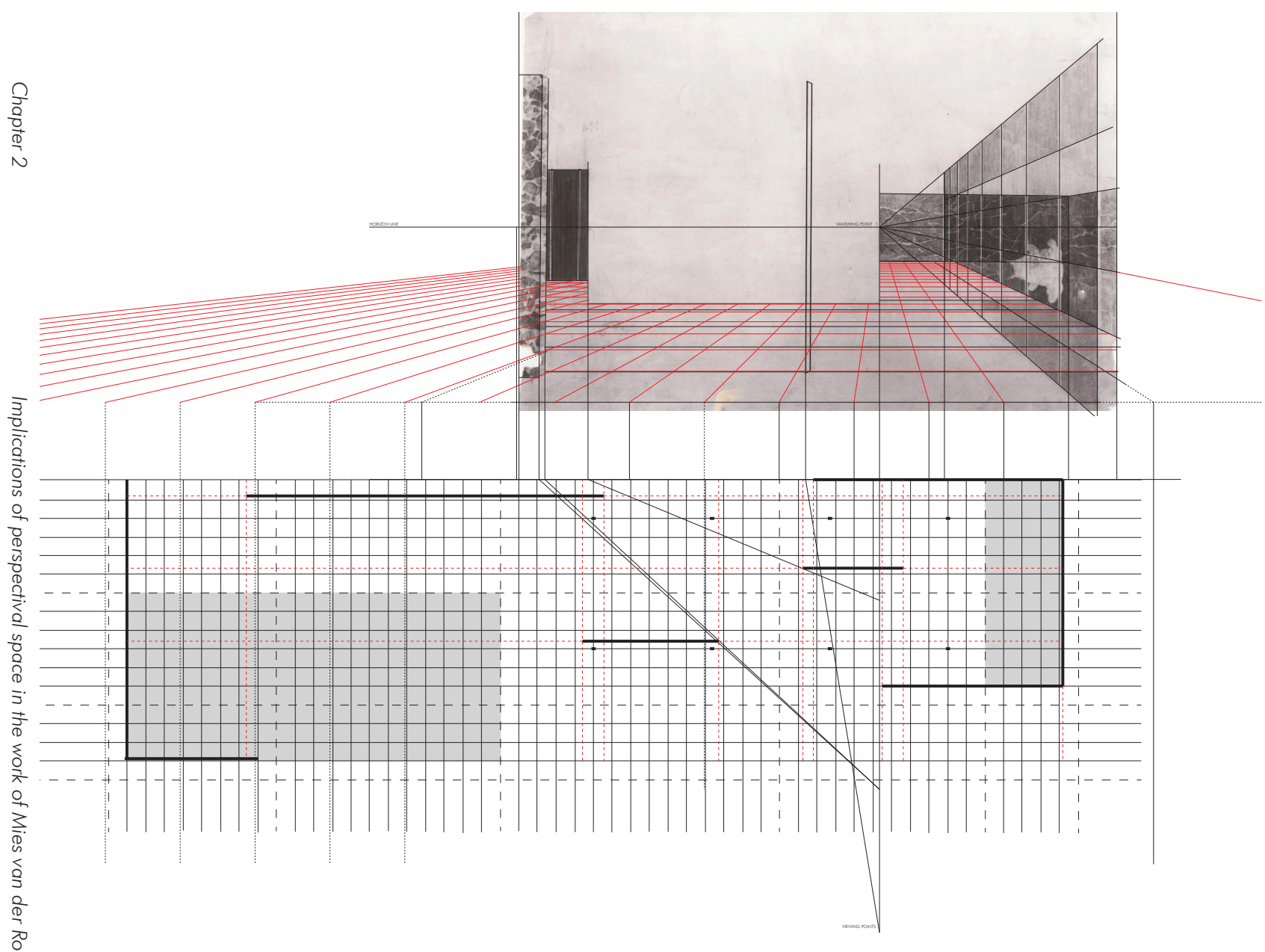

Figure 2.16 Relationship of the the architectural elements with the grid 
This drawing demonstrates an intention to carry the module through to align relationships from plan to perspective, and in a sense, elevation, and in order to do so one part of the drawn grid was carried down. This shows that regularity of the grid hasn't been carried through the rest of the building. If to fully construct a gridded module of the entire space, in real life the module would be stacked three high and would resonate in each of the systems.

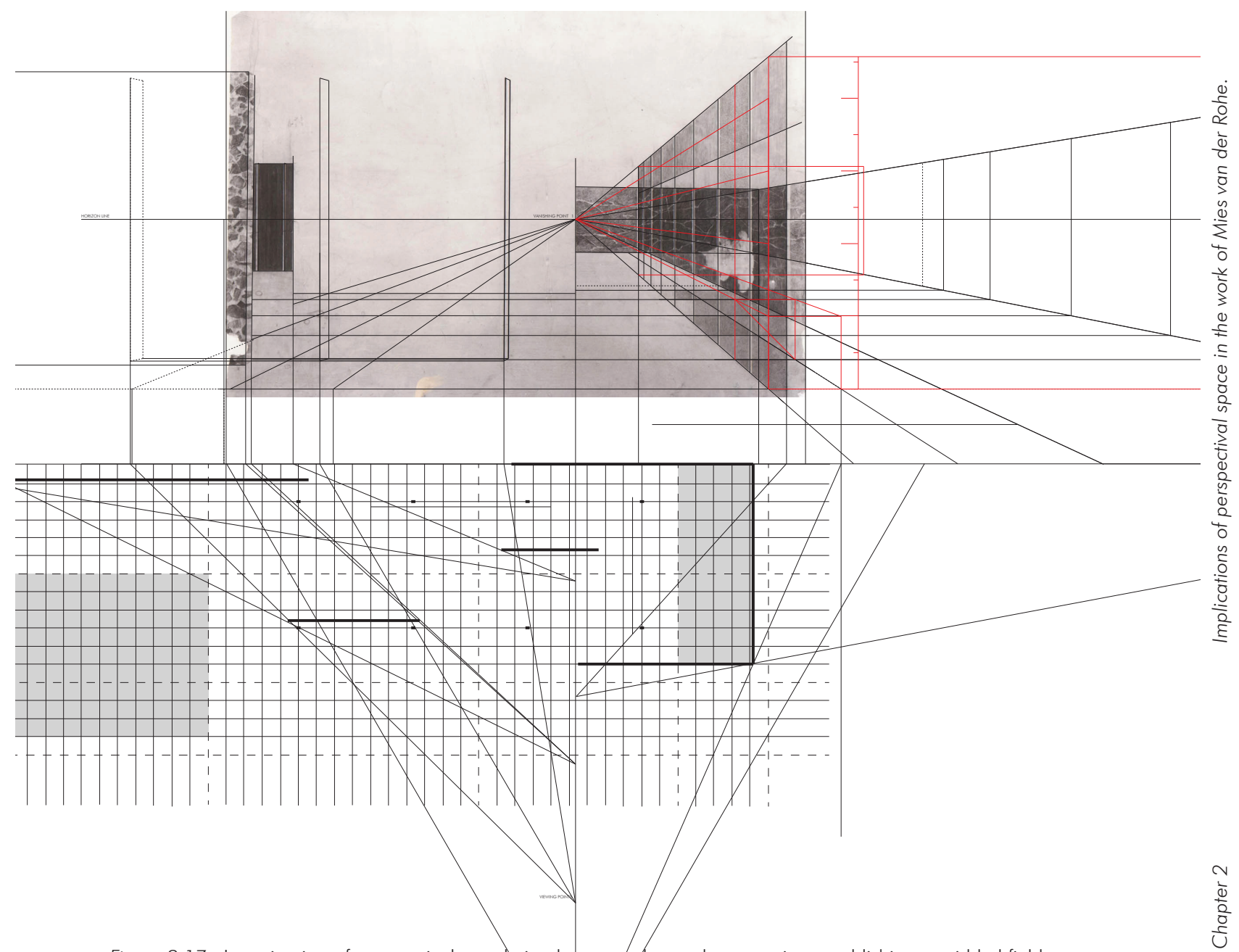

Figure 2.17 Investigation of perspectival correlation between plan and perspective, establishing a gridded field 



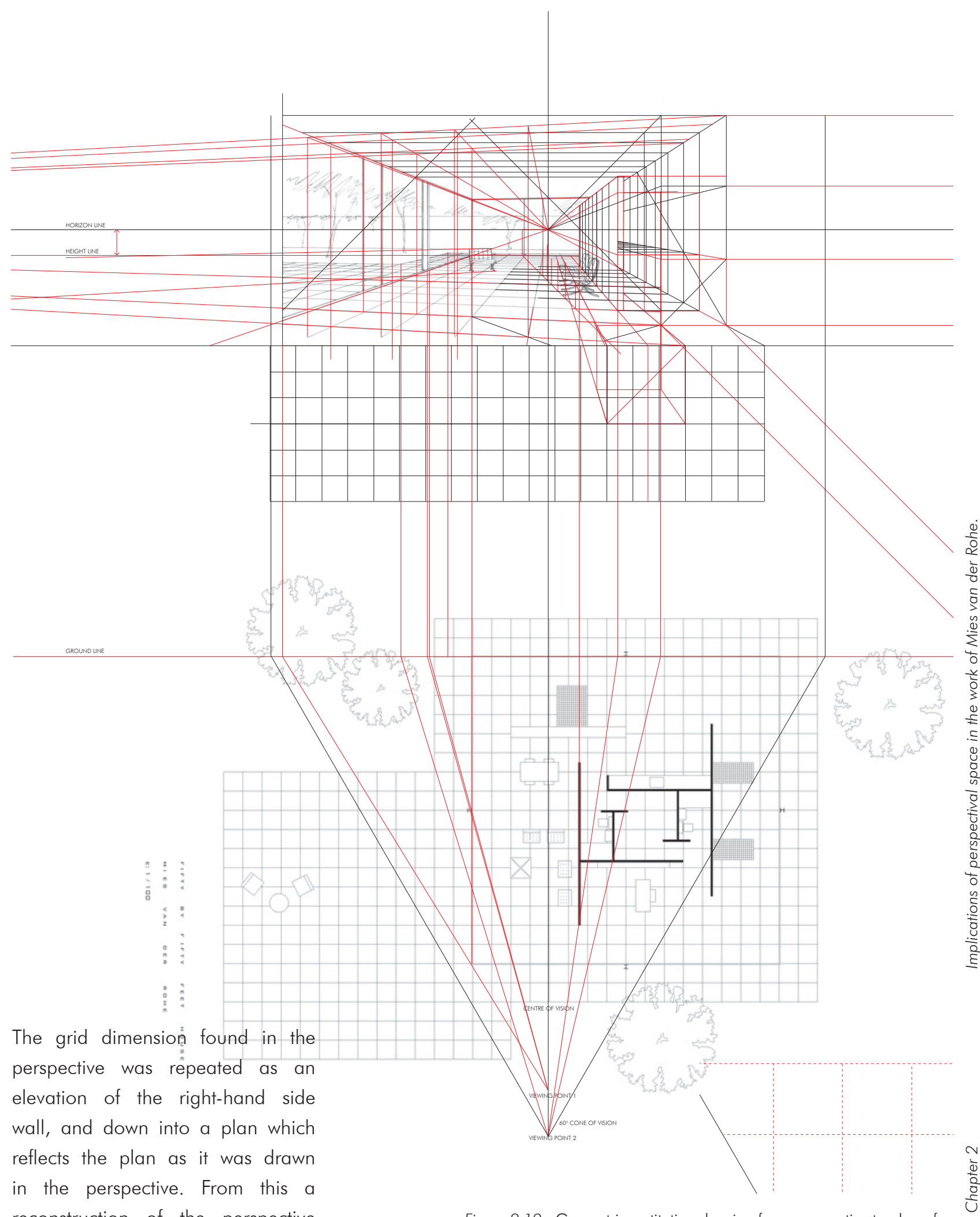

reconstruction of the perspective view as if considering all of the space

Figure 2.19 Geometric restitution drawing from perspective to plan of Mies van der Rohe's perspective drawing of his $50 \times 50$ house within the 60-degree cone of vision could be achieved. 
The limitations of drawing back lines and analysis of vanishing points and proportions of elements within drawings, both on the computer and on the drawing board, are essentially limitless. The computer enabled more accuracy of lines back to the drawing's vanishing points, and in the case of Mies' $50 \mathrm{x}$ 50 house as an example, the vanishing points are entirely off the sheet and suggest that Mies was drawing on a very large drawing board, or more likely taking the lines back to vanishing points by sight. This fits with the outcomes established so far, as while appearing to be an accurate perspective drawing, the accuracy of the drawing was far less important than the representation of the spaces it shows.

That is, while Mies' work is caught up in truth and universal truth, the construction of both the representation of it - the drawings and the photographs - and the materiality of it, is far less important than the truth of the International Style.

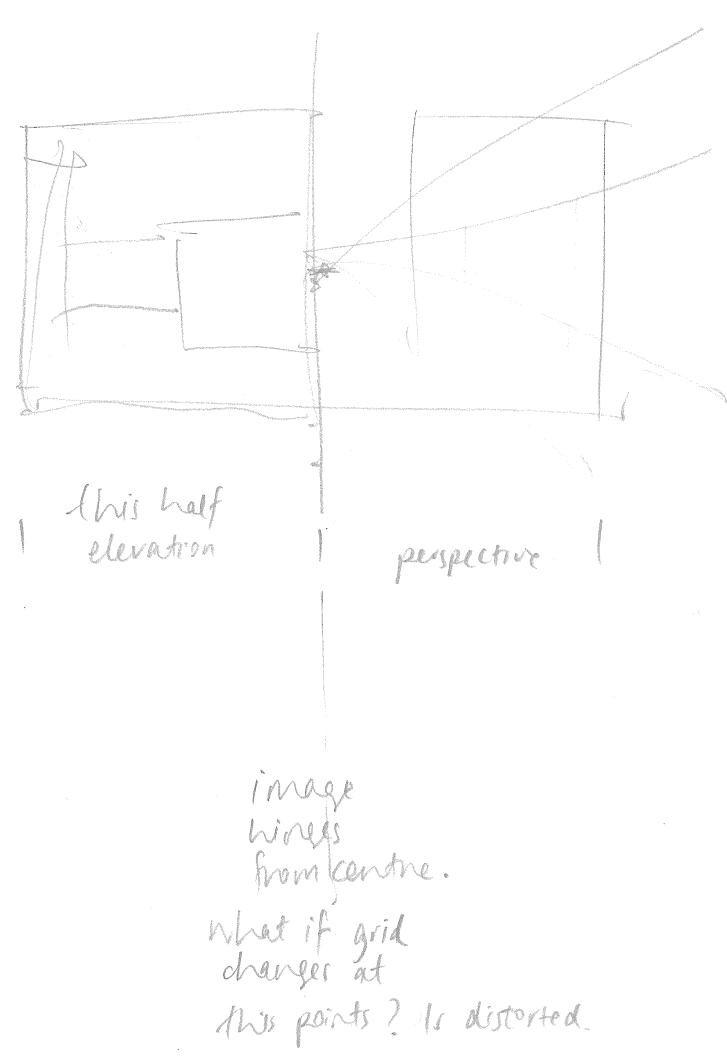




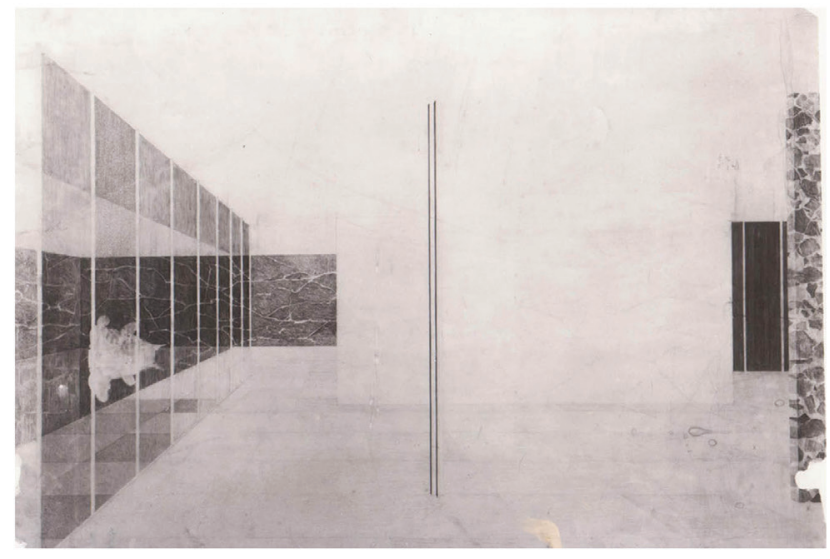

Figures 2.28

Reflection studies from the Geometric Restitution analysis

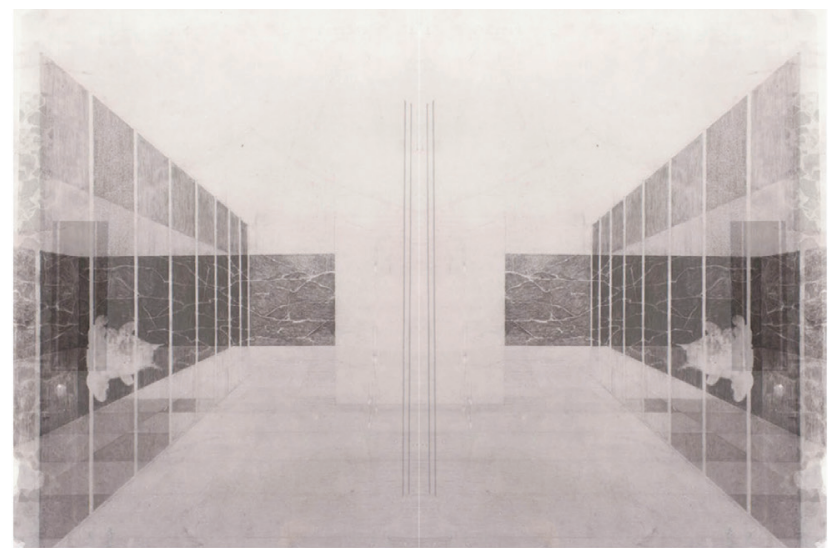

The nature of the Barcelona Pavilion perspective as an elevation was questioned and this led to setting up a series of reflection explorations, motivated in the way that Mies' wall are like vertical mirrors; reflecting and creating illusions of space. This photo of the Pavilion shows the maintenance of sightlines through the transparent walls, and again emphasising the interiority that there is to the entire project that allows ambiguity of boundary. The subject-focus of representation, and theatrical reference, in the way in which Mies' drawings reference the performance through the spaces, links Mies to Karl Friedrich Schinkel.

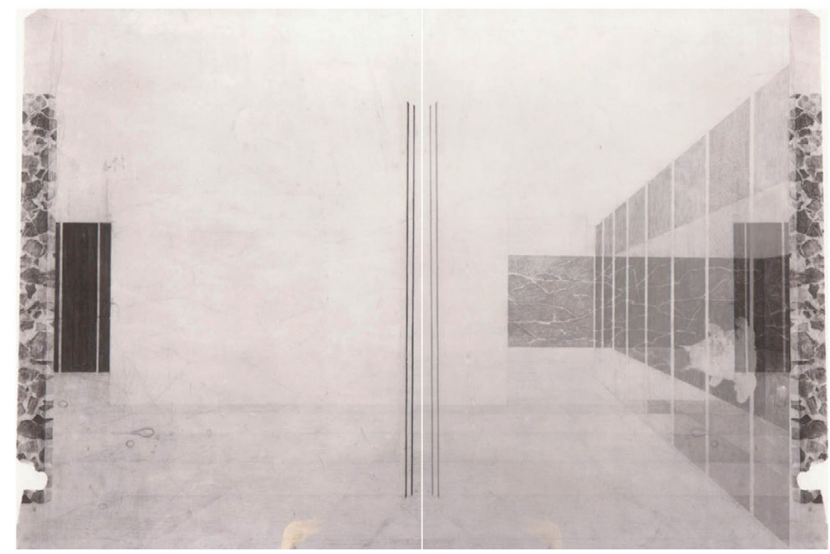


$\rightarrow$ recreate what appeass to be reflected in the pool.

(an see refuctors of wall is the pool If restend these limes us

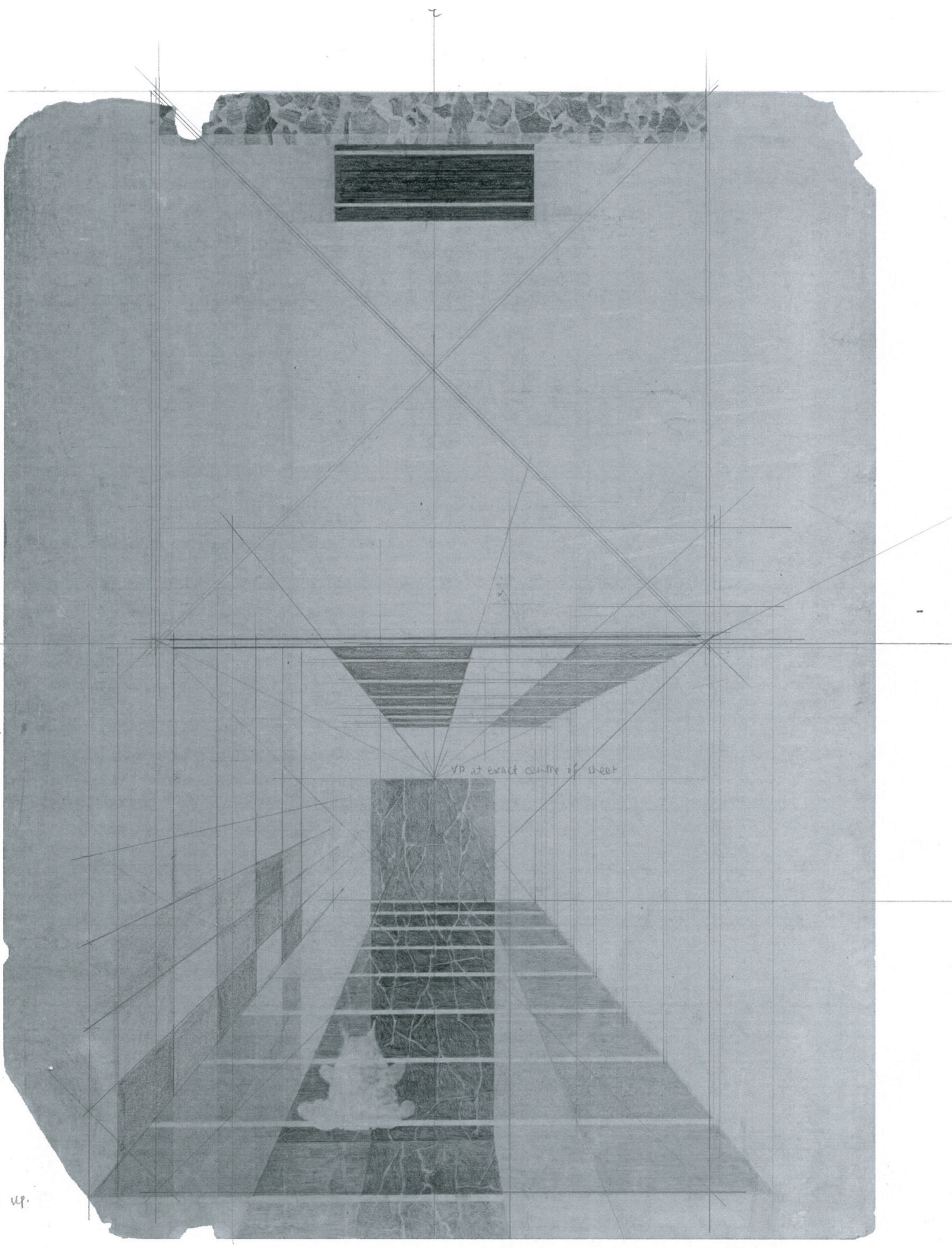

ground ine

appeavs that the glass walt is a poot and the back wall is reflected in it.

Figure 2.29

Viewing the perspective differently
Ludwig Mies van der Rohe

Interior perspective, Barcelona Pavilion, c. 1928-29

Original size $39 \times 511 / 4^{\prime \prime}(99.1 \times 130.2 \mathrm{~cm})$ Graphite on illustration board

Scale 1:5 


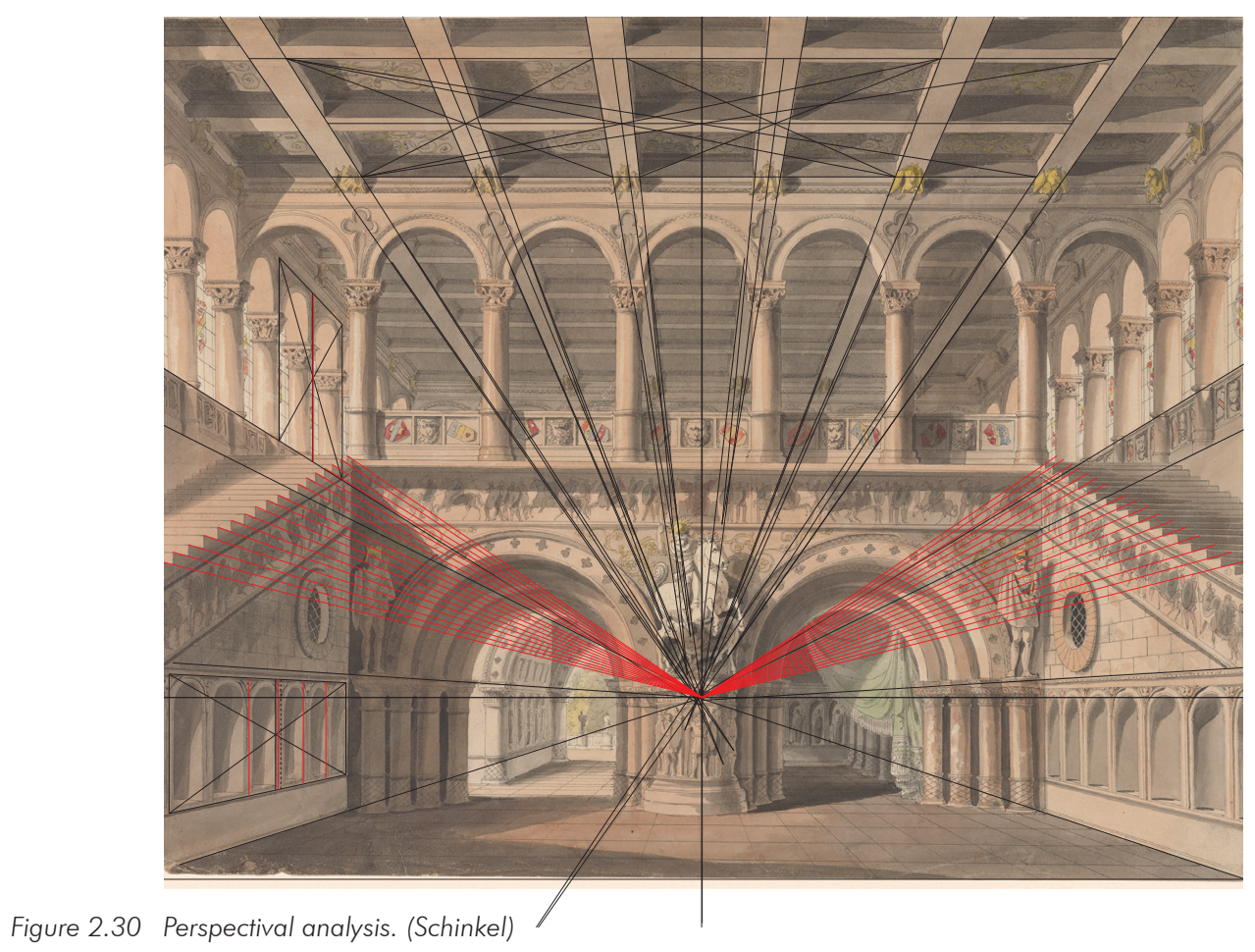

Schinkel's analysis has been carried out in the same means; the perspective image is broken down into a grid, and the lines taken back to the vanishing point. In these perspectives the horizon lines are always lower down than in Mies' perspectives, putting emphasis on verticality rather than optical equivalence of top and bottom planes as evident through Mies' perspectives. Perhaps attributed to the nature of Neoclassical drawing in that the setting is more framed to the sculptured figures and detail that through this era was characterised by a return to classical antiquity. Simple line drawings were seen to be the purest classical medium, although opposed to this are Schinkel's paintings which depict moody scenes more characterised as Romanticism. While Neoclassical architecture was monumental and ordered, Romanticism also placed emphasis on emotion and individualism.

This drawing appears symmetrical although is not, and has also been proportionally set up correctly, although the coffered ceiling projects back to multiple viewing points. A figure is always at the vanishing points. The questioning of representational approaches through the drawings of Mies and Schinkel has established a rigorous and strong methodology. 

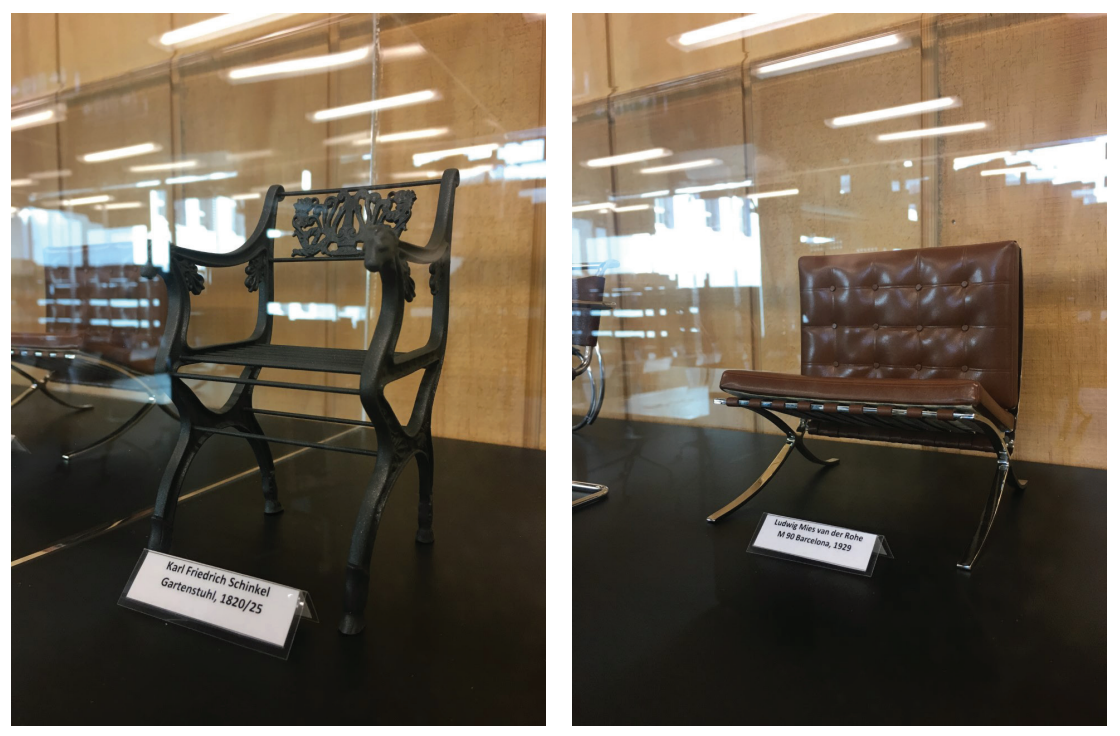

Figure 2.31

Figure 2.32

Chair by Karl Friedrich Schinkel

Chair by Mies van der Rohe, with similarity of design to Schinkel. Author's photographs 



\section{CASE STUDY ANALYSIS}

This chapter identifies case studies which raise questions concerning 'representation' in architecture. Collectively they address the research aims and objectives. By questioning the correspondence between architectural drawings and built form, this section looks to identify drawing tools that unpick conventional drafting methods.

To discover original and inventive design, the work of Liz Diller and Ricardo Scofido's Slow House project, and their innovative 'drawing apparatus' is evaluated. Designed as a drawing tool to conceptualise the project, this work calls into question the nature of architecture, and how the tools of architectural representation can be challenged. The Slow House hasn't been analysed in terms of the design of the house, but regarding the drawing apparatus. It sets up an approach for the design of a drawing apparatus that breaks the boundaries of linear perspective as it has been drawn since the Renaissance, and aids in the design process. Through this project, they are reconsidering the role played by a representational tool, in that the design process directly determines the formal outcome, and links the idea of mediating a view, through the drawing apparatus. The drawing is set up with two centres, in a similar way to Piranesi's example of setting up the drawing from two viewing points. There is consideration of different views at different viewing points. The curve of the house arrives from the apparatus, and the effect of this form became apparent in architecture studios where students all had started to draw curved shaped forms (Lubow, 36-41).

This study has established a strong methodology, through the unpicking of drawings by restitution method; and by setting up grids to place elements. The analysis would be taken further if the relationships within the grid were questioned (the nature of perspective as elevation for example). There needed to be parameters and constraints set up (as any testing) to determine what would change under certain parameters. Since working the whole time between plan and perspective a drawing machine that could correspond between perspective and the orthogonal plan, would change parameters to continue to unpick the nature of these drawings. The changing viewing points which underlie Mies' perspectives established the fundamental question; how to draw out perspectives with changing viewing points and up to plan with the same component? Thus, enabling to control the one variable, and maintain its relationship to the other parameters of linear perspective. 
A controlled device would ensure greater consistency and therefore accuracy, and ideally, this device would be applied to further analyse and establish a methodology for design.

A drawing apparatus is proposed with the intention that it applies formal analysis through the work. Which controls the parameters to further analyse and carry out drawings to test design. In the way it is to conceive in plan, the suggestion of movement, (it is in this sense that it is similar to Diller and Scofidio's Slow House apparatus).

Concerning how the analysis arising from this study can be reapplied, the 13th Venice Architecture Biennale's 'Piranesi Variations' has been analysed. This case study identifies methods to locate analysis from the original drawings, back onto a site in a reinterpretation of the original design. In this study, they are looking to derive from the drawings, new space as it would be in real life, from the etchings of Piranesi's Campo Marzio. In the way in which it challenges what we expect from linear perspective. It has set up a similar system to geometric-restitution in that it derives from the perspectives the shape, size and position of the object as it would be in real space.

Further addressing narrative, and returning to the first case study in the way it suggests movement and embodiment through design,
OMA's Casa Palestra demonstrates how a reinterpretation of the Barcelona Pavilion illustrates human occupancy, through moving elements, projections, mirrors and reflection panels among others. These are suggestive of the design qualities acknowledged in the first chapter, and which are intended to be incorporated in the design as part of the study's aims and objectives.

Only one of the four case studies has been built, demonstrating the change in architectural representation that is occurring, with more and more buildings designed to not necessarily be built. Drawings are able to be privileged as the final product, and in doing so they must describe, as opposed to the building, both the organisation and the experience, and made to be as Borden puts, "virtually occupied." (15). Looking to Mies' representations; drawings, photographs of drawings and photographs of temporary buildings, their relation to built form was often unclear. Each an isolated work and interpretation and clarification was ambiguous. This allows, as learned through Piranesi Variations, a strong basis on which to reinterpret and construct space.

This chapter seeks to apply the insight that is attained, to a reinterpretation of the German Pavilion - in order to begin to reveal the time, space and quality of the original building, in the new. 


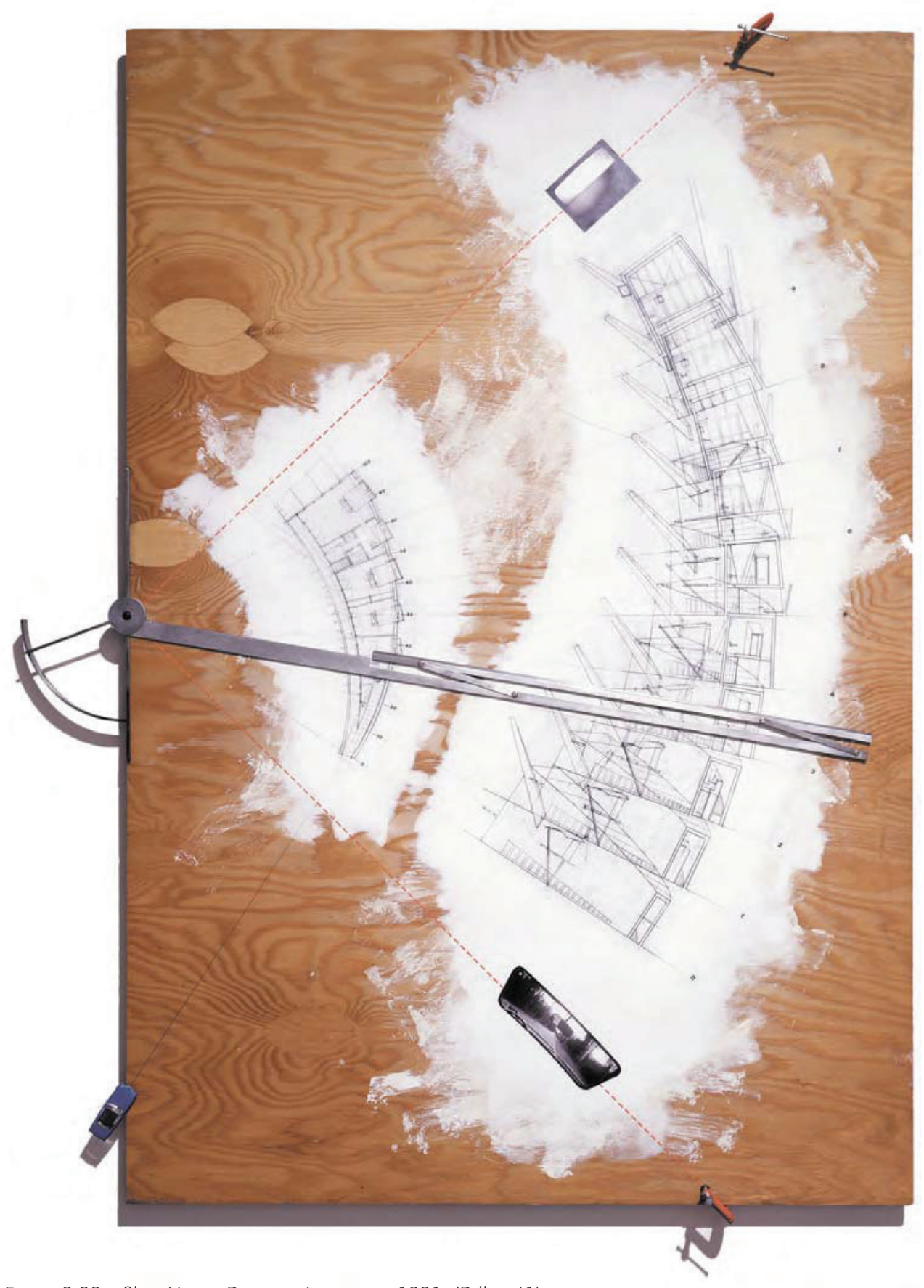

Figure 2.33 Slow House Drawing Apparatus, 1991. (Diller, 41) 


\section{CASE STUDY DILLER AND SCOFIDIO'S SLOW HOUSE}

Challenging the conventions of architectural representation, Diller and Scofidio executed the drawing of a vacation home on a wooden board with drawing equipment attached. Mounted at one edge is a stainless steel custom made ruler that pivots around a fulcrum at the centre point of the board. The base geometry is generated from drawing curved lines around the fulcrum. A ruler parallel to the main arm can slice cross sections at any location along the plan, perpendicular to the tangent of the curve. The frames cut at intervals along the apparatus are projected as elevations to form the design of the Slow House, which is conceived as a viewing device as a whole. Relative to this thesis, and to Mies' work are the concepts of narrative, cinema, photography, montage and performance. Linked also to the discussion surrounding sculpture and ornament, the Slow House has been described by the client as "like a sculpture so that no ornament is necessary." This idea of an inhabited camera, producing views that obscure the boundary between real and fake, sets up frames in the way in which Mies' architecture has been described - offering the focus of a subject, object, status, perception and possibly for play. A new conception of space that artists were striving for in the twentieth century, and that Mies achieved also.

The sectioned frames from the apparatus support the narrative of a car approaching and continuing its journey through the building to the view. The frames trace movement through the plan. The narrative suggests that the car's windshield and the view through it is replaced and merged with the entrance of the house. The frame of the windshield merges with the front façade and this is intended to read as the house having no front façade, only a front door. In this linking of image and movement, arrives the concept of cinema within the work. Bruno Taut encouraged the use of film in architecture to relieve representation from the still image, which to him was one of the main obstacles to the realisation of modern architecture. His argument was derived from the reliance of the still image as prevalent since the arrival of perspective. A change in how perspective is understood would address Taut's concerns with the still image (Robbers, 9). This leads to the use of the apparatus as a new way of 'seeing' architecture in that it mediates a view, producing architecture as a technology that creates the view. 

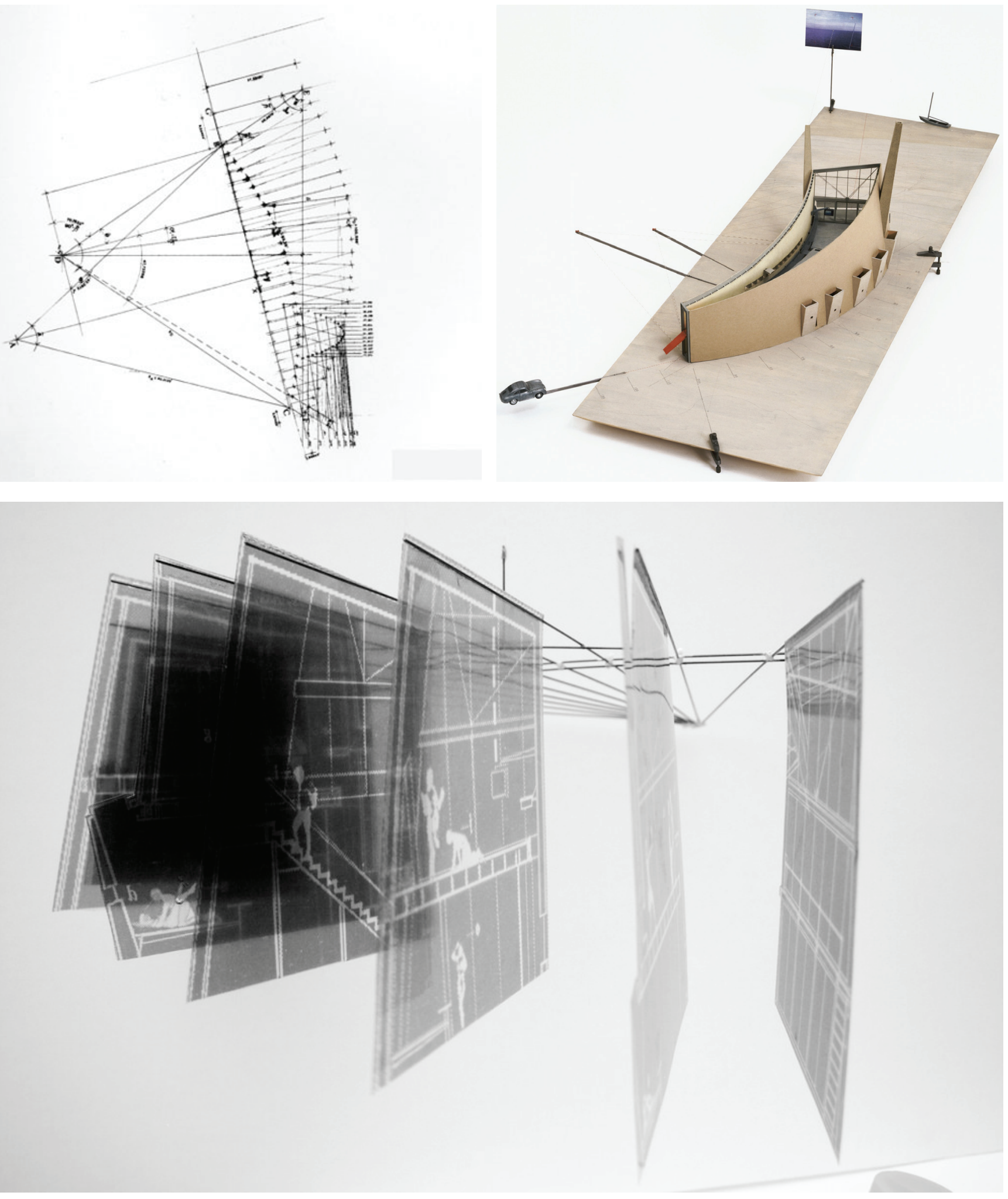

Clockwise from top

Figure 2.34 Slow House Apparatus drawing, 1991 (Dean and Lek)

Figure 2.35 Slow House model, 1991 (Dean and Lek)

Figure 2.36 Slow House sectioned frames, 1991 (Hess) 
Figure 2.37 Ground and First floor plans of the Slow House (Diller and Scofidio)
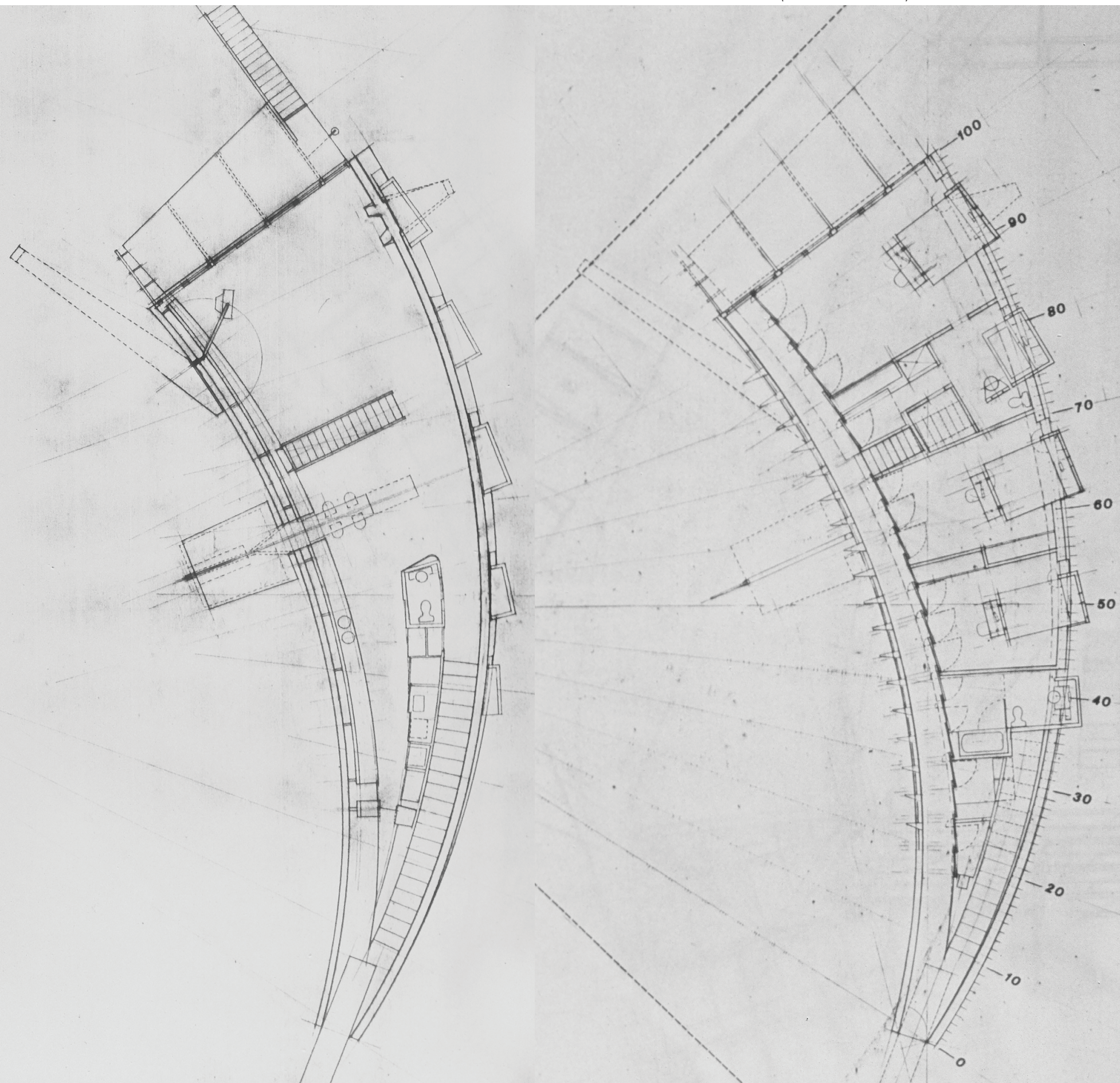


\section{CASE STUDY \\ OMA 'A SLICE OF MODERNITY / CASA PALESTRA, THE DOMESTIC PROJECT'}

OMA attack historiography through their project for the 1986 Milan Triennale. 'A Slice of Modernity / Casa Palestra, The domestic project'. It sets out to demonstrate the provocation of Modernist buildings, using the Barcelona Pavilion as a case study. In a means to show sensory and psychological qualities in the Barcelona Pavilion in contemporary culture, they have made a 'spectacle' of the Pavilion, installing a range of effects that suggest human occupancy and revealing the 'hidden' dimensions of modern architecture (Gargiani). In doing so they are confronting the criticism surrounding Modernism as abstraction devoid of people, time, past or tradition, and completely separate from the outer world. A criticism of being too pure. The use of the Pavilion as a case study proves the iconography attached to the Barcelona Pavilion. It holds status at the height of Modernity and beyond; the Pavilion is representative of Germany; and Dodds describes it as a 'building as biography', in that Mies' whole career could be condensed into the Pavilion, summarising his whole oeuvre (11). This is mentioned as it is clear that is what underlies OMA's project. The entry for the exposition took place nearly 60 years after the original building of the Pavilion, in the same year as the reconstruction of it.

The notion of human occupancy in the Pavilion is discussed by Quetglas in the way people experience it as a stage, observing a space from a space which one doesn't occupy. This experience is one of exclusion. (Quetglas, 93), and clear that in the spatial construction of the building itself, the observer to the Pavilion has been considered (Mertins, 54). Describing the spaces as being experienced ascribes cinematic connotations as opposed to denoting the still image. Twentieth-century representation became preoccupied with constructing its subject in space and time. This took into regard movement and the consideration of the viewing subject, hence film terms such as 'framing', 'montage' and 'sequence' have all become common terms used 
in the architectural discourse. (Robbers, 37). The coming of age of cinema was said to have inspired a group of artists and intellectuals, which Mies belonged to during the early 1920s, to radically rethink through their work; the role of the subject, the quality of the object, the status of the image, the regimes of perception and knowledge (Robbers, 6). Understanding this may perhaps help to read Mies' work differently. Walter Benjamin is an advocate for discussing cinema alongside architecture. Cinema provides material for collective, simultaneous perception. (Mertins, 129).

It is interesting to note that in the interpretation of induced movement through the plan, OMA's curved plan of the Casa Palestra, and the curved plan of the Slow House have much in common.

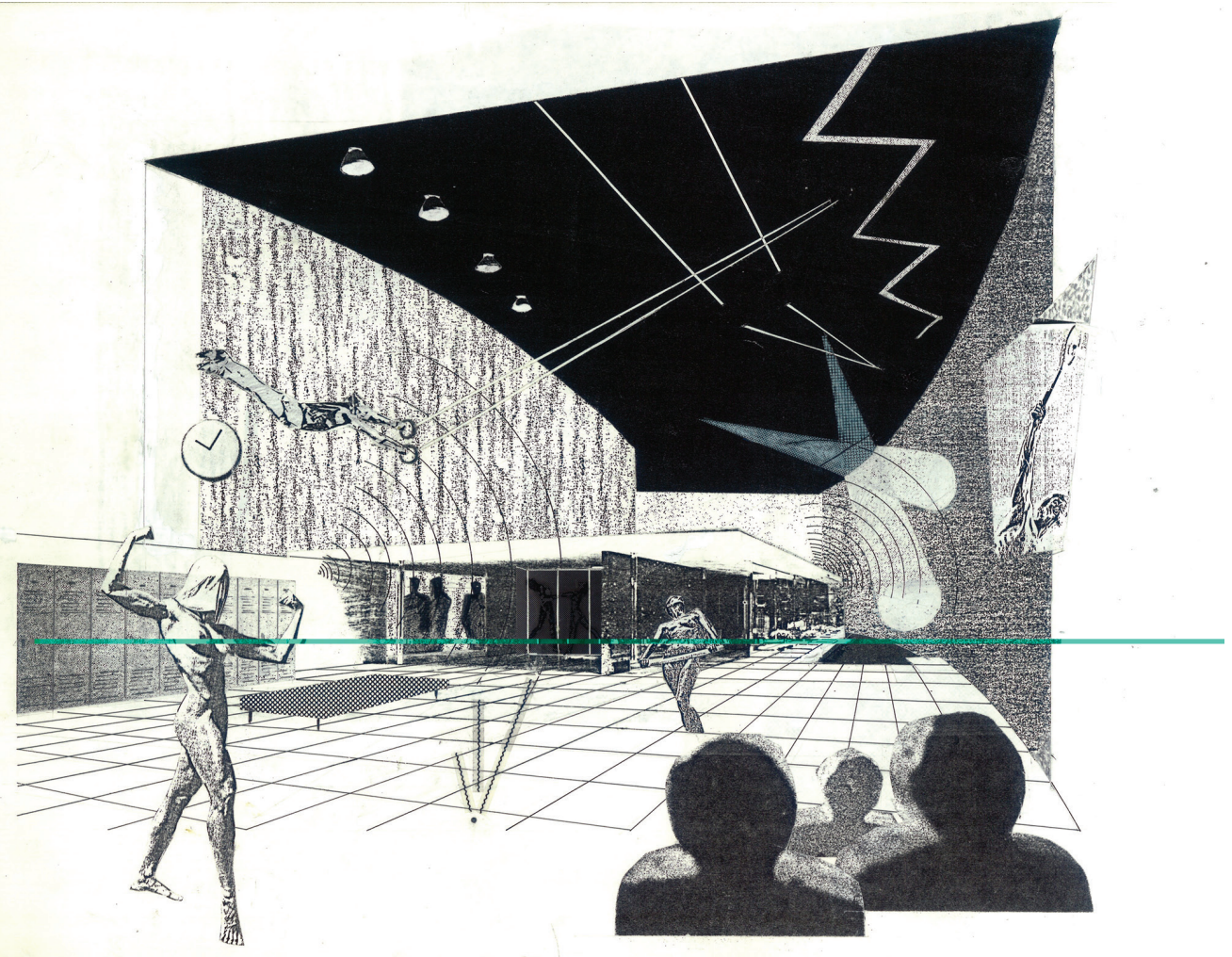




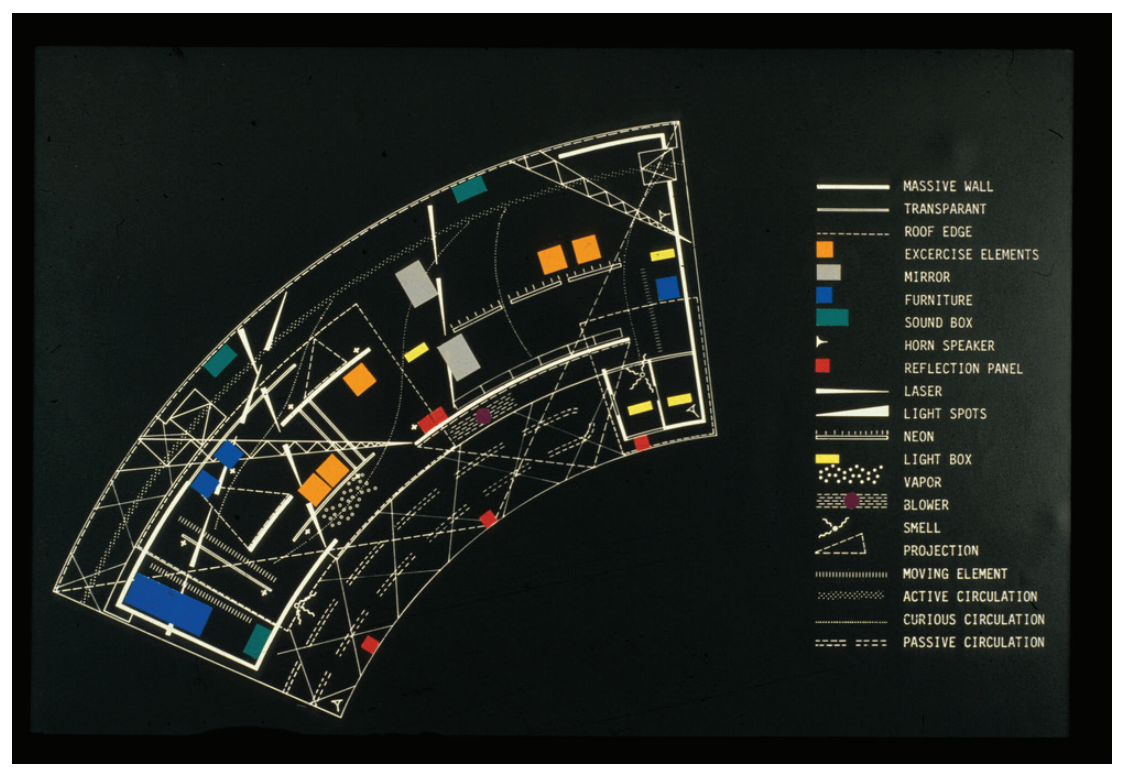

Figure 2.39 Casa Palestra installation key, (OMA) 


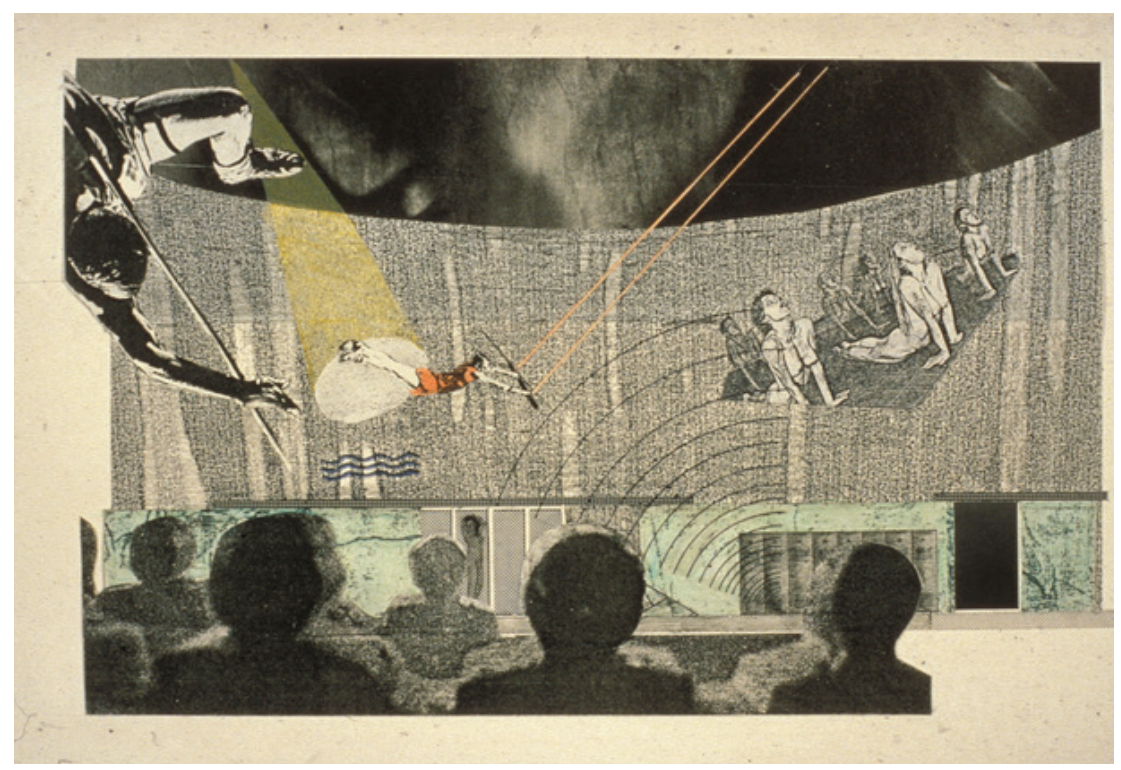

Figure 2.40 Casa Palestra collage, (OMA) 


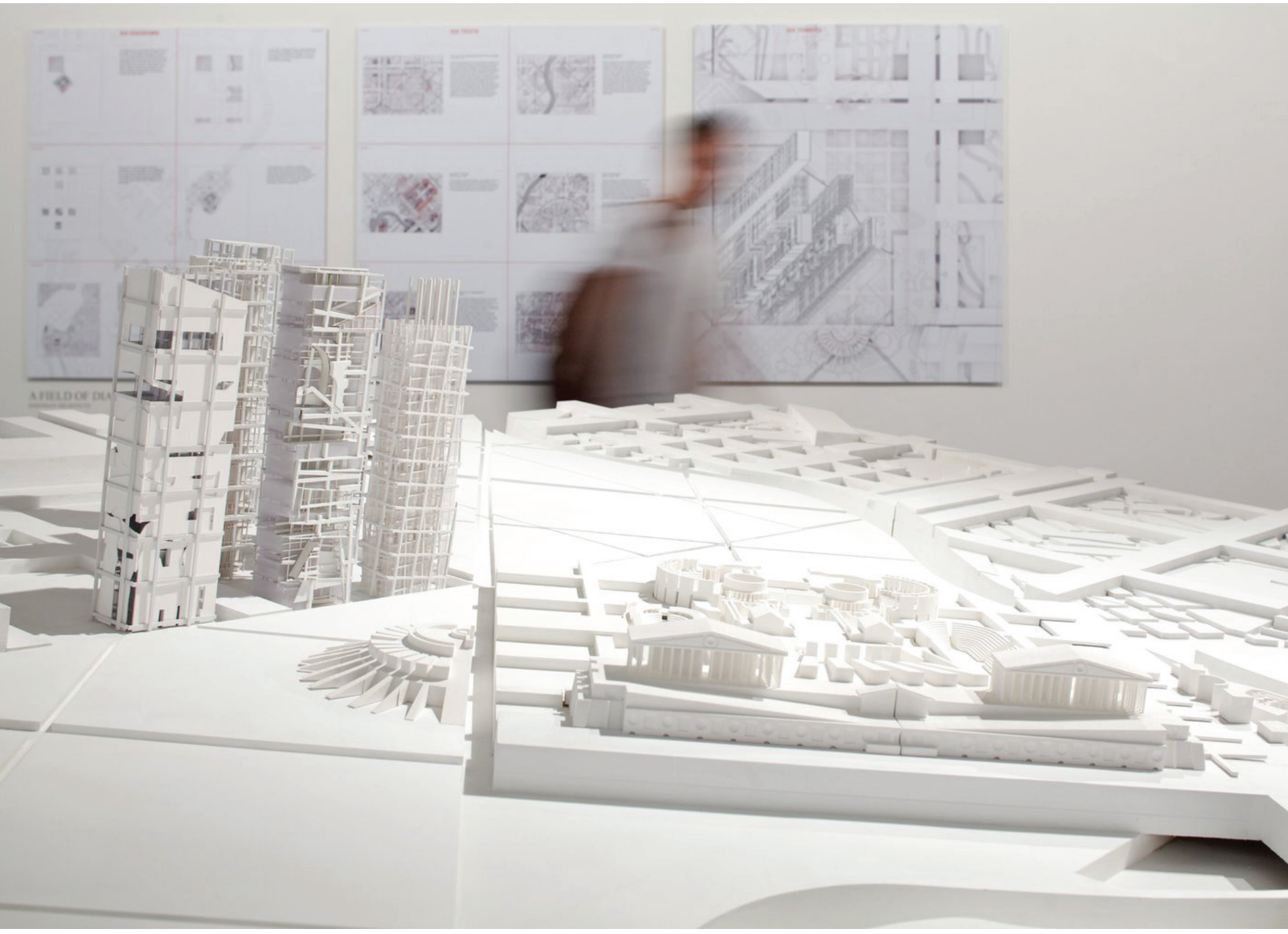

Figure 2.41 A Field of Diagrams (Eisenman Architects) 


\section{CASE STUDY VENICE BIENNALE 'PIRANESI VARIATIONS'}

For the 2012 Venice Biennale, Peter Eisenman formed a team to "revisit, examine and reimagine Giovanni Battista Piranesi's 1762 folio collection of etchings, Campo Marzio dell'antica Roma." (Rosenfield). This was inspired by the 13th International Architecture Exhibition's theme 'Common Ground', dealing with the common ground between the profession and engaging in the process of architecture and its language of communication. From years of fieldwork measuring the ancient Roman building remains, Piranesi's etchings depict what ancient Rome might have looked like; a re-conception of the past architecture. These are referred to in reinventing the present. Described as "precise, specific, yet impossible, Piranesi's images have been a source of speculation, inspiration, research and contention for architects, urban designers and scholars since their publication 250 years ago." (Rosenfield). Affecting the subject of the relationship between history and the present, Tafuri recognises "of perspective as a symbolic instrument for the quantitative control of space" (38). Interested in the composition of the structures, Tafuri notes of the perspective 'reconstructions' of the plan as telling a great deal of Piranesi's method of composition. Leading back to the initial restitution analysis in Chapter One.

Piranesi, after Tafuri, is the guy that you work through the reinvention of the present. Or is the figure in relation to who you work through the present. It's not Piranesi, it's the potential abstraction, introjected into modernity, through the figure of history for which Piranesi stands. (Jeffrey Kipnis)

In the reimagining of Piranesi's etchings of Campo Marzio, Eisenman architects, in their project 'A Field of Diagrams', explored through models and drawings "architecture's relationship to the ground and the political, social and philosophical consequences that develop from that relationship"(Rosenfield). 
The relationship that Piranesi's etchings have to the ground, is recognised as a condition of 'in-betweenness', establishing fluid space and ambiguity between objects. The field in which he has constructed the objects is one of homogenous, non-hierarchical relationships. To that end, Eisenman in the translation of such work introduces four key compository elements; axis, pairs, the hinge, and interstation. The use of a grid confronts this condition by organising and dividing the ambiguous in-between spaces. It integrates 'formal order' to the translations, and a language that Tafuri suggests was absent through the Campo Marzio. (Tafuri, 38). As Eisenman rotates, overlaps and layers -introducing form to the two-dimensional etchings- a degree of ambiguity of placement remains. Additionally, narrative plays a fundamental role through the work, in translating the drawings and creating new histories over the 'superimposed historic and contextual grids' taken from a translation of Piranesi's imagination.

Relevant to this thesis' working, is how compositional aesthetics were altered - but still bearing visual traces to earlier form - to the spatial and temporal qualities between Imperial Rome and today. Through the narrative of comparing Altes Museum with the Pavilion, the new building also looks to be a palimpsest, between the Neoclassical Berlin that was epitomised in the distinguished building of the Altes, and to the twentieth century Berlin that became manifest into the pavilion in Barcelona.

Frascari discusses Piranesi's work that proceeded Campo Marzio as that was what characterised it, describing his work as testing the established canons of classical architecture. In reconstructing the past, it does not speak a classical language.

Piranesi uses that [Classical] language, applies the rules of the architectural orders and breaks them to empty them of their meaning and symbolic value. He applies the rules of representation to go beyond representation: the spaces he represents are at all times impossible: the medium of representation and its conventions are challenged; the space of representation, detached from that of material production, becomes the space for the production (construction) of ideas....(Frascari, Hale and Starkey, 101) 
This is also said of Piranesi's Campo Marzio work, by Eisenman, in that the ground doesn't produce or act as a datum in the sense a figure/ground relationship would, but rather "the ground becomes an interstitial trace between objects, which are also traces in both time and space." (Frascari, 106).

The parallels this specifically has with this thesis is exciting. It is in this sense then that Eisenman must be referring to the work as not representing a literal place or actual time, and it must be in this sense that it becomes such an interesting set of representations, for re-representing. Examining how Piranesi's new way of conceiving, thinking and recording the city can be applied throughout contemporary architecture.

This thesis doesn't seek to apply the term figure/figure but does align with some of the principles of this. The hierarchy of grids that Eisenman achieved through layers, was built upon a field that was isotropic. A hierarchical system would normally maintain a distinction between figure and ground, and this is where the gridded relationship becomes interesting in that the figure/ground relationship is already dissipated, and the use of grids successful.

Also significant to Eisenman and this study is the emphasis on the process by which to drive the project. In order for this thesis to successfully discuss translation through Mies' and Schinkel's work, into built form, it must be articulated through rigorous process-driven explorations that explore what each of the 'Piranesi Variation' teams are doing individually.

Figure 2.43 Model of the Campo Marzio, as interpreted by the Yale Students (Eisenman Architects) 


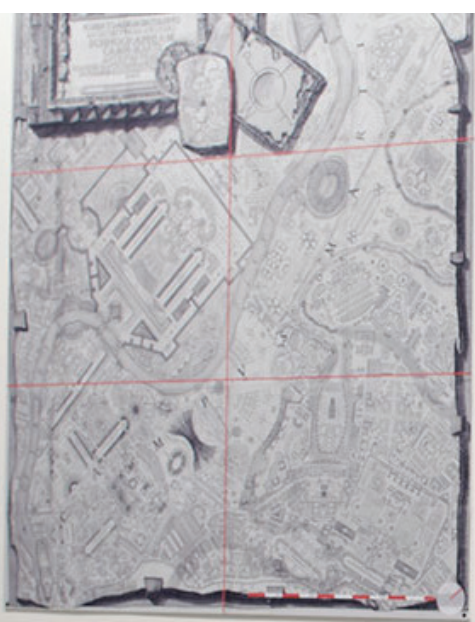

IL CAMPO MARZIO DELLANTICA ROMA

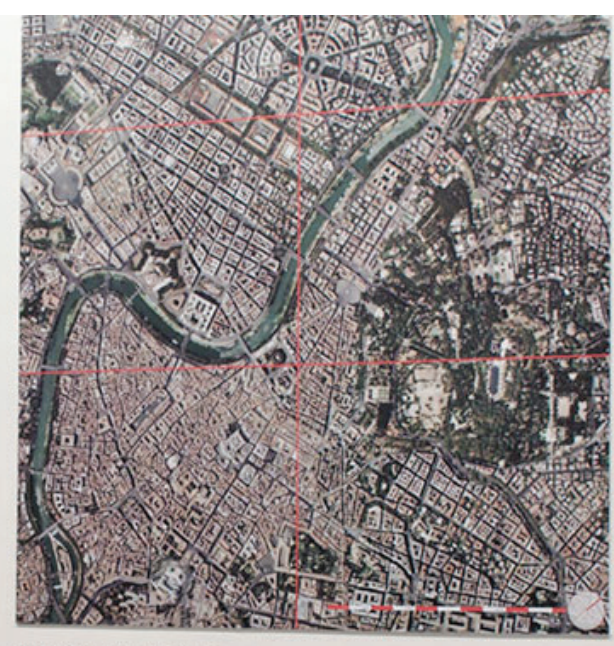

PRESENT-DAY ROME
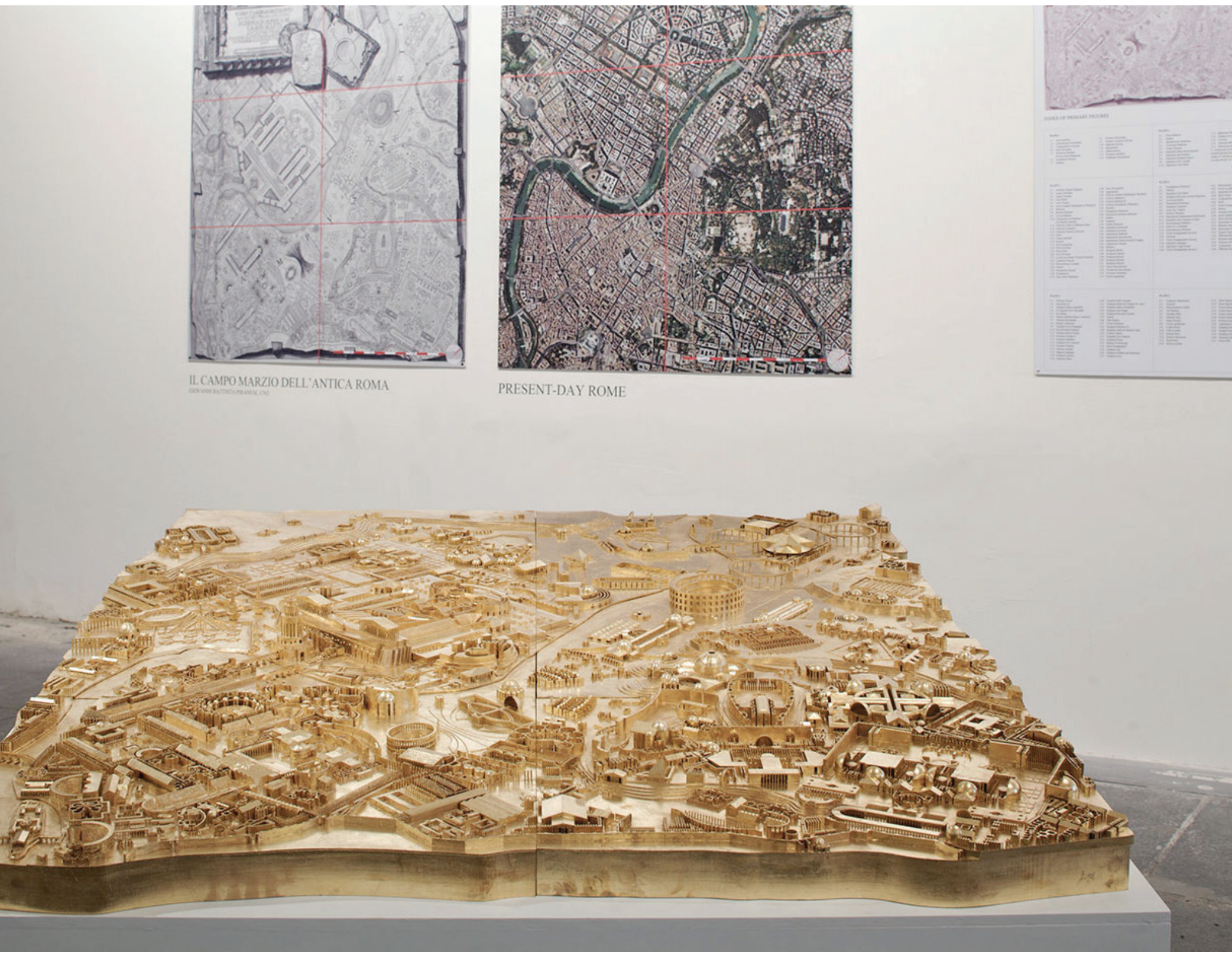




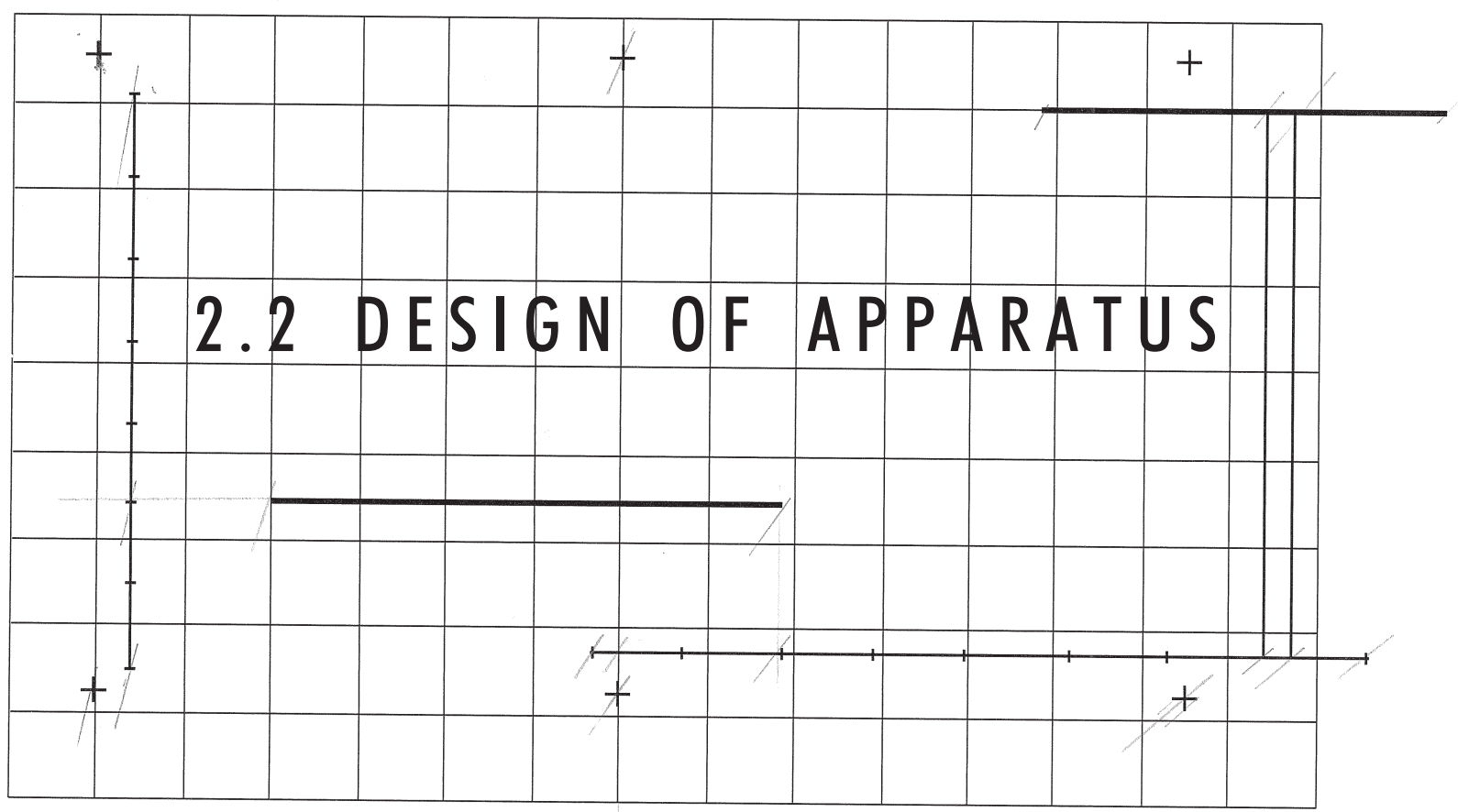



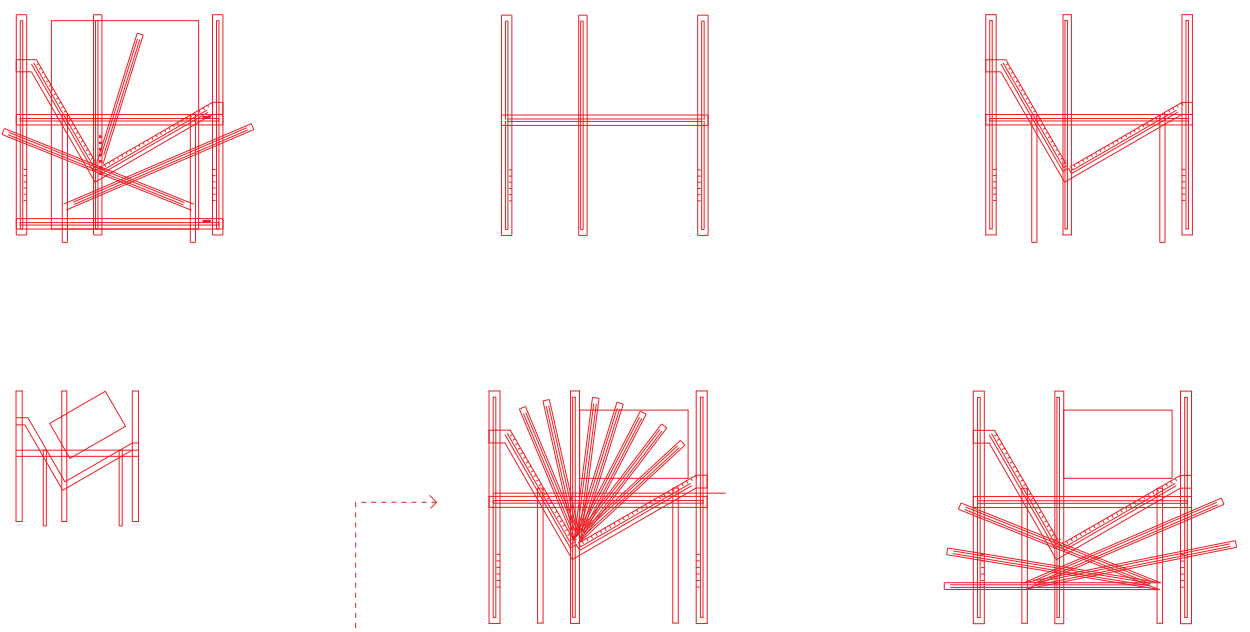

construction rulers taike points back to the vanishing and viewing points
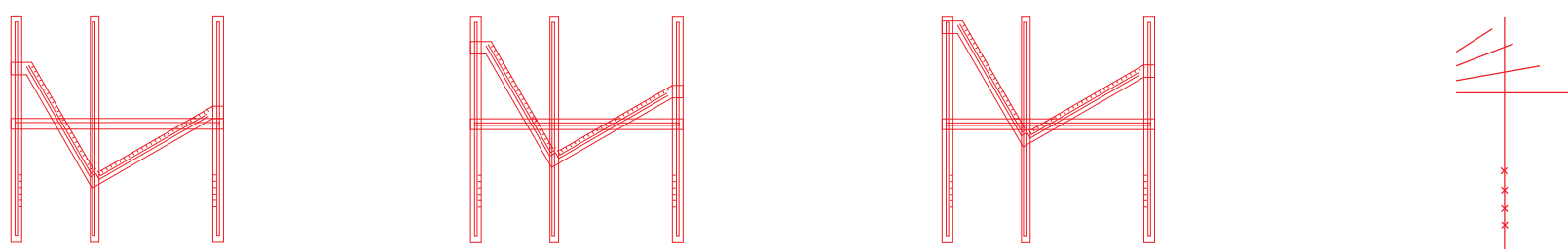

changing viewing points skew the angle of the object
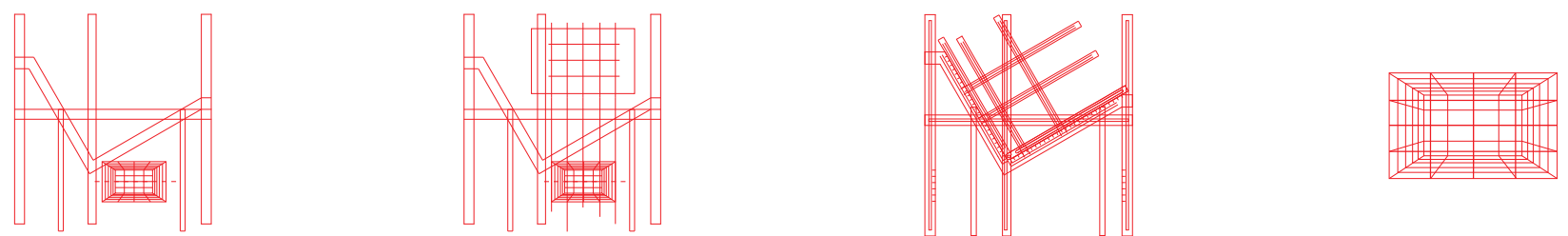

projection from perspective to plan using a gridded volume to place elements

Figure 2.44 Diagram of the construction of the apparatus 
Investigating the perspectival correlation between plan and perspective has led to the design of a drawing apparatus that serves to test the boundaries of how we use linear perspective and change the way we see it. A novel tool designed to control the parameters that have been set up through the study; to further analyse and reapply ideals to carry out drawings to test design. It conceives in plan the suggestion of movement, exploring a new way of drawing, making the drawings become witnesses of the performance, connecting movement and geometry. If to change the use of one variable of perspective; the viewing point, control of the other parameters are to be maintained and analysed.

The conception of this was through drawing out Mies' Barcelona Pavilion perspective from each of the different viewing points he constructed it from. This recognised each 'frame' as able to stand alone as a perspective, albeit framing a completely different perception of space respectively. A reduction of four perspectives down to one portrays more within the one image, exemplifying the architectural drawing as moved beyond mere representation. The freestanding wall, while recessive in the rendered perspective, acts as a dominant object through the frames and governs the movement through them. The multiple perspectives determined both the design of a drawing tool, and the results that the tool will enable. Whether or not the single perspective existed as four beforehand is not imperative to the study. This discovery is a demonstration of Mies' architectural thinking through his architectural drawings.

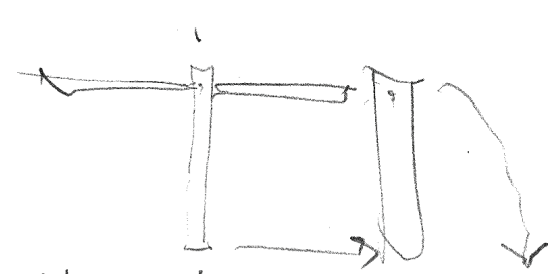

How de'draw in plan and then trandate to perspective with the rame device?

Figure 2.45 Sketch, questioning the role of the apparatus

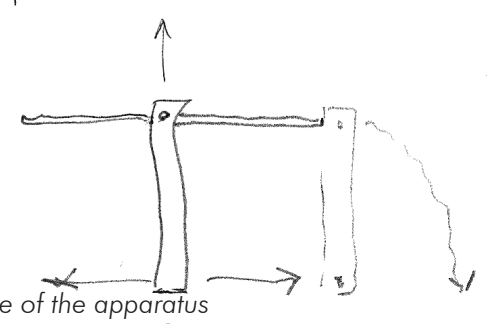




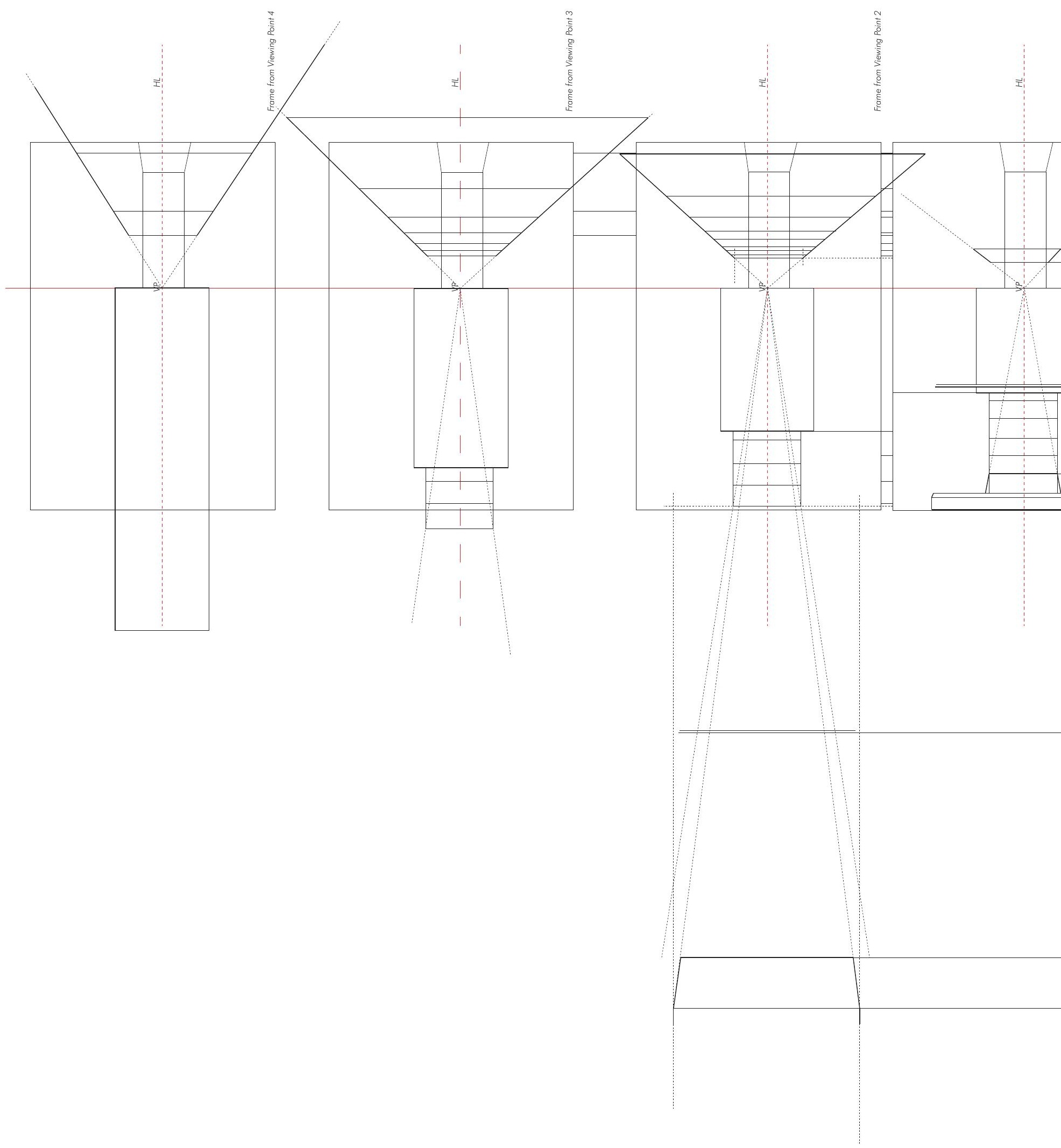

92. 
Perhaps the best way to consider cinema alongside Mies' perspective images is how cinema constructs spaces in the mind, suggested by Pallasmaa. These montages present the viewer with a series of choreographed views, as frames in a film are constructed. Imagination plays a role in the construction of the perspectives, and also through the reading of them, inviting to form a space from the images and to form different perceptions. This establishes the idea that the creative act is not performed by the artist alone and that the spectator adds a contribution through "the phenomenon of transmutation'" (Haralambidou, 5). Both film and architecture can be discussed through the work of Walter Benjamin and his belief that both are perceived in a state of distraction. In the way that "cinema demanded a completely new way of thinking about the image and its active role in the ways the subject perceives, comprehends, engages with and creates the world of objects" (Robbers, 39), the representation of architectural drawing has been reconsidered.

This concept is taken directly into the apparatus; to take multiple perspective frames that are drawn out as moving along the centre of vision of line into the plan, and combine into one overlaid image to capture movement through a still image. And the need for an apparatus for this study, confirmed. Drawing allows, quite unlike digital modelling programmes, to document, or develop drafting techniques or ways to allow experimentation.

"Paradoxically, the fragmentation and temporalisation of space initiated by film montage and modernist collage that opened up a truly infinite realm of poetic places for the human imagination still await their translation into architecture." (Frascari, Hale and Starkey, 11)

Fundamentally the apparatus is a means to test the way that perspective has always been drawn. At the core of this, is the contemporary thinking that the computer is the most sophisticated machine, albeit, computers still draw perspective as it has always been drawn, since its conception 600 years ago. This underpins a foundation to explore the nature of drawing manually through an apparatus. The apparatus instigates a new way of thinking about drawing linear perspective. A new facture for architectural representations. 
Eisenman states that he builds from the 'cuts', from the plans and sections (Ansari and Eisenman); "Buildings are both imagined and constructed from accumulated partial representations" (Carter, 7). And this is what the apparatus achieves also, designing through partial perspective representations. Complexity is built up within the apparatus and then controlled through the overlaying on site, with consideration to site cues, alignments and design intuition.

The principles of perspective were derived from the analytical studies into Mies, and it was necessary to return to the basis of the projection of linear perspective to set up the framework for the tool. In drawing out a traditional Cartesian drawing, refer to figure 2.52, the process of the projection from plan down to perspective has informed the construction of the apparatus. With the missing elevation, the Pavilion's perspective was used as the elevation component. The perspective is incomplete but the principles are what were important.

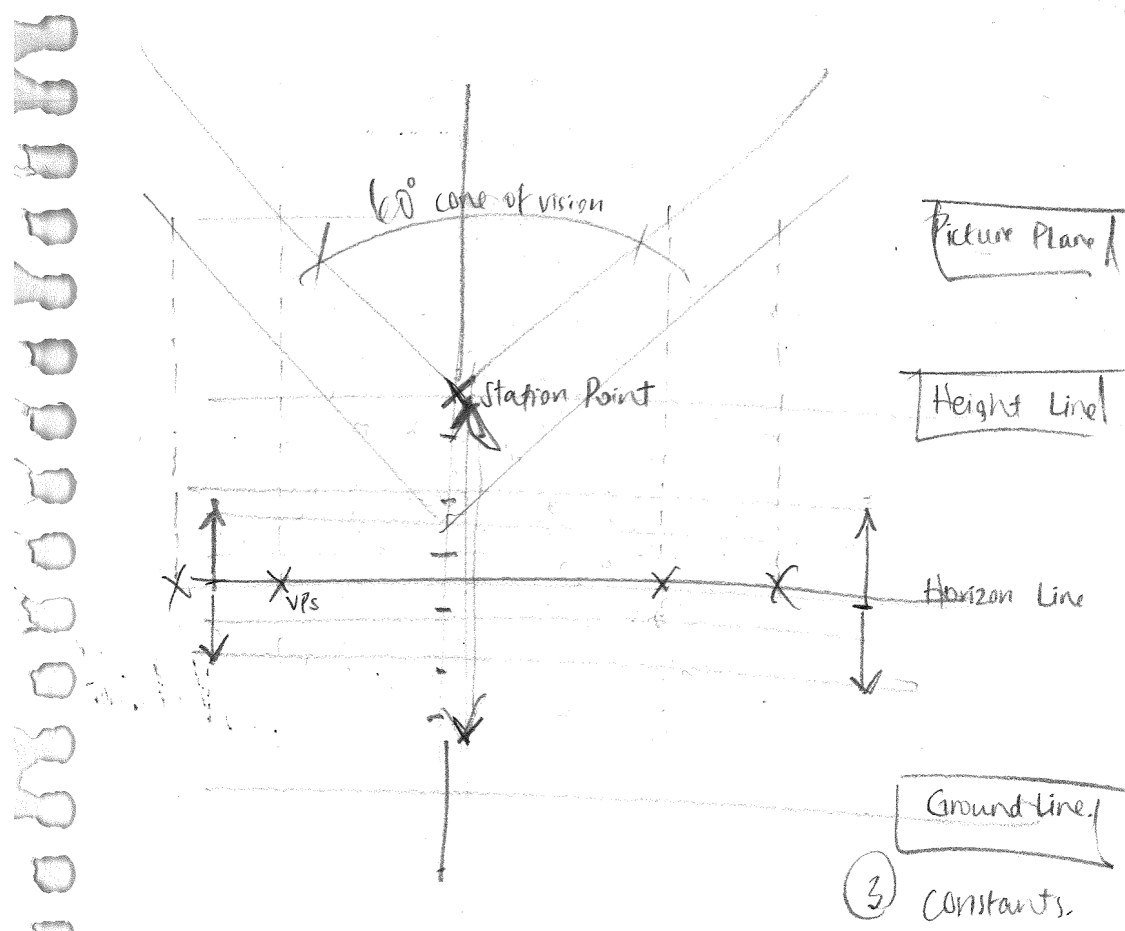

Figure 2.47 Sketch forming the basis of the apparatus components 


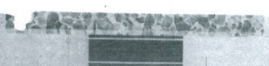

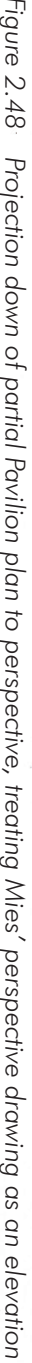

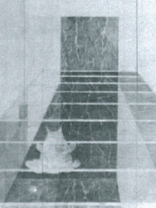

高影新 
The height of the drawn perspective - as missing the elevation component - is estimated. Where a ruler parallel to the picture plane, horizon line and ground plane, would (from an elevation) determine at what height the perspective would be drawn from the plan, through the apparatus the height of each element on the plan was intuitively drawn, with the horizon line through the centre of the perspectives. The ambiguities come from the absence of an elevation, yet these ambiguities when analysed are to be quite revealing and will show values that take the projections beyond the project.

The picture plane and centre of vision line, (offset as it is in the Barcelona Pavilion perspective), remain constant. The frame for drawing up the plan creates a fulcrum along the centre of vision that creates the viewing point and by moving the viewing point up, or down, the centre of vision line, the vanishing points change, thus the closer the viewing point is to the object, the narrower the vanishing points and the more distorted the image becomes. The horizon line is an independent variable, able to be moved up or down the vanishing points and changing the angle as well as the distance, the perspective is viewed at. Construction lines enable to draw in plan, and then also bring points on the plan back to the viewing point so that it can be deduced down into perspective. There are construction lines coming from vanishing points in order to draw out the perspective.

After setting up the horizon line, and drawing a picture plane and centre of vision line, by using the construction ruler from the viewing point fulcrum, the lines in plan are drawn back to the viewing point. Where these points from the plan mark the picture plane, they're drawn vertically down over the horizon line.

Figure 2.49 Sketch on the constrants of the apparatus 
The frame that positions the plan defines a boundary, but there still remains a degree of ambiguity through the placement of the plan, and this can determine firstly the size of the perspective that is projected below. As the closer the plan to the picture plane, the closer the vanishing lines are together and then the vanishing lines projected vertically downward from the picture plane will be narrower. There is also an advantage had in having a variable element within the frame of the plan as plans can be drawn at a $90 / 0^{\circ}$ or $60 / 30^{\circ}$ as the frame suggests - and the construction rulers from the frame are designed for this. It is fundamentally a device to test and to analyse and the degree of variability is enabling of this.

The first apparatus exercise was taking a partial plan of Mies' $50 \times 50$ house, and drawing it down to plan from $60 / 30^{\circ}$, and then $90 / 0^{\circ}$. The nature of a partial plan stemmed from the analysis of Mies' perspectives, in relation to the 60-degree field of vision explored, with the partial extent of the plan established in the perspectives. The dimensions of the apparatus board limit the perspectives to a small scale in comparison to the size of the plan. Accumulation of larger scale partial representations achieve more detailed perspectives.

\section{Conclusion:}

The apparatus allowed to break the standard rules in the way in which the viewing and vanishing points were able to act as independent variables from the picture plane, horizon line and ground line. That is, by keeping the other components constant, and enabling movement with the viewing and vanishing points, I was able to analyse the relationship that these had in the setting up of perspectives; the closer the viewing subject gets to the object (the closer the viewing point to the picture plane) the narrower the view of the object (the narrower the vanishing points).

Figure 2.50 Perspective of the Barcelona Pavilion from the apparatus

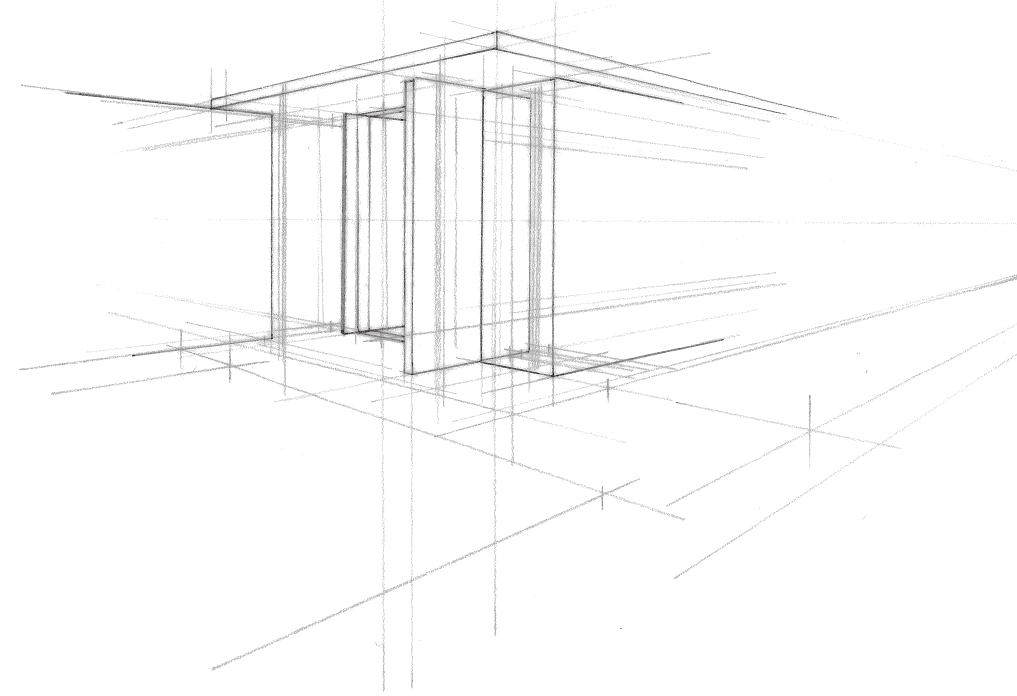




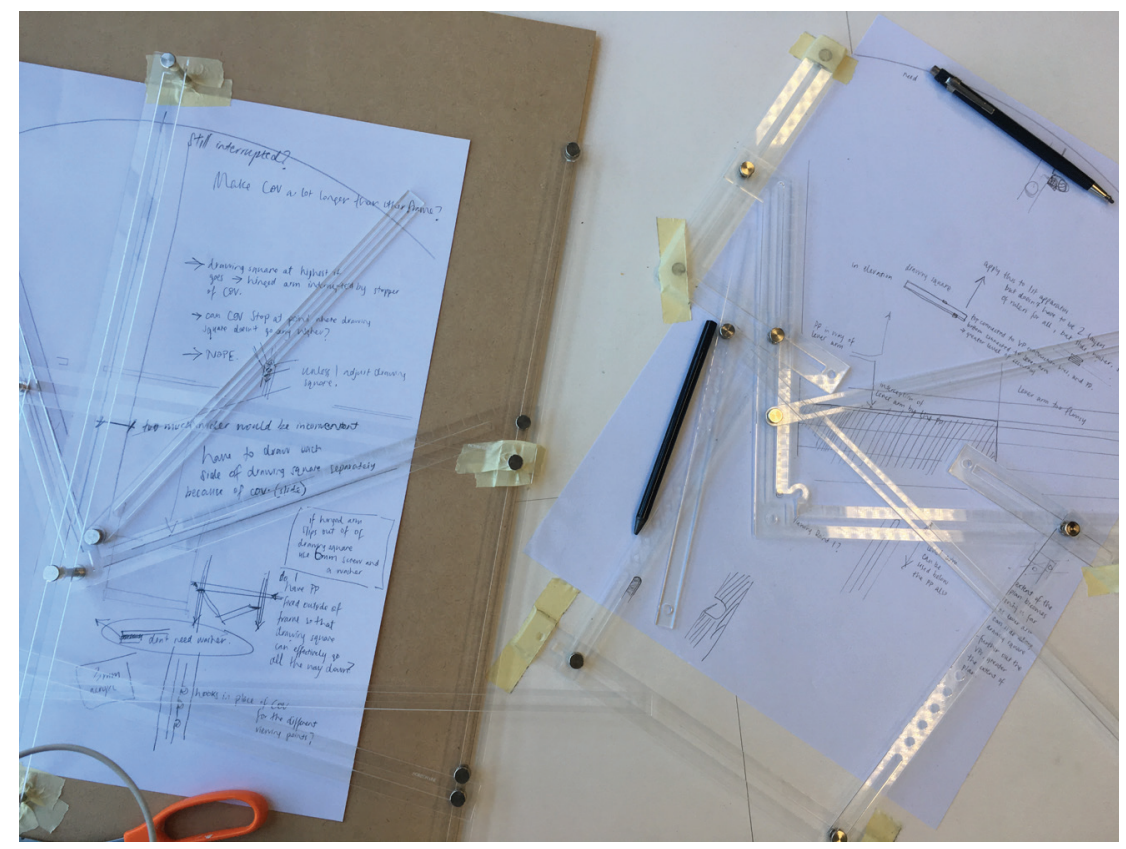

Figure 2.51 First two iterations of the apparatus

The apparatus has changed the way one can project in the mind and thus changed the way to generate a mental perspective. Therefore impacting on the way we think, even of standard linear perspective.

Rather than being restricted in the board, the parameters set up from the extent of the size and the positioning of the frames, start to determine design. While a technical and very rigorous process has been set up, design activity through the apparatus allows for a degree of intuition. The apparatus creates parameters but doesn't fully inform the design.

Feedback from the second design critique was given that even if it's not the whole building, the frames drawn through the apparatus give enough of the design to start to develop one. 


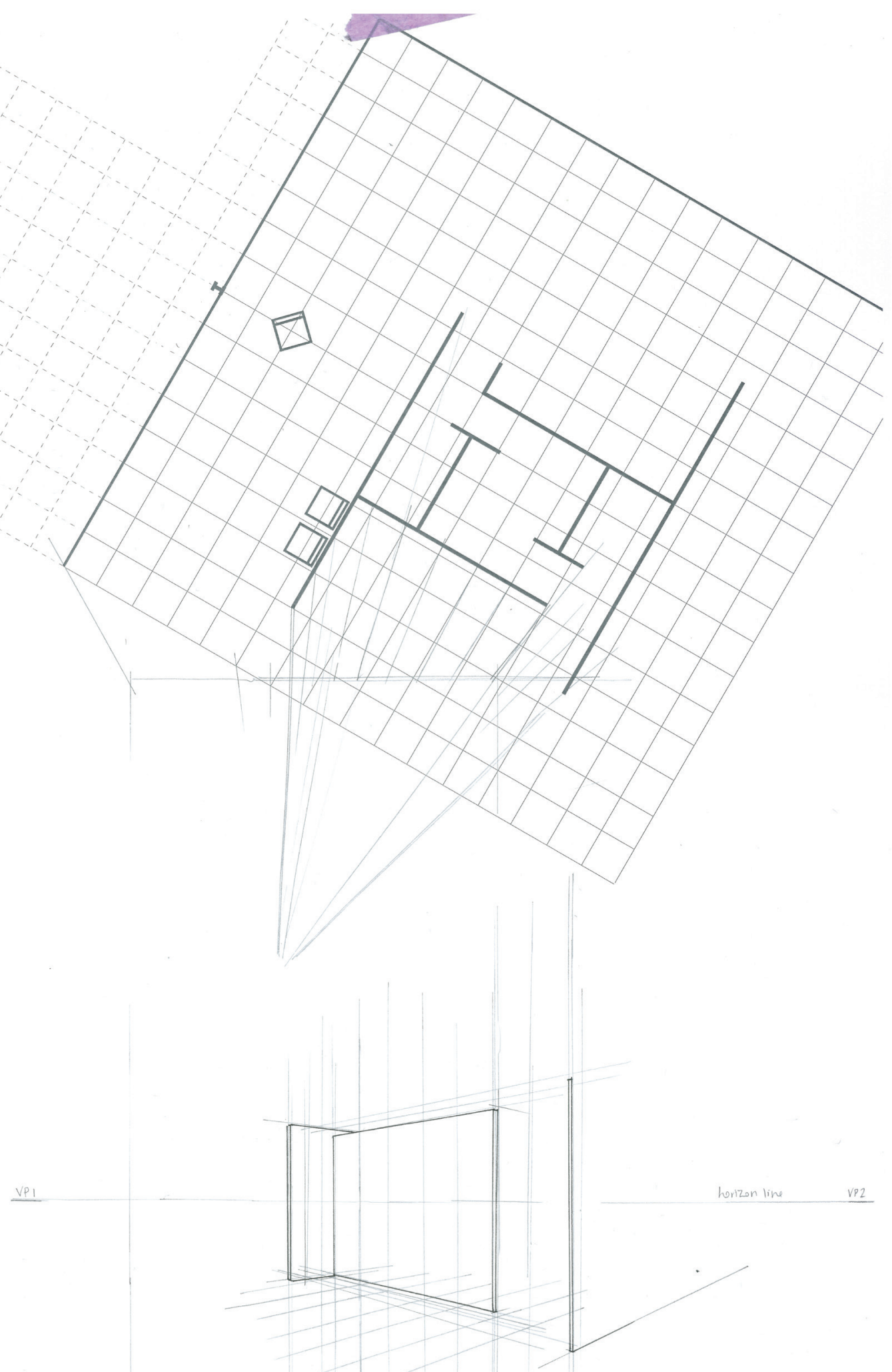

Figure 2.52 Interior of $50 \times 50$ house, Mies van der Rohe, from 60 / 30 degree plan 


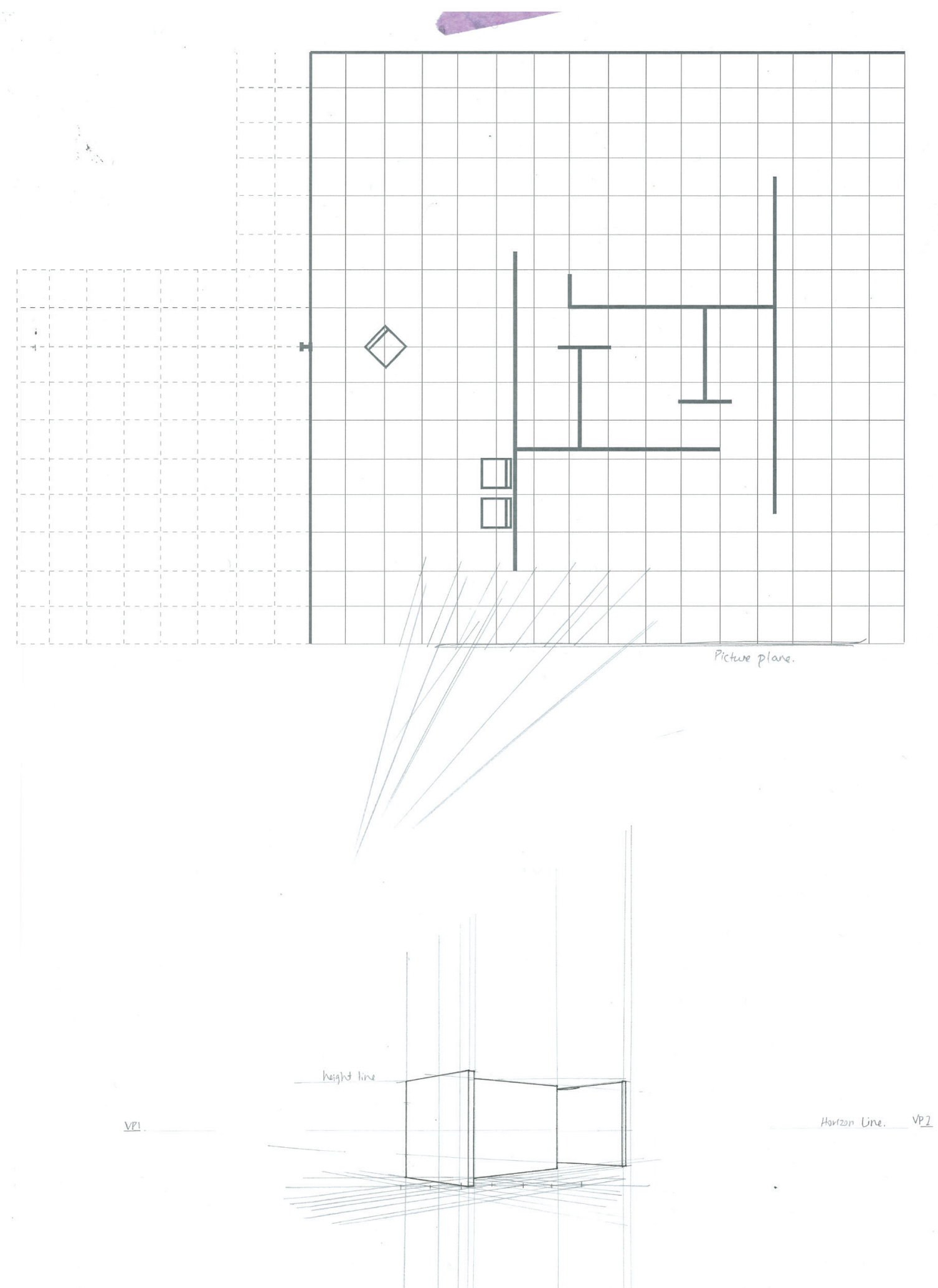

Figure 2.53 Interior of $50 \times 50$ house, Mies van der Rohe, from 90 / 0 degree plan 


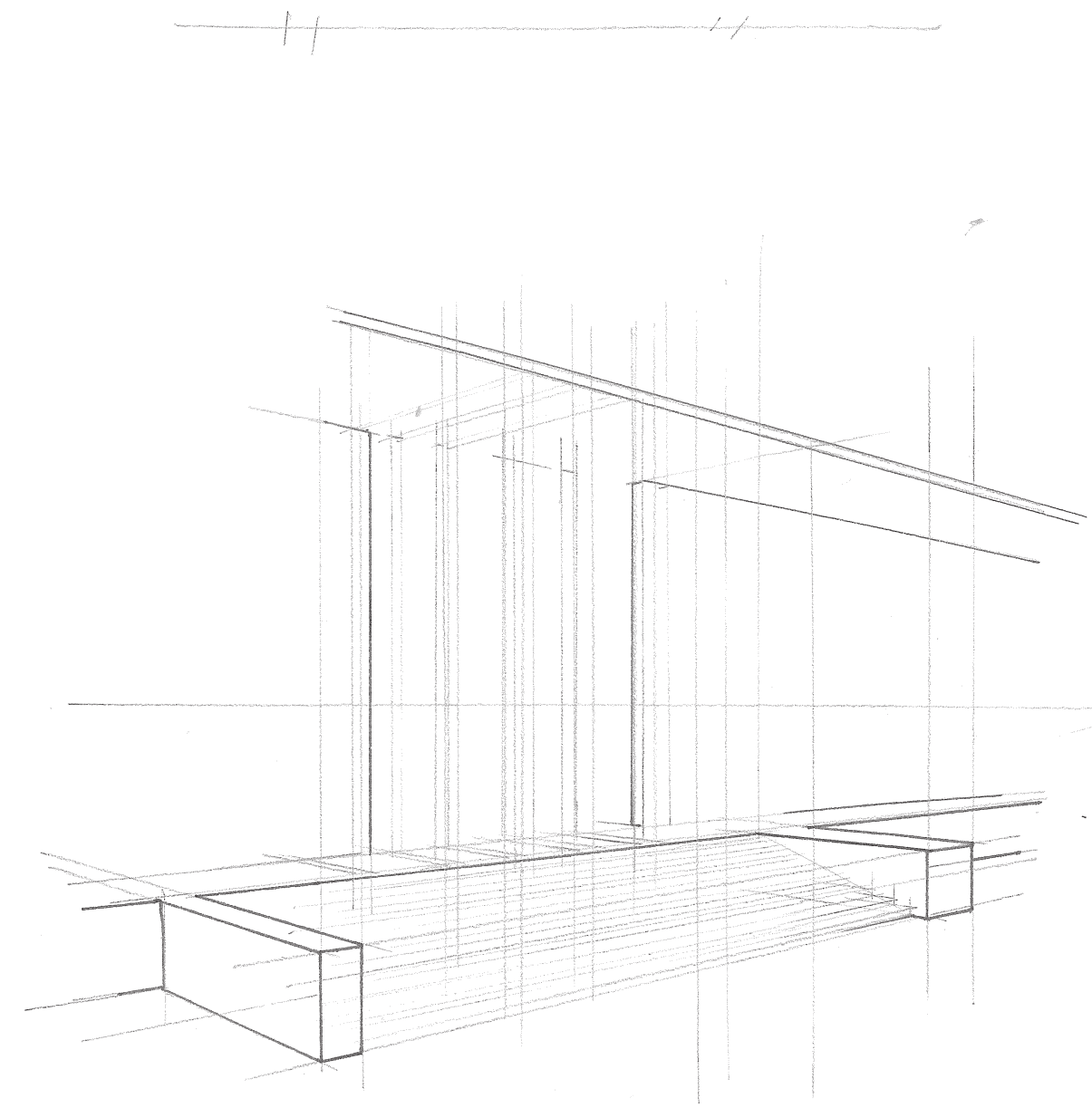

Figure 2.54 Altes Museum, Karl Friedrich Schinkel, entrance perspective

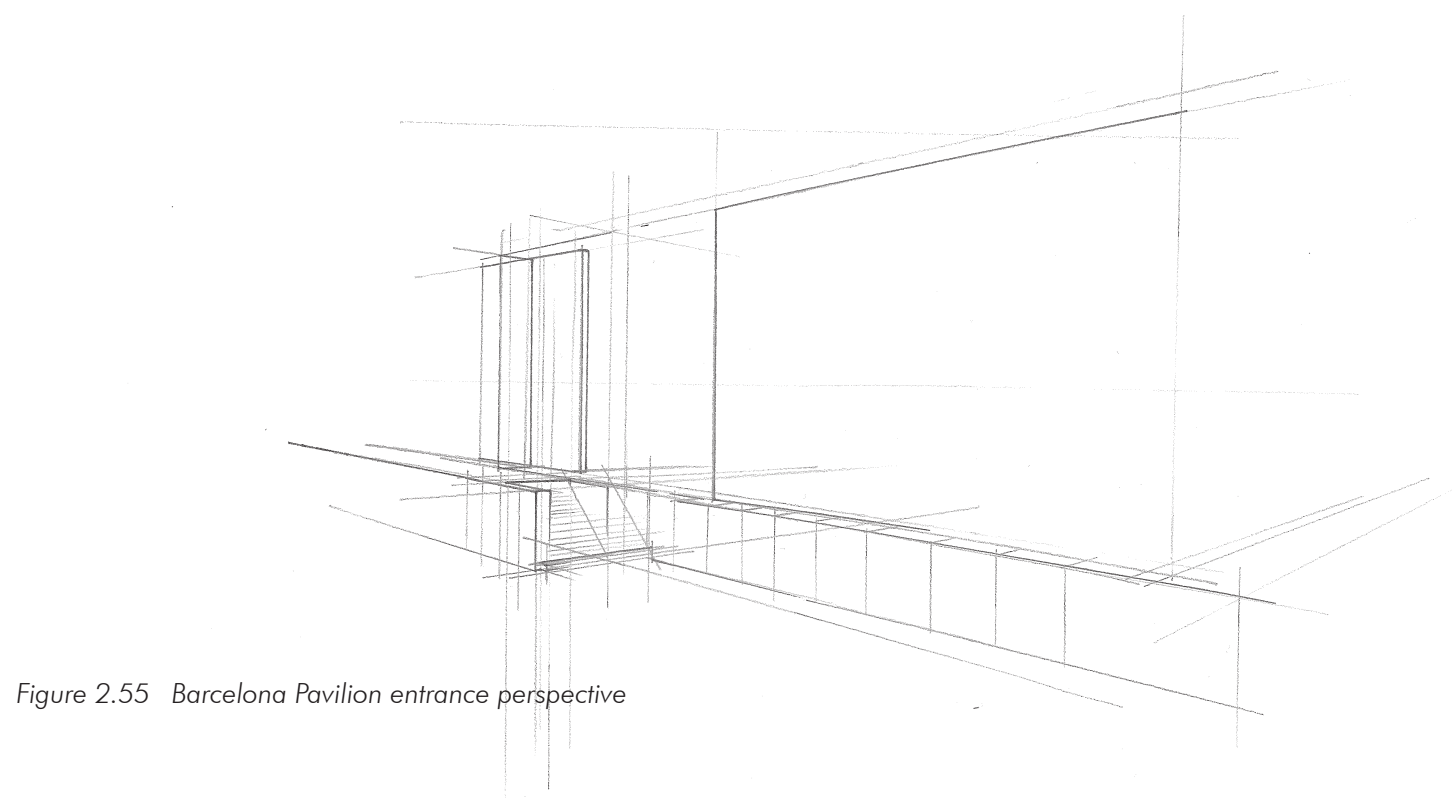



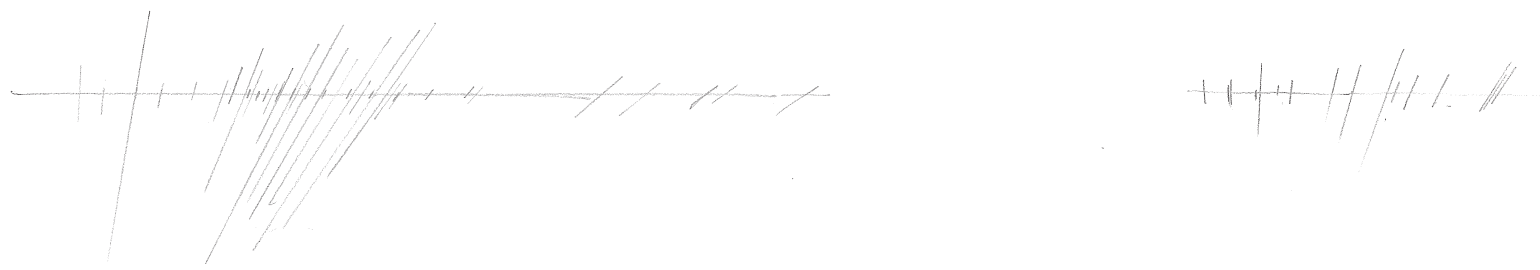

Figure 2.56

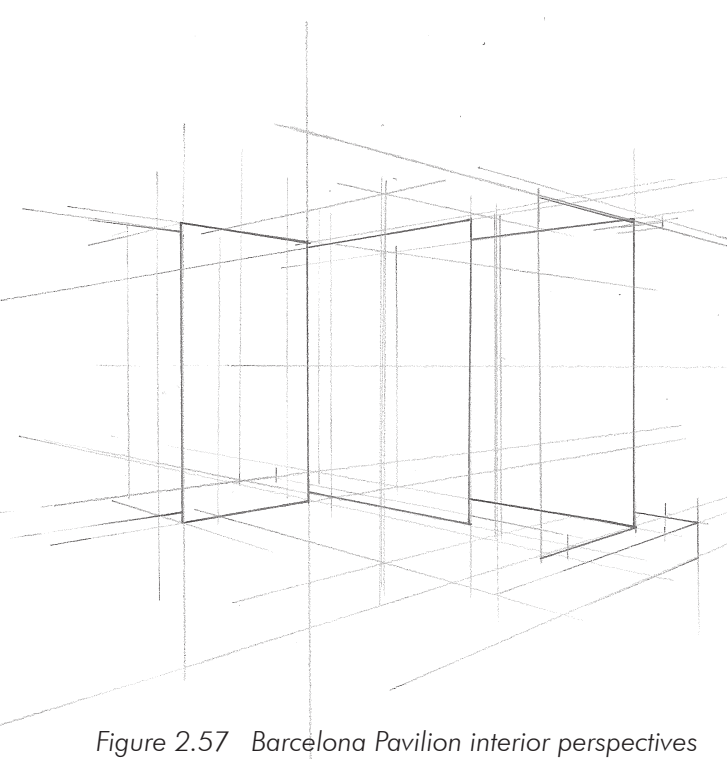

Figure 2.57 Barcelona Pavilion interior perspectives 


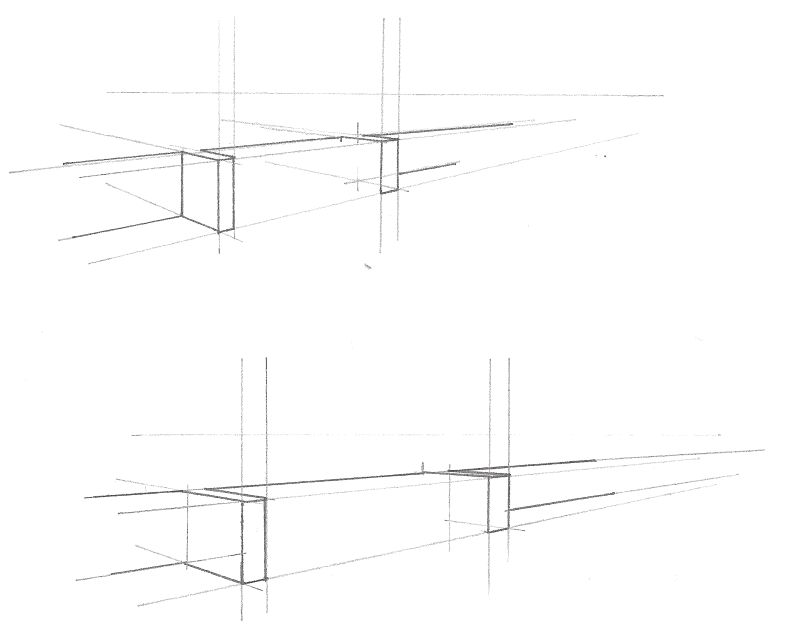

viewing
point 3

viewing

point 4

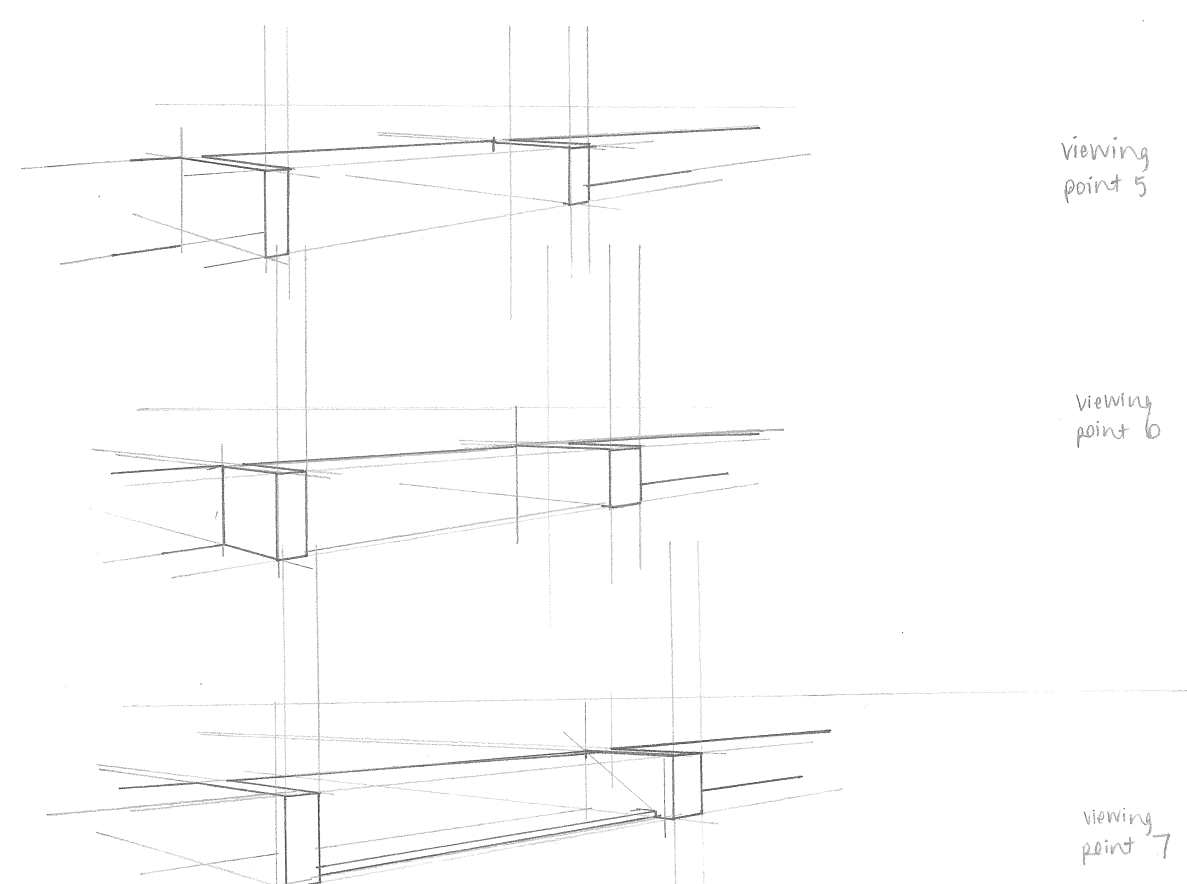

Figure 2.58 Entrance steps of the Altes Museum, drawn out through five viewing points 


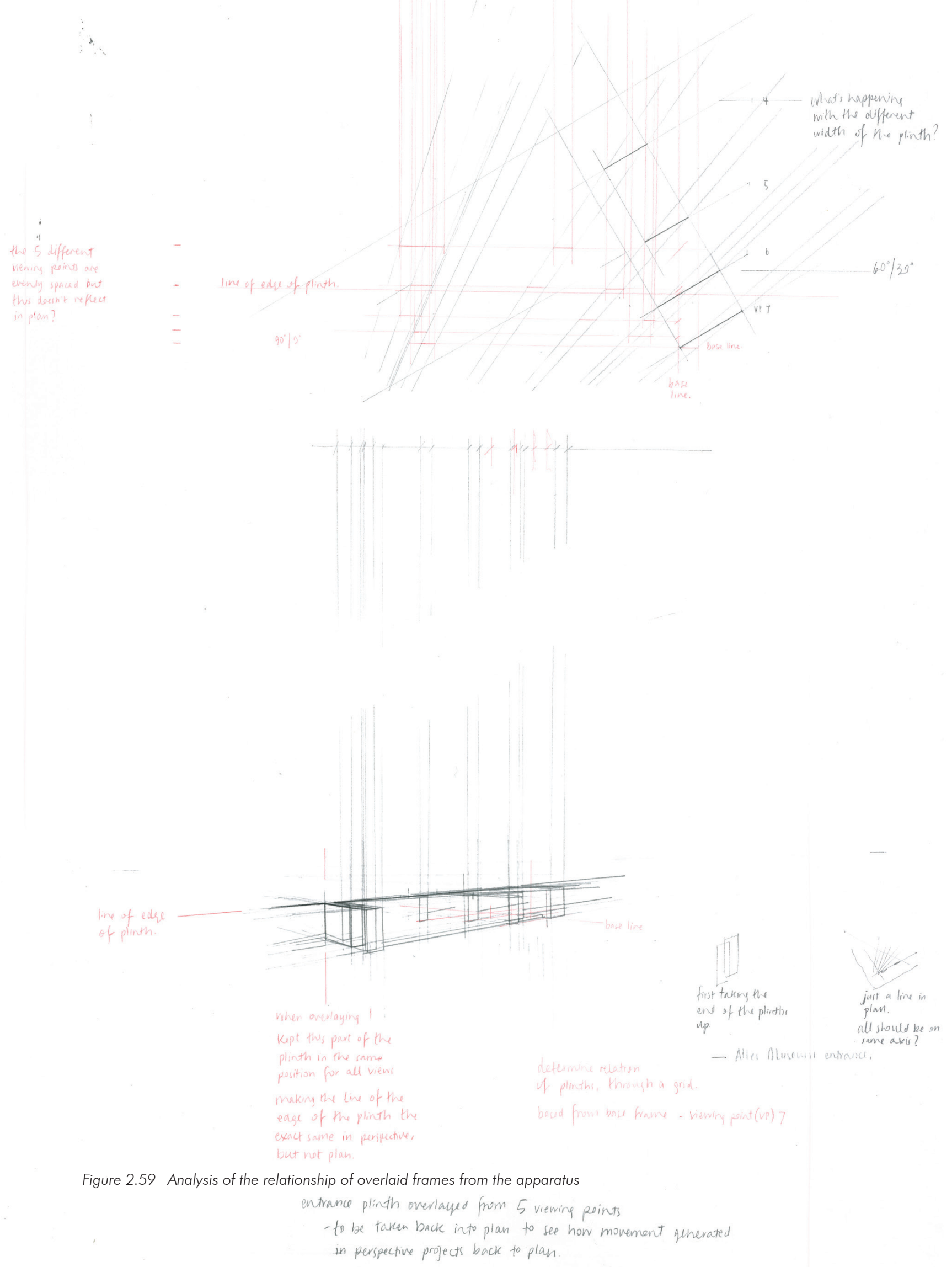




\section{CHAPTER THREE}

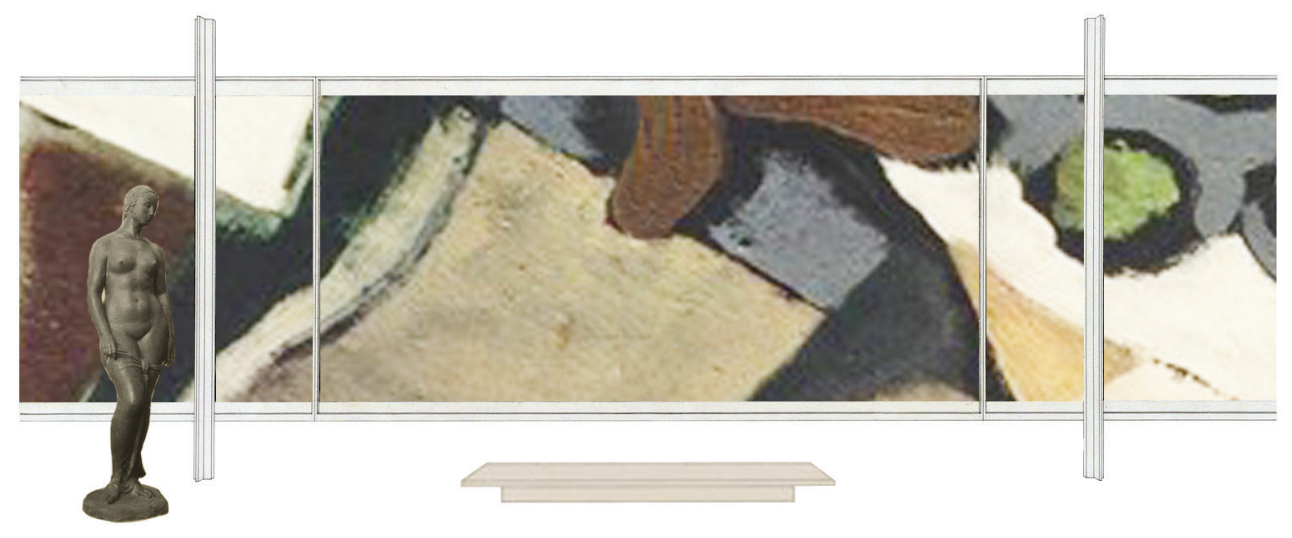

Figure 3.01 Gallery space 



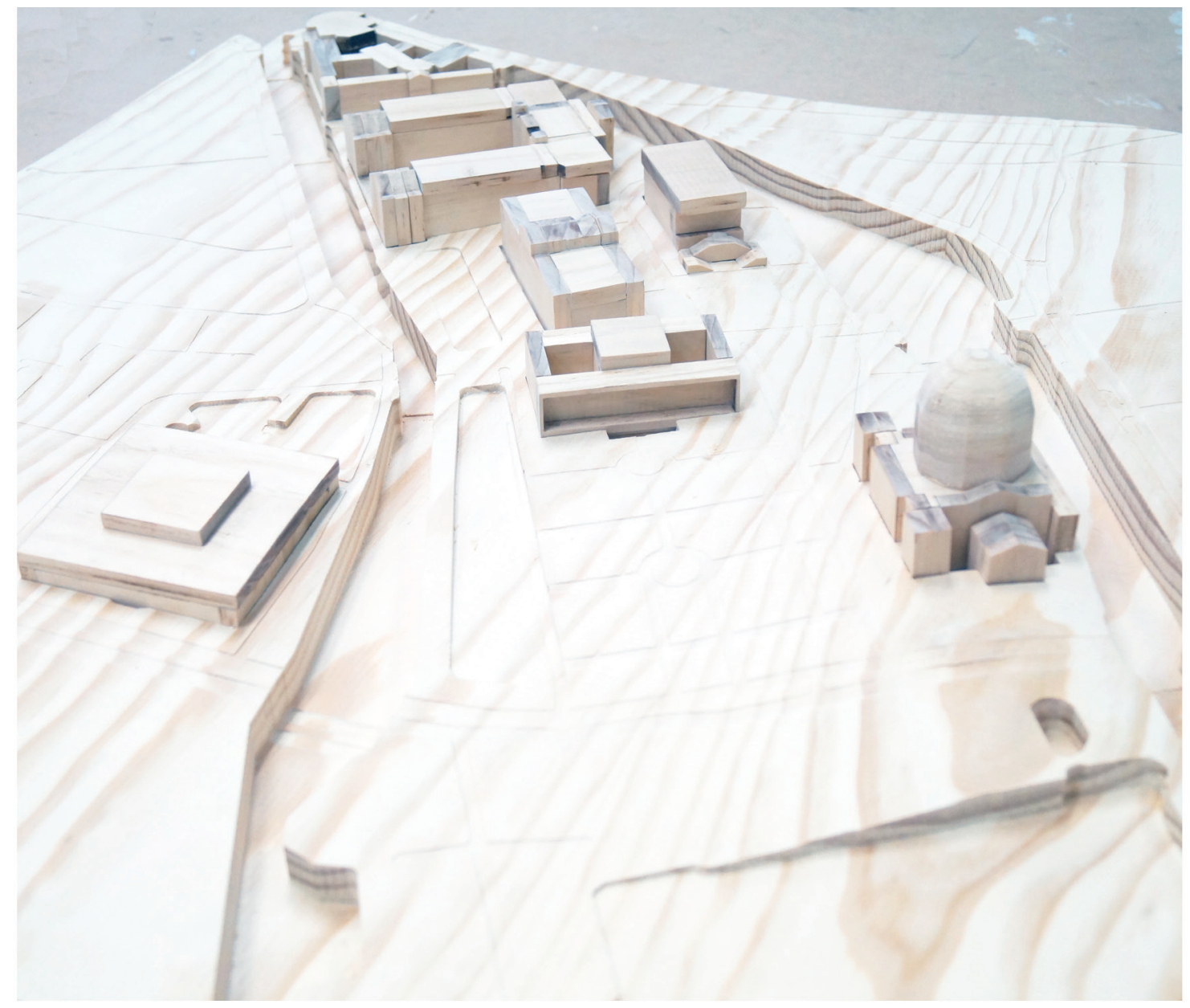

Figure 3.02 1:1000 model of the site on Museum Island, Pine wood 


\section{SITE ANALYSIS}

In the same way as Karl Friedrich Schinkel approached master planning, site analysis must be carried out with strong regard to the formal and spatial relationships of the site. In regard to Schinkel's paintings and perspective drawings, the free-flowing spatial definition can be attributed to Schinkel's occupation as a Romantic painter, and the volumetric and spatial arrangements of his successful urban sites, a credit to him as a Neoclassical architect.

The Altes Museum on Museum Island in Berlin was designed in 1822 and executed from 1823 to 1830, with the whole redevelopment of the Lustgarten in front of the museum occupying Schinkel throughout the decade of the 1820s. (Pundt, 124) The Museum is repeatedly cited as one of the most successful designs of its type and influenced Mies as well as many other Modernist Architects. The exterior composition was conceived as basically complementary in geometric form to the palace at the opposite side of the square and also to the Zeughaus across the Western bank of the River Spree. Attention to the spatial and physical surrounding context formed a comprehensive, organised urban environment.

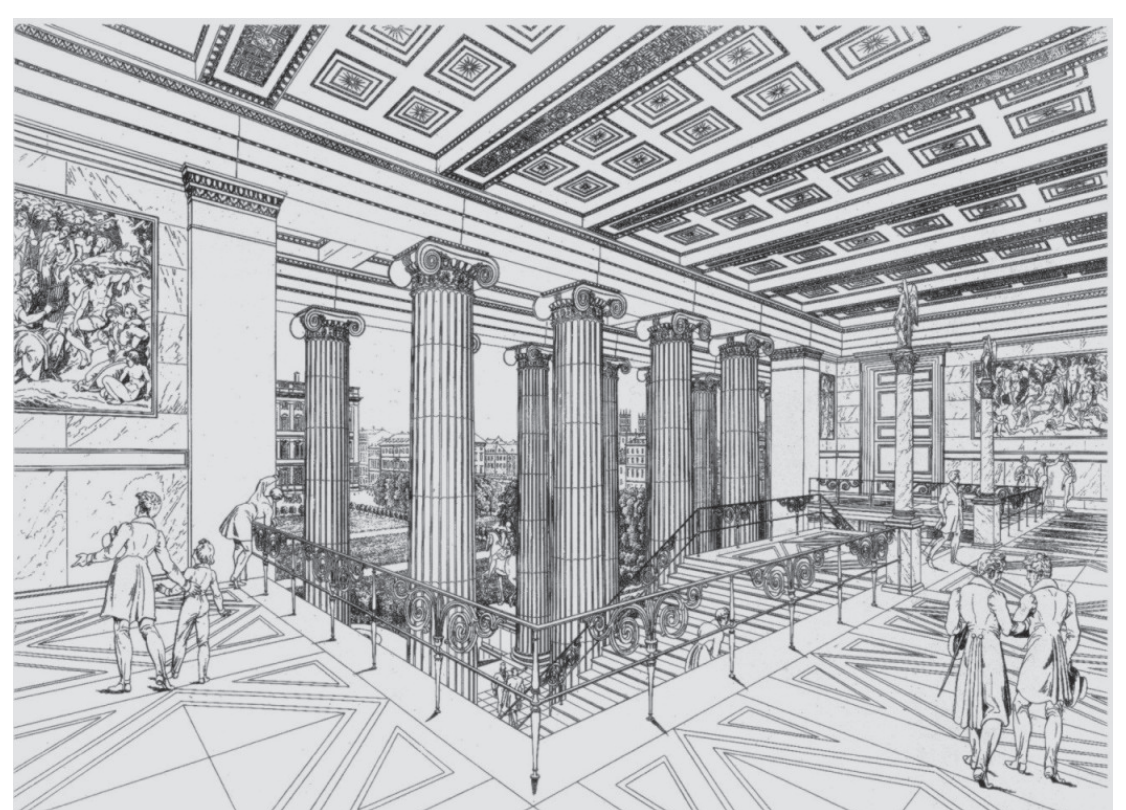

Figure 3.03 Altes Museum Berlin. View to the staircase. Drawing by the architect of the museum, Karl Friedrich Schinkel. (Schinkel) 


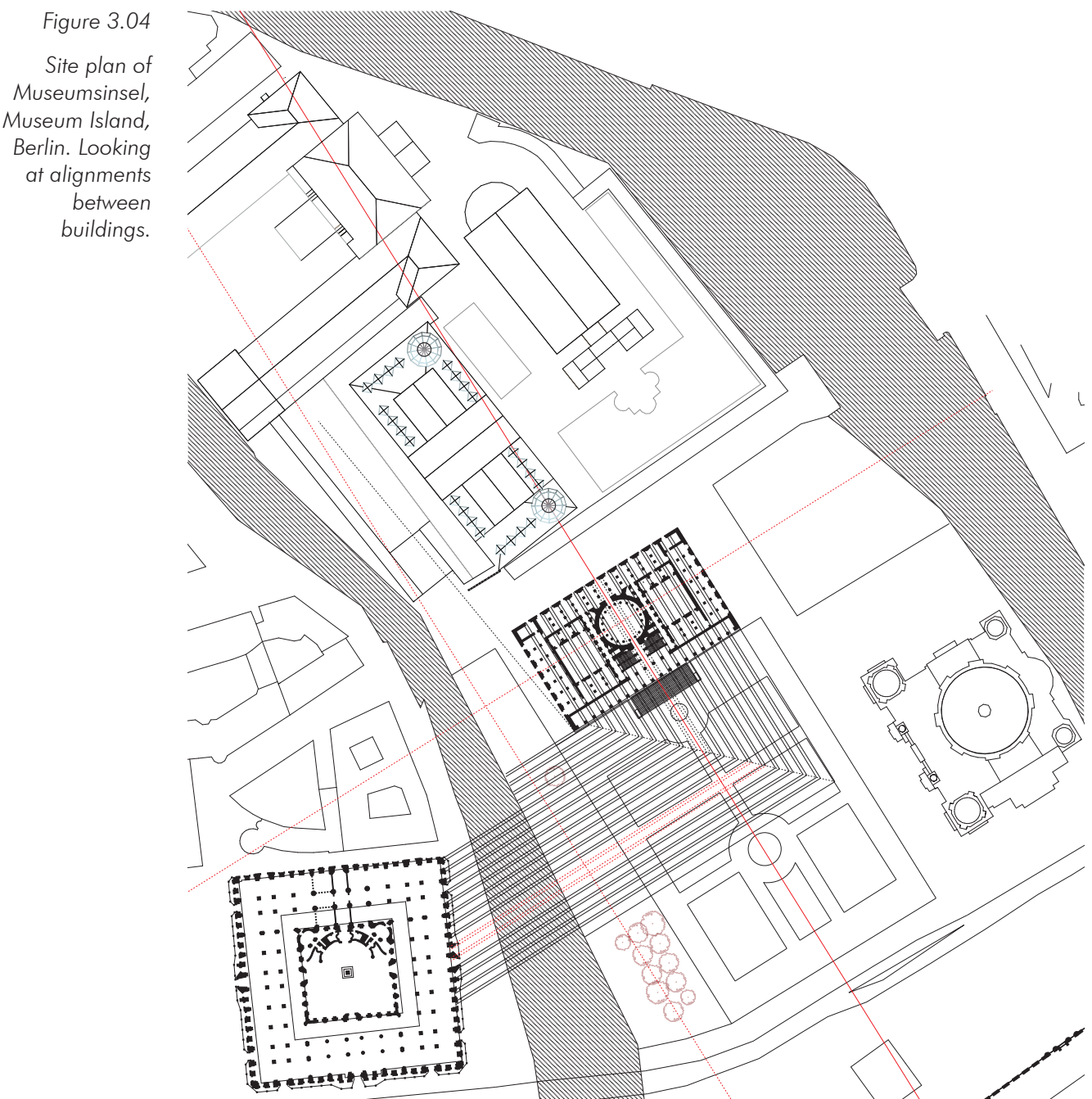

It differed from the surrounding buildings in that it was raised on a podium of which Mies has done in the Barcelona Pavilion and also the Neues Gallery in Berlin. By elevating the lonic colonnade well above the ground level it was possible to view the major exterior feature in its entirety from a distant observation point. For Schinkel, the use of colonnades served as frames. In the Altes Museum, the wide colonnade frame views out to the Lustgarten and the surrounding monumental buildings, and he sets up frames in the interior and uses columns to frame statues and direct view. 


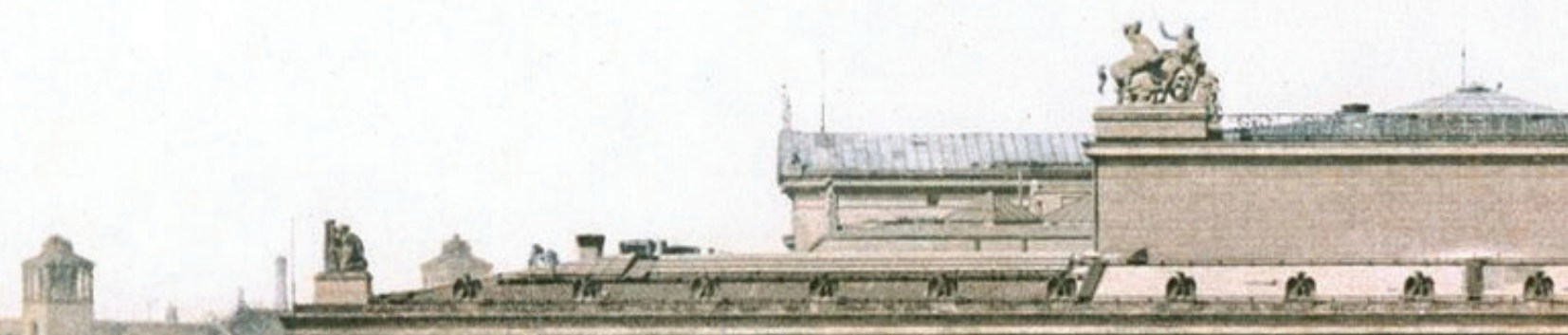

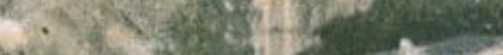

avenestat?
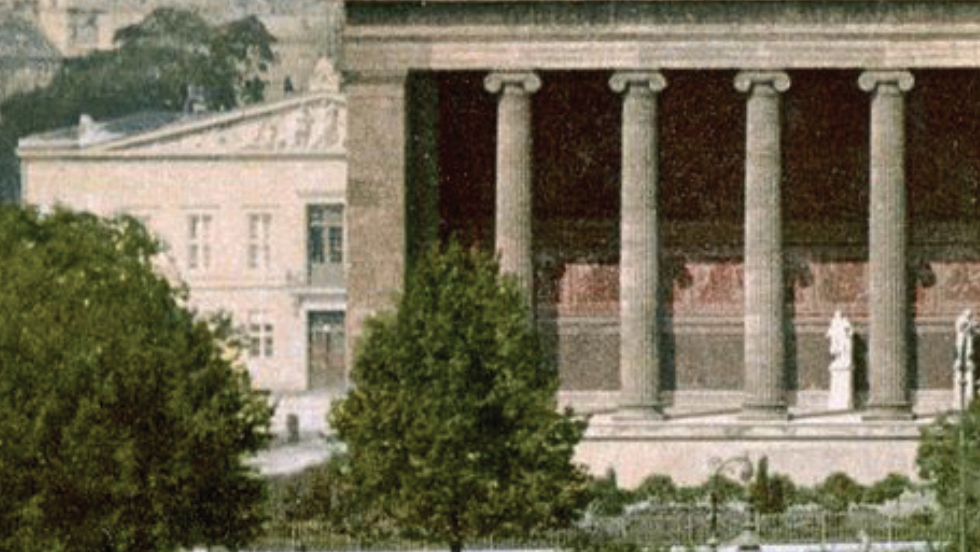

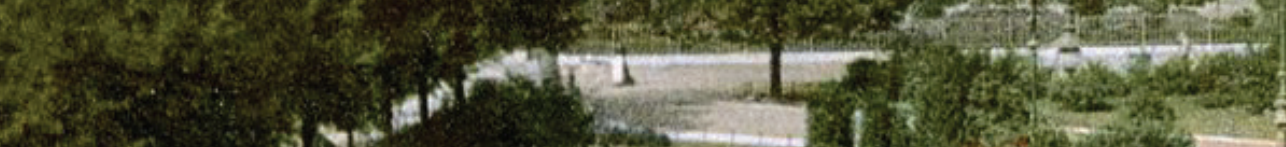

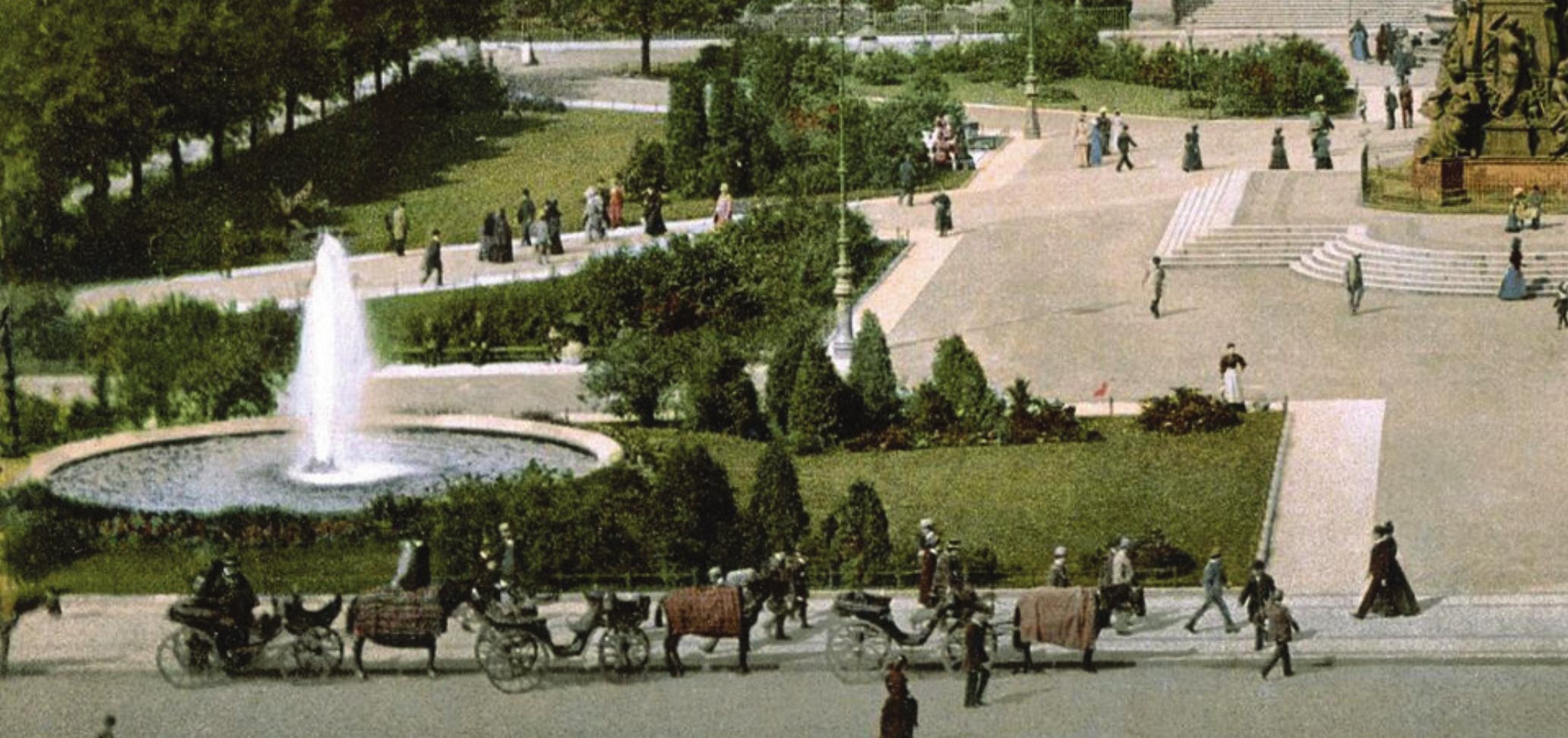




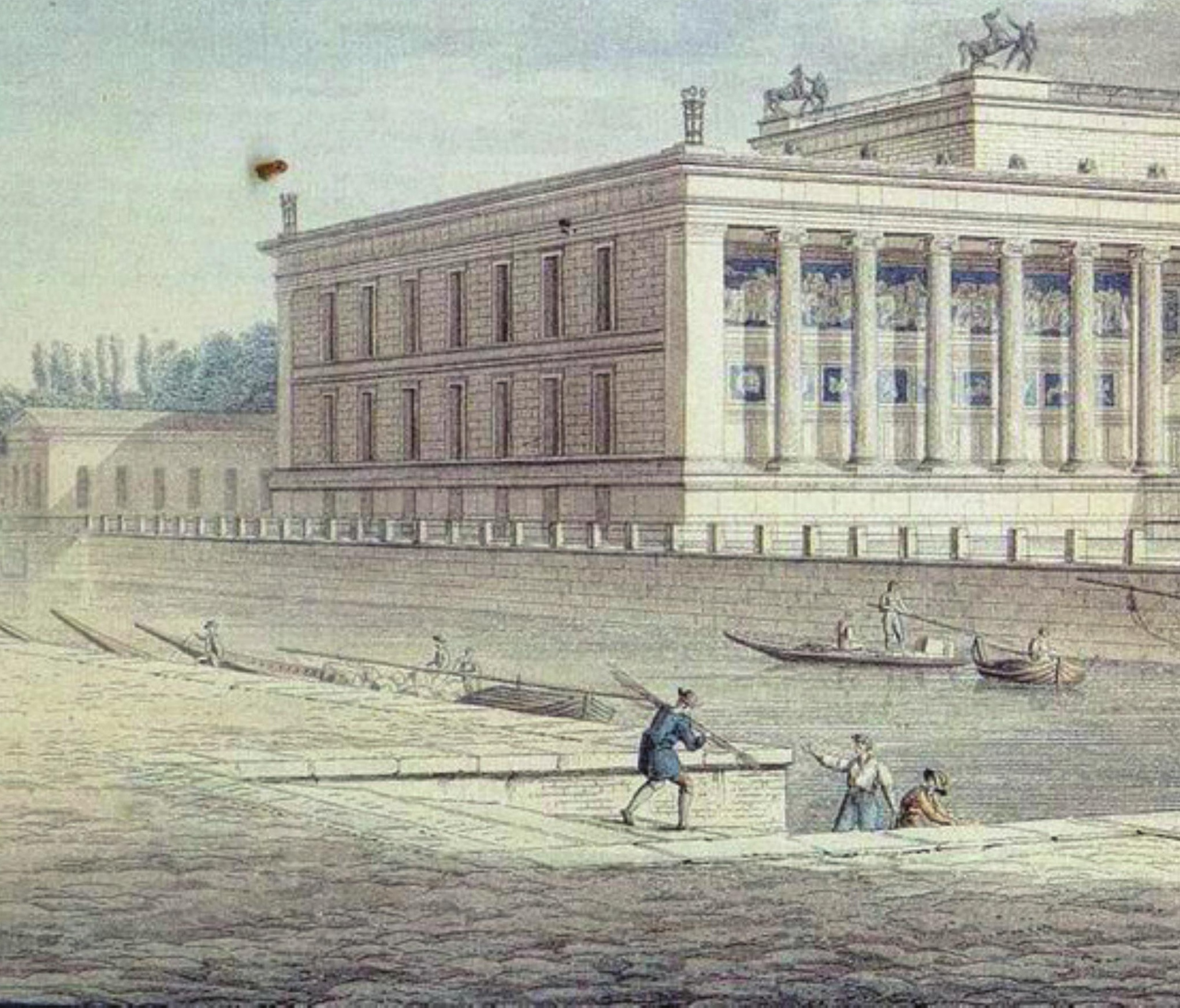




\section{dis

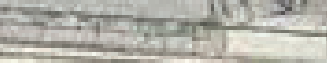

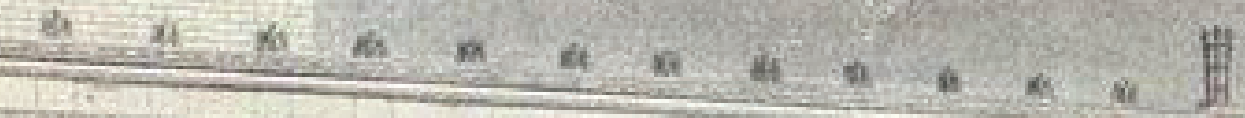

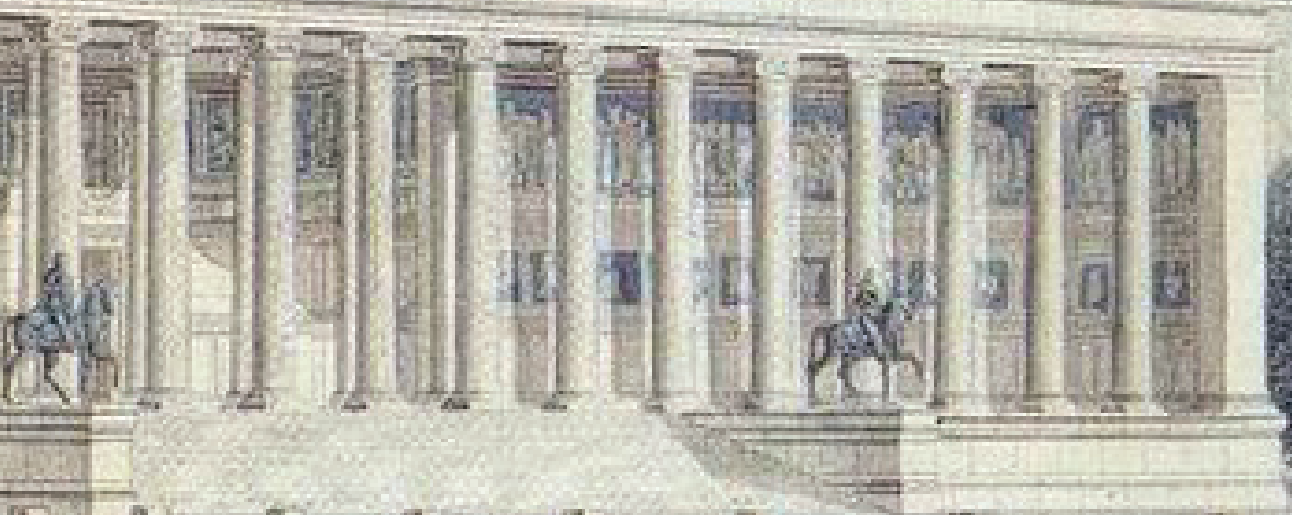

I $11-1+1+\pi$
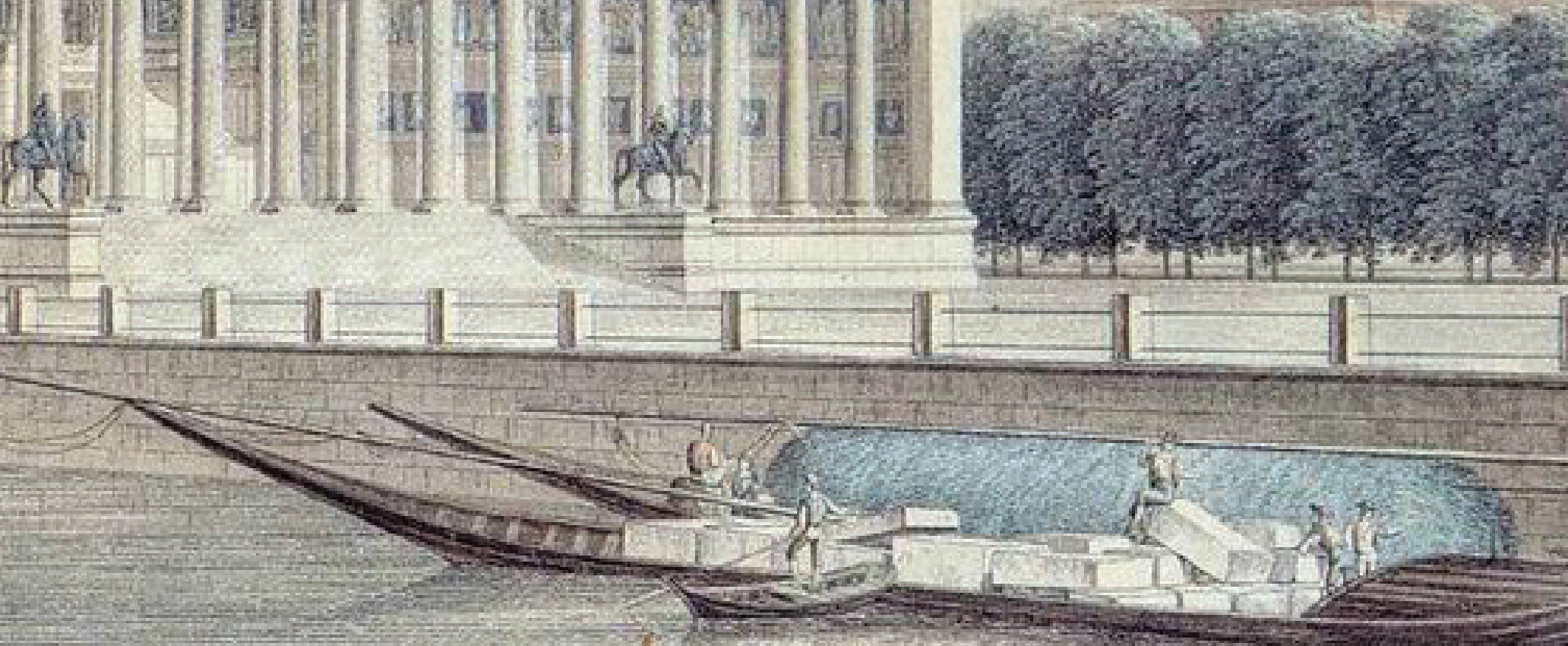

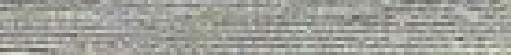

$E=-$ Figure 3.06 Altes Museum from across the River Spree (by the Zeughaus) (Thiele)

Figure 3.06 Altes Museum trom across the River Spree (by the Zeughaus) (Thiele) Whow

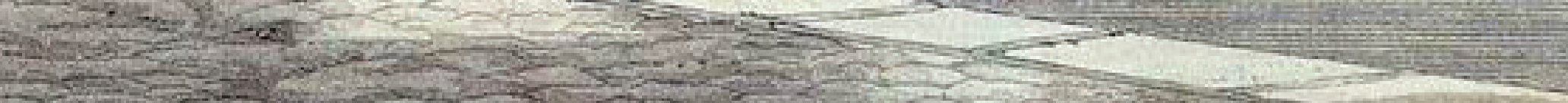

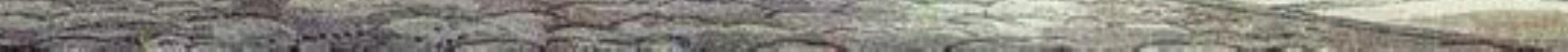


Museum Island in Berlin is the perfect site, as with 5 museums, it illustrates the evolution of modern museum design, and is cited as Berlin's civic and cultural nucleus. (Pundt, 123). The site to carry out this study's design exploration is situated perpendicular to the Altes Museum, between the Lustgarten and the River Spree. There is currently, in 2017, the development of a new master plan and a new building, the James Simon Galerie Museum at the North of the site is a project similar to the design exploration being carried out through this study, in that it references historically and contextually the surrounding buildings.

After having been flattened by the Nazis for mass rallies during the Second World War, the Lustgarten is now a reinterpretation of Schinkel's original design. Ultimately considering again the functional and aesthetic coordination between the immediate surrounding Zeughaus, Berliner Dom Cathedral, the Altes Museum, and the Palace, as well as a series of new buildings. Consequently, in revisiting Schinkel's emphasis for a controlled visual experience, the value of a design case study on this site must be considered in terms of the total context, considering the spatial relationships and formal continuity between the existing buildings. (Pundt, 117). The site, exactly perpendicular to the Altes, is harmonious with Schinkel's intention to form a 'third wall' to the Lustgarten, currently achieved through the rows of Linden trees. It was suggested in an early proposal of Schinkel's that the Altes façade be exactly perpendicular to the palace, yet was dismissed. Schinkel has maintained the desired physical distance from the Altes to the long impressive façade of the palace, however. (Pundt, 127). 


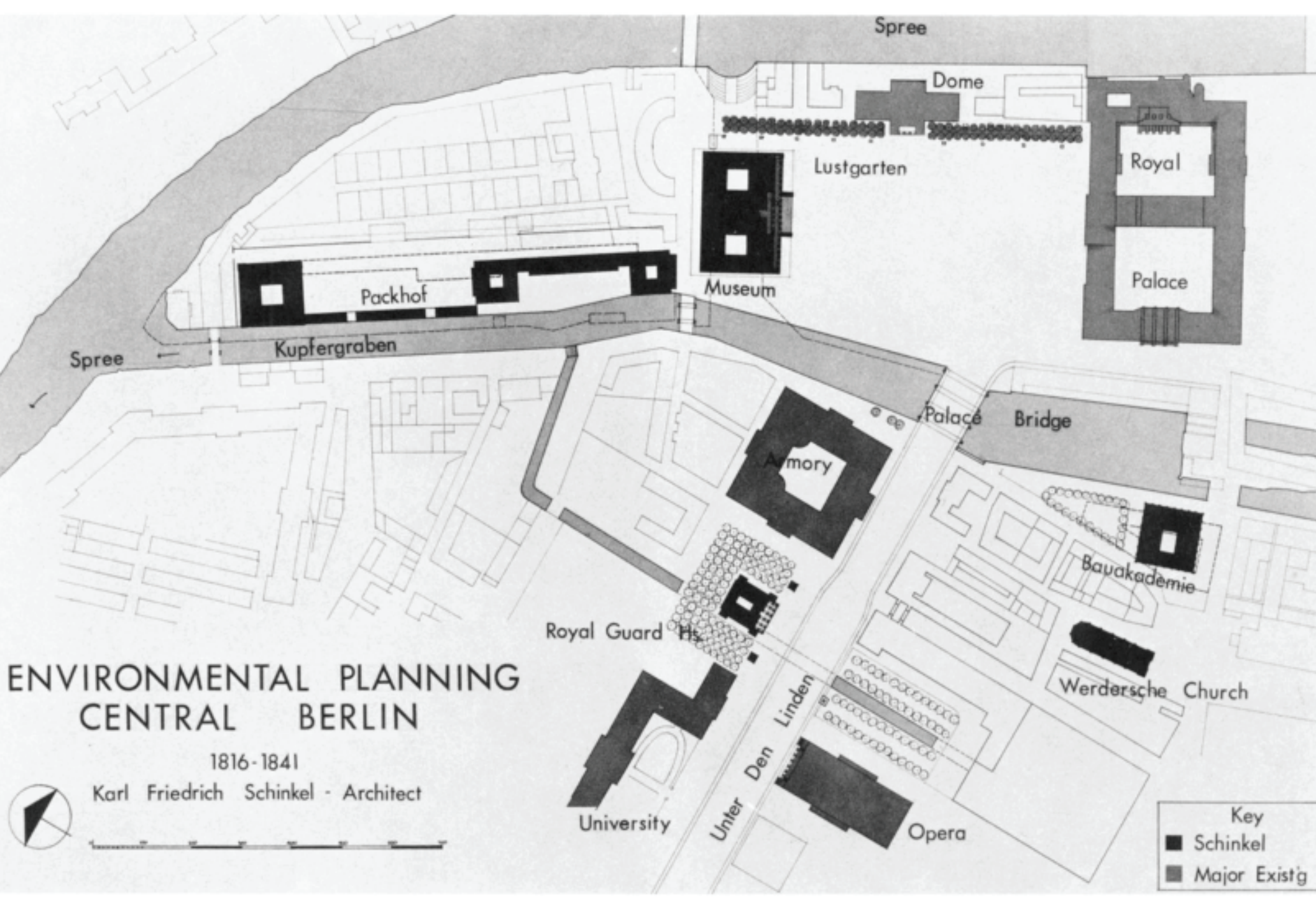

Figure 3.07 Plan of Schinkel's buildings surrounding Museum Island, Berlin (Pundt, 117) 
Through the site analysis, this study has been fundamentally concerned with setting up parameters that would continue to inform the design since parameters had been forming the rest of the process. Having since been setting up a framework that could determine a new way of designing, further site-specific parameters, as generalised as site boundaries and planning grids, could return the design to the narrative and make the design study more specific. Through the apparatus, it could be inevitable that perspective frames be drawn infinitely without any formation into a building.

The first step with the site was setting up, for scale purposes, a $10 \mathrm{~m} \times 10 \mathrm{~m}$ grid, but the exact effect of this was questioned. The grid needed to come from the narrative as if redesigning the pavilion alongside the Altes Museum. The proportions of the façade of the Museum were continued across the Lustgarten and then perpendicular at 90 degrees across the site. Indirectly becoming, a reflection of the Altes façade. Certain points on the Altes grid, when drawn across as the analysis has done, meet points on the Zeughaus façade, and these are to be addressed in the planning as well. The site and the narrative literally become a screen for projection. As the Pavilion is suggested to have been intended to be viewed through the lonic colonnade, the Eastern façade of the new site facing the Cathedral and the Lustgarten immediately was intended to be viewed the same way. This initial intuitive planning was necessary for setting up the second phase of design - and through the rigorously controlled design process, the intuitive nature of this initial planning was seen as invaluable. Important to how the partial nature of the design drawings were to come together.

What the initial planning grid across the whole site established were points of reference. There were points of particular importance, corresponding points found from overlaying axis from the surrounding buildings, further emphasising the controlled design intent of Schinkel, with these alignments suggesting that they were more than just coincidental. Any intersecting or aligning lines from site axis and grids were noted, to add to the parameters this study is to be designing within. Atop of the grid, a secondary organisational grid was established. Further than the axes, the drawing out of each of the surrounding building's planning grids established where reference points were situated in regard to each other, and determined a nucleus on the site - the centre-point of the Lustgarten - which acts as a focal point from each façade. This was with the intent to ask how the relationships between building grids, and reference points could inform the design. 


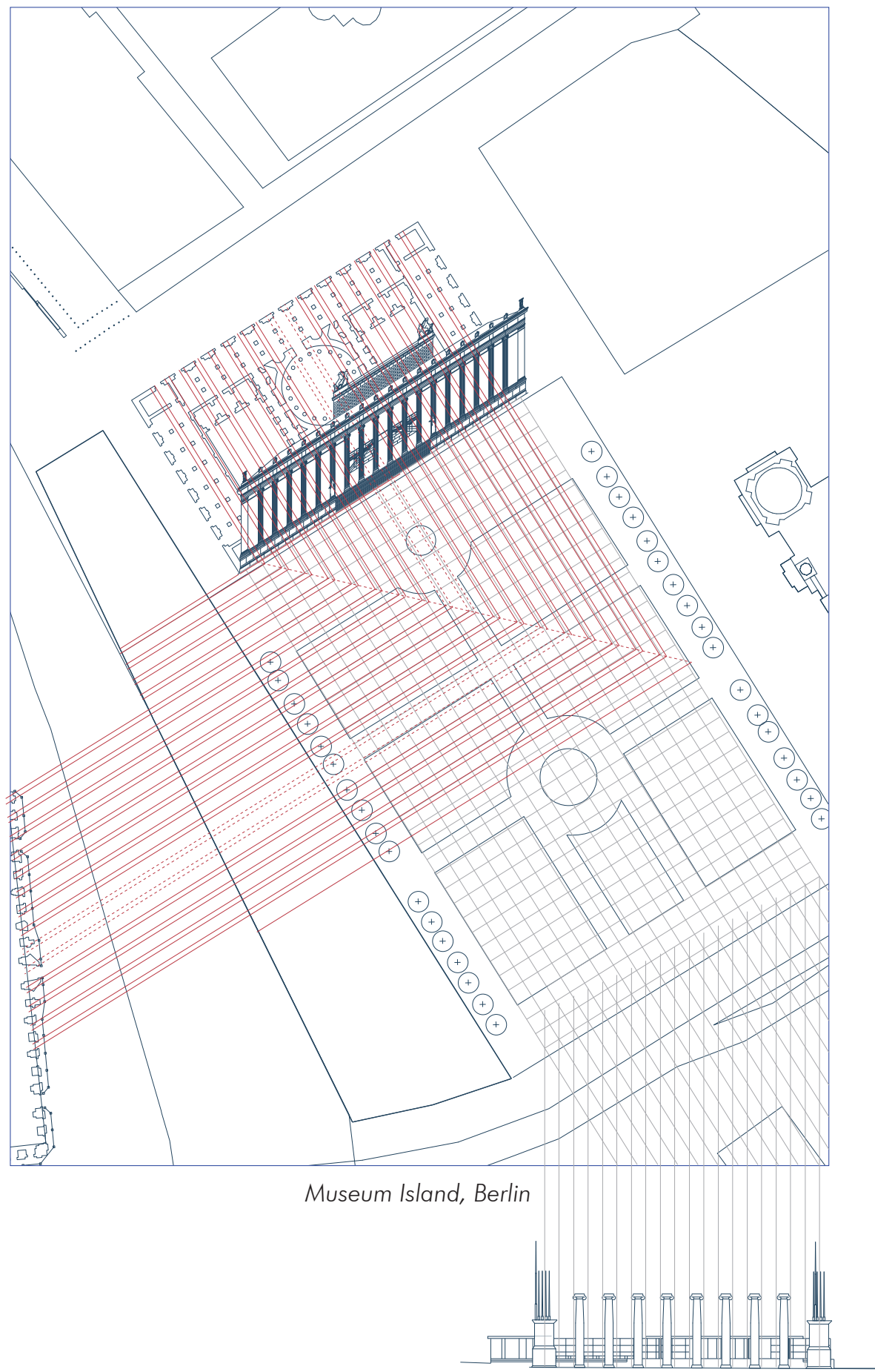

Figure 3.08 Grid from the colannade at the Placa de Carles Buiggas, Barcelona, aligning with the grid from the Altes Museum colonnade 


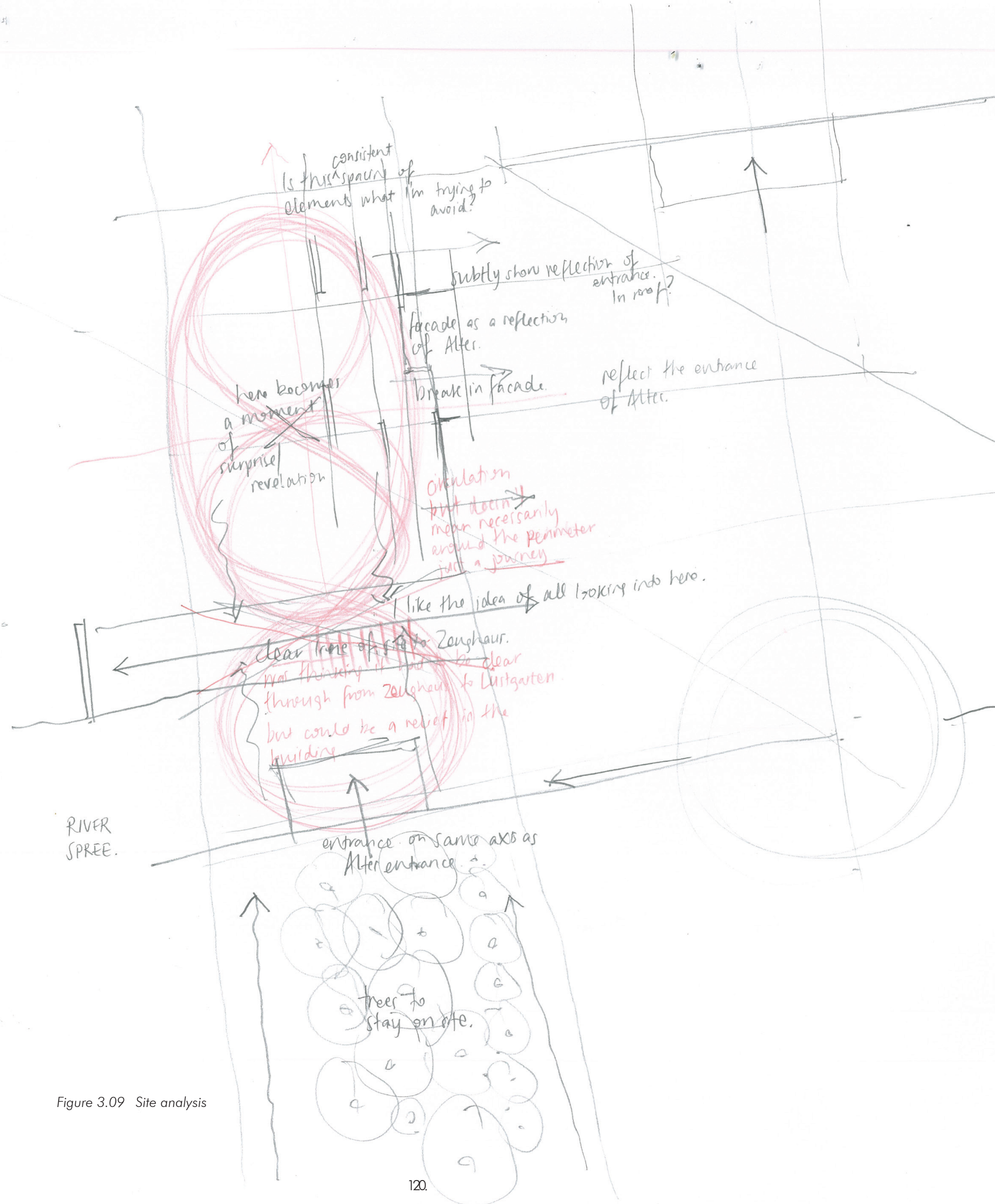


I had been considering the colonnades in both the Altes Museum and the Pavilion as on different spatial organising grids, in that that they had not produced the reference grid, nor ordered the rest of the layout. They need to be thought of in site context. In the aligning of the Barcelona colonnade with the grid of the Pavilion, the first of the steel columns align perfectly with the centreline of the longitudinal pavilion. It suggests that the existing columns of the colonnade have positioned the walls. The drawing out of this grid was revealing, after having only considered the material grid, and the gridded volume over the perspective.

As site analysis progressed alongside design, the narrative of the two buildings was carried through the [conception of the] new building through sequential circulation. The partial plans from this sequence were projected through the apparatus (distorted) and sequenced - through the grid placement - into one plan. Overlaying the plan from the apparatus onto the established site grid aligned points.

Through initial sketches, it was suggested that a reflection of the new building in the River Spree could appear - as seen from the bridge on the Unter den Linden, as a reflection of the Altes. Viewing the building from the Lustgarten, the Eastern bank of the river beside the Zeughaus is visible, and if to raise the building on a plinth like the Altes, the river bank would be seen as a continuation of the plinth. Further justifying the idea of the plinth as evident in both the Pavilion and the Altes. 


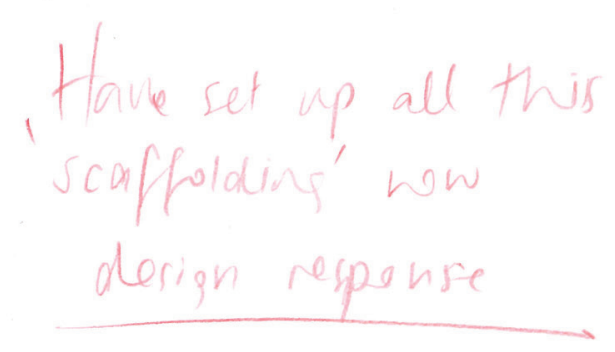

test.

experiment

analyse

rigorous right til end

122 
CHAPTER FOUR 



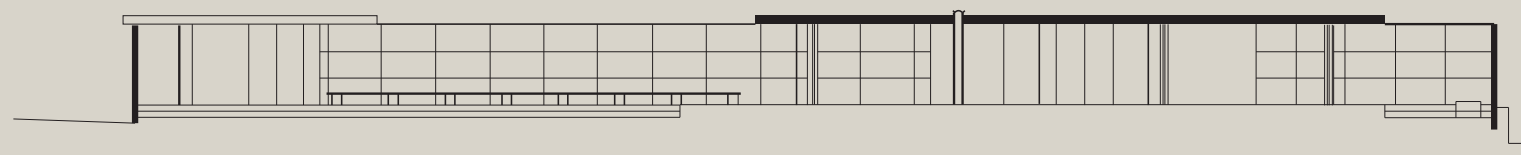

Figure 4.01 Barcelona Pavilion elevation

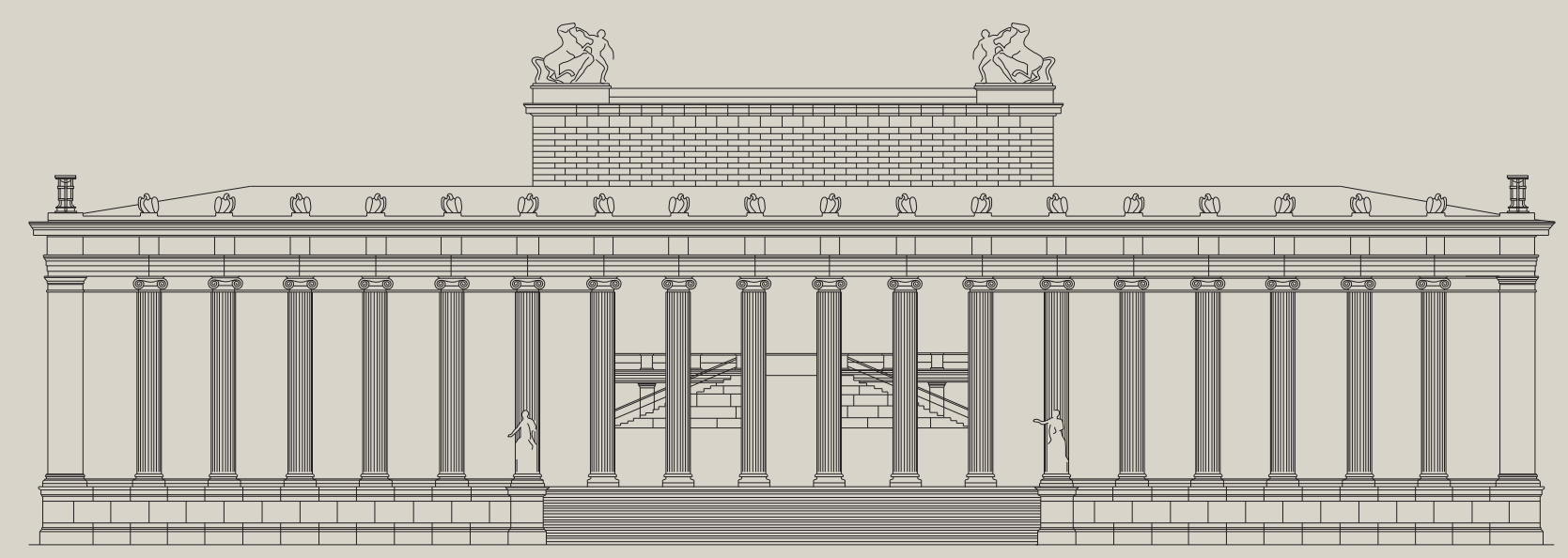

Figure 4.02 Altes Museum elevation 


\section{NARRATIVE}

Justine Clark, in her journal article 'Origin of Drawing: event, embodiment and desire in architectural drawing', outlines the myth of the origins of architectural drawing that is cited in many architectural theorist's discussions. She suggests myth as a "screen for projection" (Clark, 2). Or as with perspective, a picture plane onto which things are projected. Beyond standard projections, myth is reinterpreted, creating a level of meaning and connection that engages and provokes. Neoclassical architects and painters retold the myth of Diboutades, who traced the shadow of her departing lover, using it as a receptive screen, or picture plane onto which allegories could be projected. In contemporary architectural discourse, the Neoclassical painted versions are the allegories used for writers to construct their own projections of the relationship between drawing and architecture. In the varying settings that depict the event of the first drawing, alternative readings are constructed, emphasising the effect that an alternative screen has on projection. Through this thesis, the concepts of collage and linear perspective which are feeding into the narrative, distort and create indifferences in a similar means to the case study example of Eisenman's reinterpretation of Campo Marzio.

In a circular narrative, as this myth has continued to be projected, returning to the origin of drawing to find meaning in representation, the myth through this thesis returns Mies to Schinkel. The existing colonnade perpendicular to the Barcelona Pavilion, that while no longer there, existed at the 1929 International Exposition in the Placa de Carles Buïgas Barcelona, was a screen onto which the trace of the Altes Museum is projected. And now the Lustgarten is the screen onto which the new sculpture gallery is projected, as reflective of the Barcelona Pavilion which was influenced by the Altes Museum. A circular rhetoric. 
The version most used through the writings of the myth in the 1980s and 1990s was Schinkel's 1830s painting. Another parallel to the narrative. Schinkel depicts Diboutades' lover's shadow being traced on a rock outside, as opposed to on a wall as otherwise interpreted. Evans argues that the absence of a building, is because for Schinkel as an architect, drawing precedes and prefigures architecture: architecture is absent until drawing is invented (Evans, 3). The act of the bodily practice of drawing is also described through the portrayals of the myth, as "the thinking of drawing as an active, inventive and productive process." (Carter, 8). It depicts architectural drawing as an embodied activity. Yet in the painting, there is another figure doing the tracing while Diboutades directs, said to be speaking of the indirect nature architects have on the practice, for while they make drawings, they make buildings only indirectly.

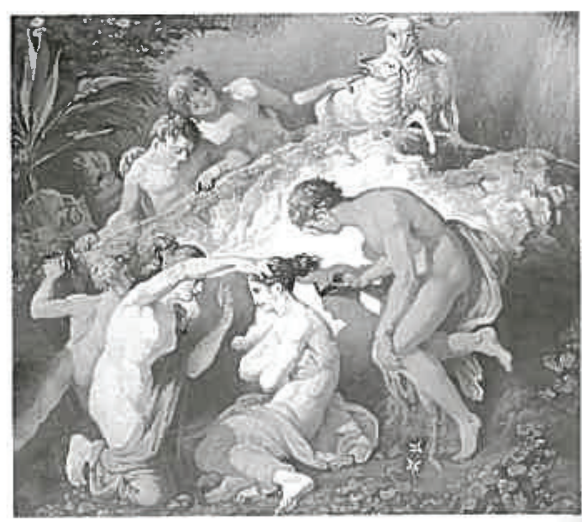




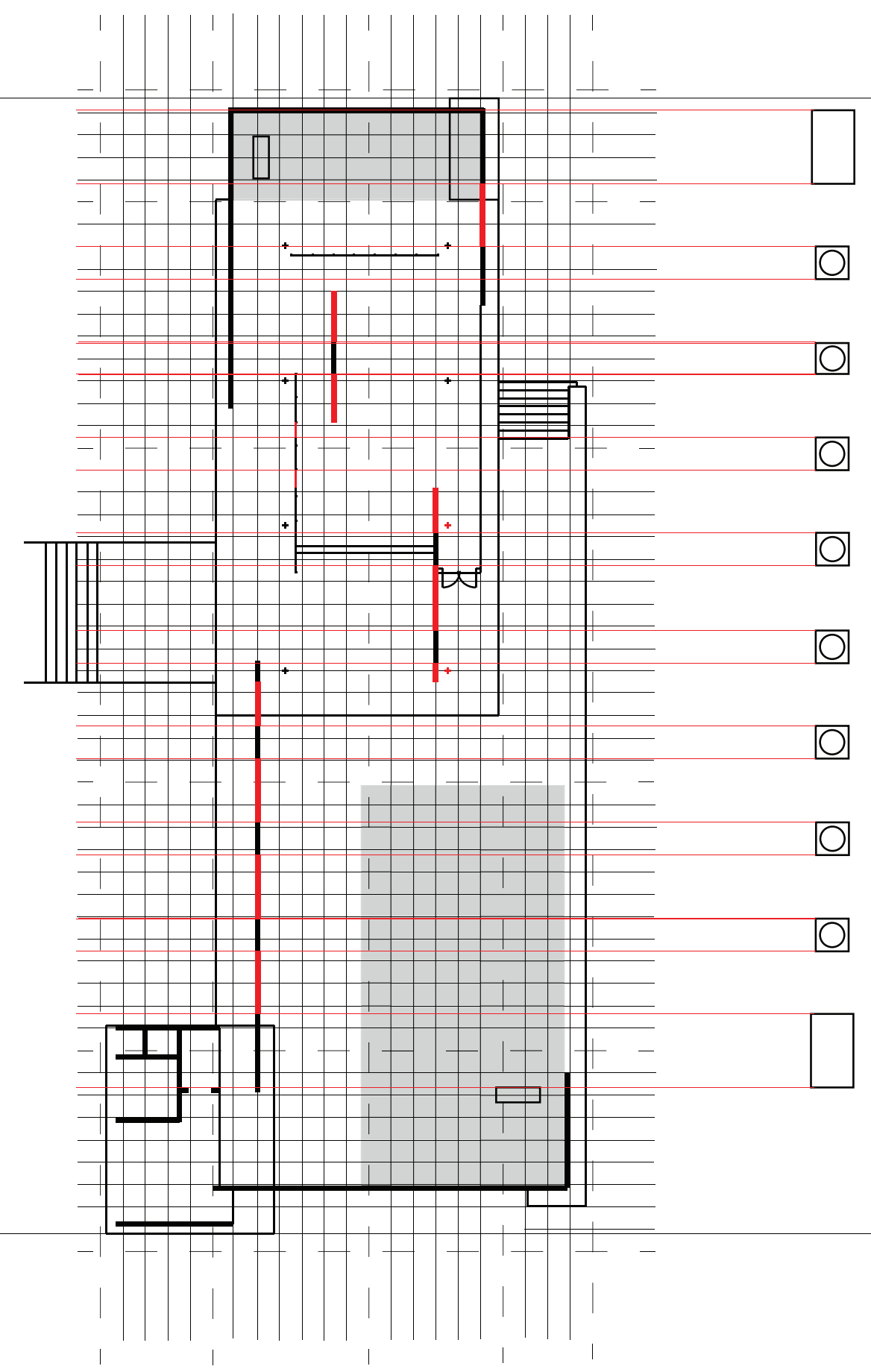




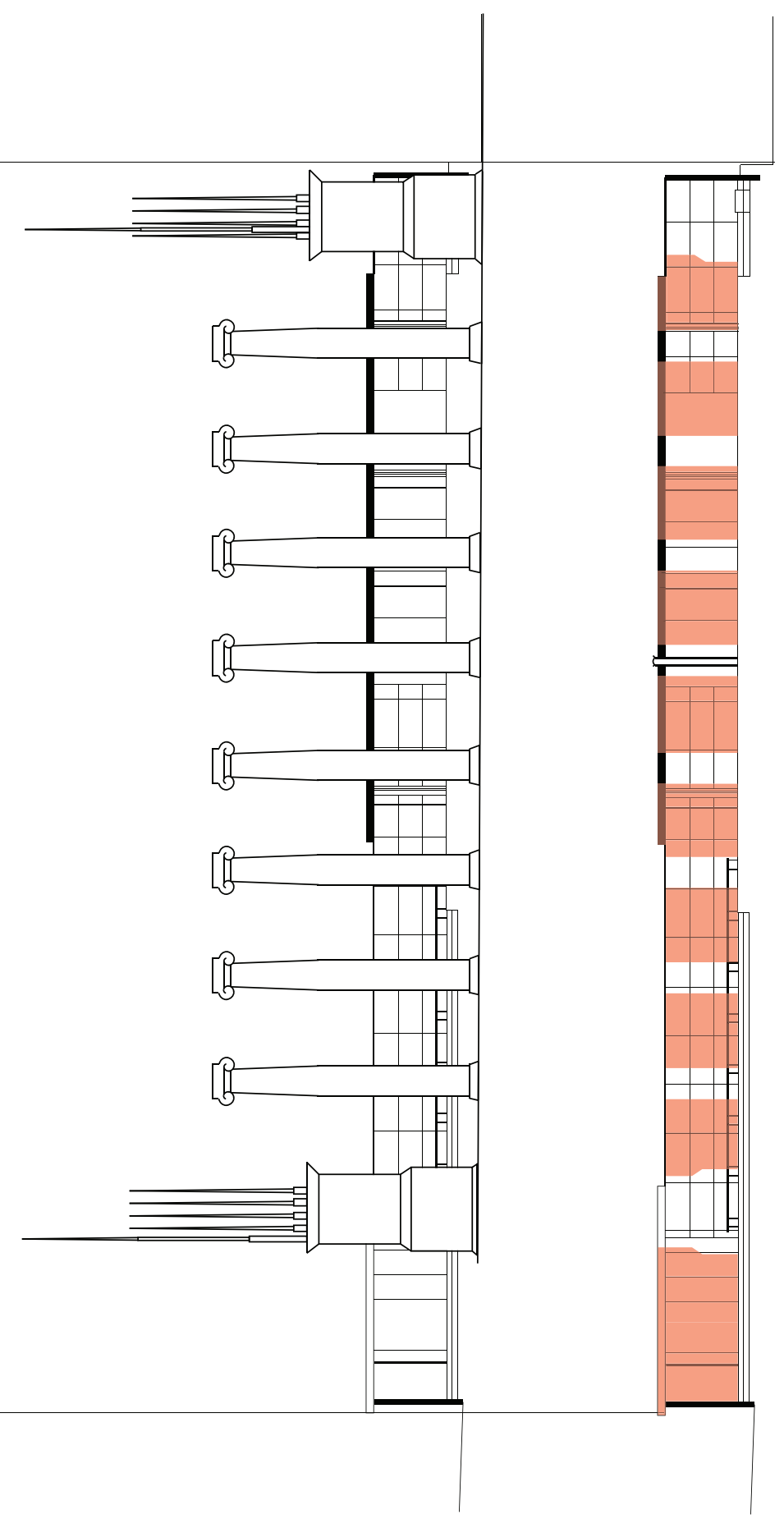




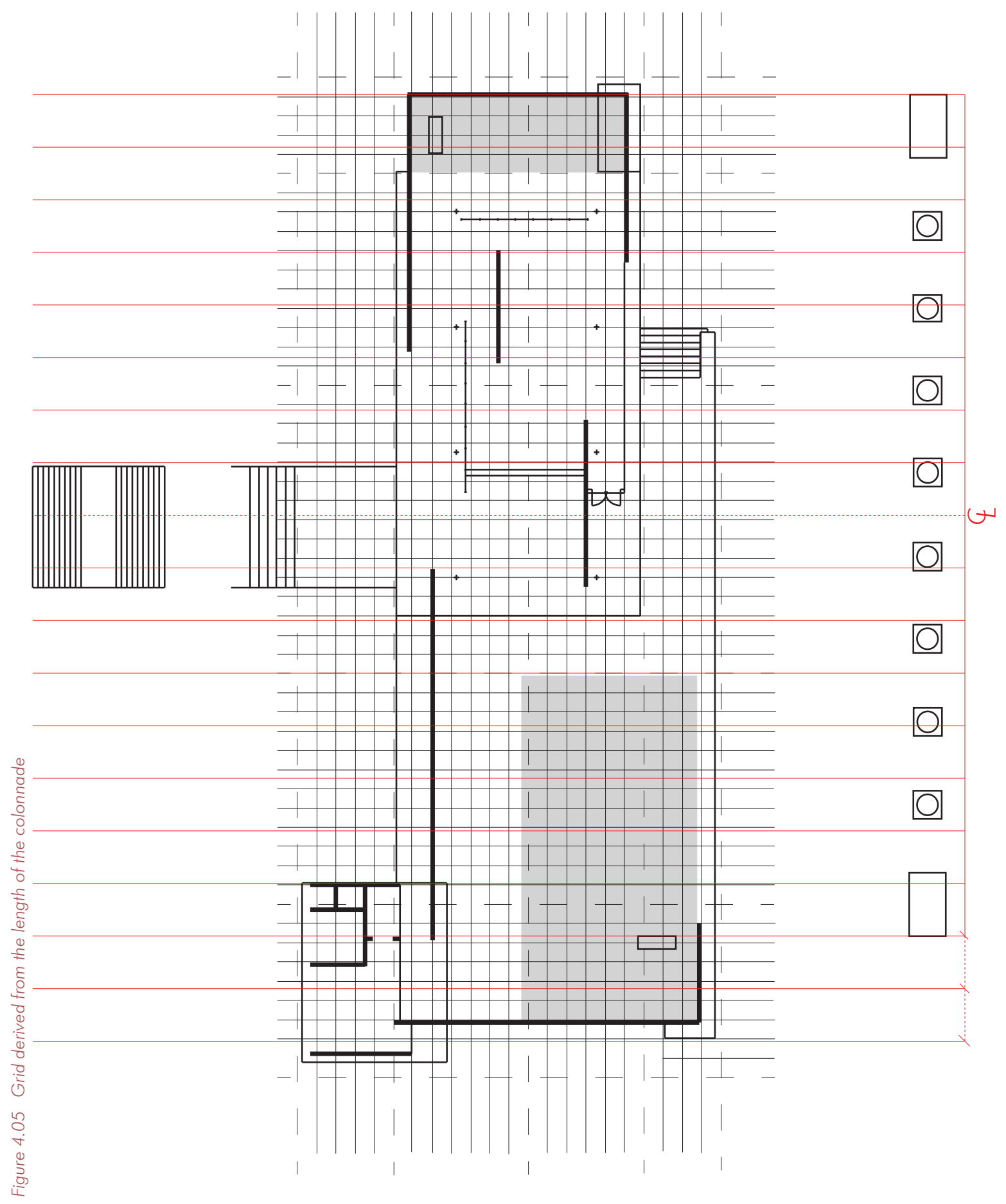




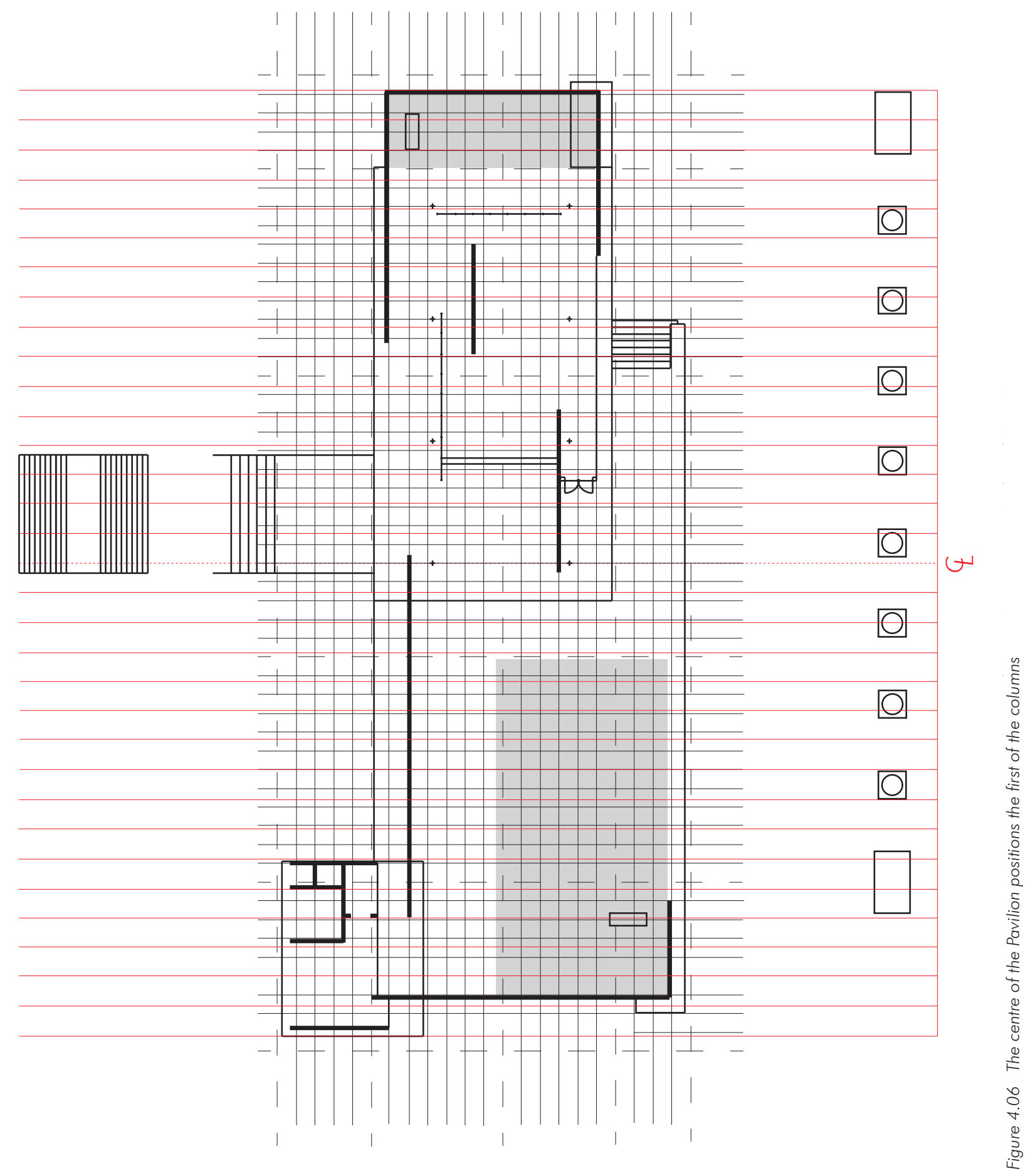




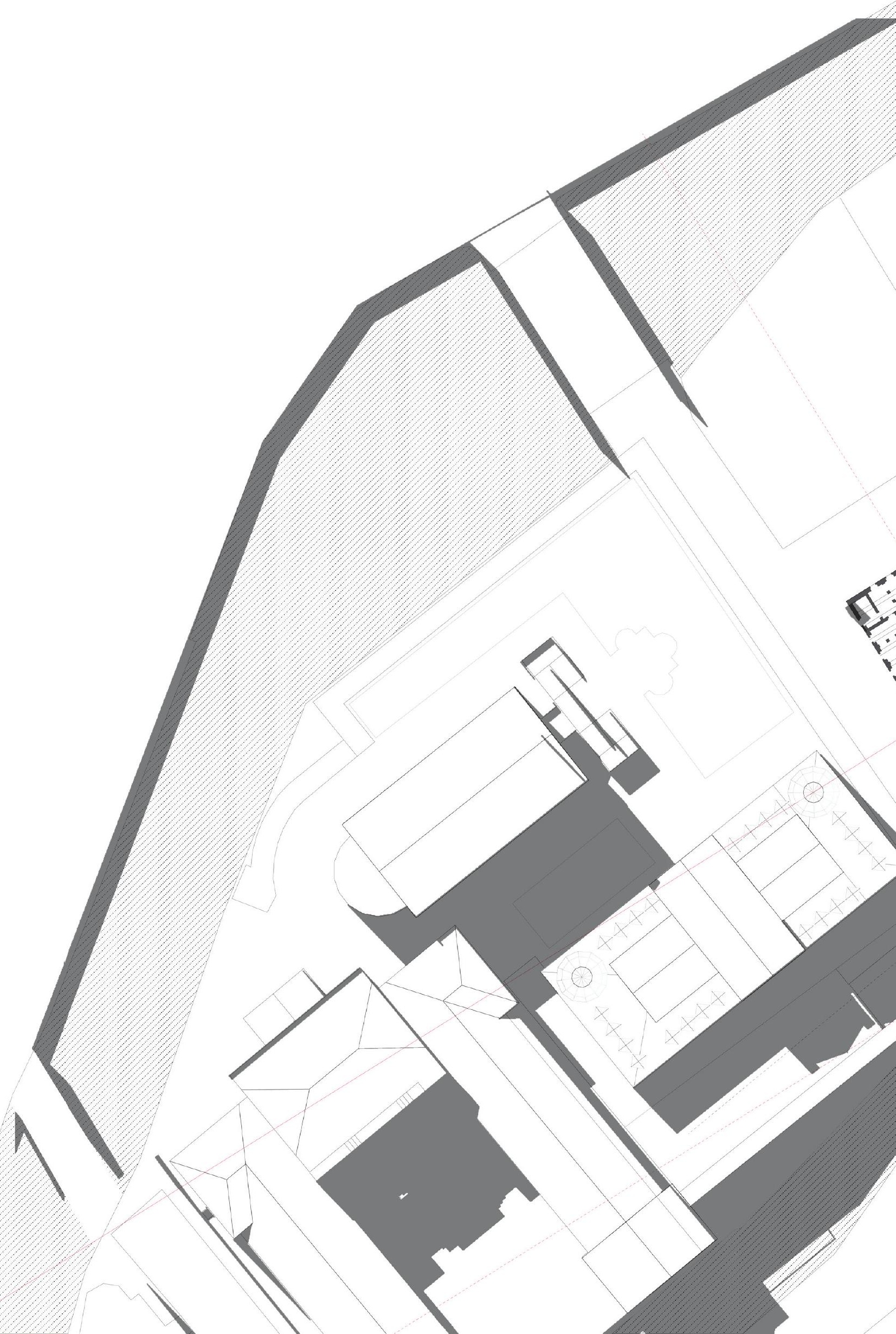



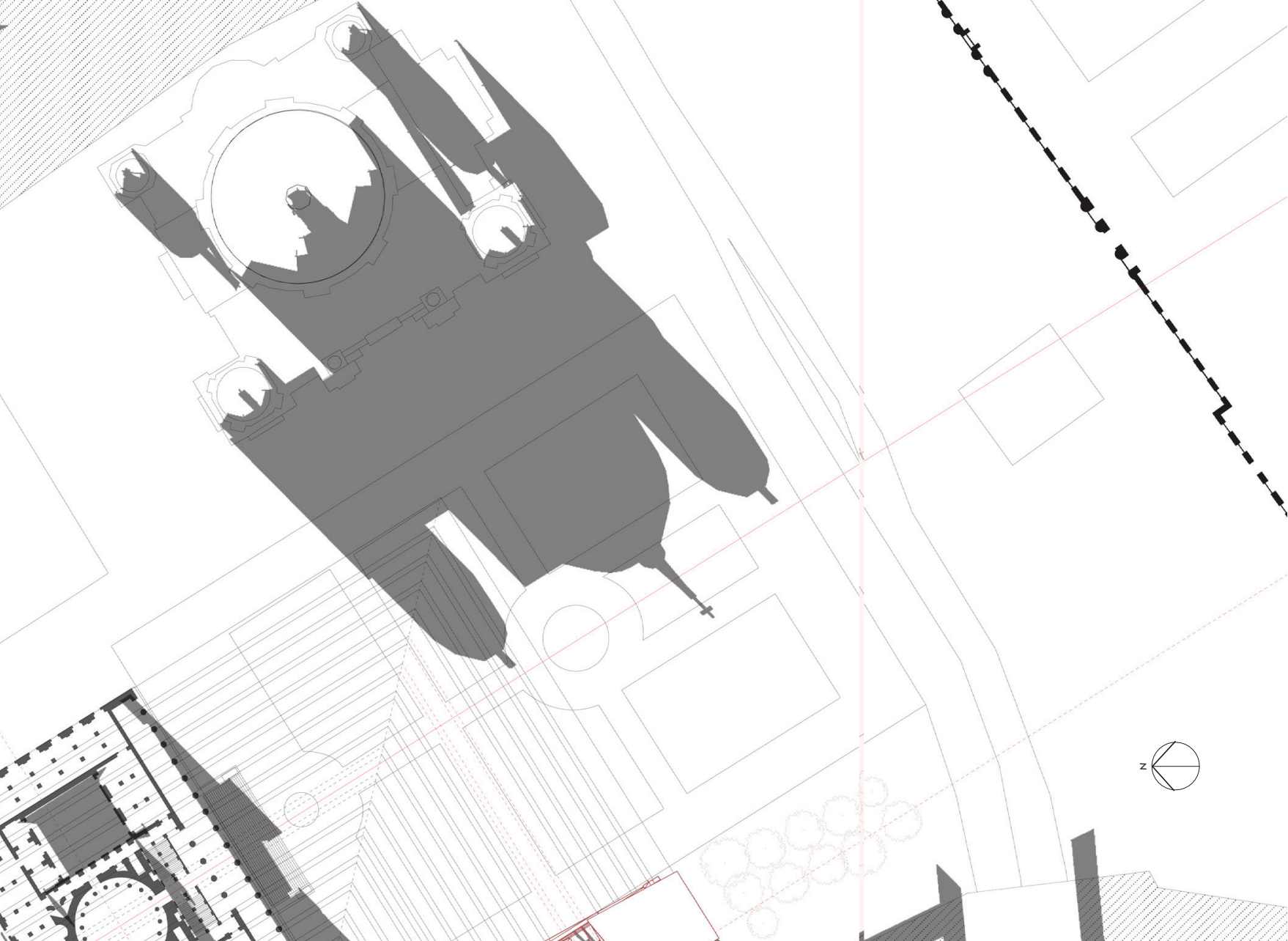

$-10 \div$

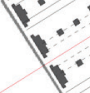




\section{DESIGN OUTCOME}

Translation from drawing to building

This section discusses the design with reference to the decisions that were made regarding the aims and objectives. It seeks to further enable the correspondence of architectural drawings and built form, by evaluating the resolution to a physical model. The execution of this has been essentially methodological, and this chapter will discuss the final design to test this.

The start of the final design outcome arrived by overlaying a series of 'movements' through the entrances of the Altes Museum and the Pavilion. These were drawn out two ways; by moving the viewing position into the plan, this framed different fields of vision, as a literal motion inward; and by analysing the relationship of the main object in the perspective, (the plinth or entrance stairs), as the viewing points got closer. These concepts are taken back into the design framework that was set up through the unpicking of Mies' drawings. The whole time this narrative continued, as a rule set was built up, intending then in the design to use this framework to control the complexity arising through the drawing apparatus.

These frames from the Altes and Pavilion were distorted in the apparatus through the projection of partial plan down to perspective, and then the skewing of these perspectives through the projection from multiple viewing points. The perspective frames were then projected back up to plan, using a gridded volume to place the walls back onto the orthogonal grid.

Important to this working process was how a partial plan, with a corresponding grid, can be projected down to perspectives and then back up to plan so as to offset elements from the original grid lines. Mies had done this with his architecture. 

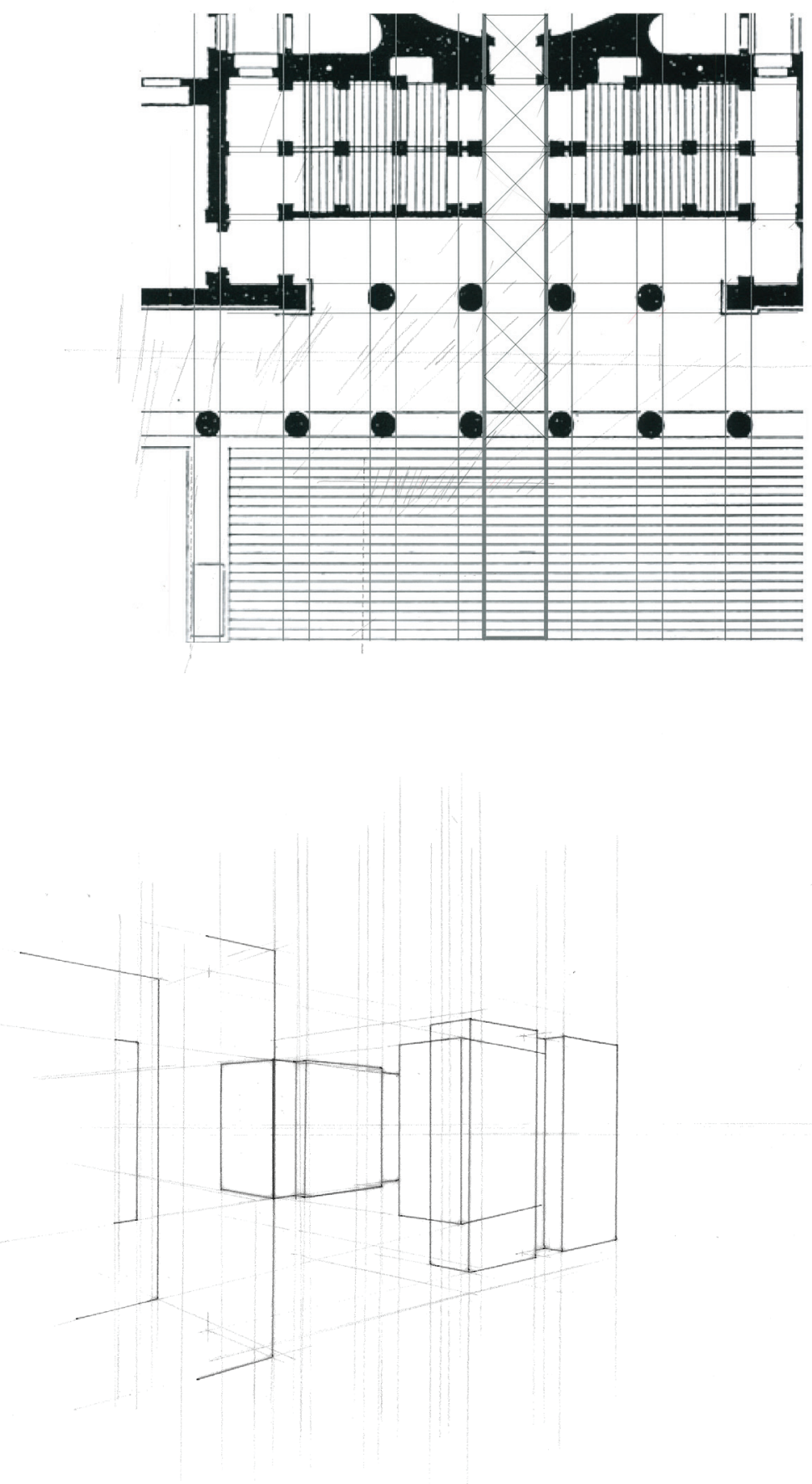
Drawing part of the Altes Entrance

Plan $\rightarrow$ Rerspective from scratch - se

inaccurate

interested in the formal relationship

of the
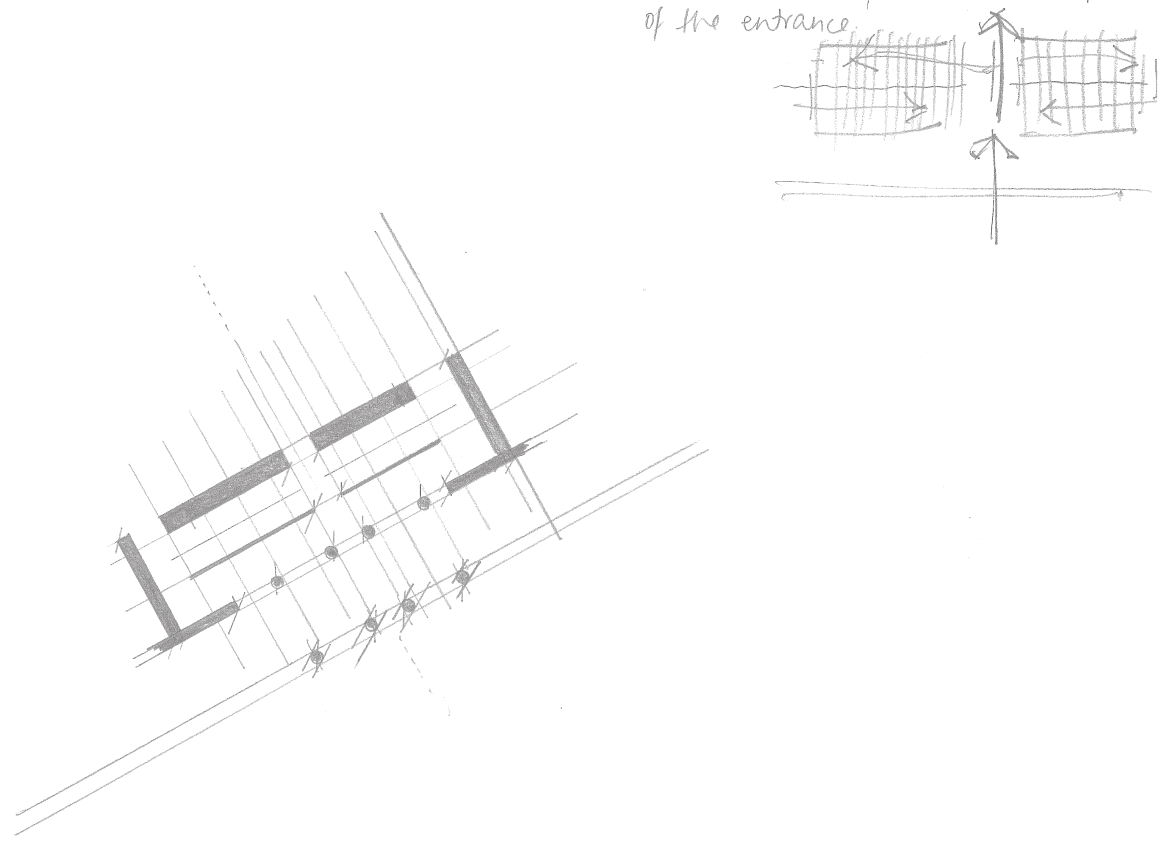

Figure 4.09 Considering movement through the Altes Museum 


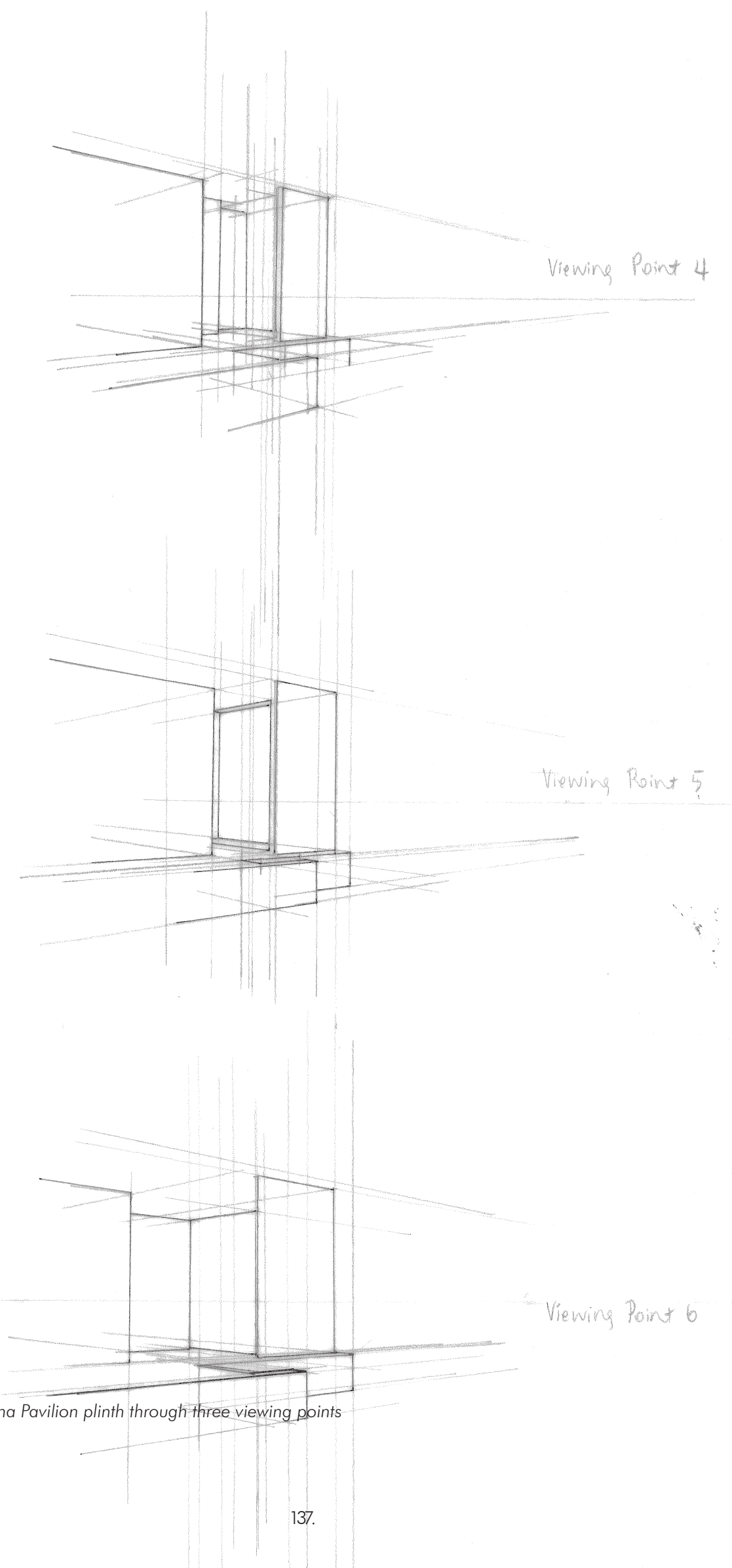


movement through building

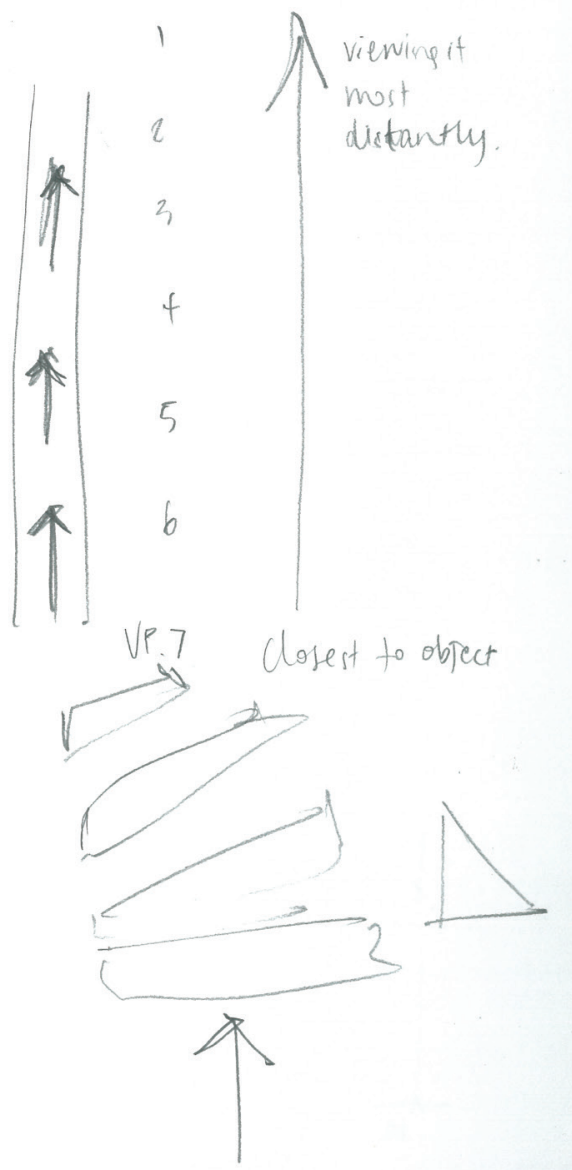

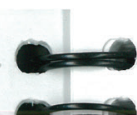

$\Xi$

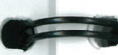

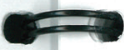

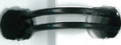

$\Rightarrow$ the object gets claser the further into $\Longrightarrow$

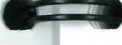

$=$

$=$

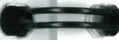

$=$

$=$

$=$

$=$

$=$

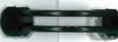

$\Rightarrow$

0

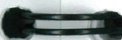

$=$

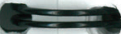

but

in the unpicking of the Barcelona Pavilion. the drawing.
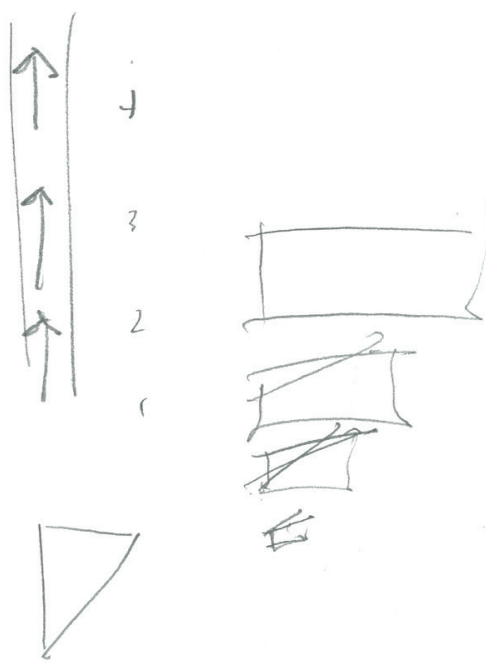
Ambiguity, and thus distortions also arose from the absence of an elevation on the board, and again in the projection from both the perspectives and the plan into elevations in order to establish a three-dimensional form. This is where the most intuitive design moves occurred, as little physical models were set up as the way in which to take the design further. The ambiguity of these drawn frames is evident in the two completely different models that came out of overlaid frames of the Pavilion entrance. The first model (figures 4.23) was taken directly from the elevations and plan (figure 4.20), and was effective in setting up rules around what was occurring within the grid. The other (figure 4.28), the more productive one, was an interpretation of the perspective frame. By drawing out 'frames' from this model, further physical models were made, and frames drawn out again from these. With a grid for positioning, the frames were taken back to plan, to be reapplied back into the building matrix. 'What if's' were again asked which took the methodology outside of the linear process. For example, it was how these frames could be viewed, the entrance plinth becoming viewed as a roof, and setting this up on a matrix.

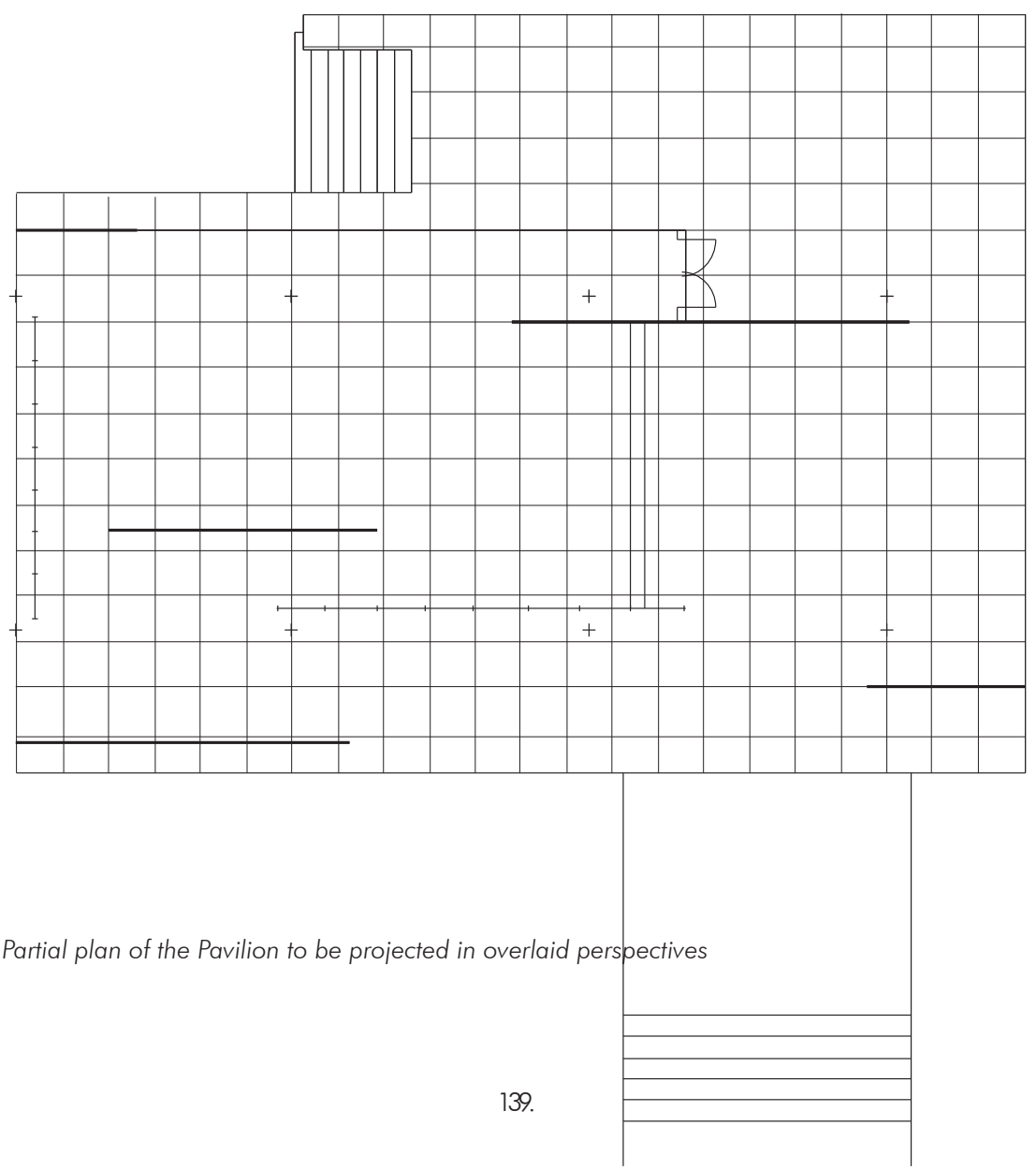



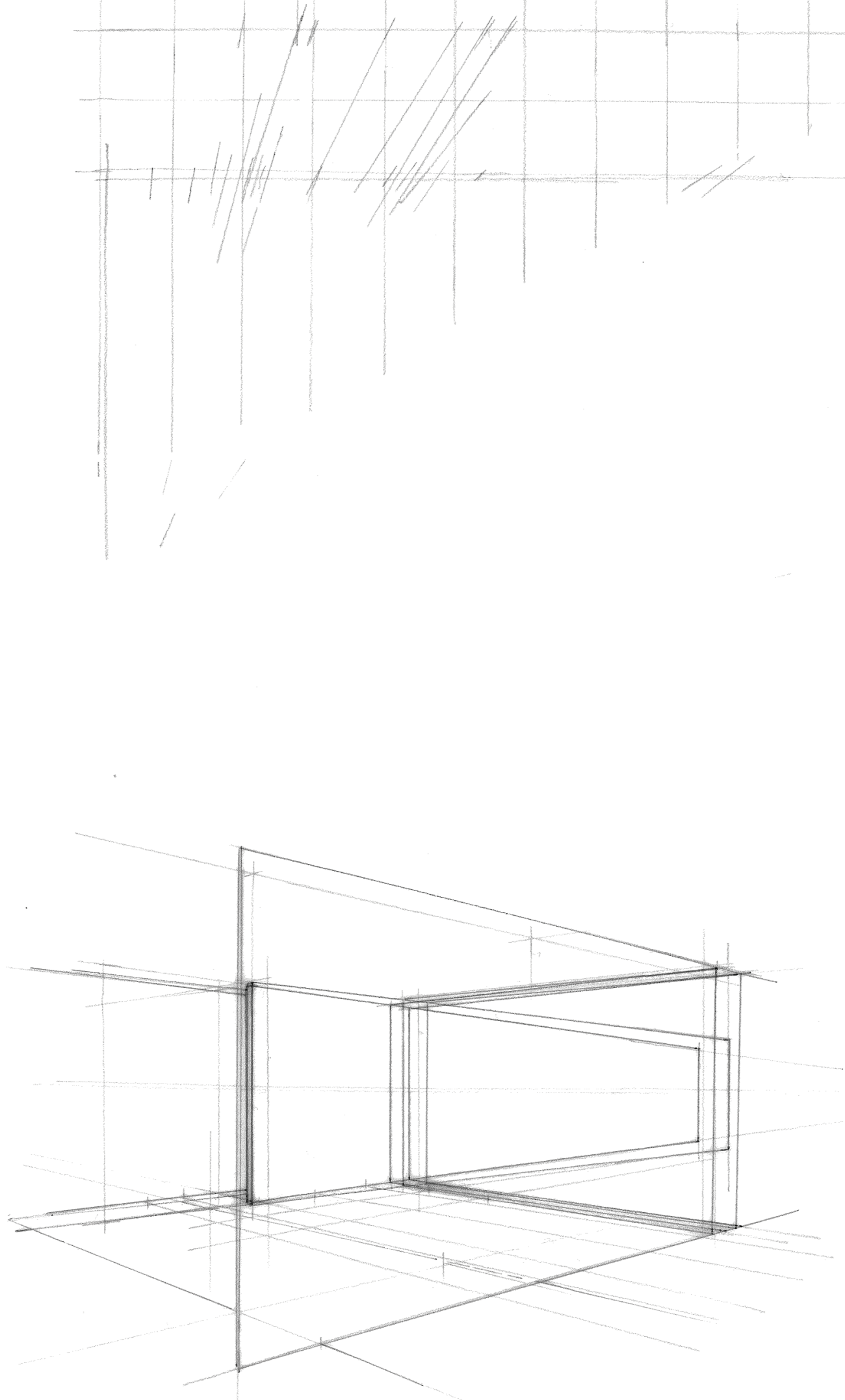

Figure 4.13 Overlaid perspectives of the Barcelona Pavilion 


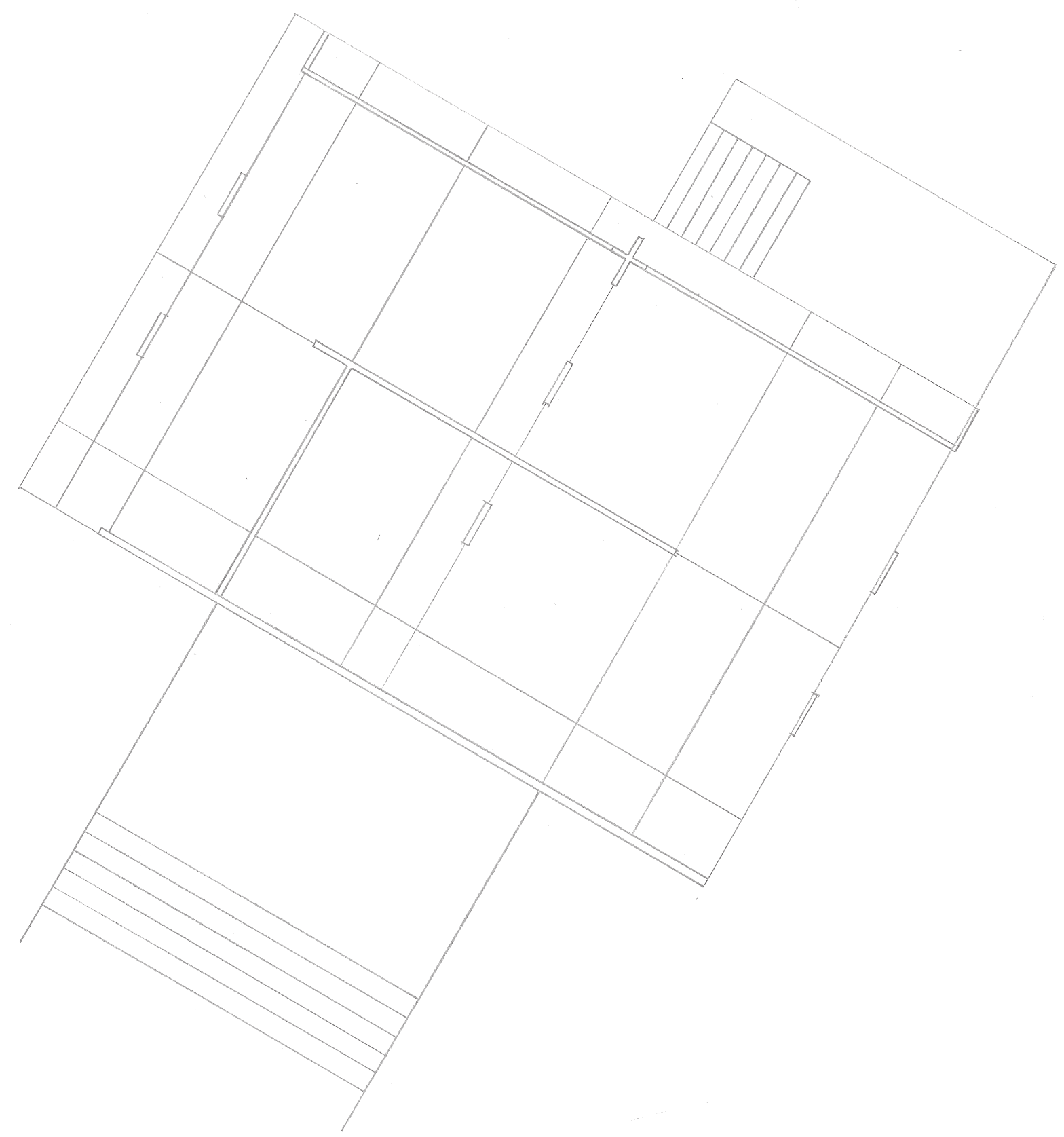

Figure 4.14 Plan taken back up from the overlaid perspectives, distorted Barcelona Pavilion plan 


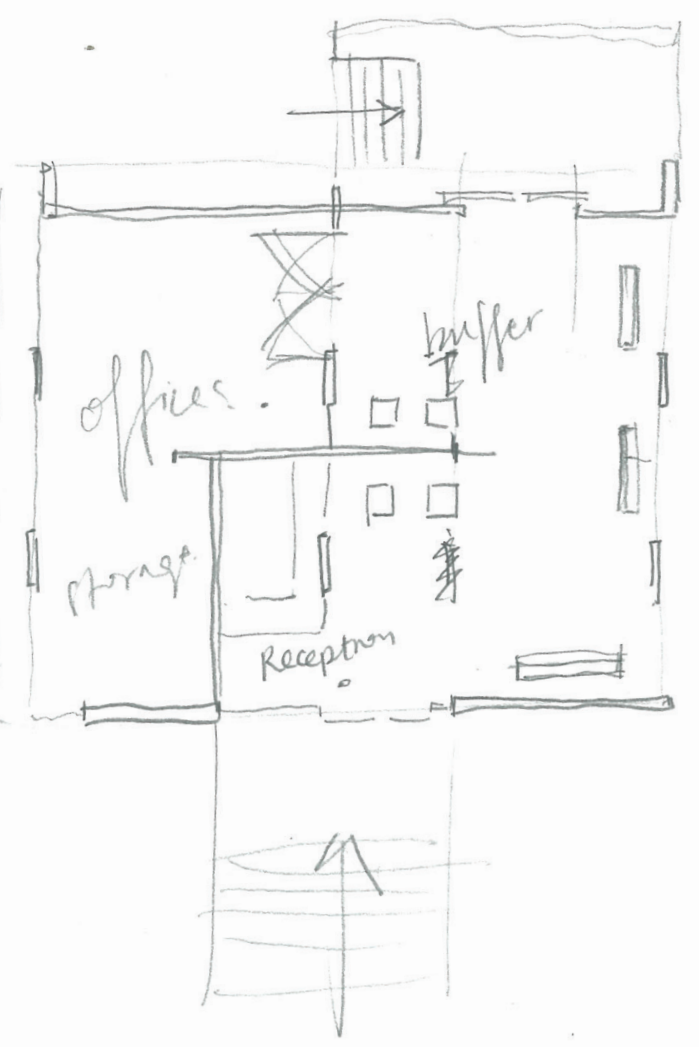

Figure 4.15 Sketch of plan from the apparatus, Preliminary Design 


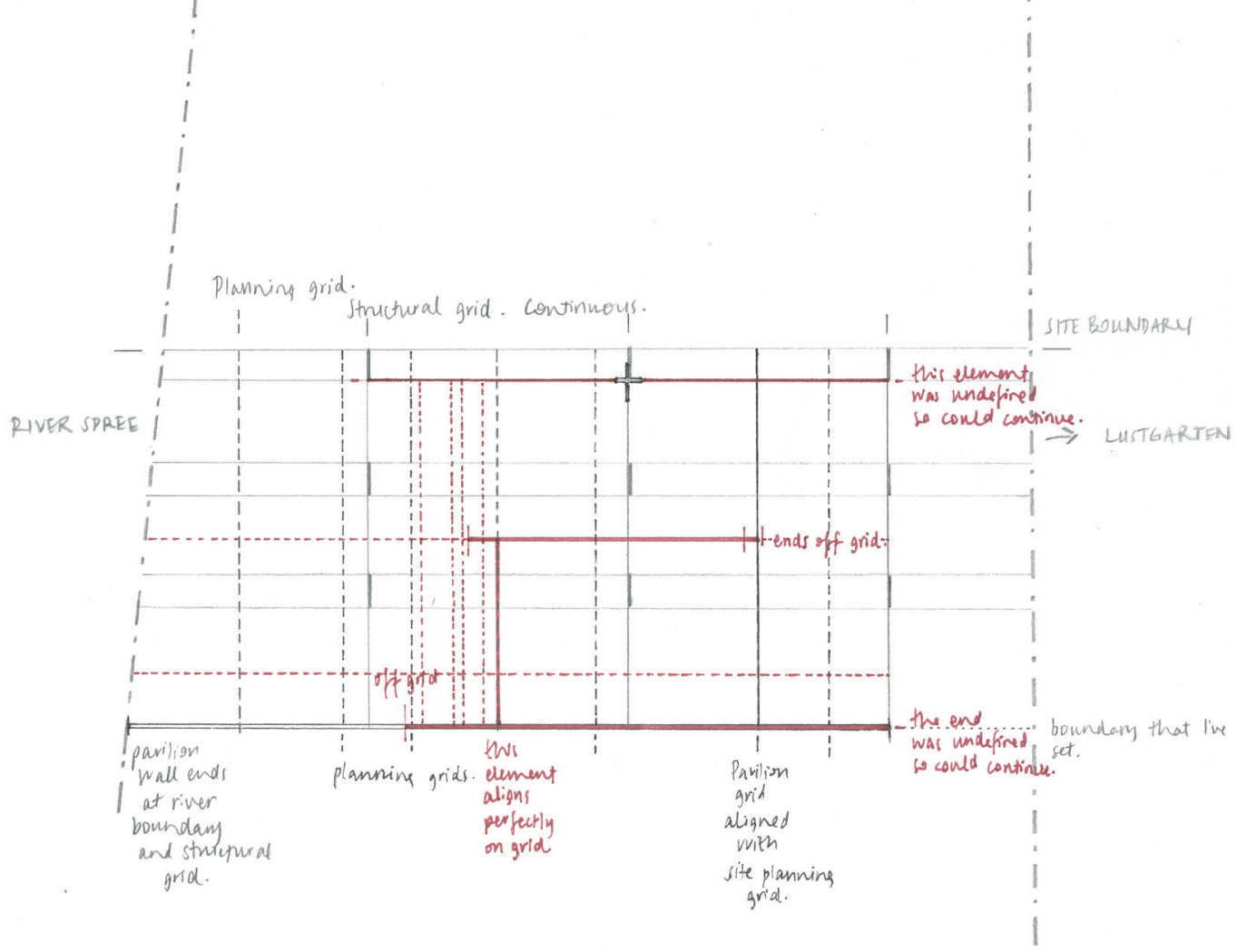

Figure 4.16 Overlaying the plan onto the site grid and projecting down to perspective frame 
In Bi Pavition

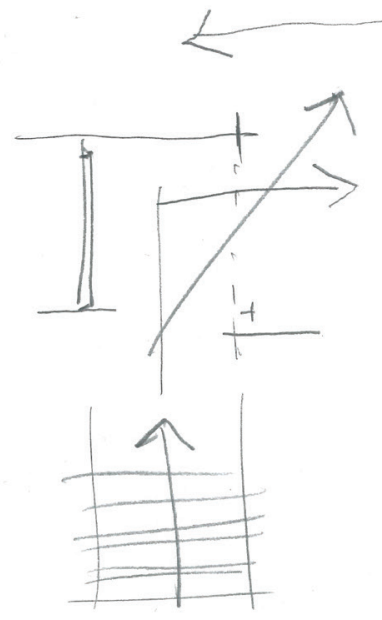

In my plan what's going on is -

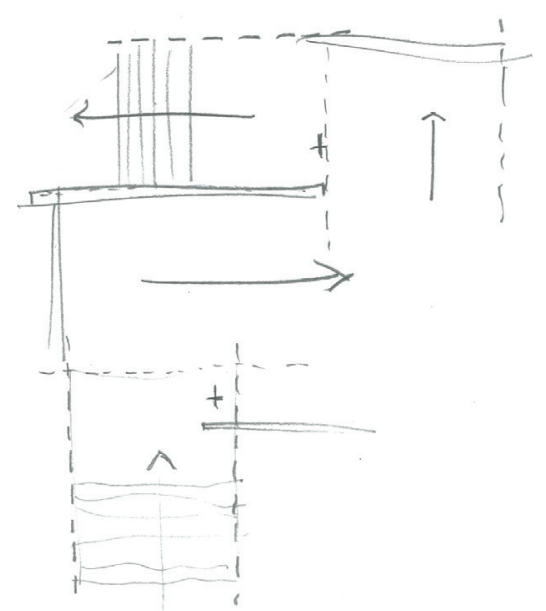

Figure 4.17 Narrative through the plan 

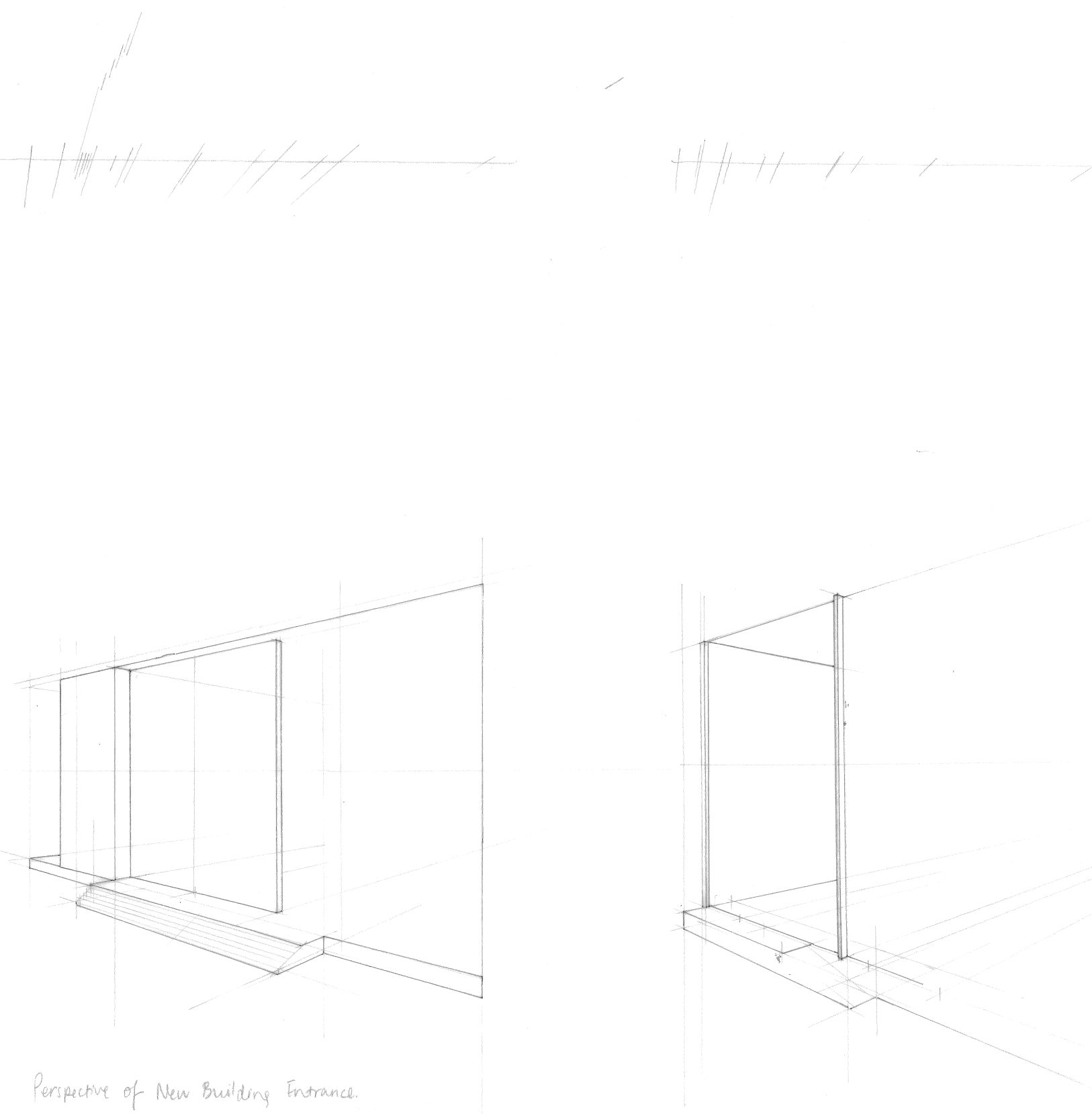

Figure 4.18 From one viewing point from the new plan 
Figure 4.19 Overlaid perspectives of the Barcelona Pavilion perspective, projected up to plan and down to elevations

back to tar

through sewing

point?.

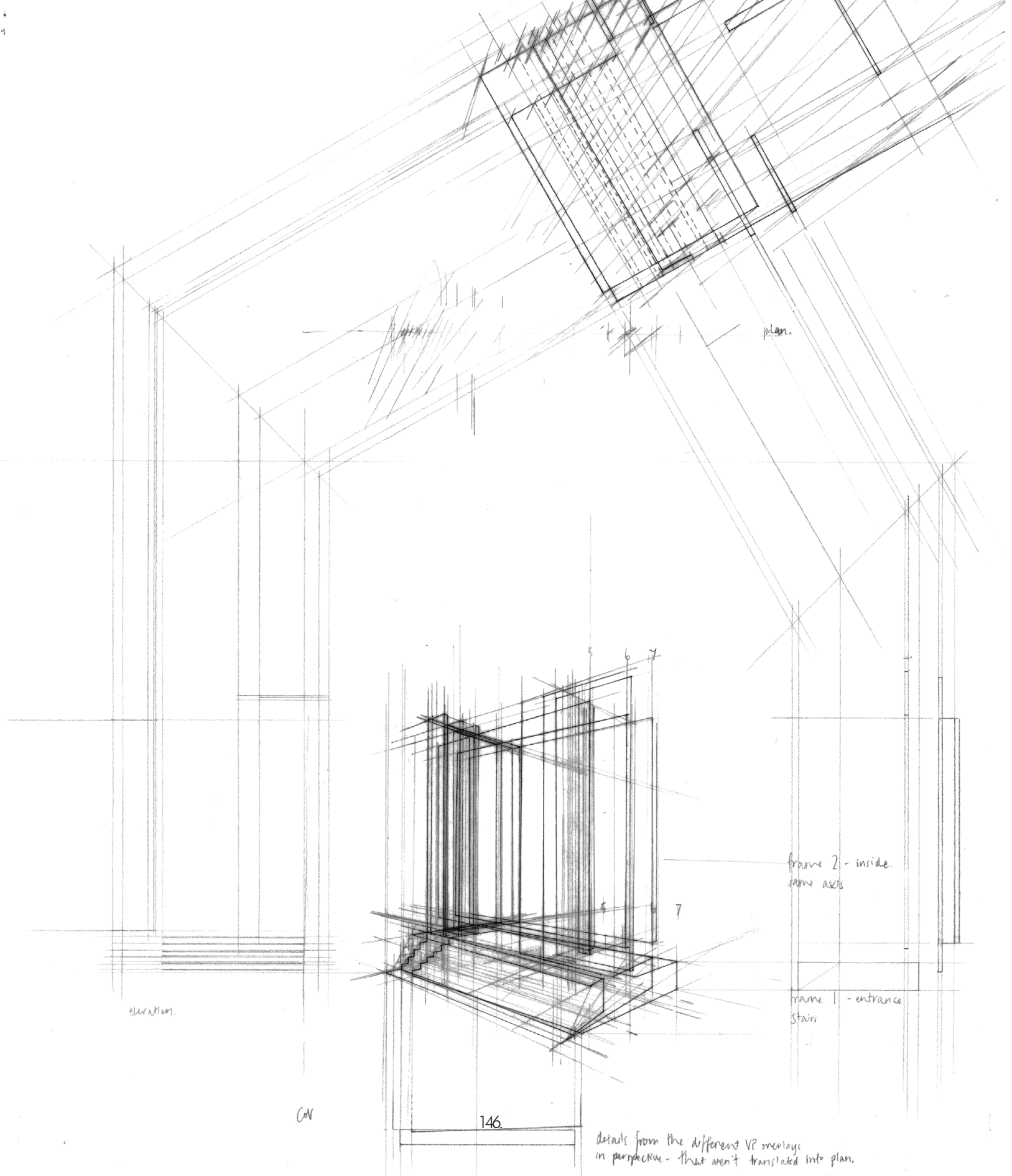


Figure 4.20 Catalogue of wall heights in elevation, in order to take the design in three dimensions

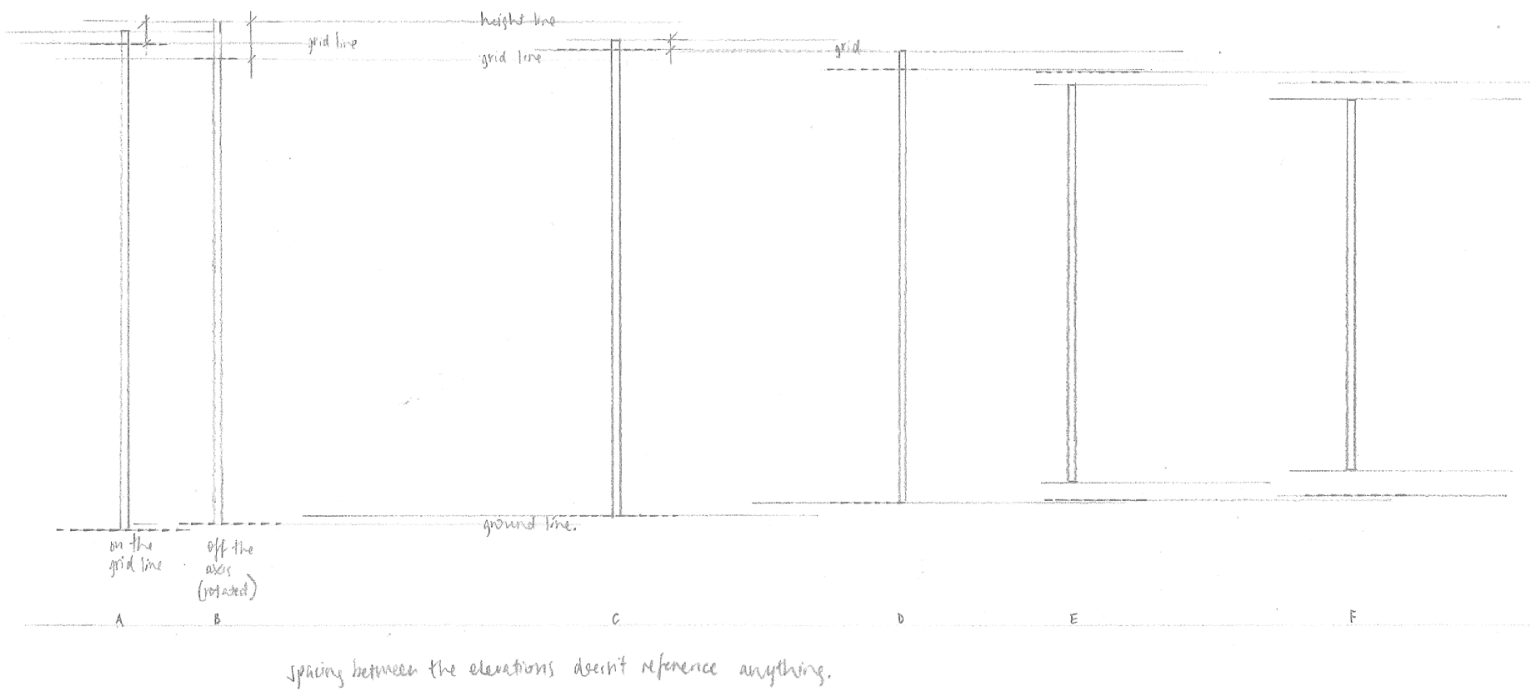

taking elevason 'framei of each of the walls 
Figure 4.21 Placing the offset elements onto the plan using a gridded volume

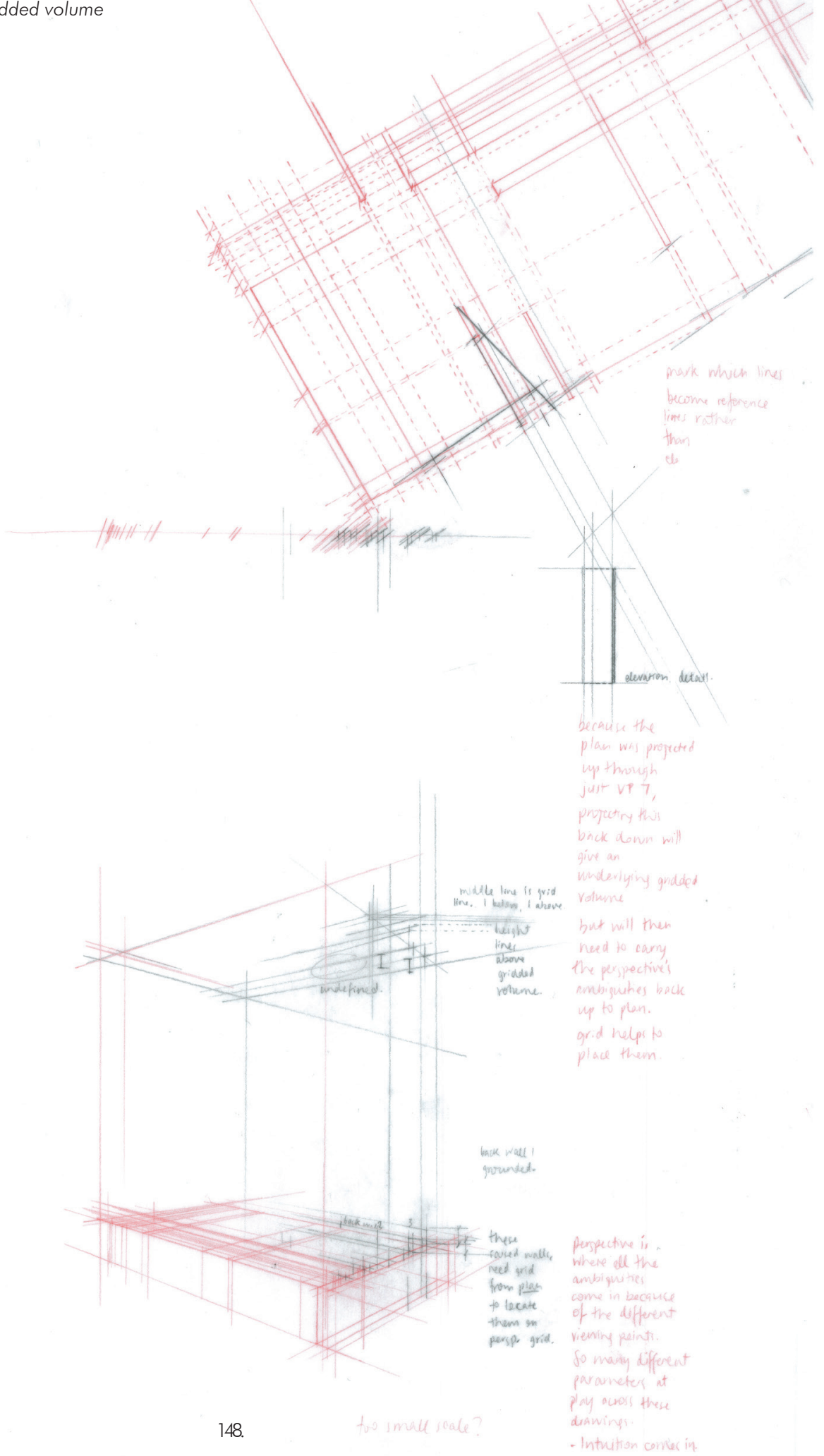




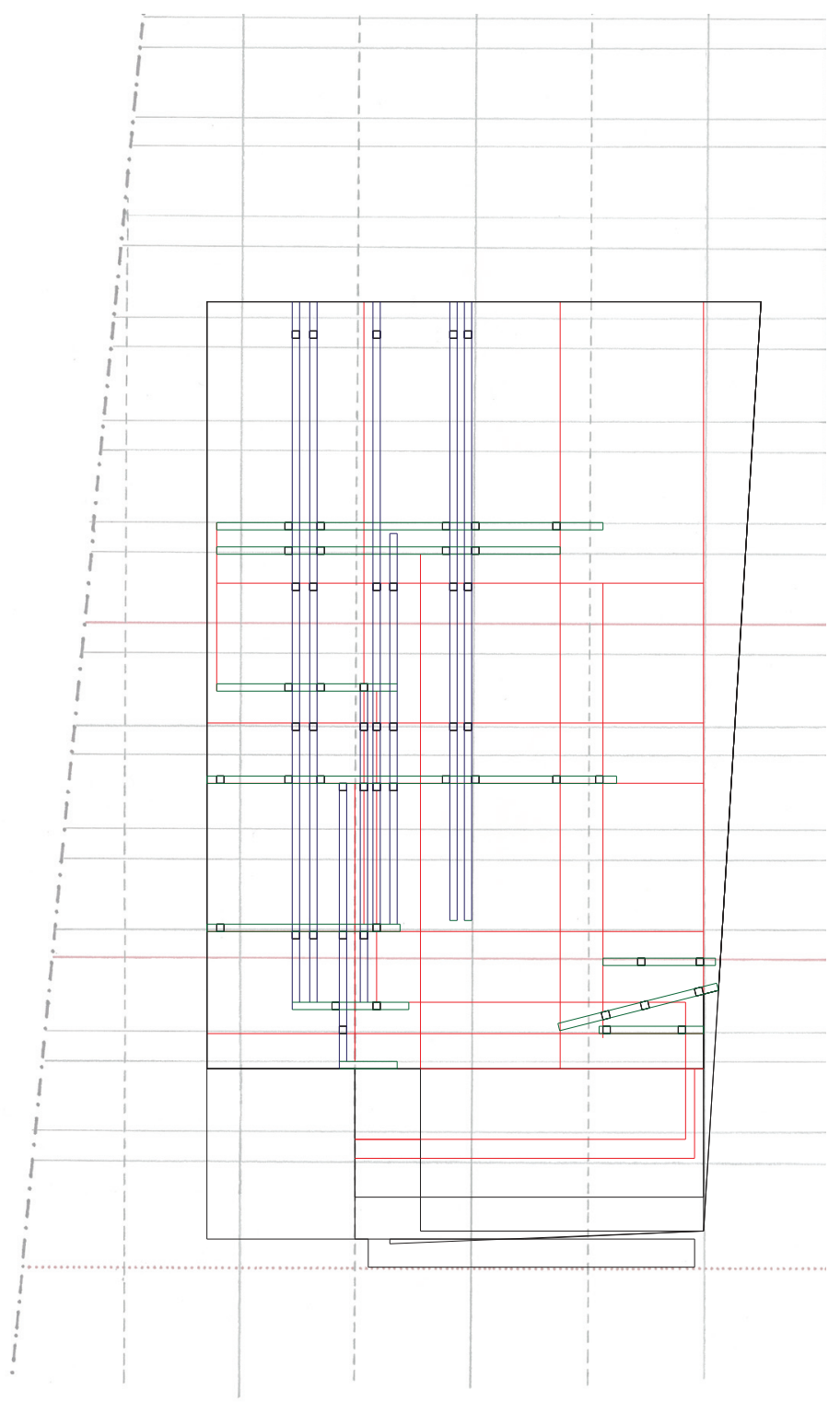

Figure 4.22 The plan drawn out in illustrator, placing nodes on the grid intersections so that the physical model clips together. 

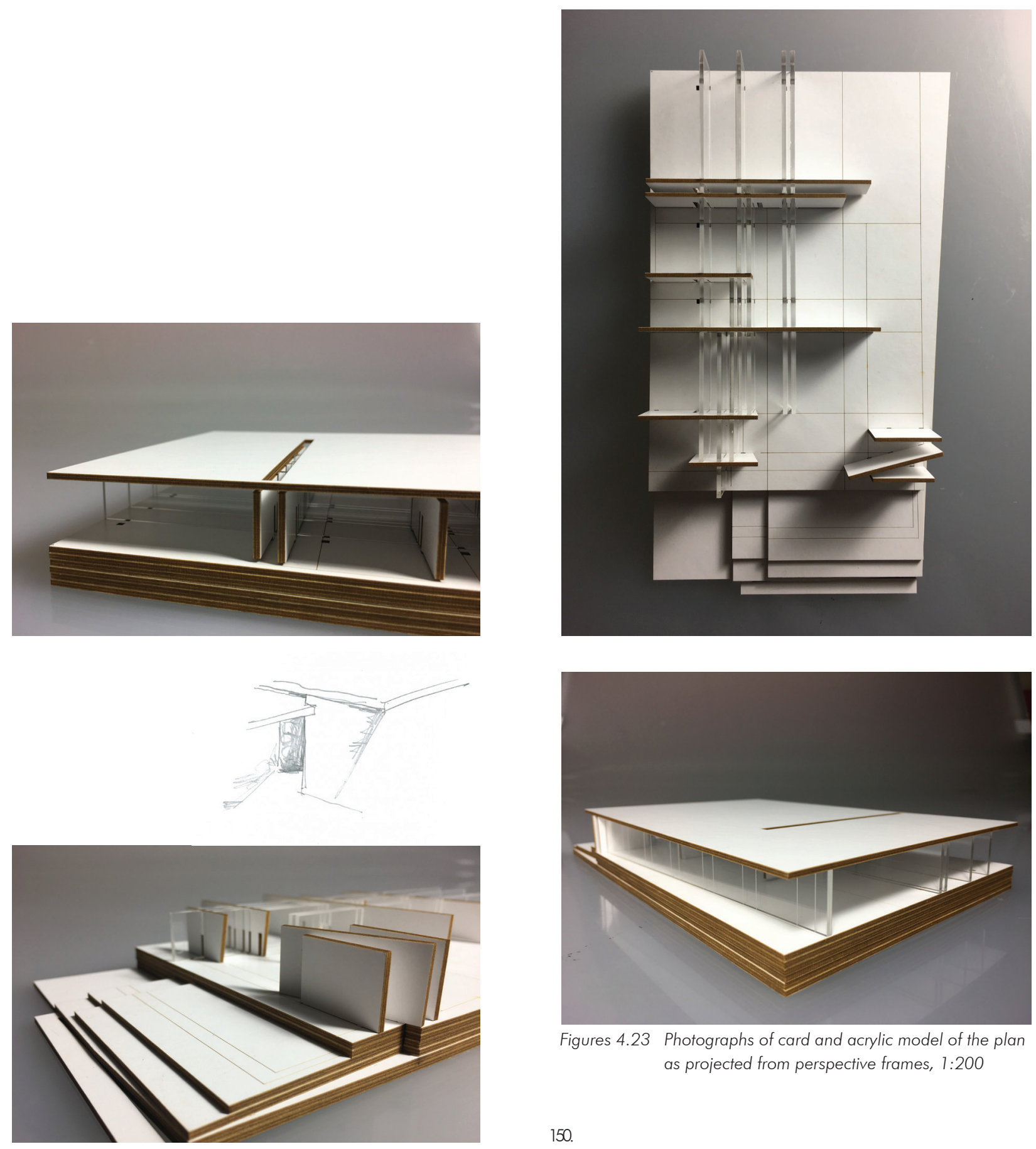

Figures 4.23 Photographs of card and acrylic model of the plan as projected from perspective frames, 1:200 

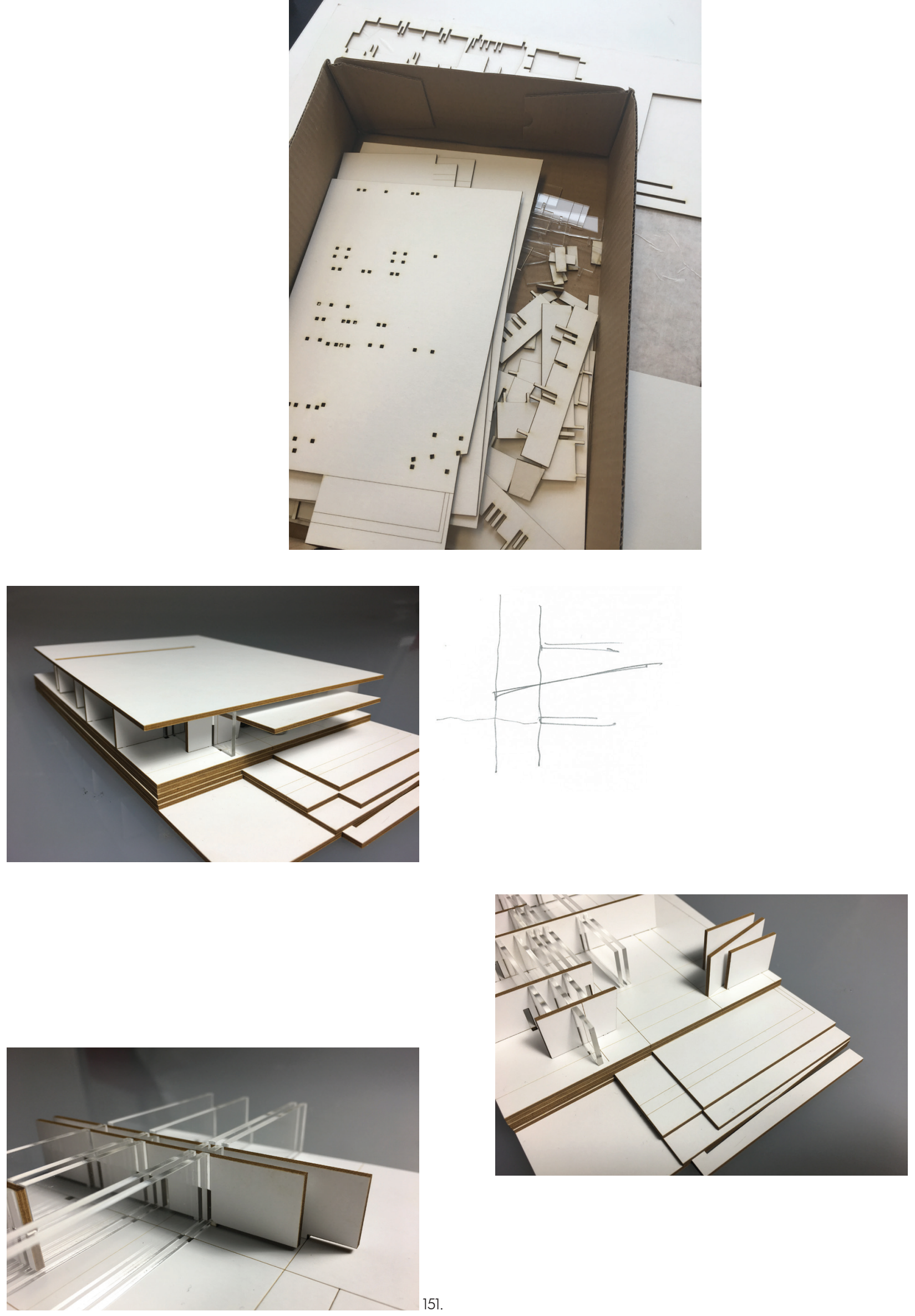


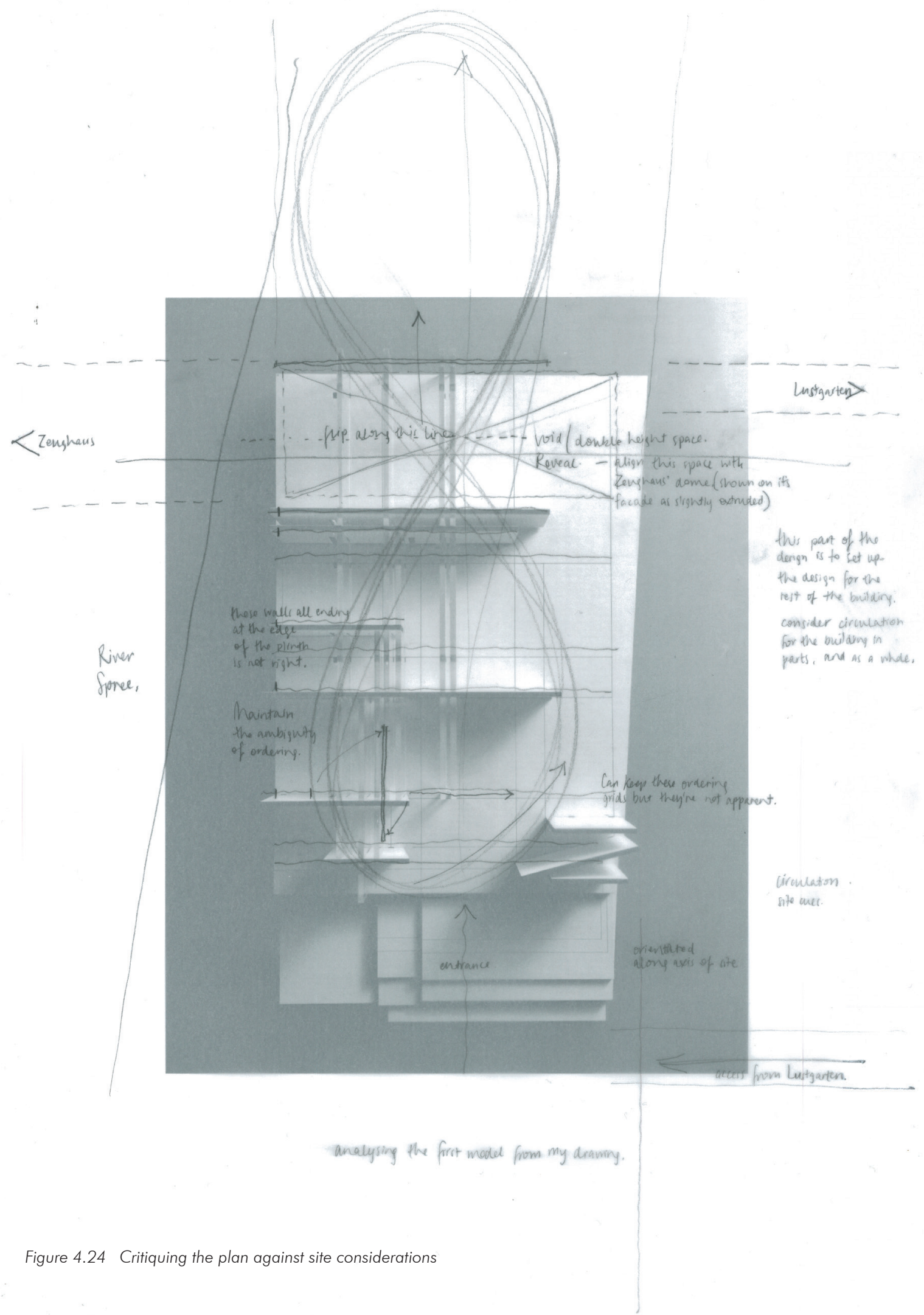


- Column placement.

still reed to determine noof form.

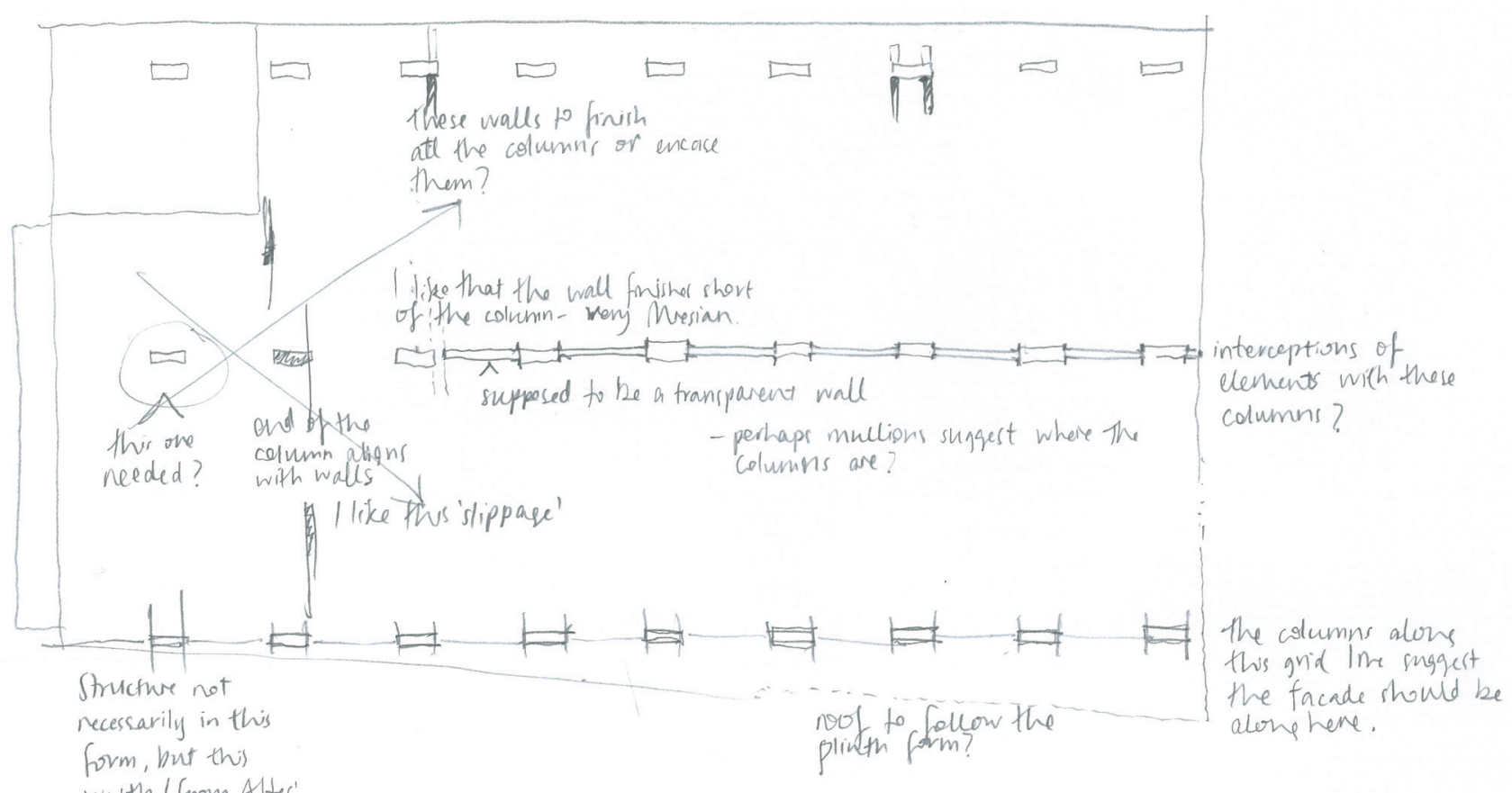

width (from Altes'

shructure)

planning and circulation.

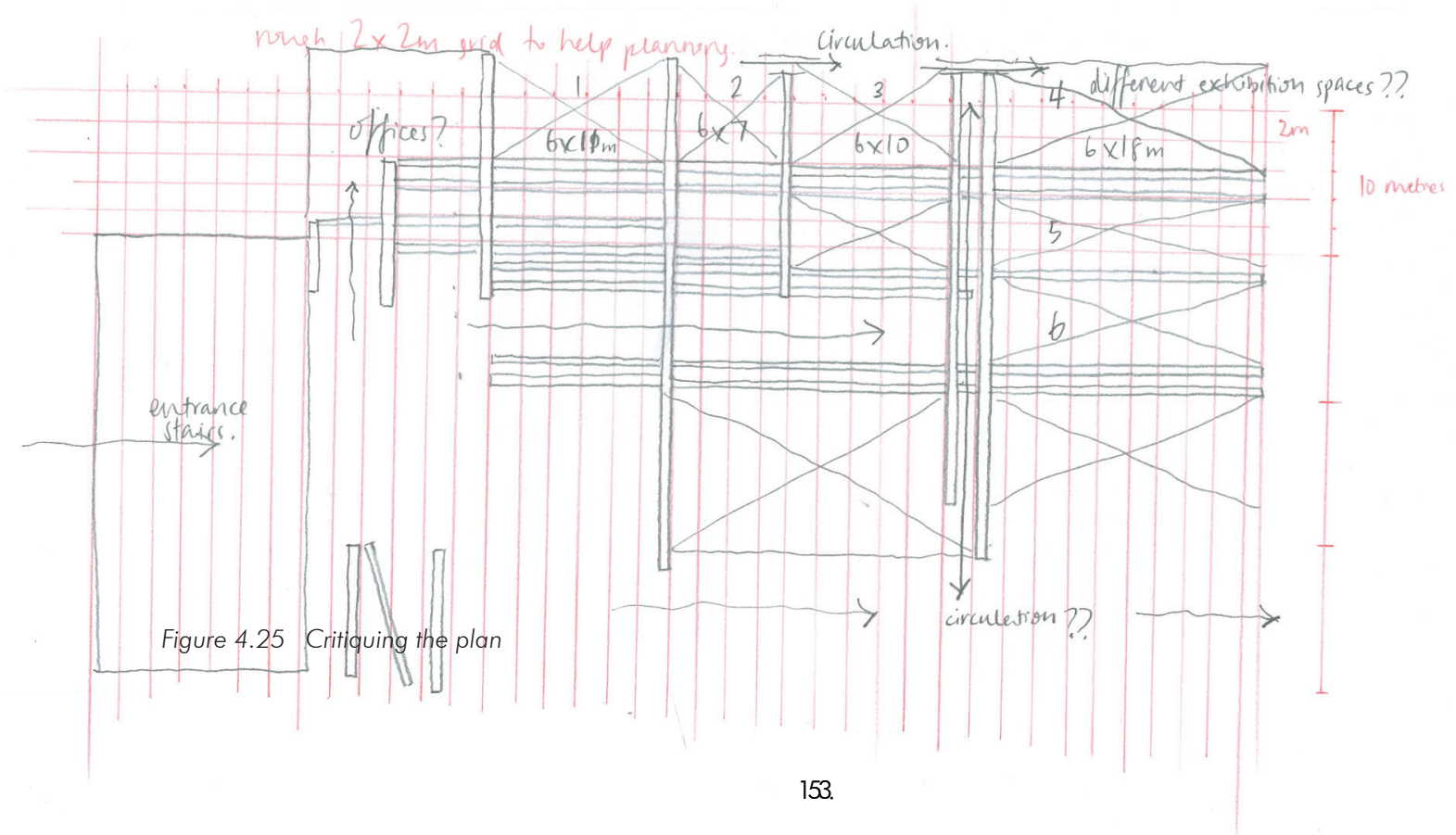




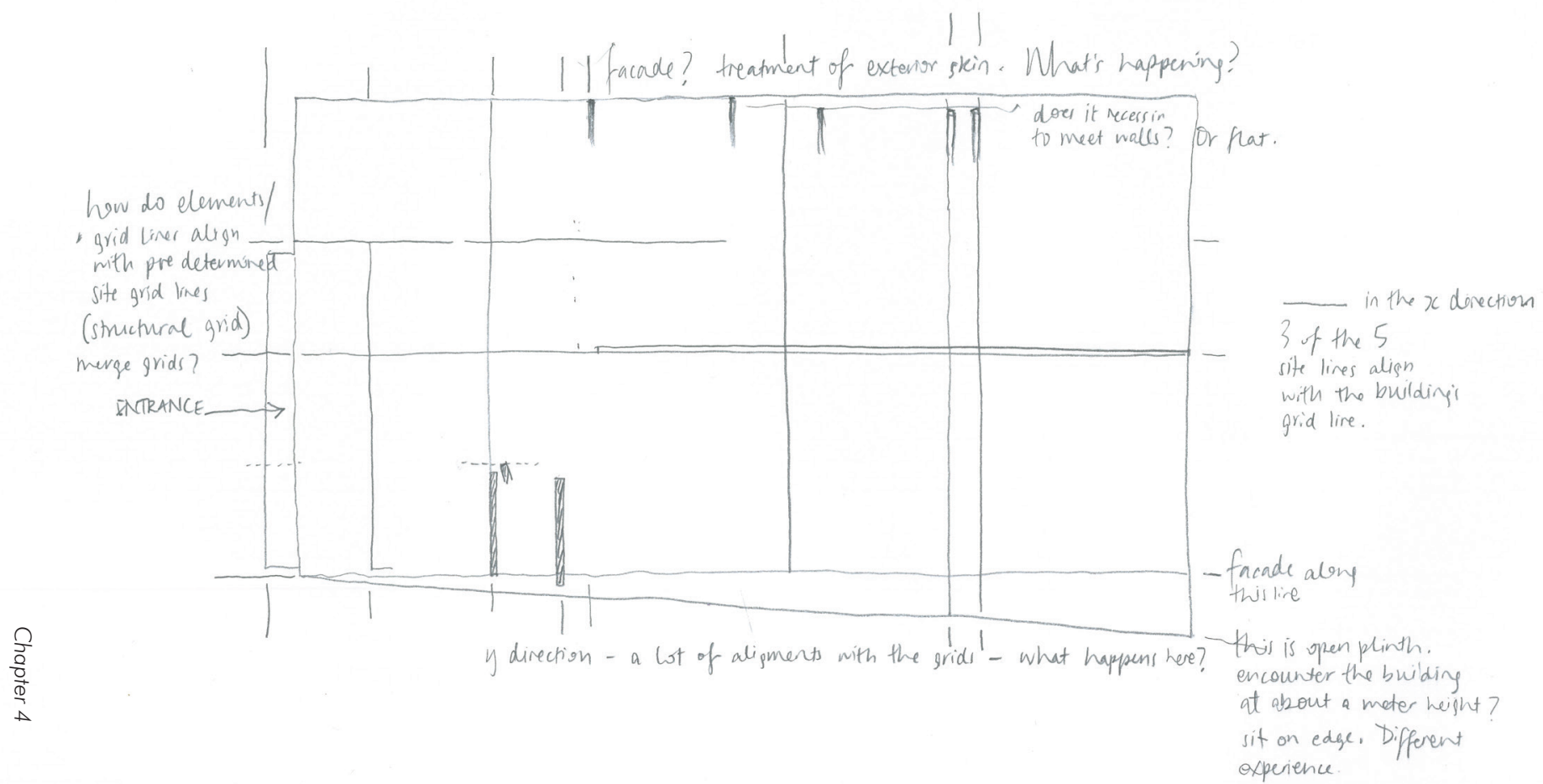


70 


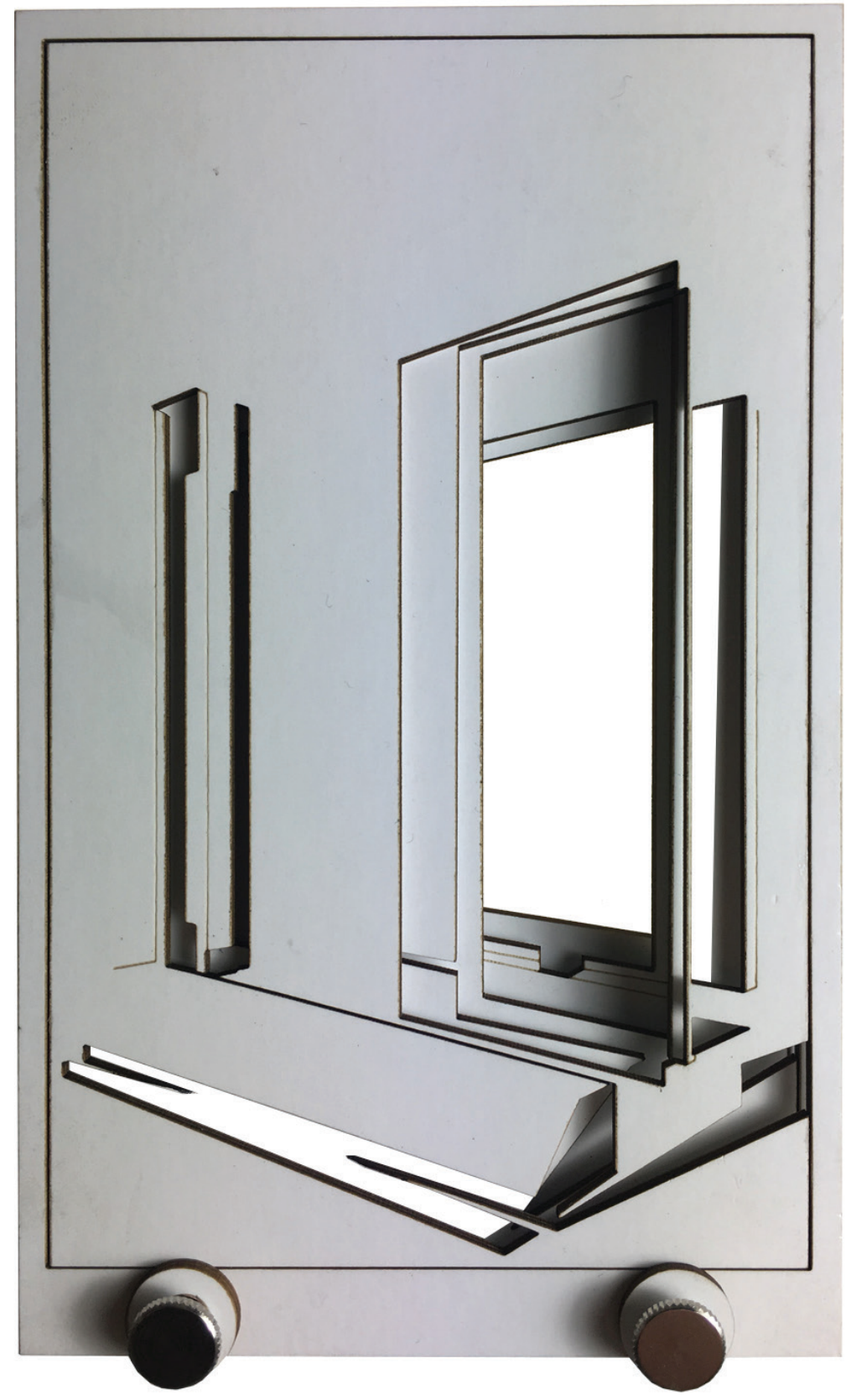

Figure 4.28 Model of the different frames in the overlaid perspectives, white card 


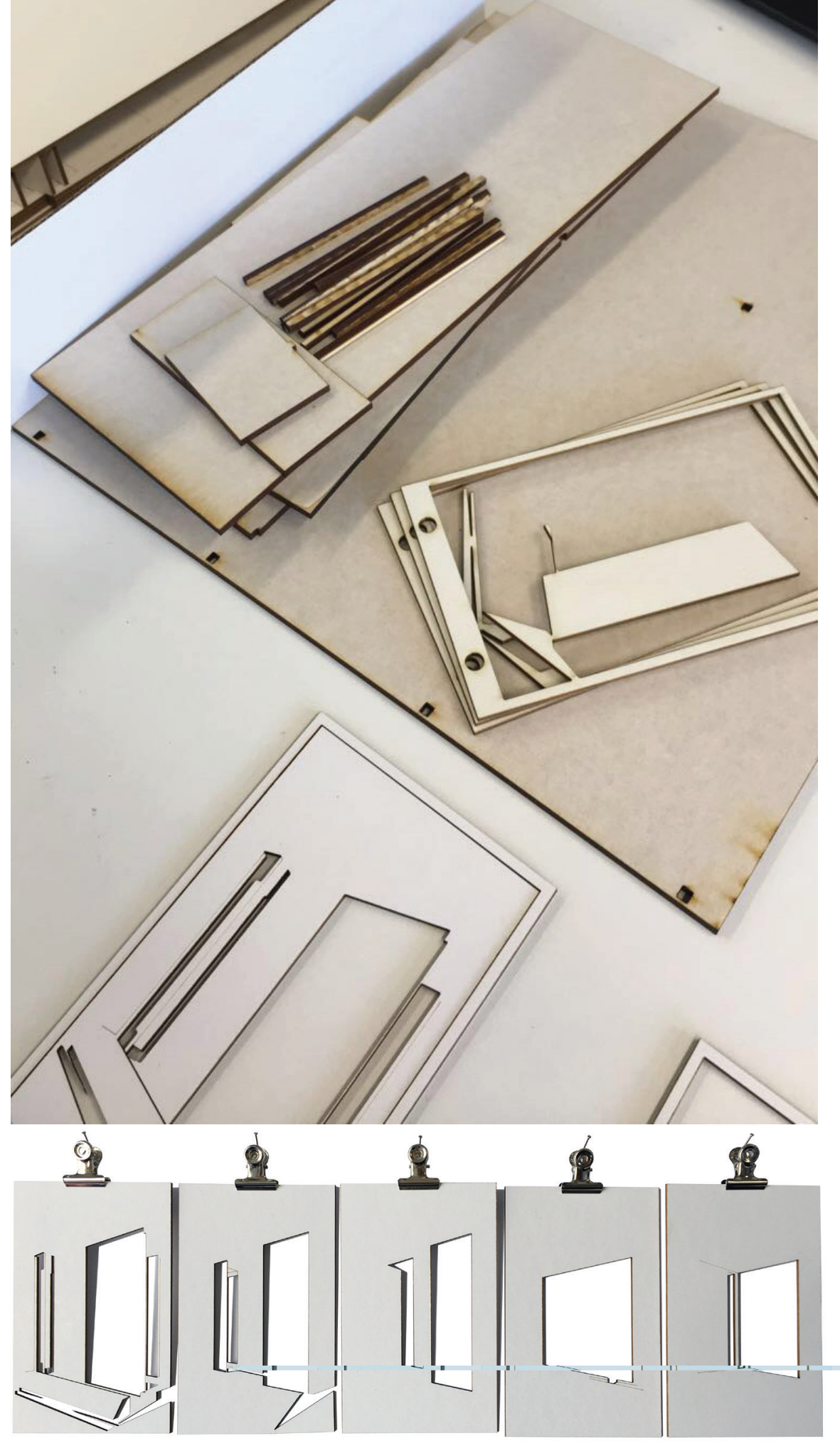

Figure 4.29 The overlaid perspectives being viewed differently, to take relationships between the elements into three dimensional form, white card. 


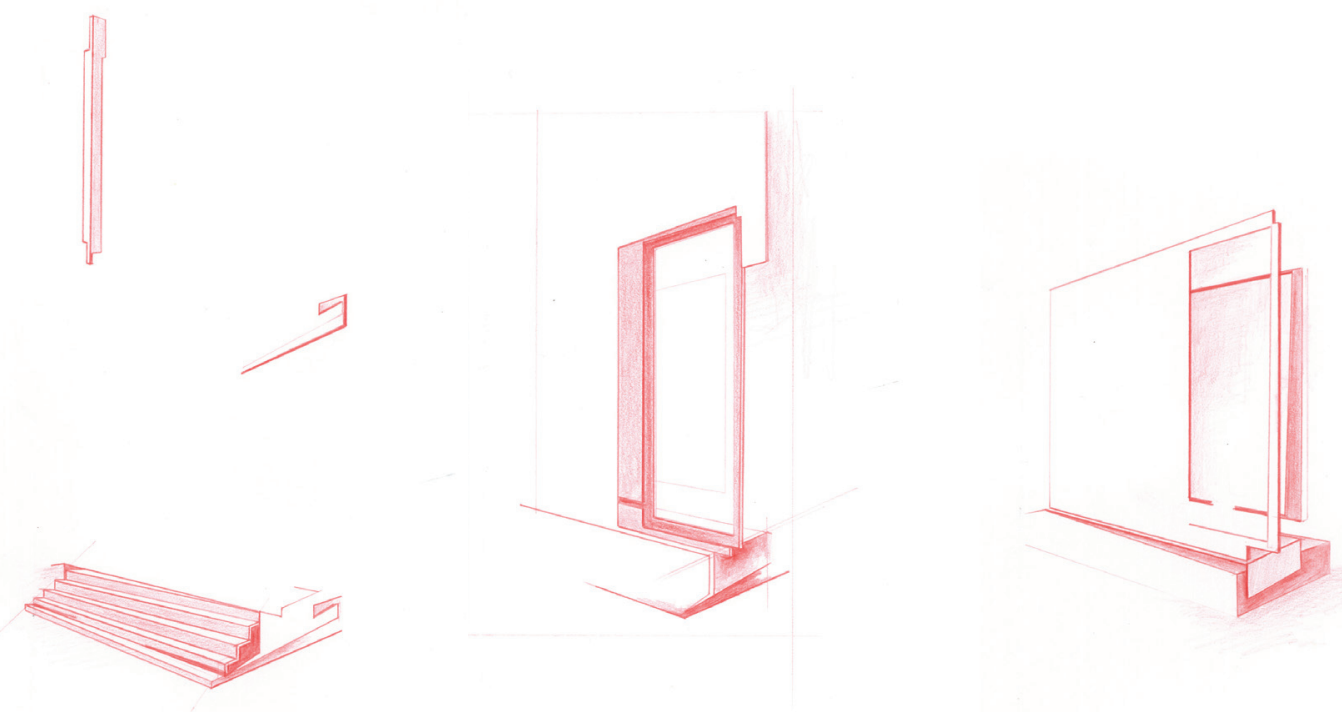

Figure 4.30 Frames drawn out from the card model, to take relationships between the elements into three dimensional form 

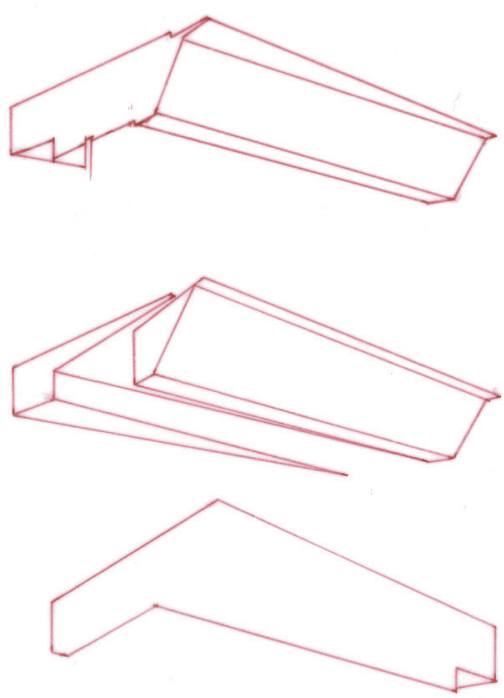

viewing the perspective's plinth-upside downas a noof.

Figure 4.31 Middle sketch was taken forward and considered in terms of bringing light into the spaces 


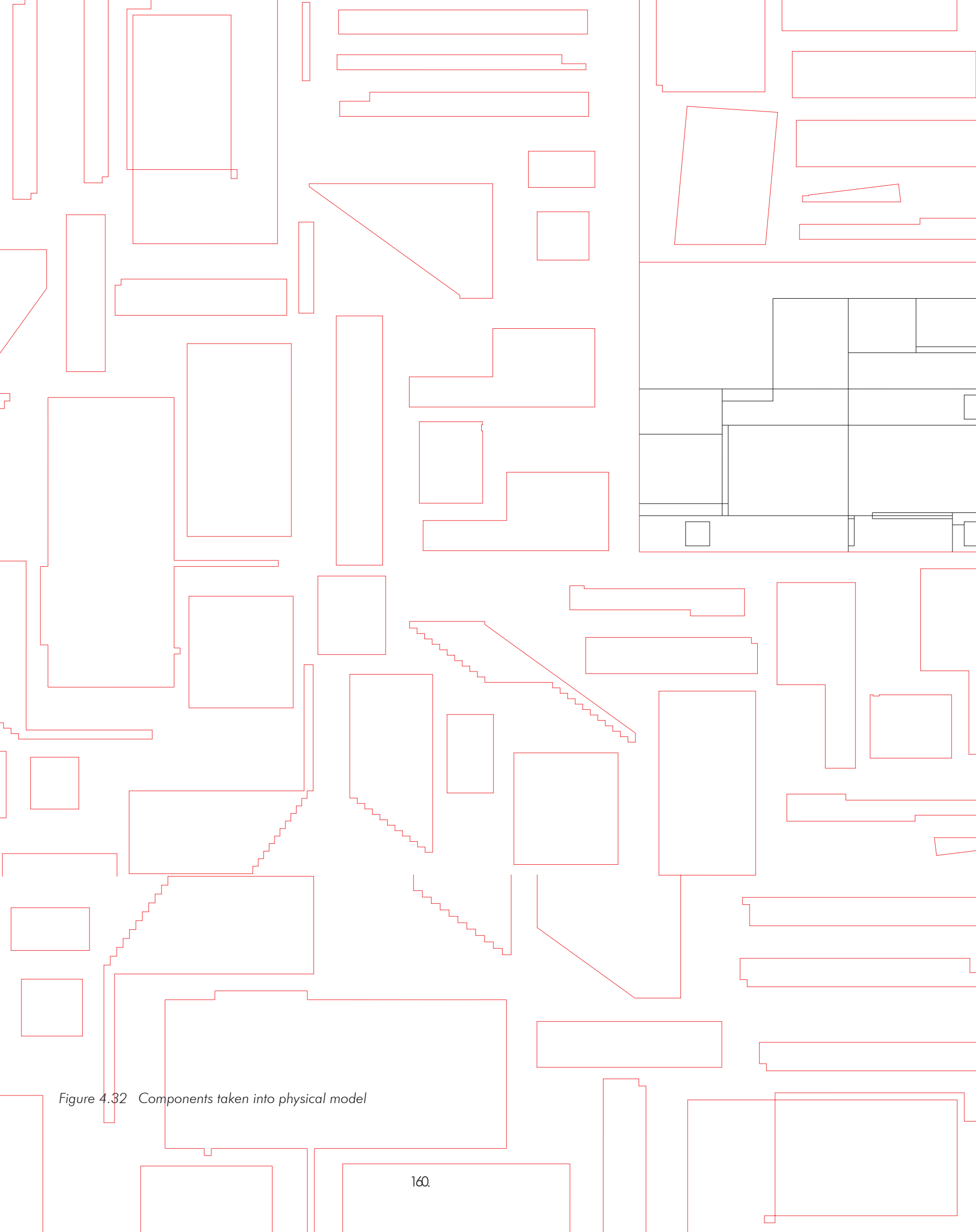




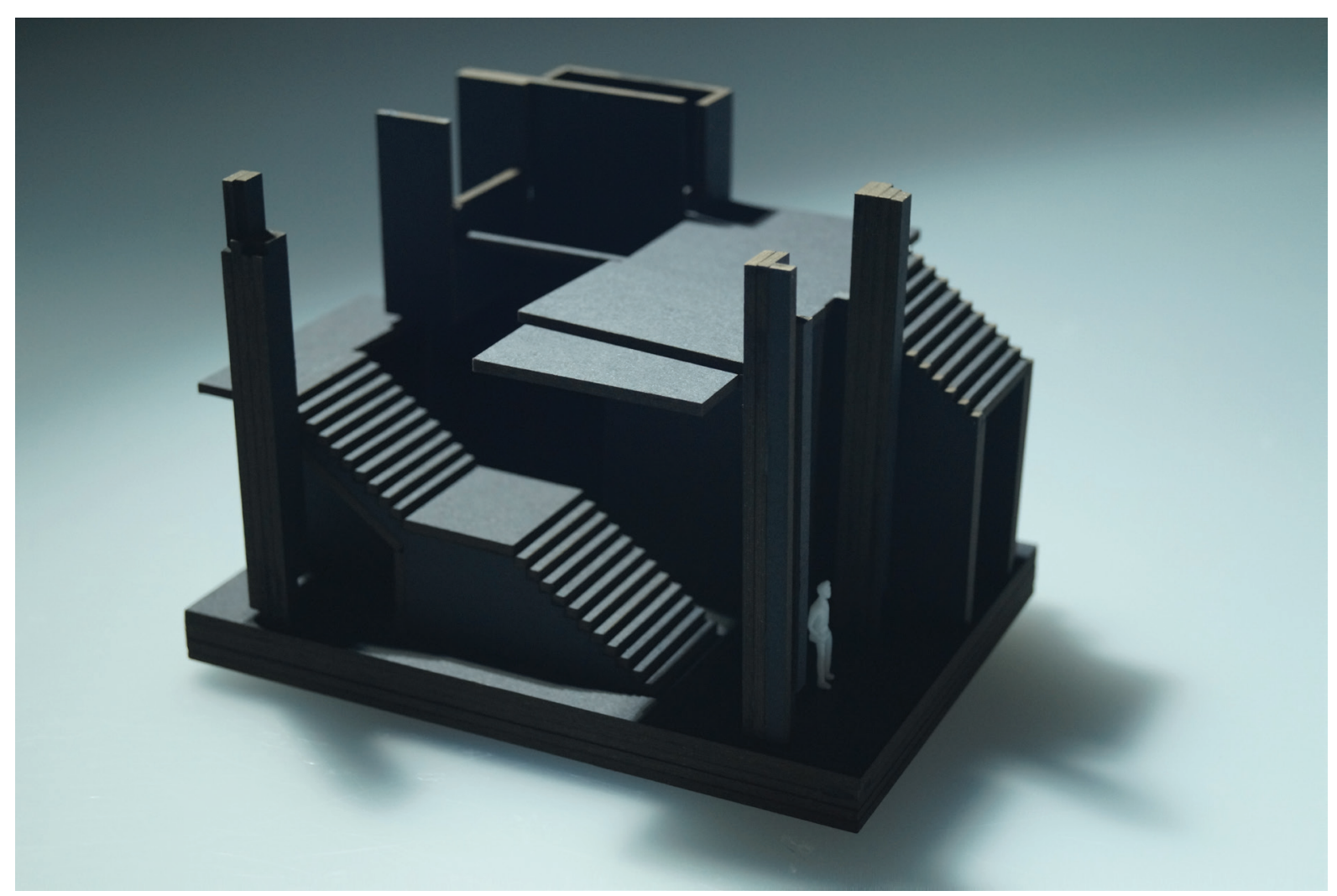

Figure 4.33 Black card partial model of the circulation core, final design, 1:200 


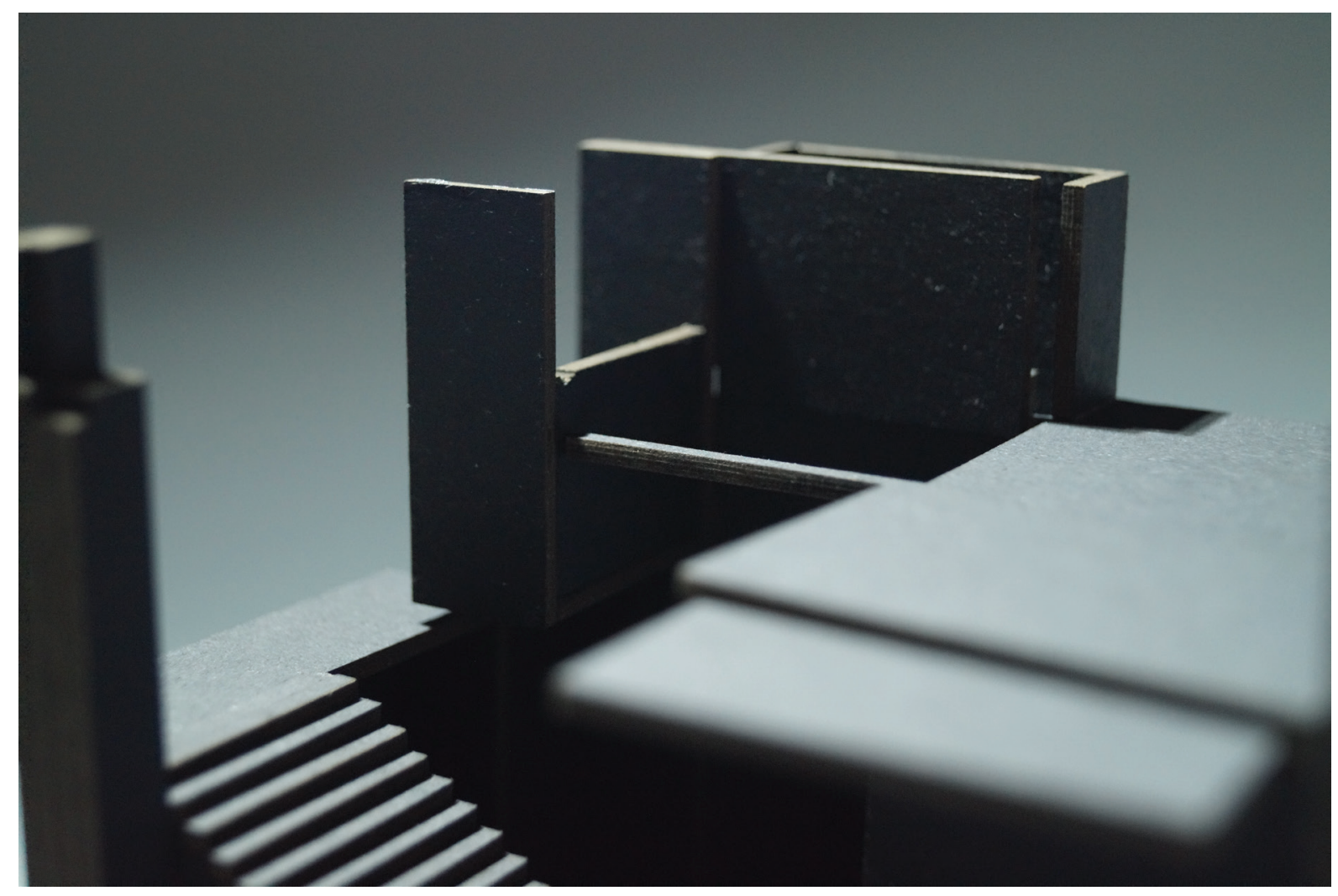

Figure 4.34 Black card partial model, final design, 1:200 


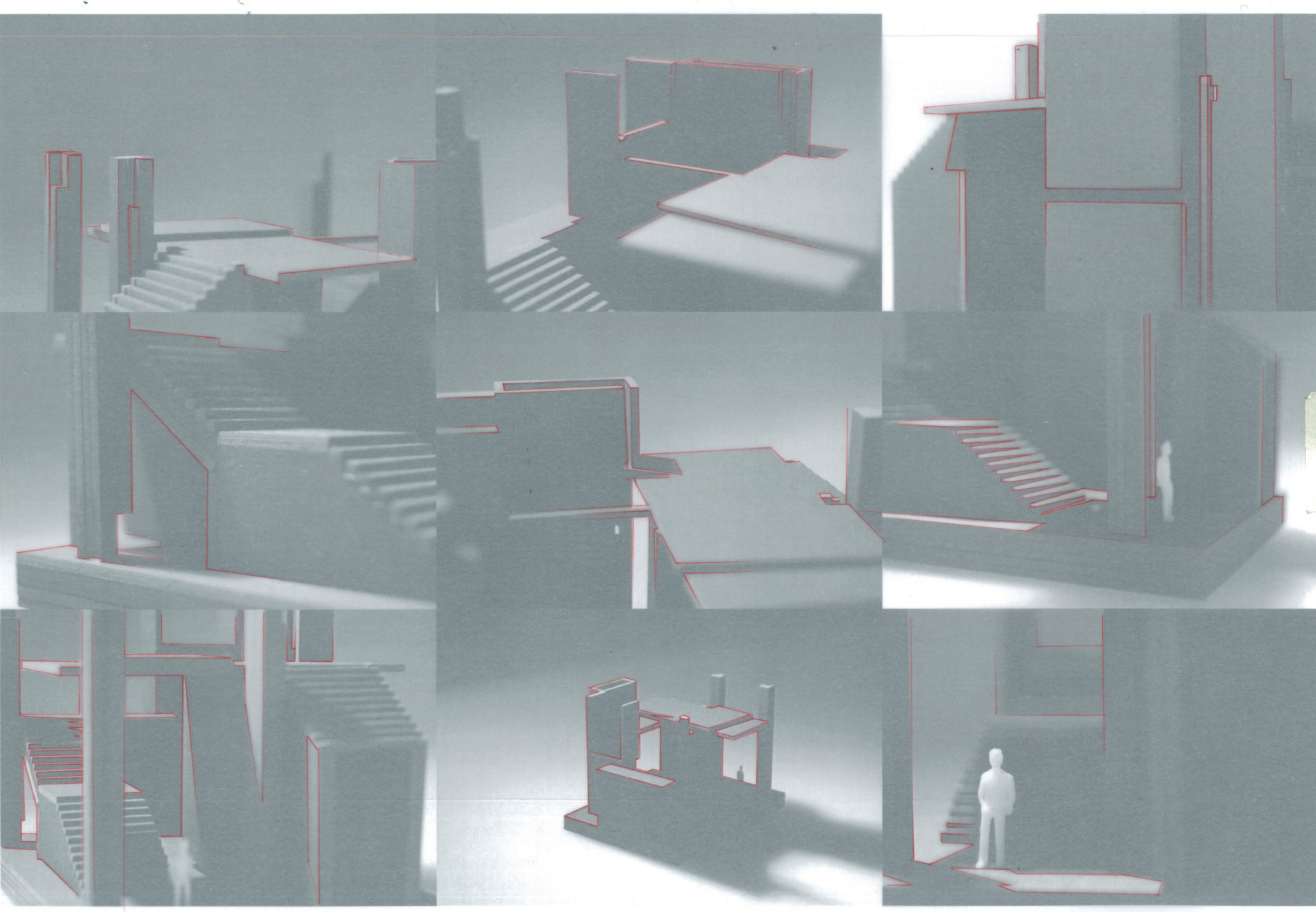

Figure 4.35 Sketches over partial model 


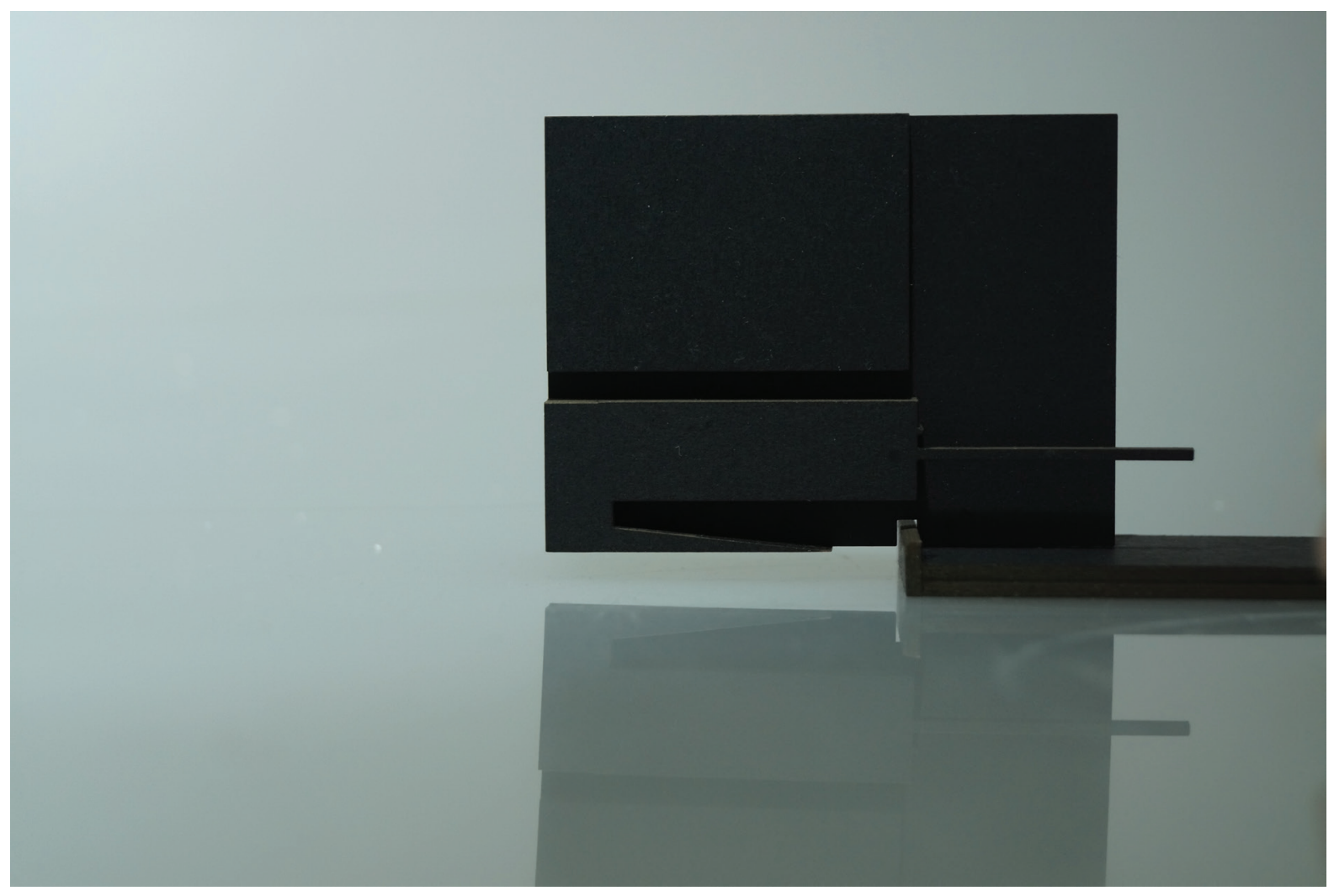

Figure 4.36 Black card partial model, no scale

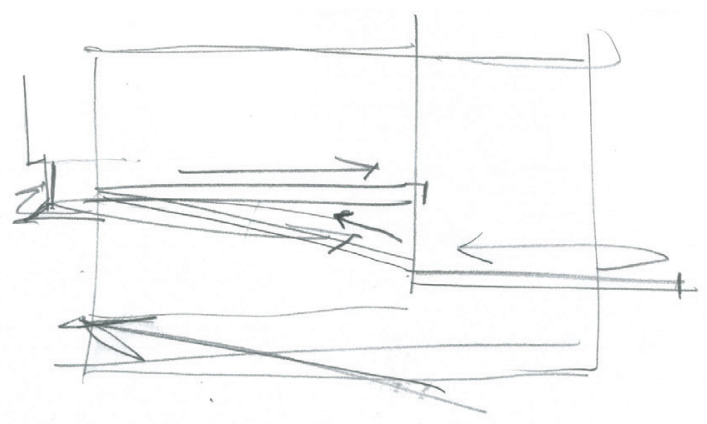




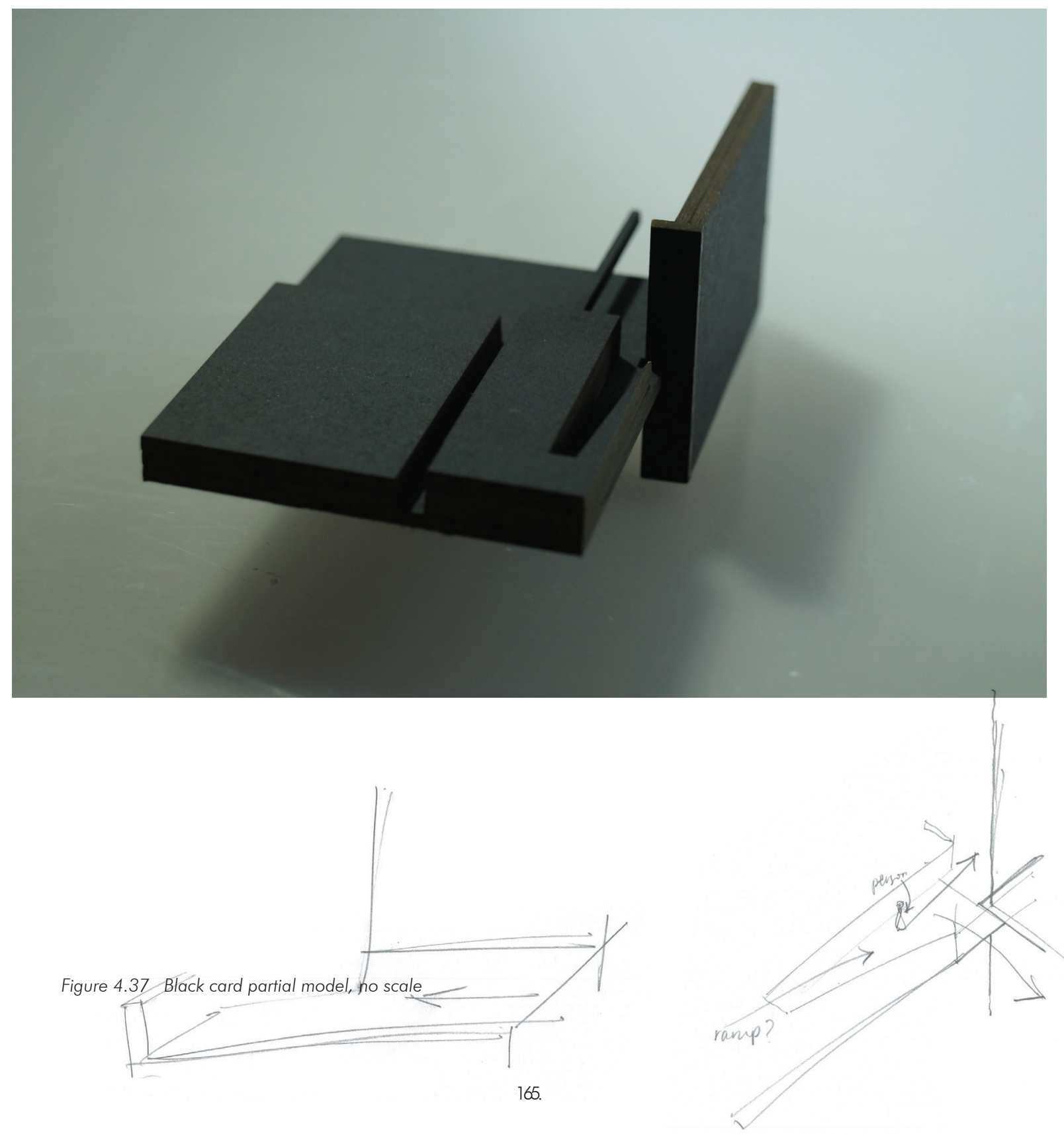




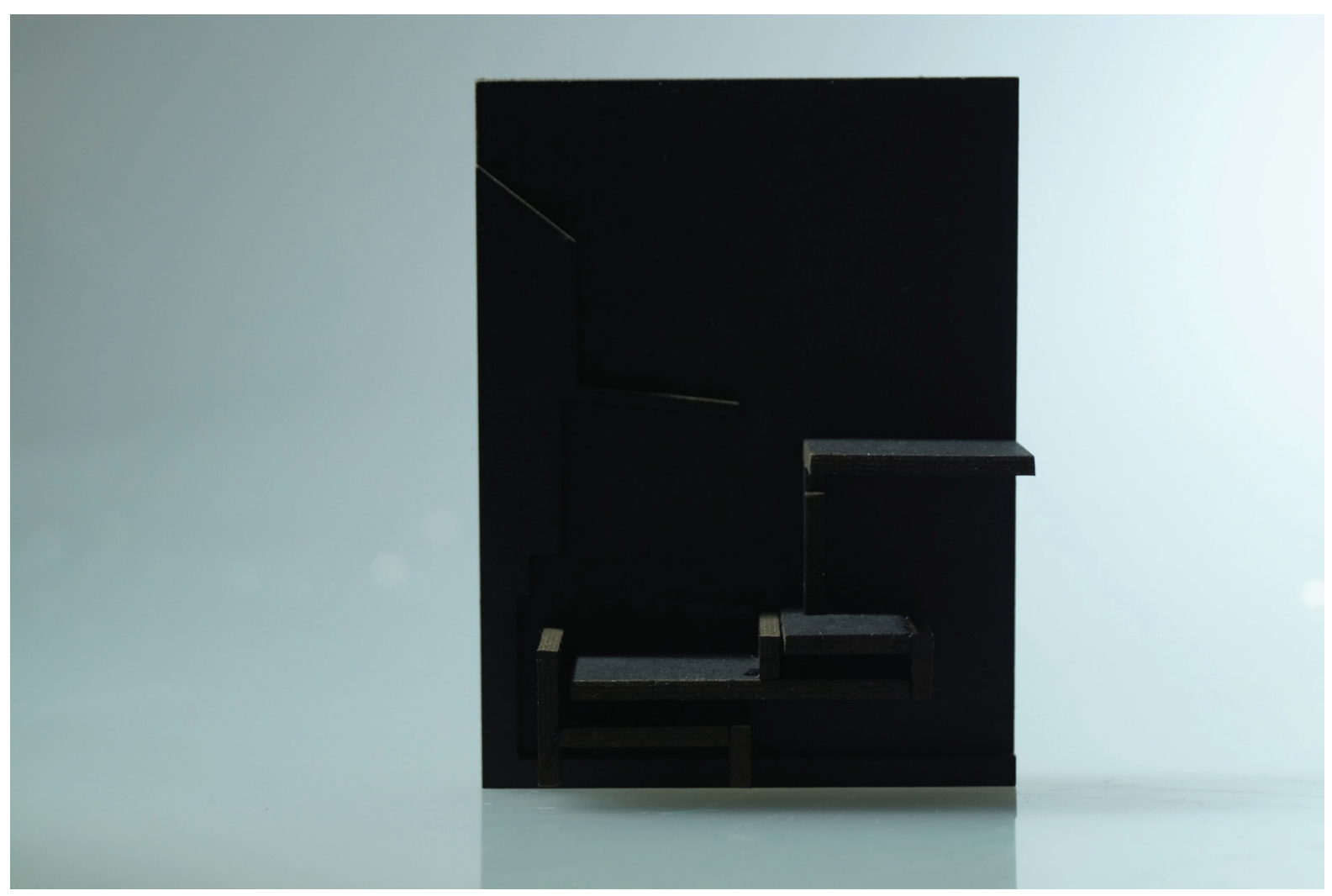

Figure 4.38 Black card partial model, no scale 


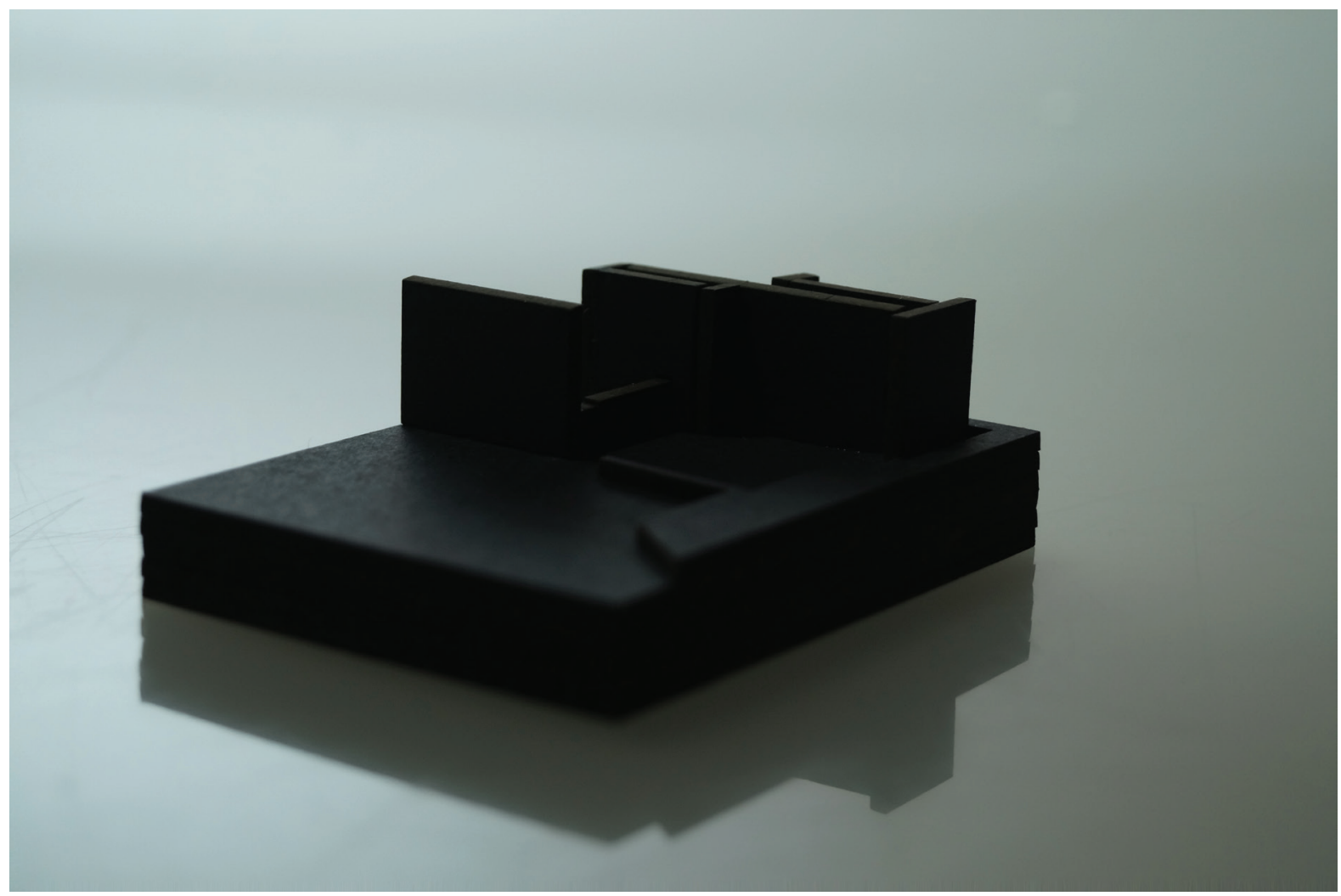

Figure 4.39 Black card partial model, no scale 


\section{DESIGN OUTCOME}

Linear Perspective's impact in the role of architectural drawing/ representation

This chapter reflects upon the developed design as a test of the boundaries that define linear perspective. It then goes on to outline how these boundaries have been challenged. The preliminary design chapter through the design of the drawing apparatus, outlined exactly the changes that this study has implemented, to how linear perspective is set up. This section discusses the apparatus explicitly with the effect it has had on design.

The final design demonstrates a complex matrix that establishes an ordering system to piece together the partial frames arising from the distortions in my projections.

Through the final drawings of the finished sculpture gallery, there is also a 'vagueness' to them. Alluding to the truth of materiality left out of Mies' perspectives, "the representation drawings of his Glass House projects reveal the contradiction that resides behind the implied simplicity." (Neumeyer, 115). This contradiction calls to question the value of representational perspectives as instruments of translation, together with Mies' ideal of absolute truthfulness of work. The ambivalent quality of the perspectives as representative of my final design, is in wanting to separate the representational from the built form. There is nothing vague or unsure about the built model - acknowledging the importance of the process of interpretation - at 1:50 scale the model was an exercise in taking the design outside of the realm of representation and into built model form. The representation drawings, through alternating perspectives in one frame, imply a sensory role (as focus of the work). Taking these frames into 'built' form embodies the very responsibility of the drawing; an opportunity to closely regard the process of interpretation of the drawings, to the form that they transcribed.

The plans are considered fundamental in the truth of the work and in this translation. Whereas with Mies' work, much cannot be read from the plans, and the focus was in revealing what the perspectives could inform about the plans. 
The idea of frames which have been carried through this work suggests a static way of viewing architecture. However, it is the shifting of frames that brings movement to the spaces by the shifting of the eye across the horizon. Detlef Mertins in 'Presence of Mies' believes that Mies' architecture is all about constructing a horizon. Evans sees the horizon line in Mies' architecture as working to stabilise the asymmetry of his plans, similarly, Mertins looks to them as defining spaces. "If Mies' projects are frames for a view, what these projects frame is a horizon. It is not just that they frame an existing horizon, rather the frame is a mechanism for producing a horizon." (Mertins, 182). In a way of considering the viewing subject through the designed spaces, the consideration of frames that had arisen from the apparatus were considered in exactly this way; arranged to produce a horizon, and this is exhibited more clearly in these sketches.

The changing viewing points in the apparatus, (with consideration of a field of vision), is considered in the same means through the planning of the spatial arrangements, in that the subject is considered along a controlled axis. The ordering of the frames is achieved by configuring elements to maintain framed views to the surrounding context, as well as mediate sight lines internally. Interpreting the relationship between the spectator and the elements demonstrates a thorough consideration for the participant in the spaces. 


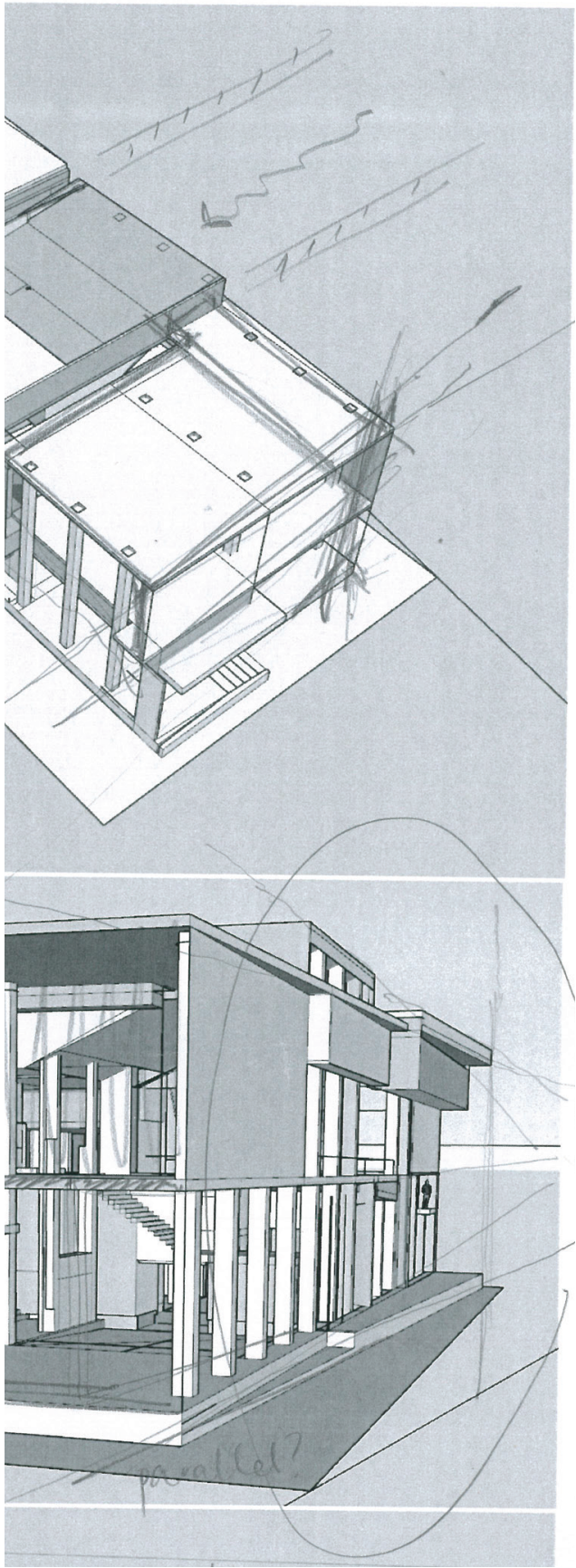

Figure 4.40 Sketches of the exterior form, crossing over of frames Figure 4.41 Barcelona Pavilion interior photo, 1929, Ludwig Mies van der Rohe / photo: Berliner Bildbericht. Bauhaus Dessau Foundation. (Dodds, 92, edited by author)

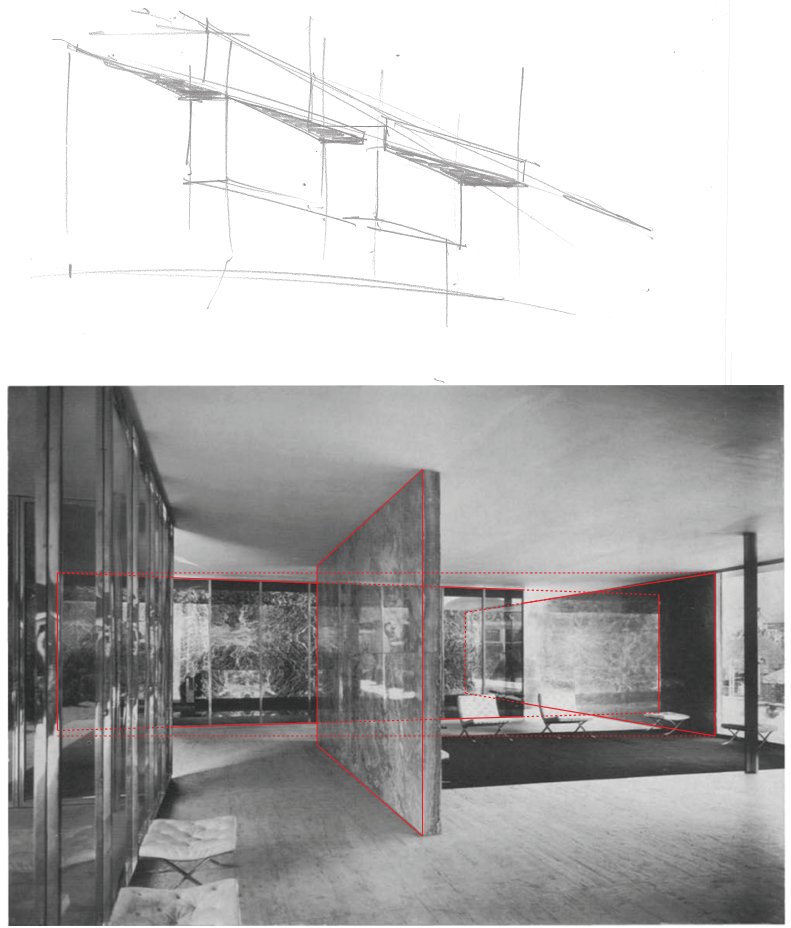


The spatial organisation as true to the plans is from the ordering of frames as outlined above, and also the structuring of partial planes, or details within the plan. They have been ordered through an underlying grid established from the site, but broken up into three grids which control the complexity of the details coming together, and acknowledge an ability to piece together spaces. Complexity though is maintained in the spaces by the shifting of elements from the grid lines, where elements that were drawn out in the apparatus have been offset from the overlaid gridded volume in the perspective. It demonstrates order versus chaos.

Appreciation of complexity in architecture does not stand in conflict with demands for simplicity. Venturi recognised that the buildings of Mies van der Rohe opened valuable opportunities for the development of architecture but also that their selectivity and formal language represented a limitation. (Neumeyer, $x v$ ) 


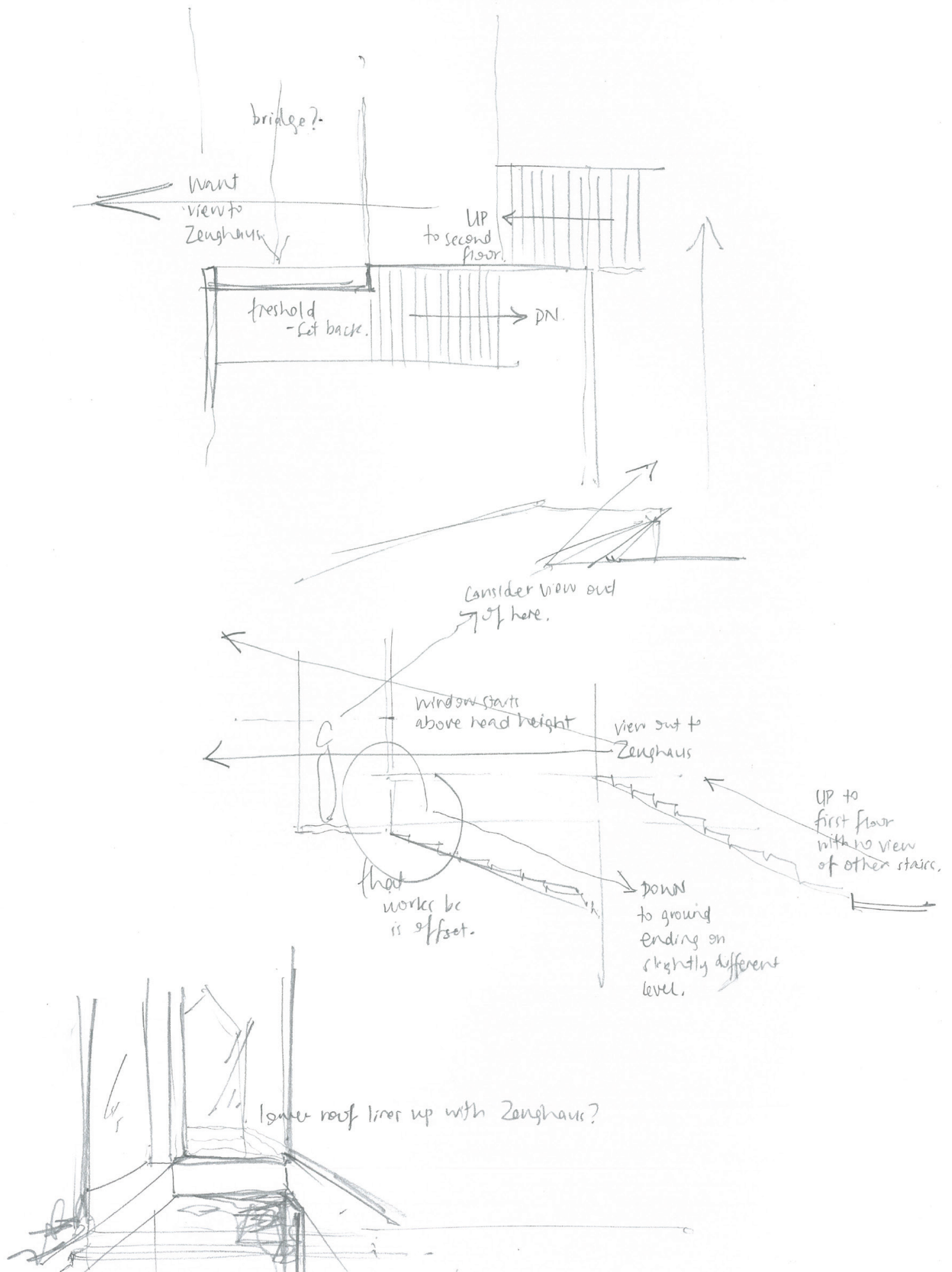

Figure 4.42 Interior planning of vertical circuldtion within the matrix ' 


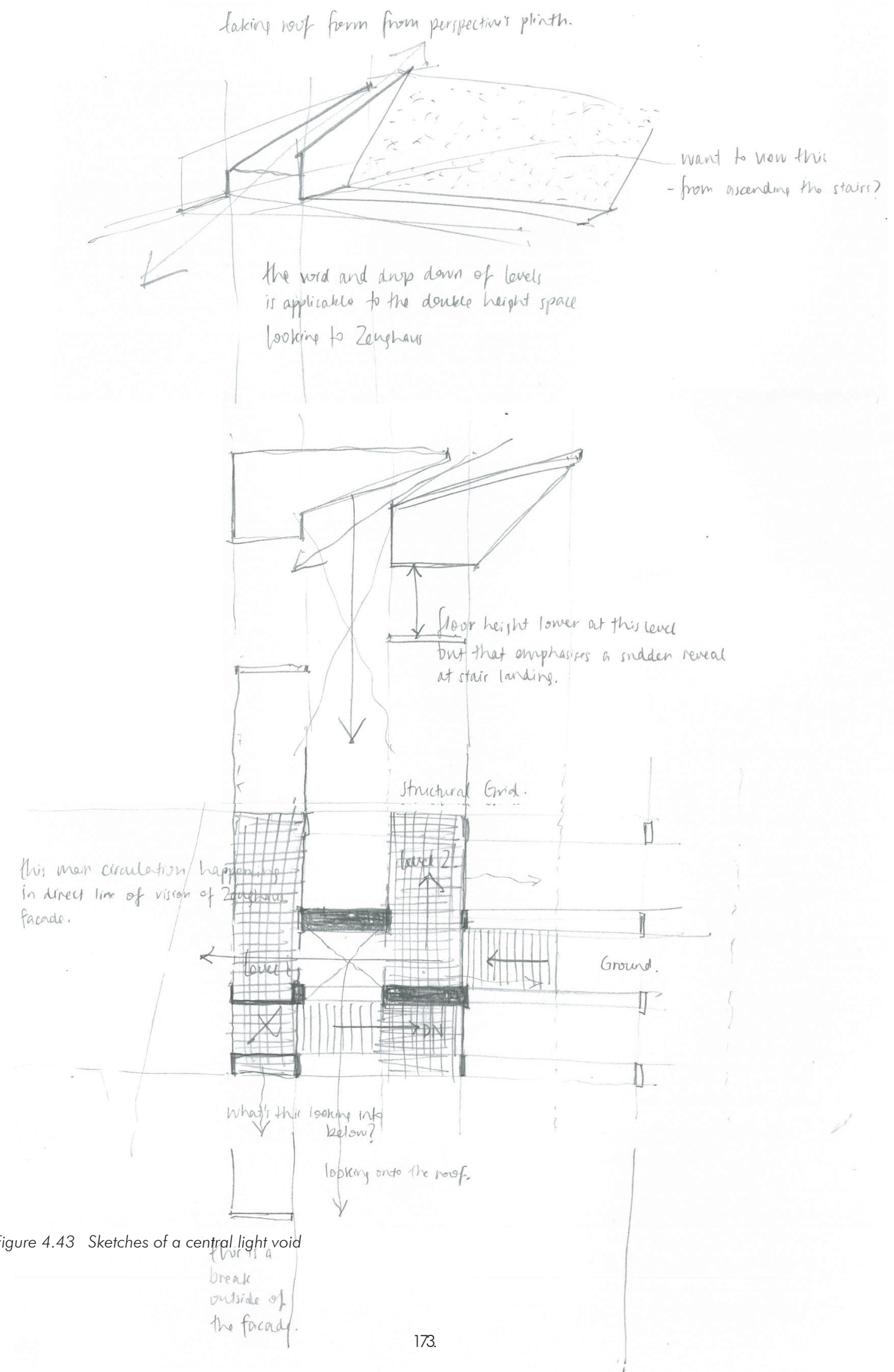




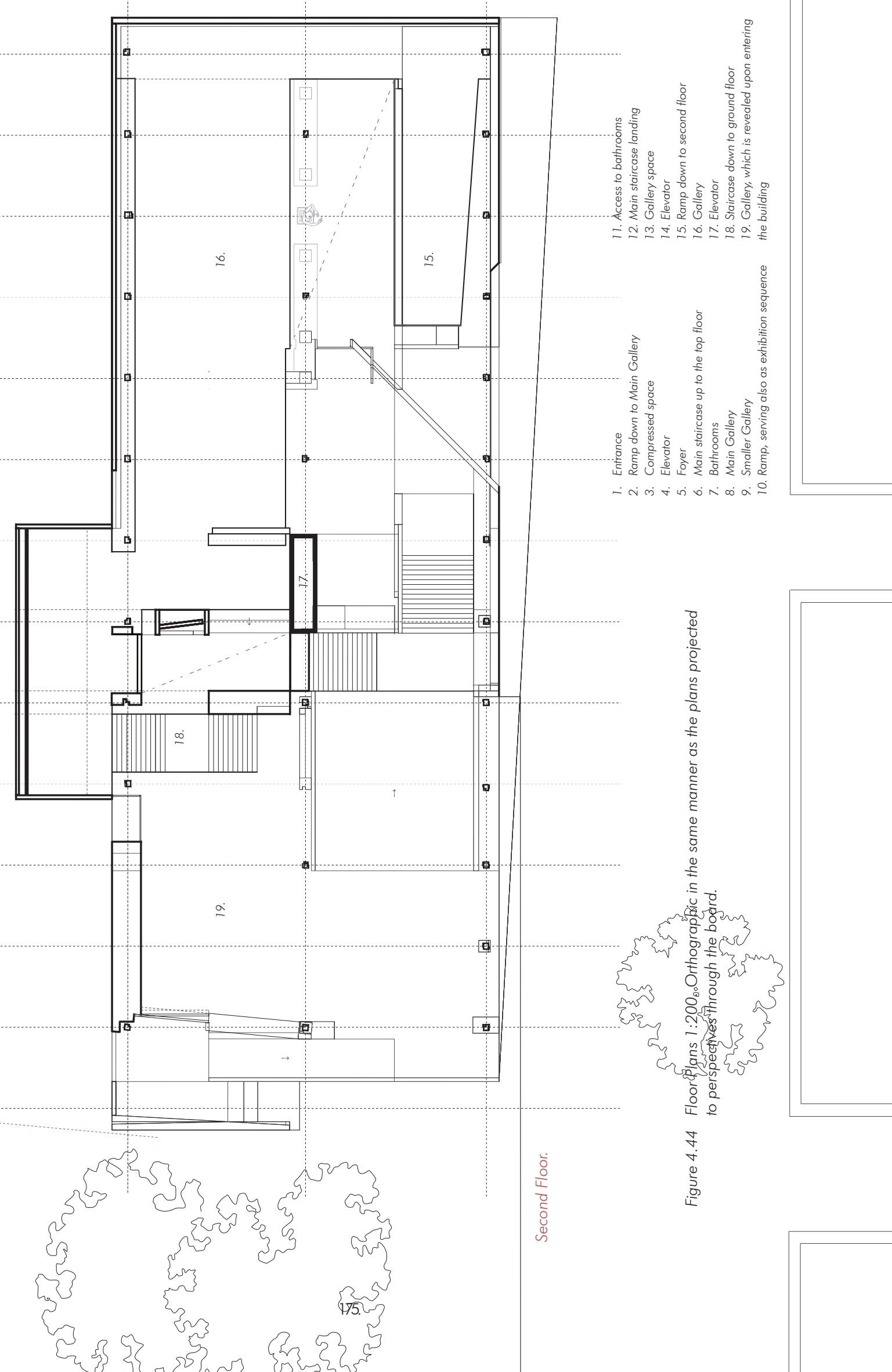




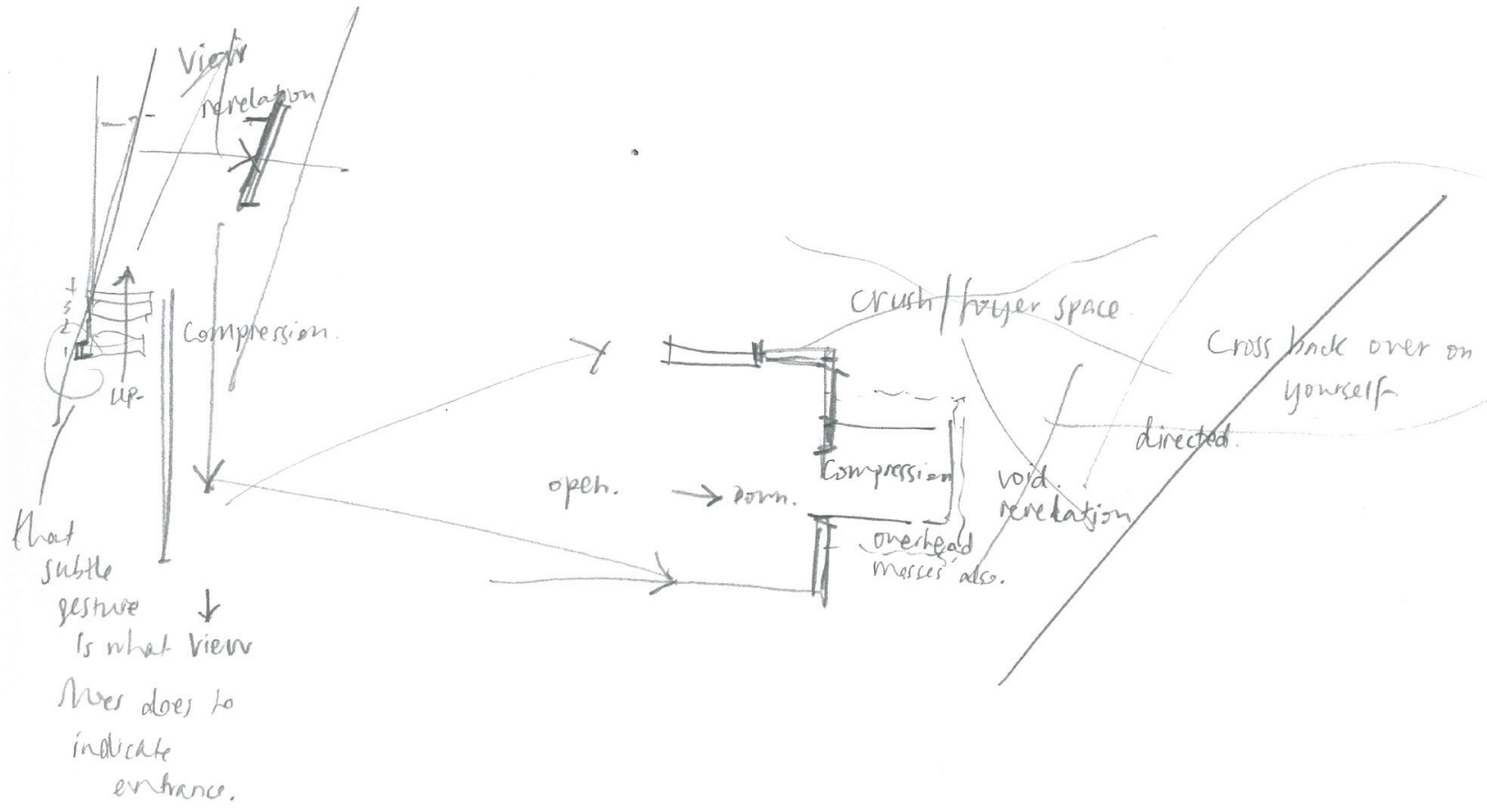

Figure 4.45 Sketches of the circulation through the building 


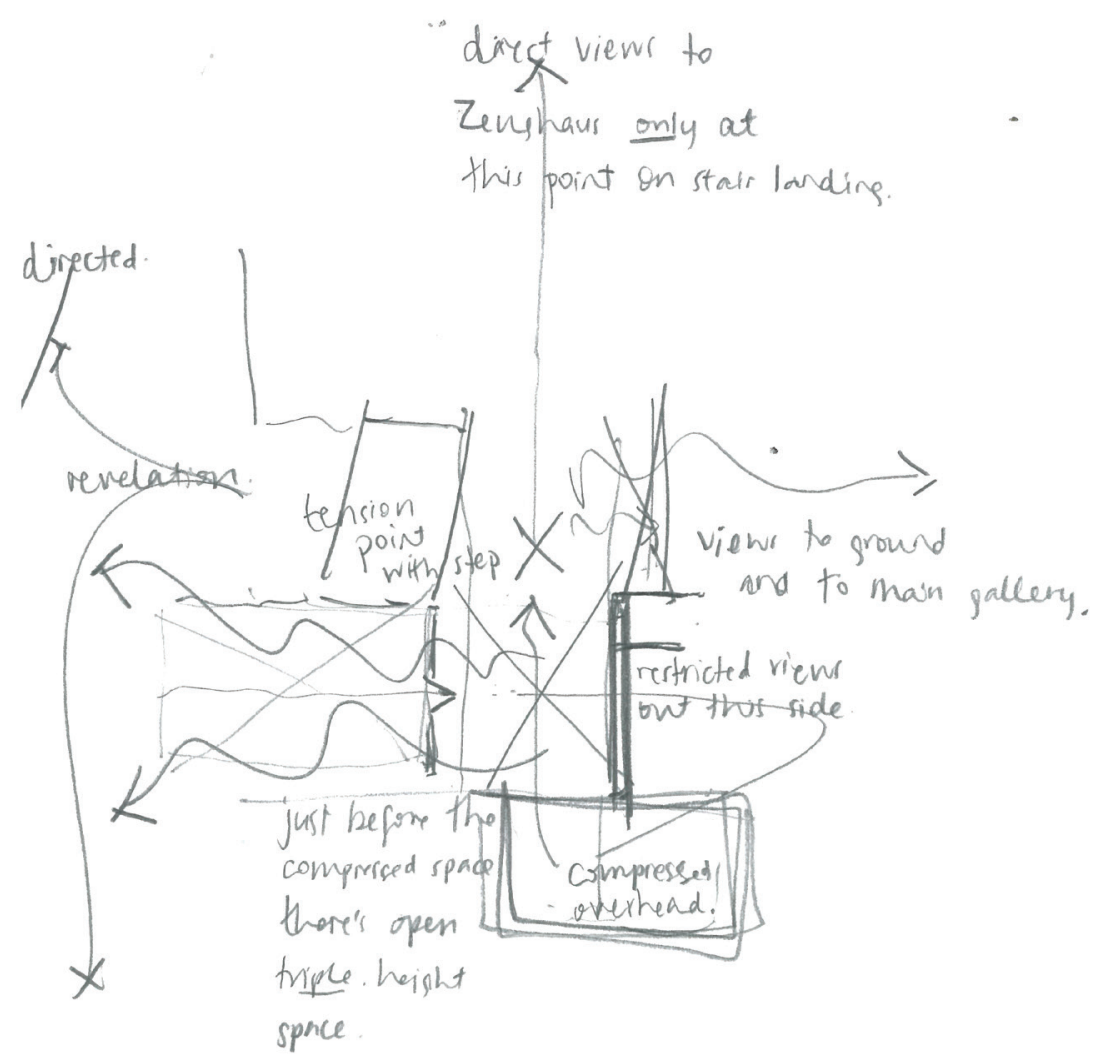

Figure 4.46 Sketches of the circulation regarding sight lines 


\section{DESIGN OUTCOME}

Narrative through Design

Linking the Barcelona Pavilion, to Karl Friedrich Schinkel, and to Schinkel's Altes Museum, the design explorations intend to reinterpret both buildings, to make a connection back to Schinkel, as the inspiration to Mies. The building which exhibits sculpture, would be a nod to a representational history of both Schinkel and Mies.

After establishing a grid, circulation was strongly regarded as fundamental in representing the rhetoric, and the principles from the Altes Museum and the Barcelona Pavilion. Considered foremost, were compressed and then revealed spaces; as I believe Mies shifts the perception of the occupant with the same means. At one point in Mies' buildings, space can appear to be fully enclosed, and on taking one step the wall is revealed as freestanding. This thinking was taken through the planning of this design in a set of three grids. Three scales within the grid were established as an ordering system to locate the frames. The structural grid or primary grid was established through the alignments with the Altes Museum and the site. A secondary scale concerns circulation. A tertiary scale places details of the columns and walls. These arrived from distortions occurring through the multiple frames from the apparatus. These slippages create tension points at the thresholds and are shown in the off-axis elements that direct the visitor. The main off-axis element draws circulation around the main gallery (ascending the stairs to the third level, with views into the main upper gallery) and around. 


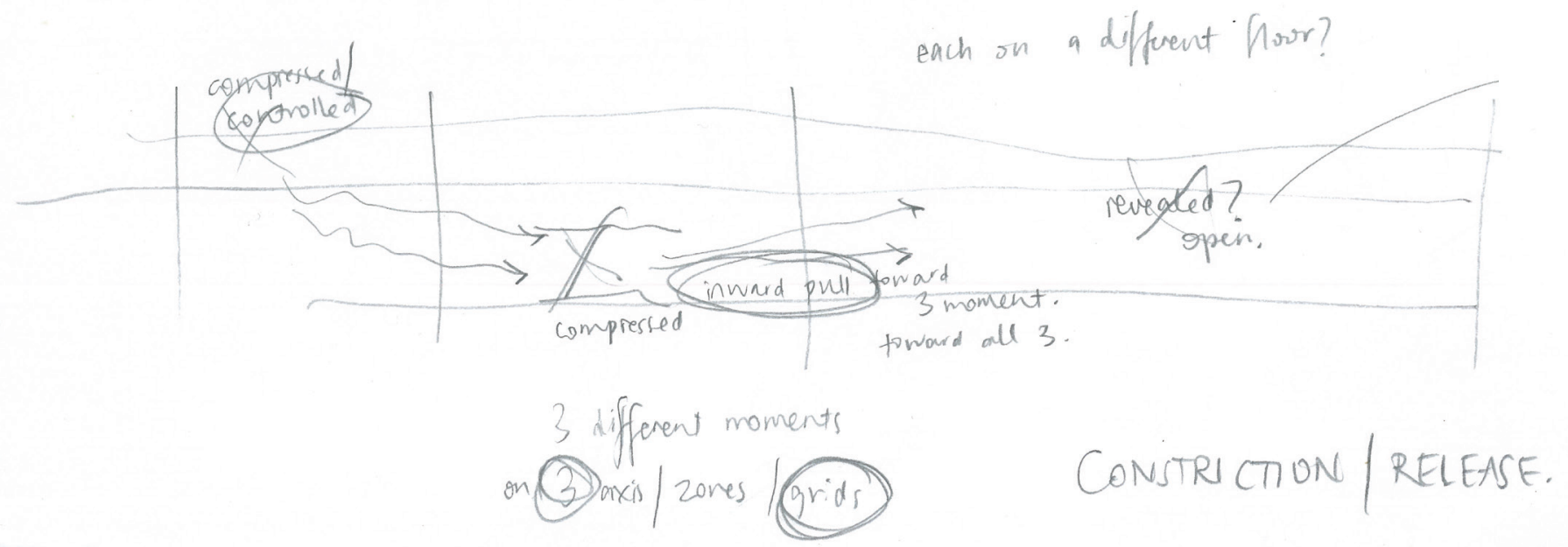

The three parts of the building were broken up through the contextual grid, and in maintaining a dialogue within the surrounding context, 'moments' were considered through the Gallery spaces. As a set of three moments through the three parts of the building and on different floors, these are all offset from the grid, moments where circulation is diverted or where it crosses over; points of tension where the axes and line of vision changes and the columns have been treated as reactions of these.
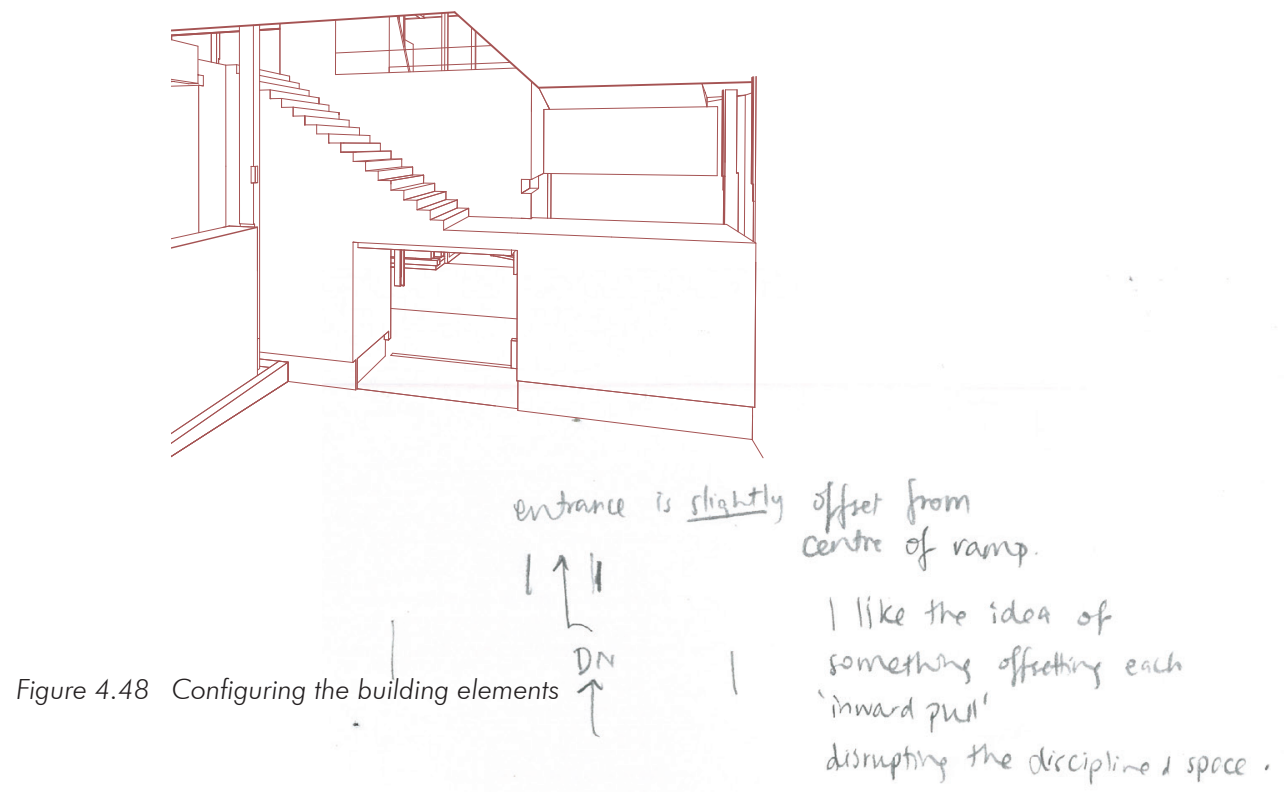


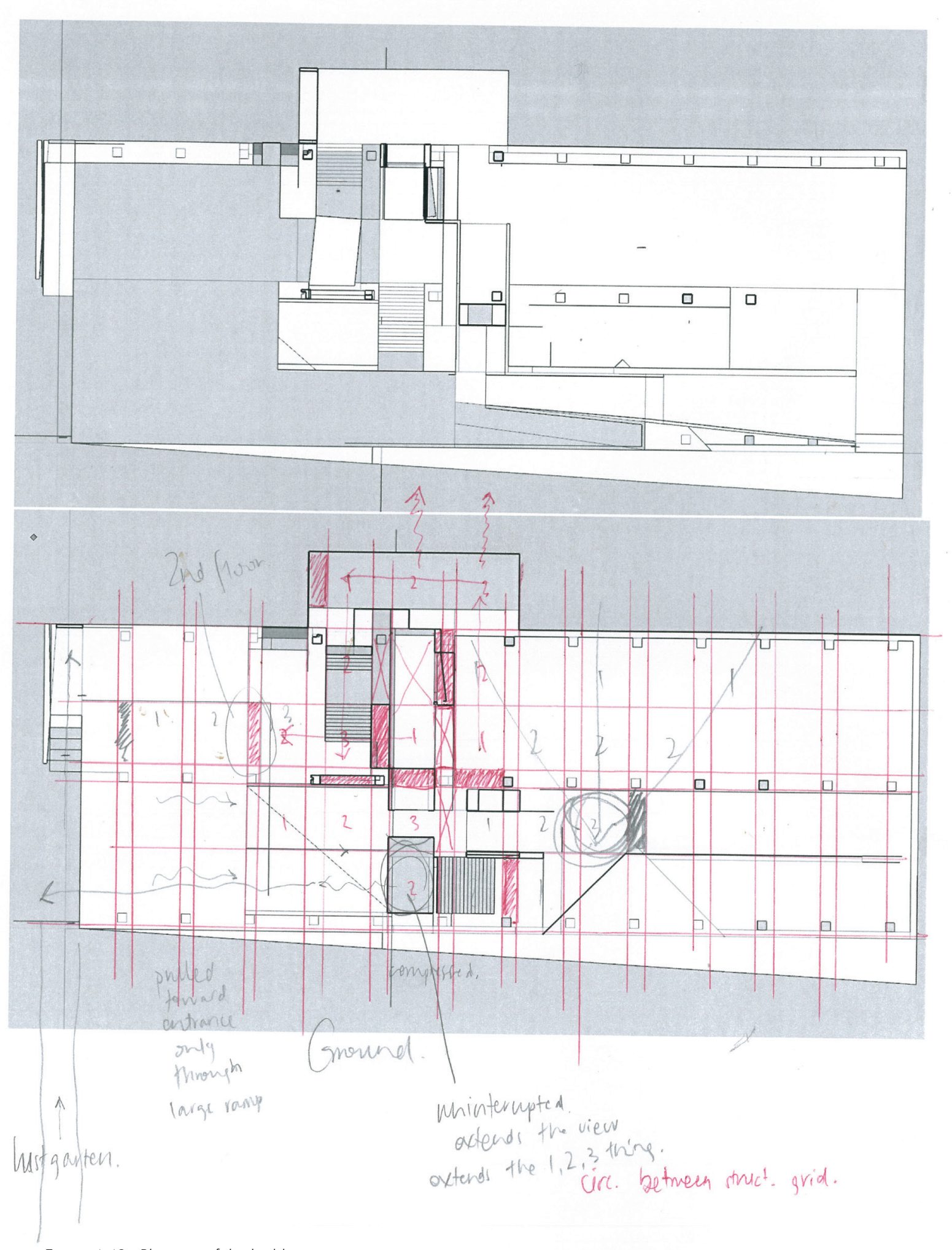

Figure 4.49 Planning of the building matrix 
Circulation is considered through the building in double interconnected loops of circulation, a sort of figure eight. A controlled journey by means of compressed masses through the thresholds of these spaces and then revelation, it alludes to the spaces that one is moving into. At play within the grid are changing levels and alternating floor heights as the visitor is brought up to the top level from ground, down to second, and to exit the way they are brought into the building, experiencing alternating framed views of the spaces they are moving into. This controlled journey has been established through the grid, and through the alternate scales, by the layout of elements along the circulation path, one to every three open spaces within the grid lines. The play of constriction and release teases out the notion of void and solid, (supported by play of light and shadow, transparency and enclosed spaces). The elements within the design were to have a 'reaction' to each other, thus through the play of contrasting properties. The roof form is intended to react to the internal formal relationships. Formally the roof was conceived as appearing to reach across the whole site as a sculptural gesture, in an expression distinct from that of purity through Mies' flat roofs. 


\section{0}

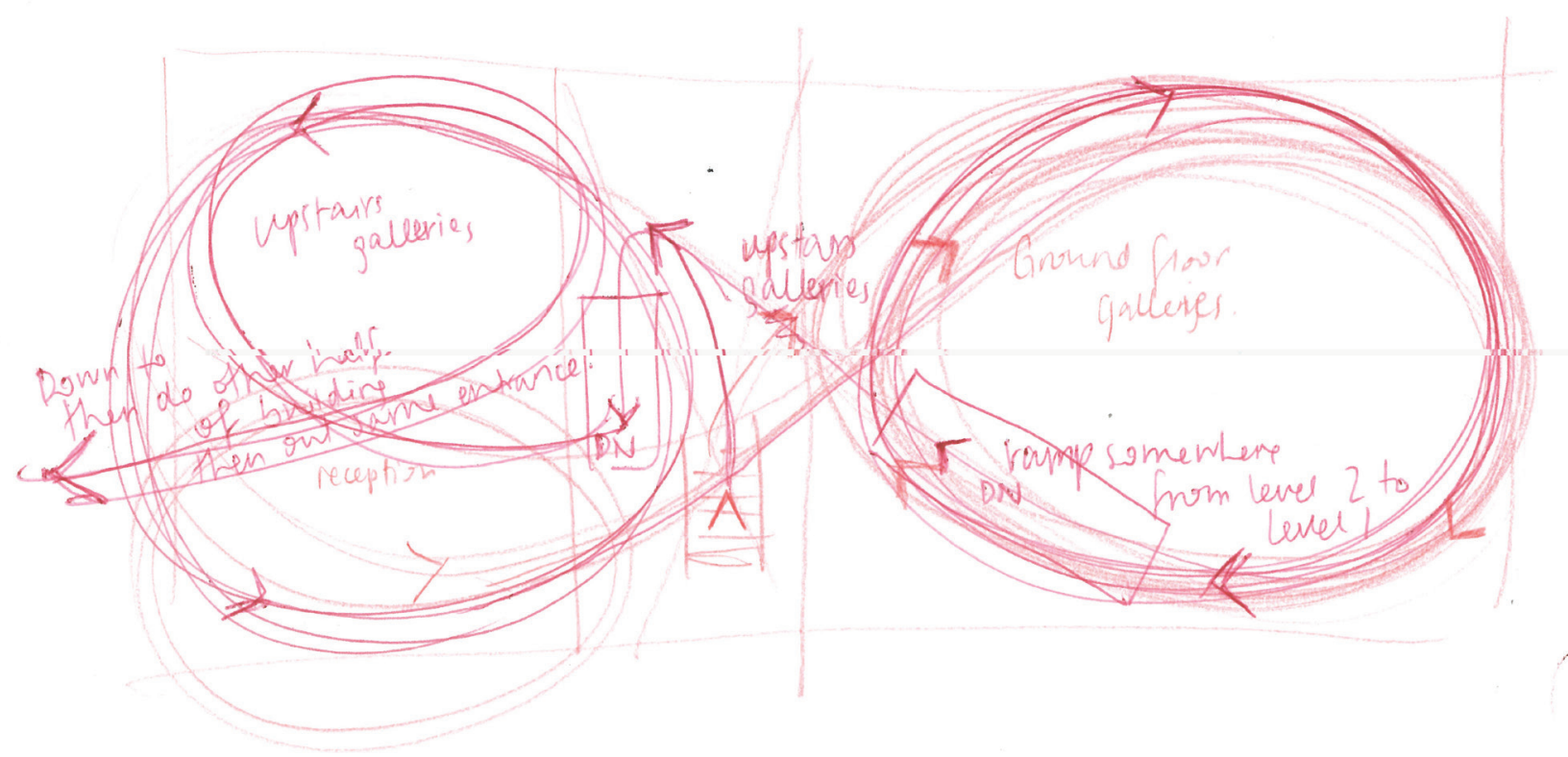

Figure 4.50 Initial circulation sketch, double interconnected loops 


\section{DESIGN OUTCOME}

Architecture as a frame

Geometry is a rational science whereas architecture is a matter for intuitive judgment, therefore important that geometry gives architecture a reasonable ground but does not confide it to rationality. On top of this geometric rationality, the creative, intuitive and rhetorical aspects of architecture can develop. (Evans, 283).

To progress the frames from the apparatus, vocabulary of gallery spaces from Mies' architecture is considered, along with creating my own from the analysis of ambiguities arising. Early analytical drawings, and literature reviews set up a brief that addresses the research objectives of accommodating human experience through the spaces by considering the occupants' movement and journey. Through the apparatus, the design considers movement through multiple viewing points as explained, and through the experiments, the design should be seen to consider to;

Create a sense of horizon

Play with light and shadows

Create framed views

This chapter of the design development will reflect upon the implementation of this brief. The brief set became important in structuring the project however, was not necessary to form the design; as the methodology that has such hold over this research has set up parameters itself that inform the design. The brief that is enabling control over the design decisions, the ability to plan and arrange spaces within the building, is through the interpretations of Mies' approach to architecture.

Through his architecture, Mies frames views that induce movement, and through the frames on the apparatus that are created as each one moves into the building plan, this is translated into built form also. The perspectives frames are translated into partial plans to be read as 'sequences'. 
The site lines and transparency through these frames were analysed. To explain these site lines, it is the consideration of the crossing over of frames so that from some angles it is read as enclosed and some as open. By varying materials and surface conditions, as Mies applied through the Pavilion, the transparency, reflectivity and opacity of these enable to control these spaces, to determine the degree of openness. The conditions of these shift perception, and likewise in Mies' Pavilion, 'frames' create an architectural promenade where framed views from the offset wall planes and low roof, encourage movement through the narrow passages to open to a larger volume.

Figure 4.51 Sketch, considering sight lines

idea of being

able to see disurtion

of the soaces about

to be going in to,

- and of where have

been? - and also

have some spaces

revealed 


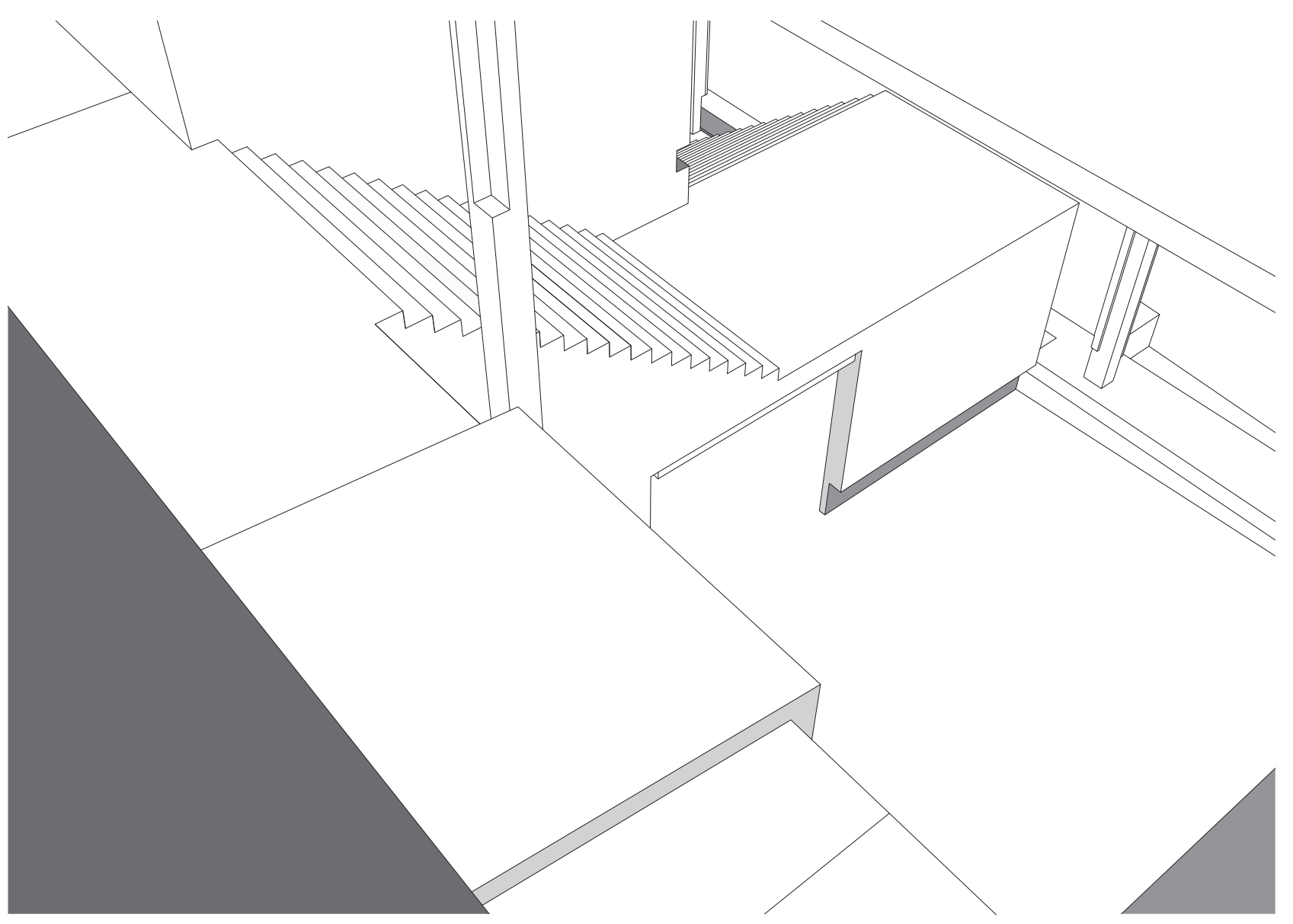

Figure 4.52 Perspective, third floor looking down to the foyer 


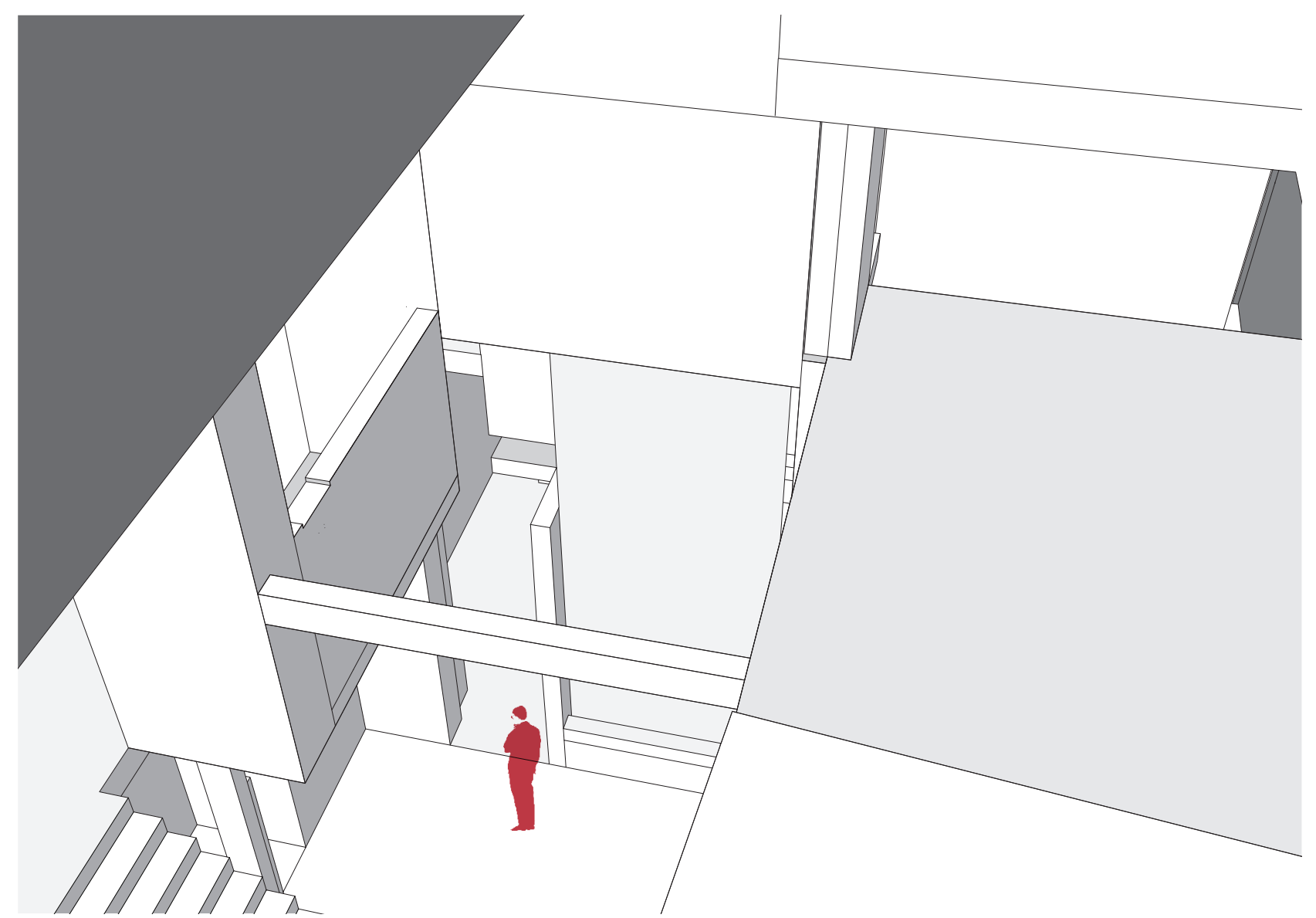

Figure 4.53 Perspective, third floor landing 


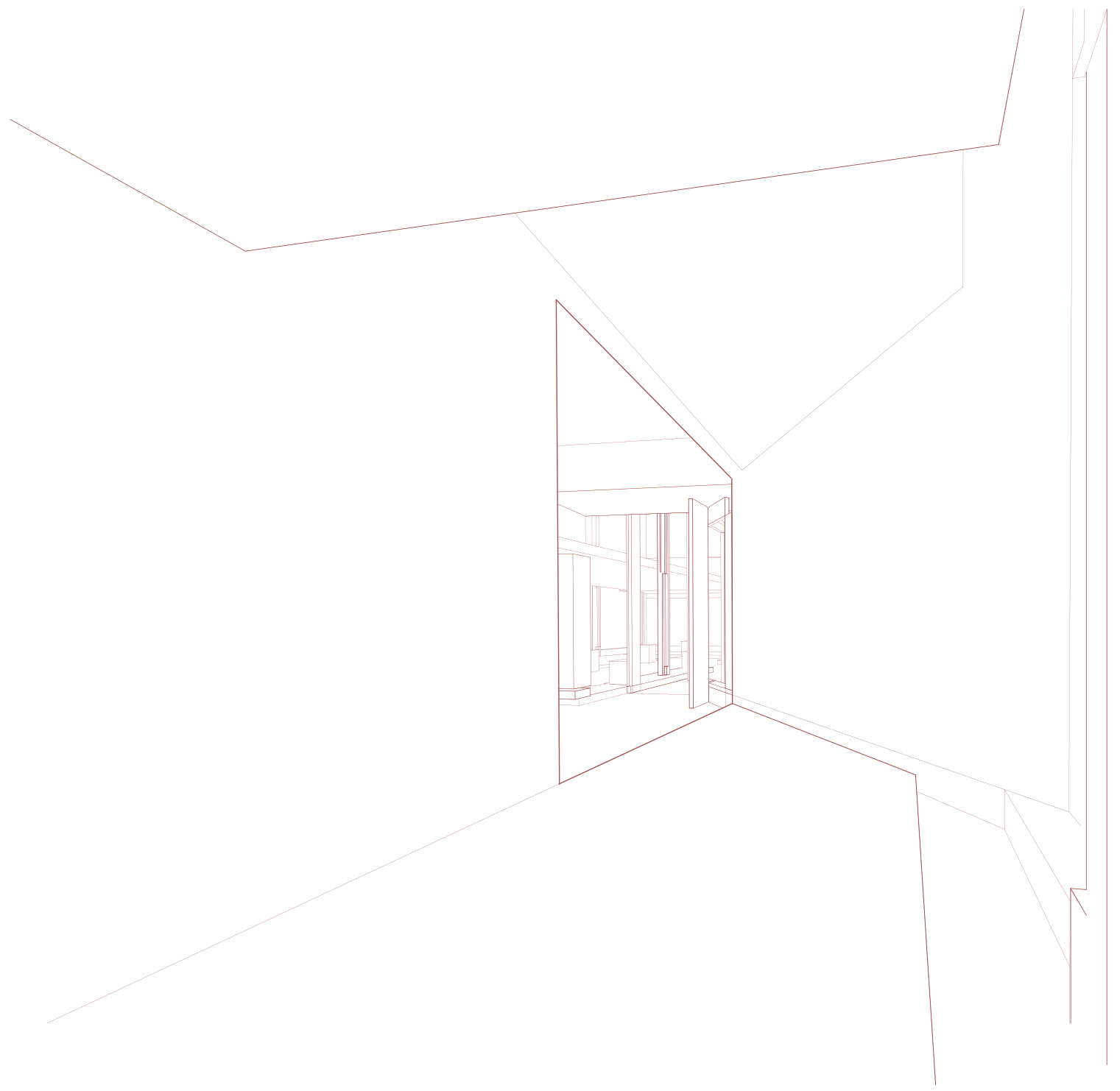

Figure 4.54 Perspective, from the Main Stairs toward the Gallery 


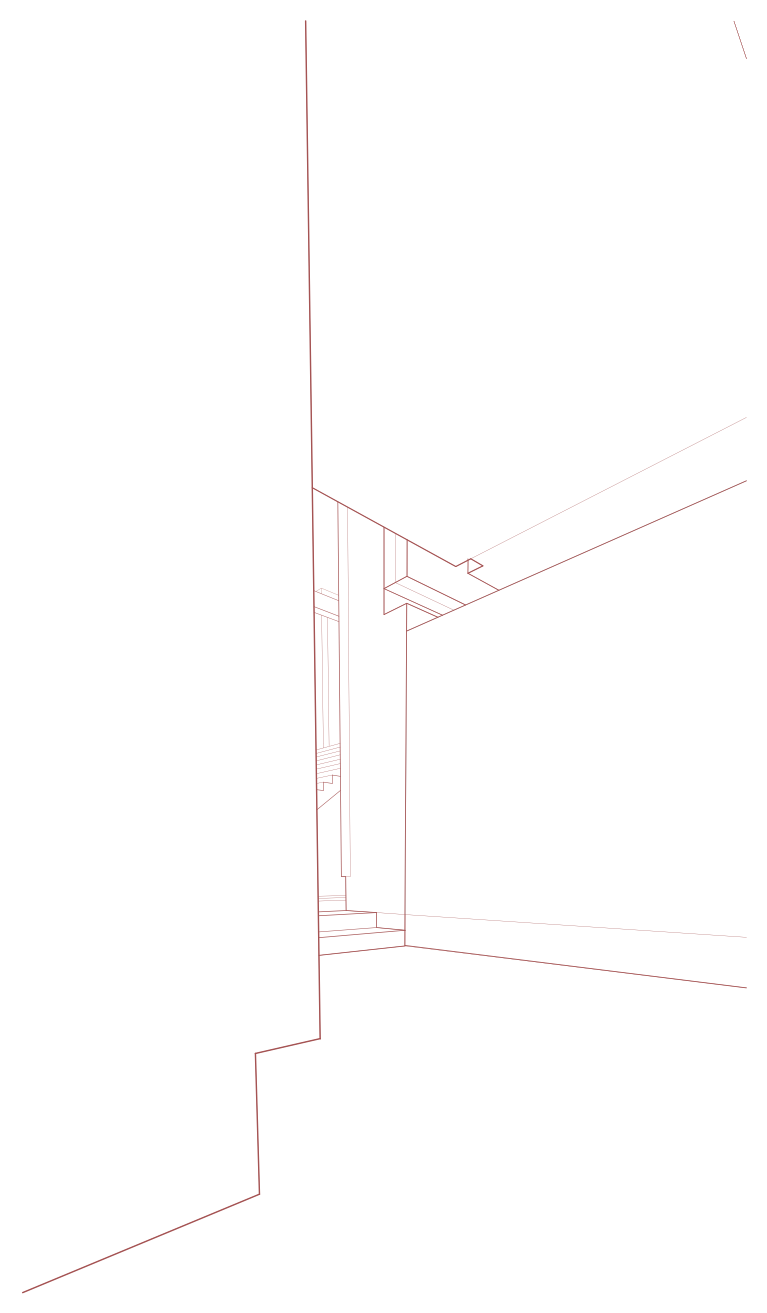

Figure 4.55 Perspective, Ground Floor Foyer 


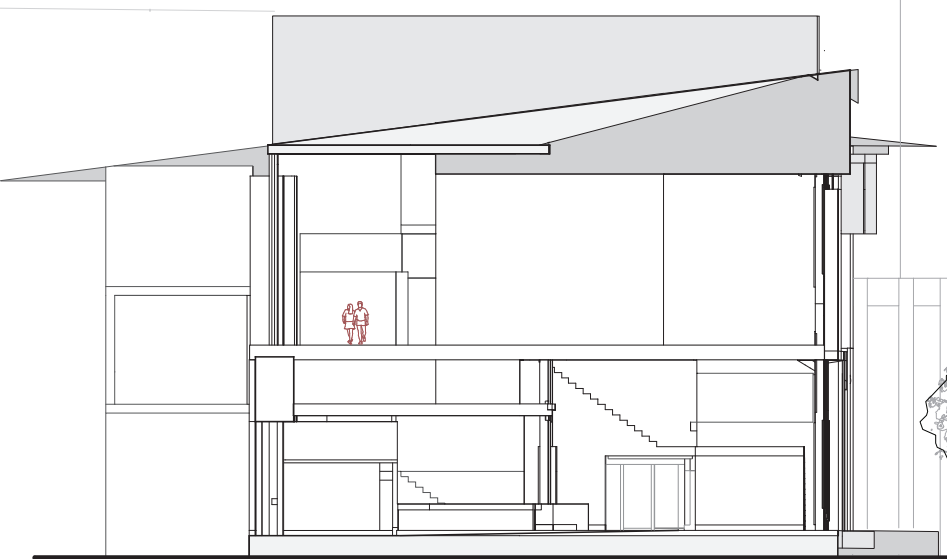

Ast 


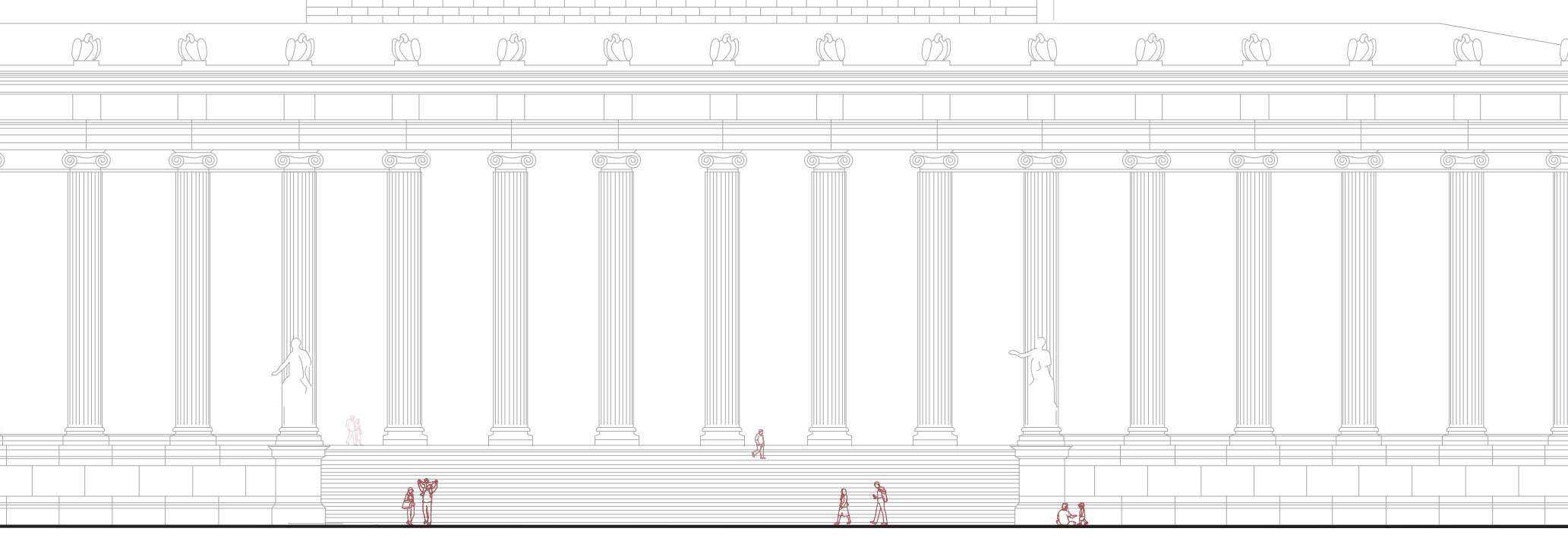

Figure 4.56 North Elevation, with the Altes Museum. 1:200

Figure 4.57 East Elevation, with the Zeughaus across the River Spree. 1:200 


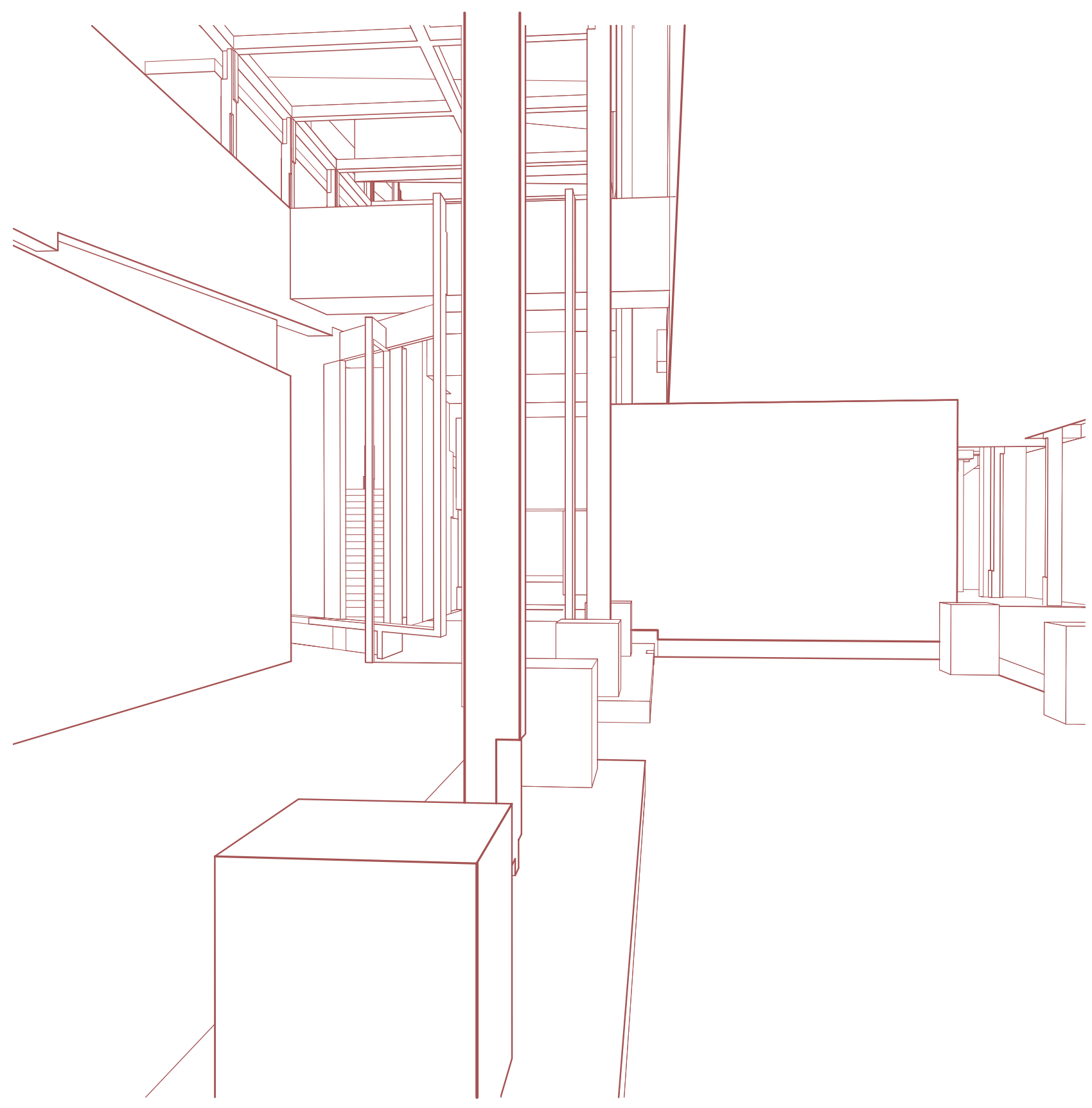

Figure 4.58 Interior Perspective drawing, Main Gallery looking back toward the entrance 


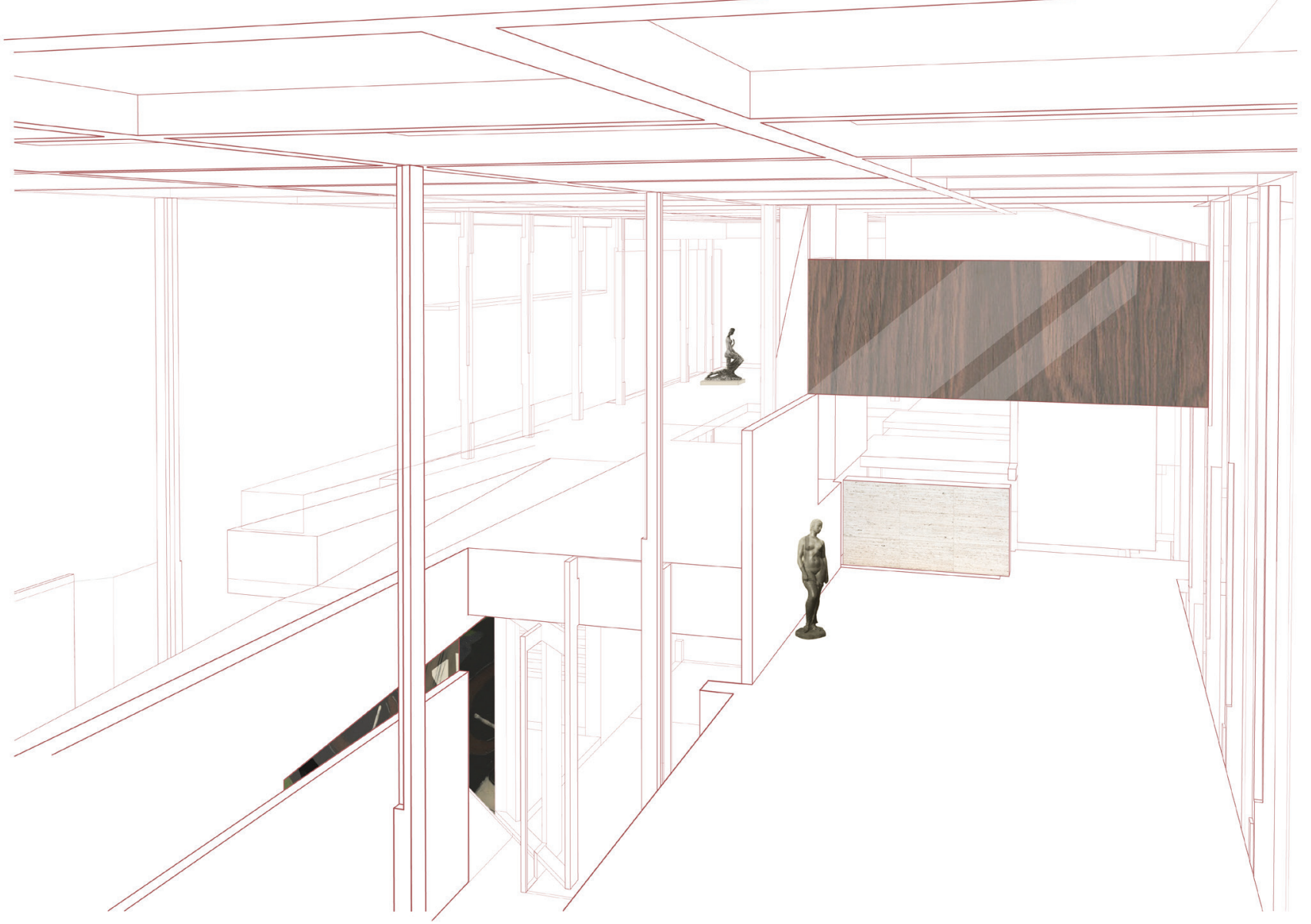

Figure 4.59 Interior Perspective drawing, collaged. Main second floor Gallery space 


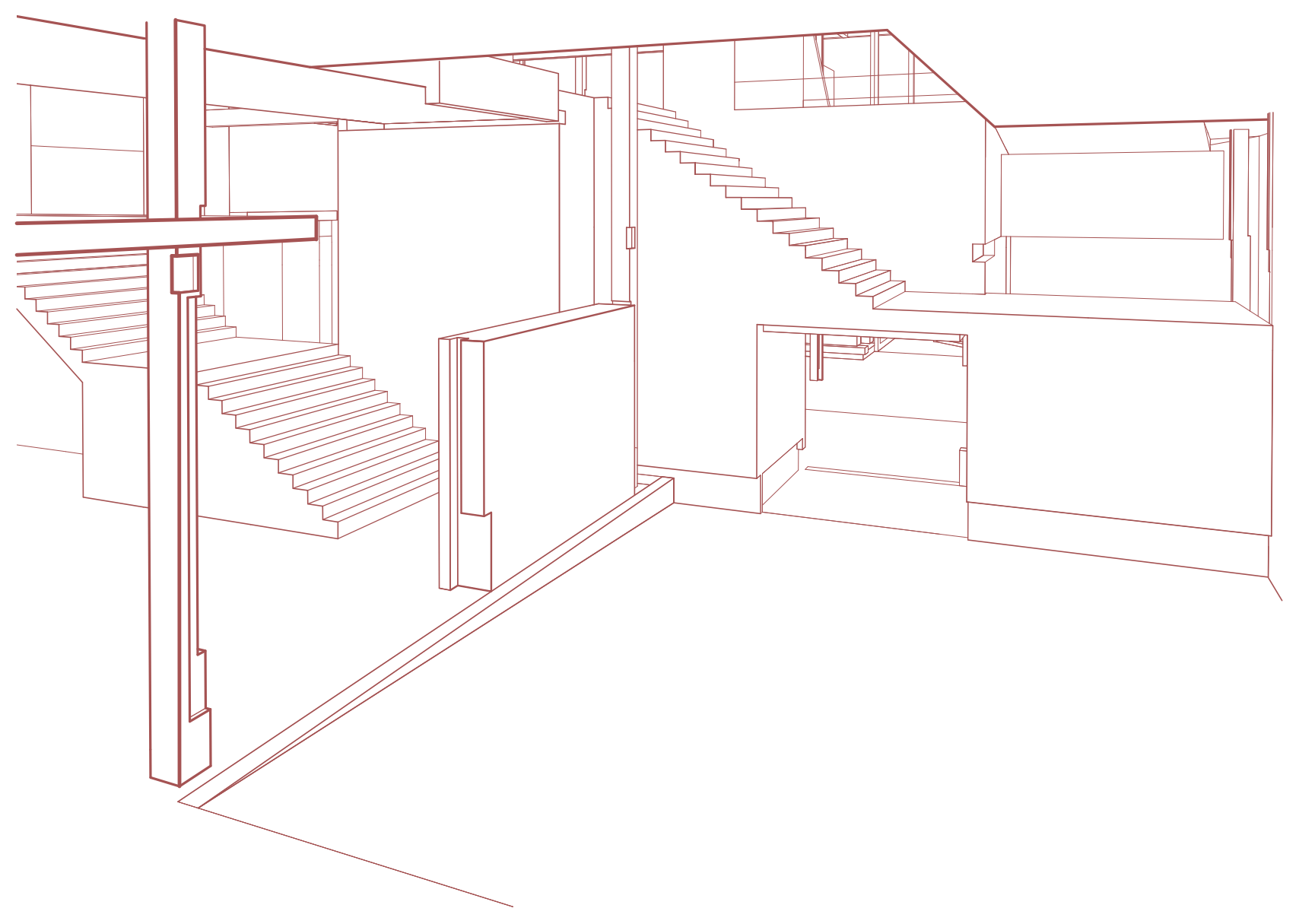

Figure 4.60 Interior Perspective drawing, Entrance Foyer 


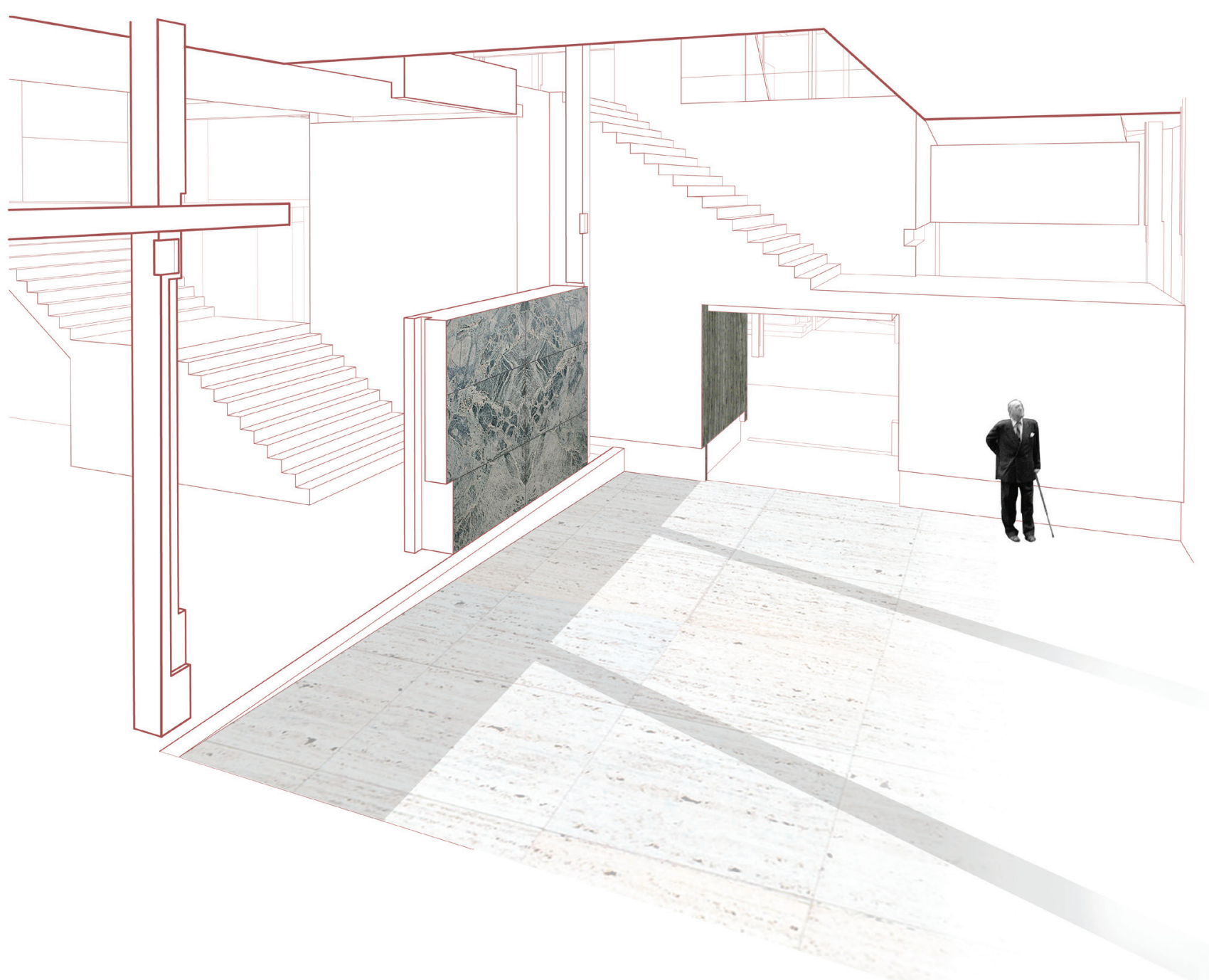

Figure 4.61 Interior Perspective drawing, collaged. Entrance Foyer 


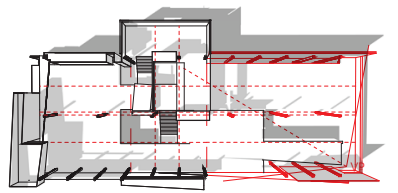

Figure 4.62 Interior Perspective, the Gridded Field established by the structure 


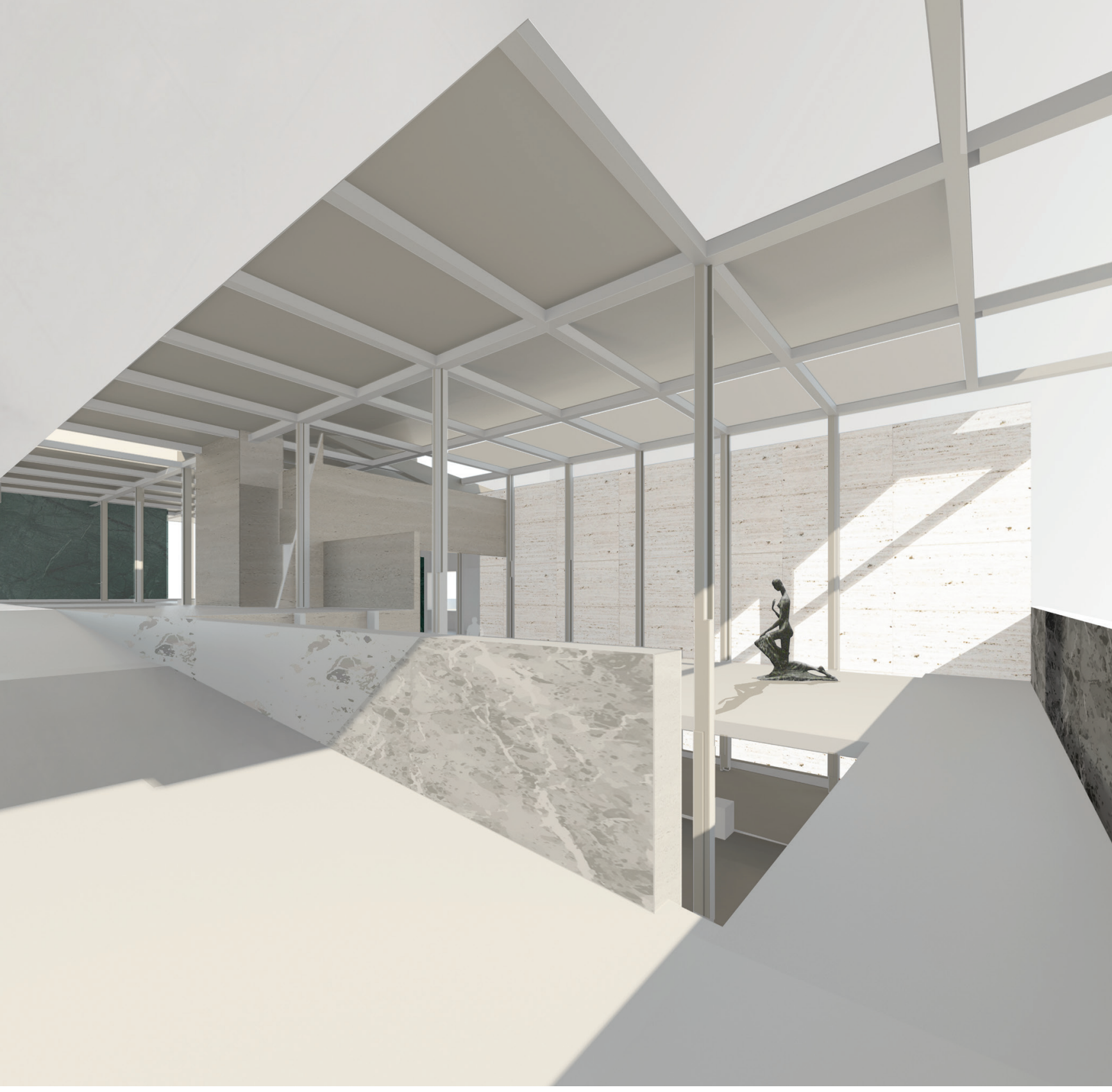




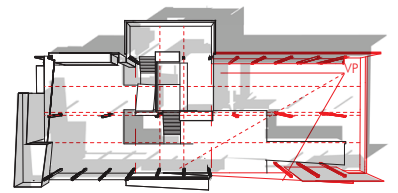

Figure 4.63 Interior Perspective, looking across the Gallery Spaces 


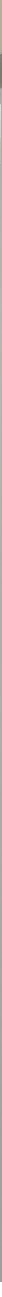




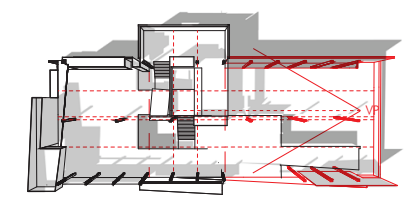

Figure 4.64 Interior Perspective Main Gallery 


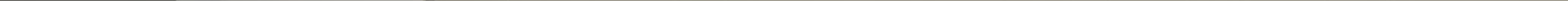




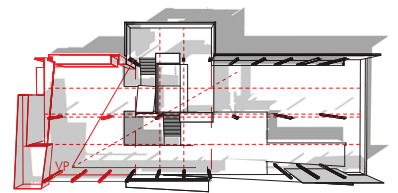

Figure 4.65 Interior Perspective Entrance Foyer 



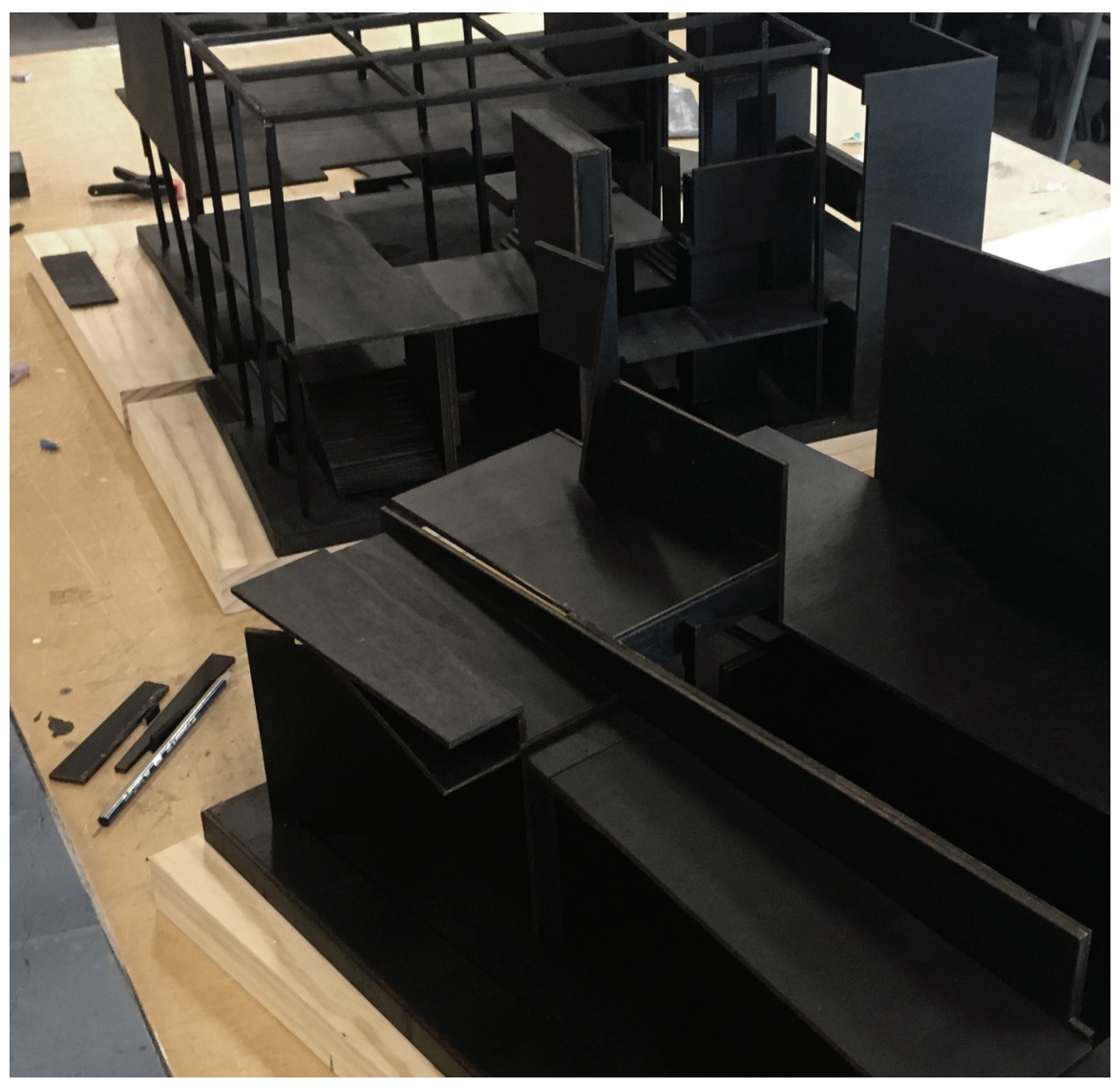

Figure 4.66 Photograph of the construction of the final building outcome, in 1:50 black-stained plywood model 


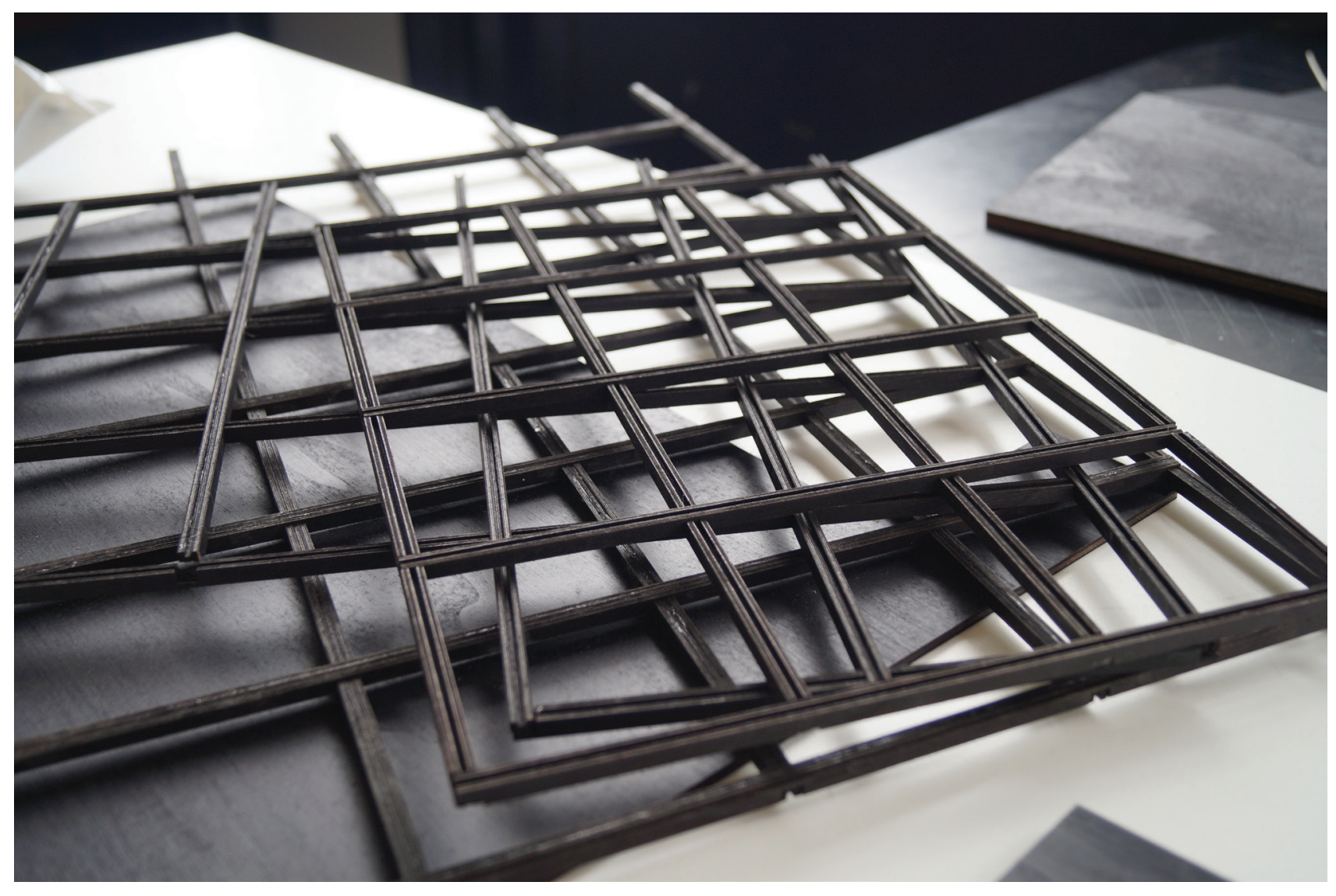

Figure 4.67 Photograph of the gridded structure, 1:50 black-stained plywood model 


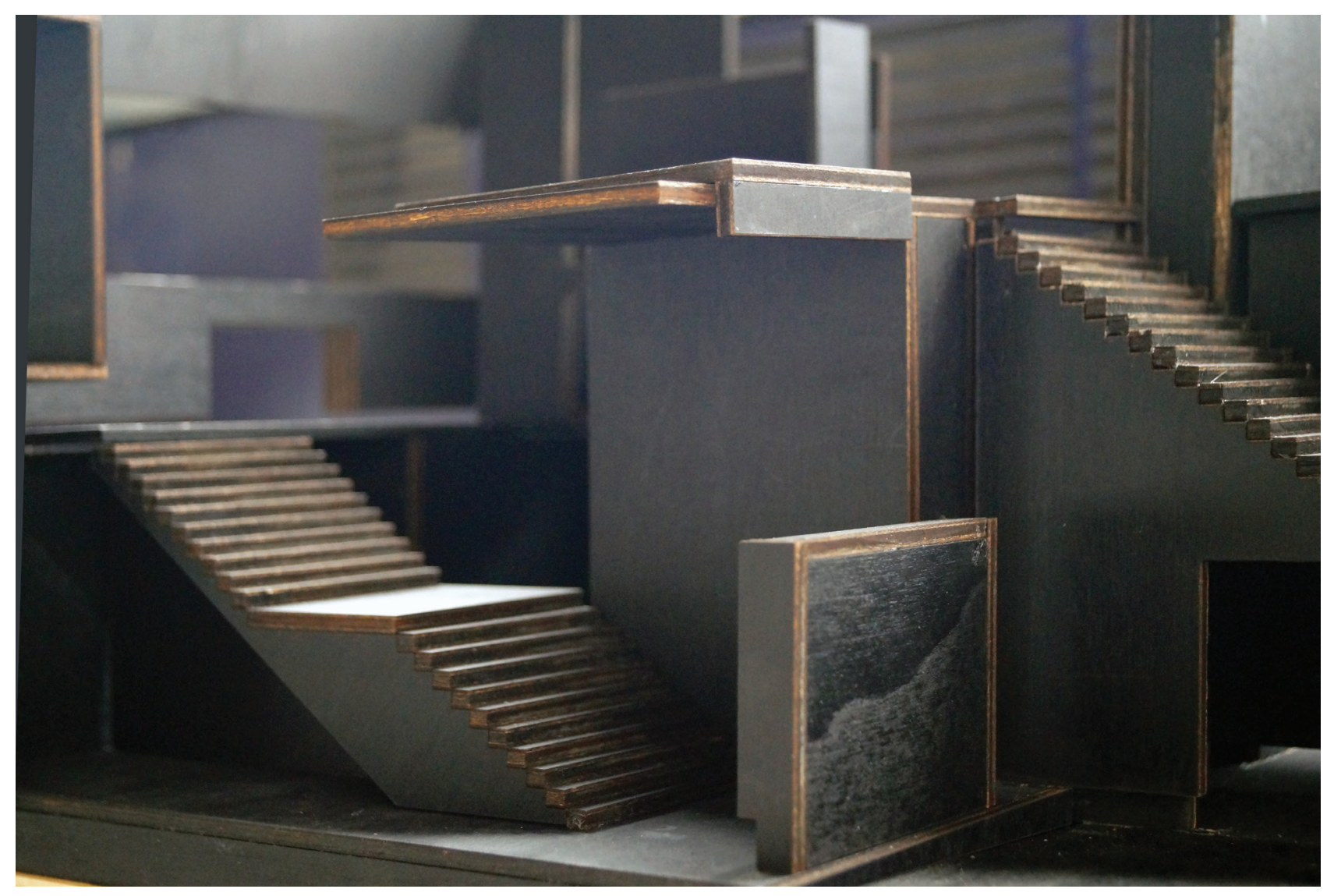

Figure 4.68 Photograph of the central void section, 1:50 black-stained plywood model 


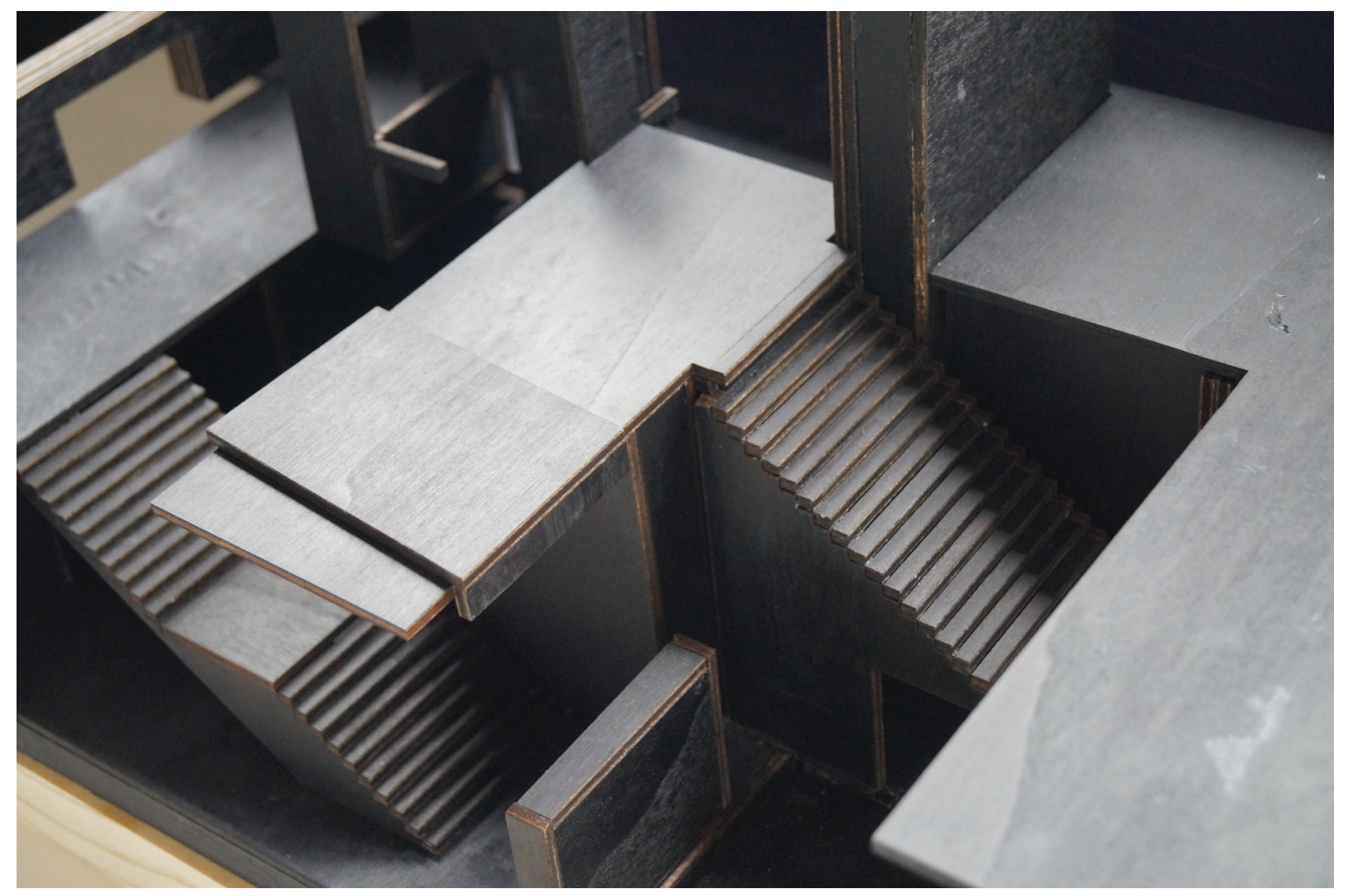

Figure 4.69 Photograph of the central void section, 1:50 black-stained plywood model 


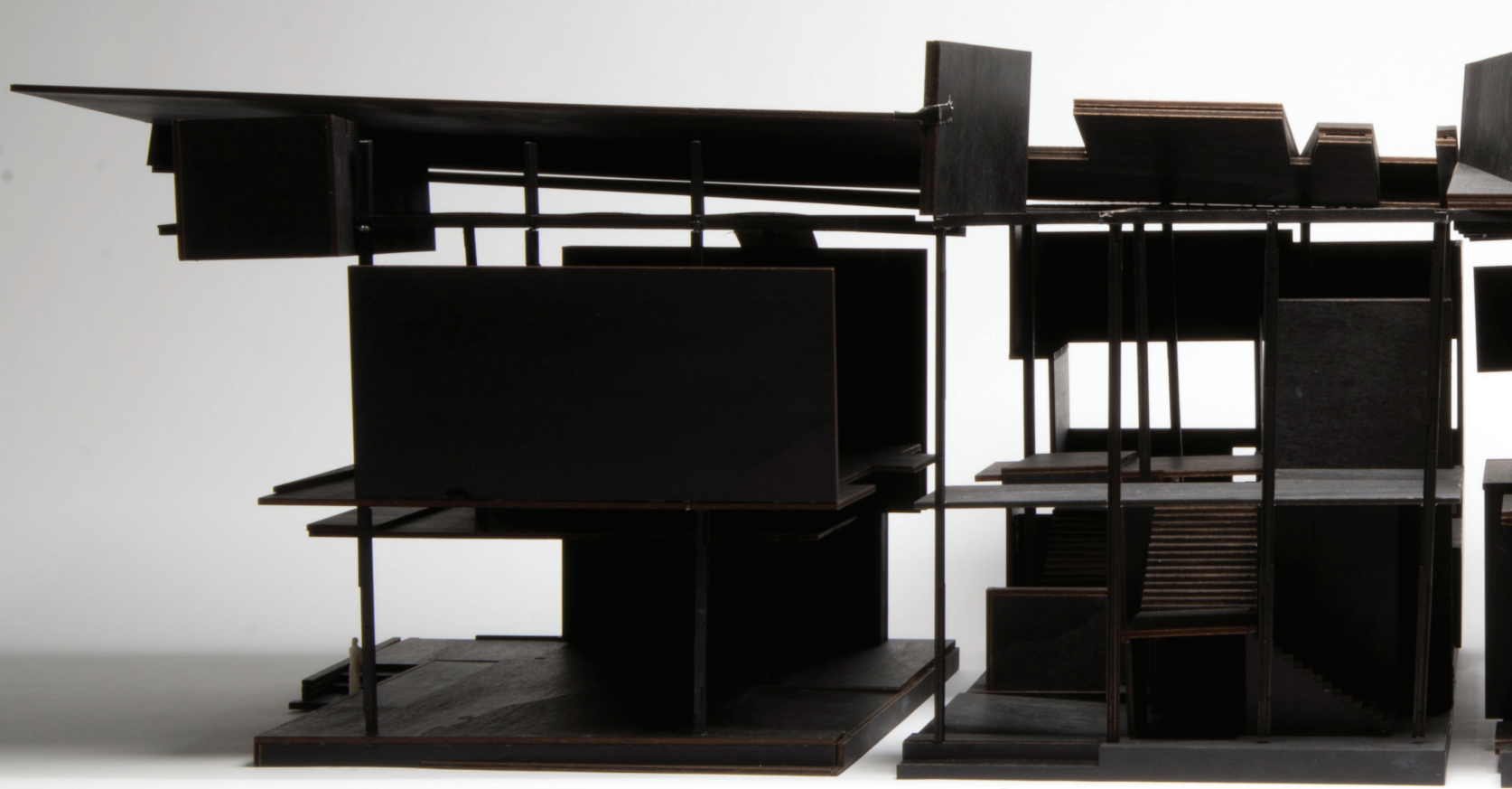




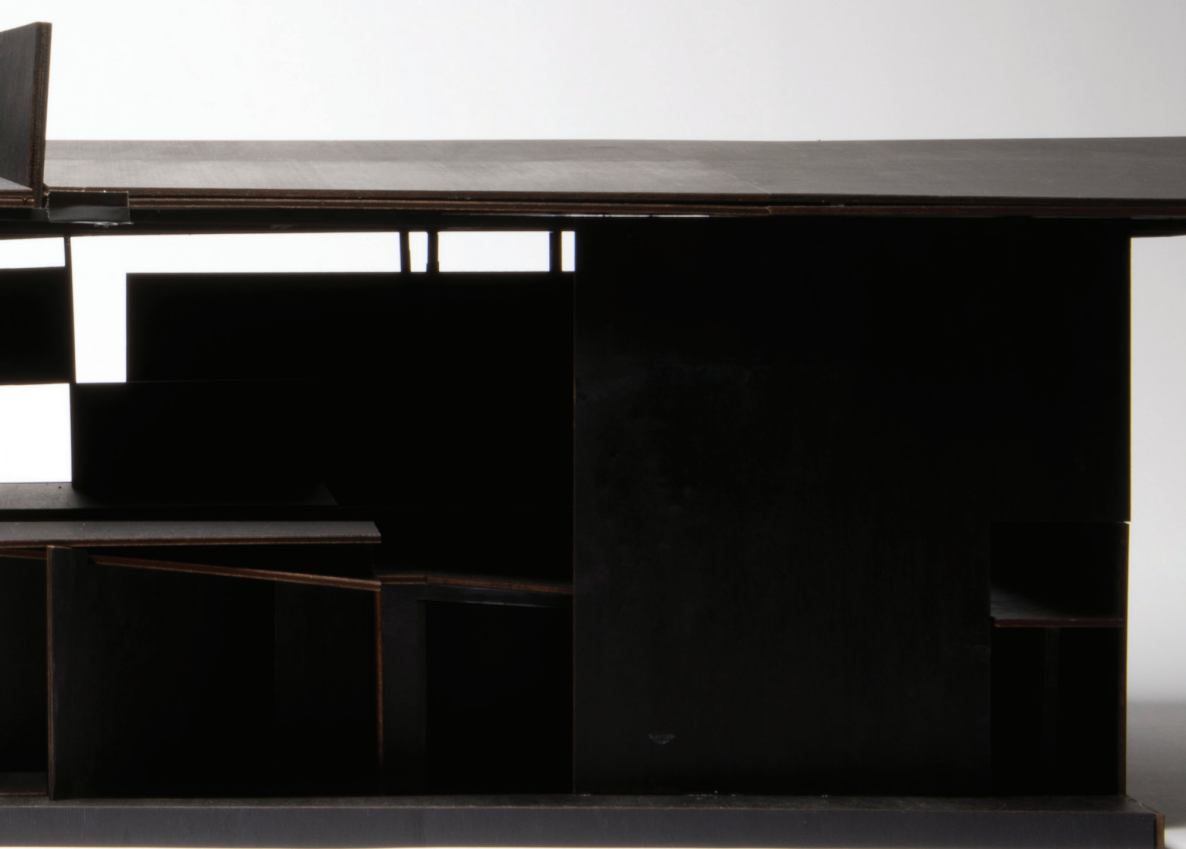

Figure 4.70 Photograph of the whole 1:50 model of the final design outcome, $1200 \mathrm{~mm} \times 600 \mathrm{~mm}$, black-stained plywood 


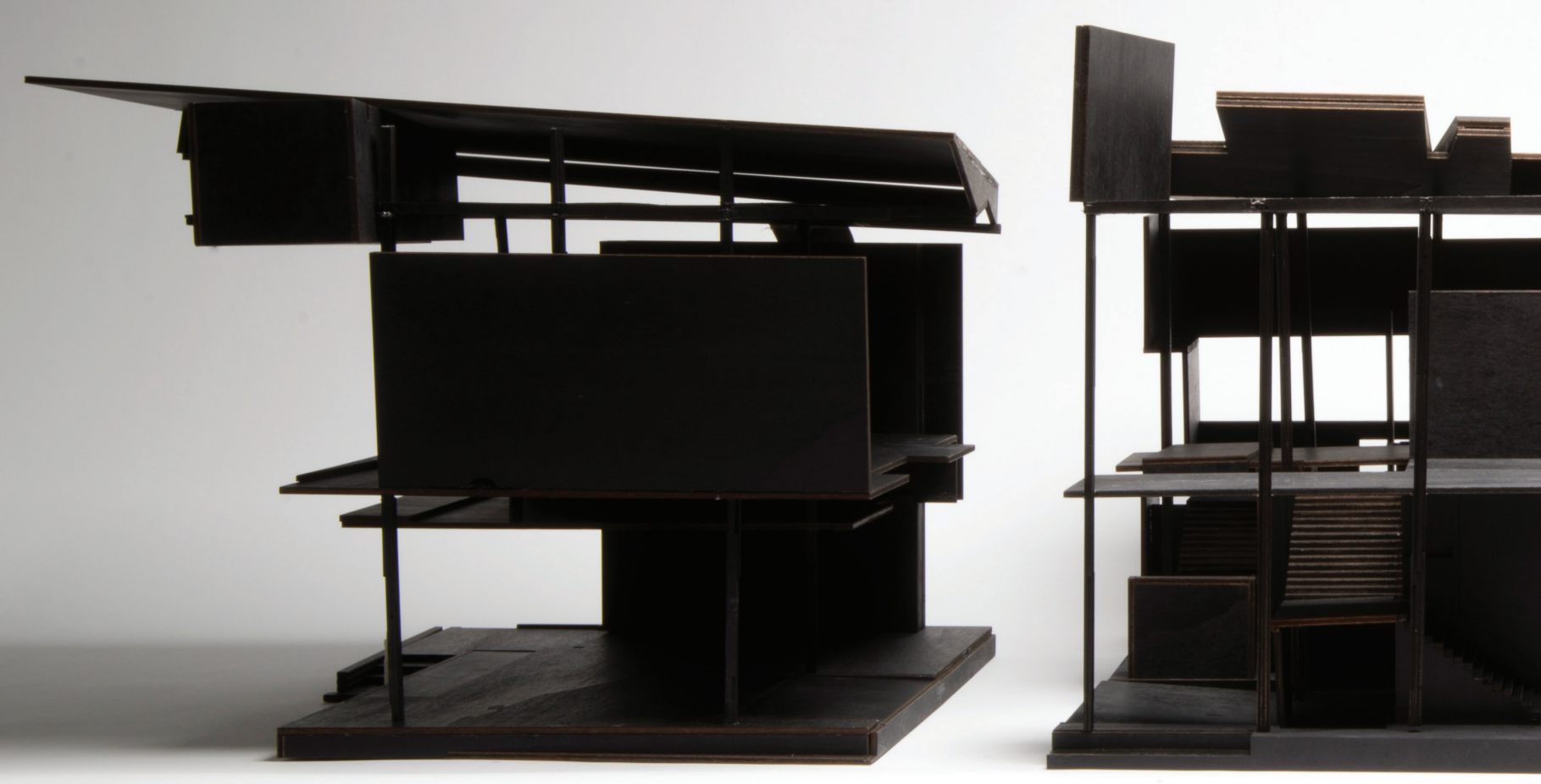




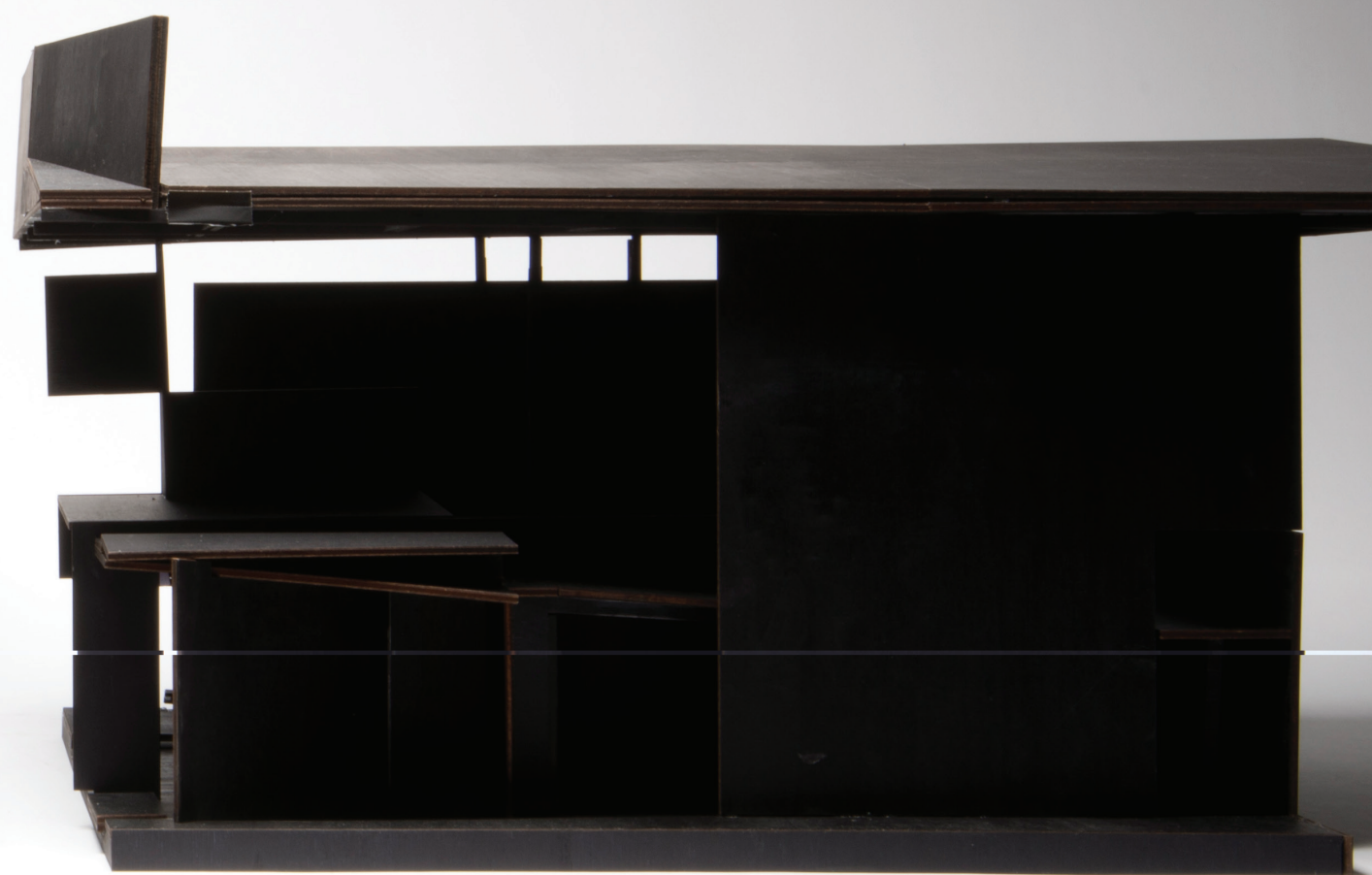

Figure 4.71 Photograph of the transverse section cuts through the 1:50 model of the final design outcome. $1200 \mathrm{~mm} \times 600 \mathrm{~mm}$, black-stained plywood 


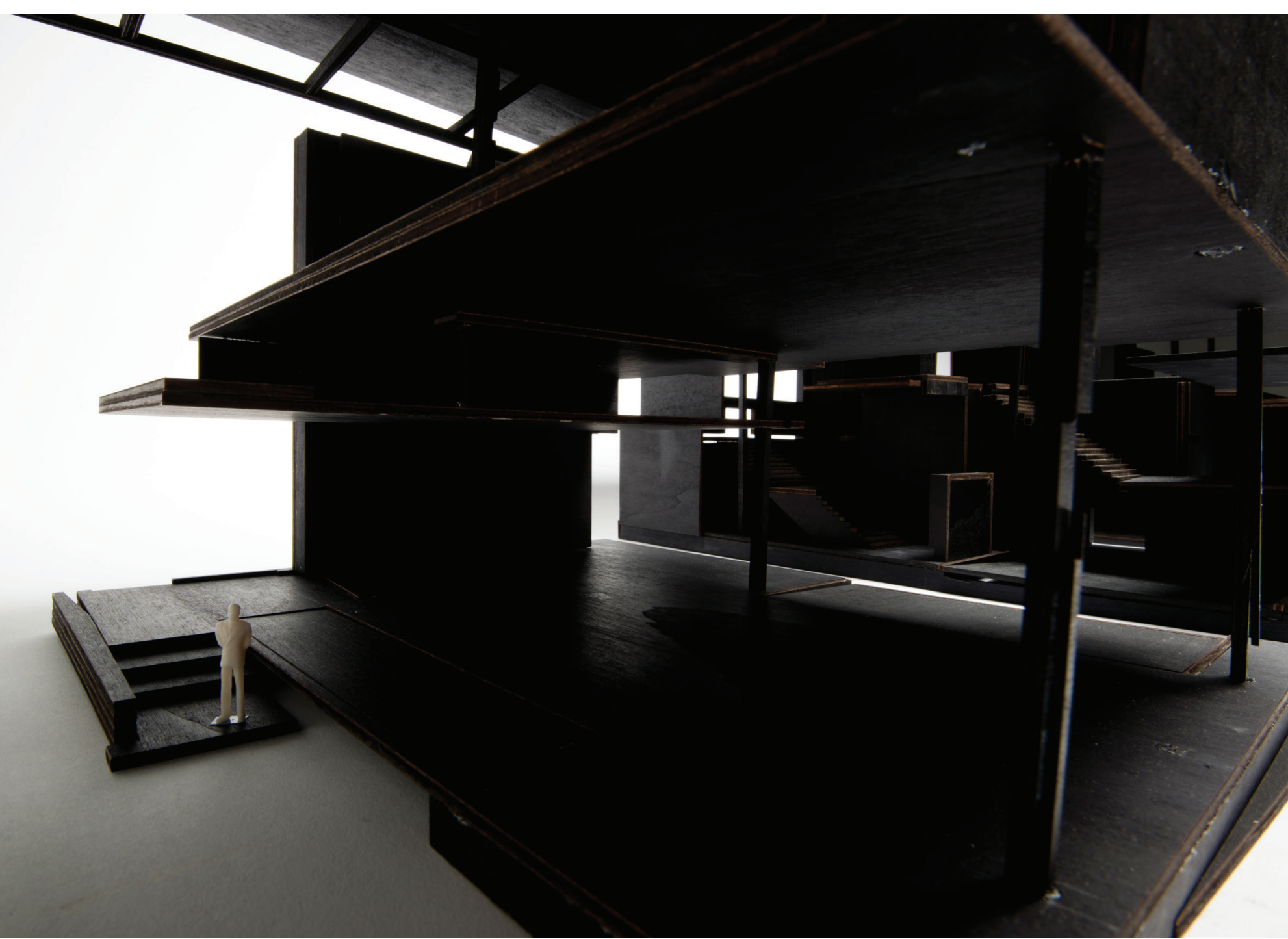

Figure 4.72 Photograph of the entrance of the final building outcome, 1:50 black-stained plywood model 


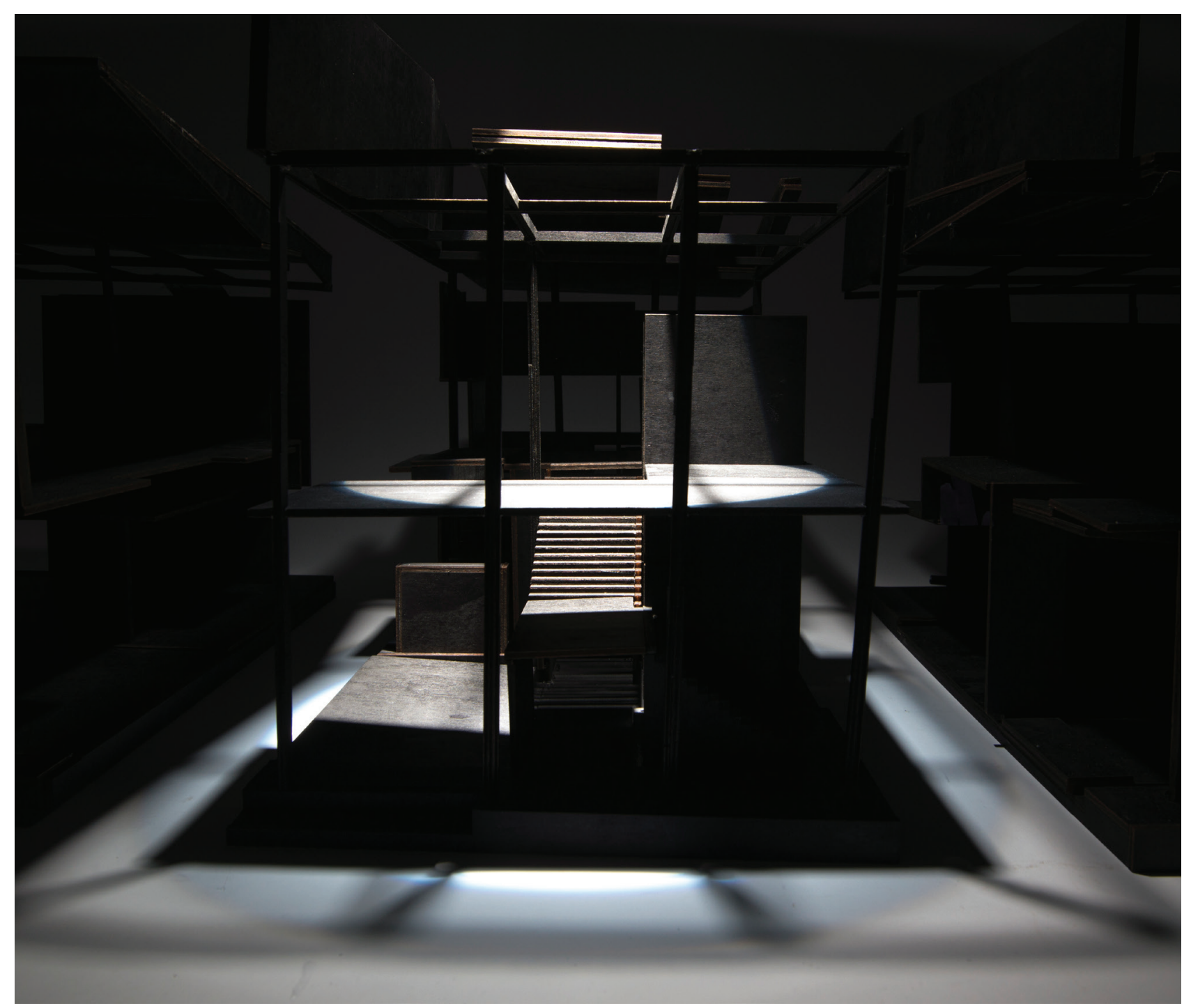

Figure 4.73 Photograph of the central circulation void, 1:50 black-stained plywood model 


\section{DEVELOPED DESIGN CONCLUSION}

This thesis and its narrative use the representational drawings of Mies van der Rohe as a generator of architectural ideas. The applications of these findings, as Mies' thinking of his perspectives as independent of each other, are what have formed the design as derived initially entirely from one projection. The oeuvre of Mies and specifically the design of what is coined his most successful building, the Barcelona Pavilion, as the design study, has been linked back to Karl Friedrich Schinkel's Altes Museum. The site of the Altes Museum on Museum Island in Berlin has historic, social and political relevance. Mies and Schinkel are both German Masters and the site links the narrative's main figures and also provides the perfect site to test design that arrives from the exhaustive methodology. Taken from the case studies of Rapp and Luscombe was the value in translating these drawings between plan and perspective. This is what was fundamental in deriving a whole plan, from one perspective. What the project achieves in regard to the site and programme analysis of the rhetoric, is the interpretation of projections onto an emblematic screen, to make sense of the projections coming through the methodology. The rhetorical screen for projection has established a means to reduce the principles that were attained through the analysis, to a design framework. 
The nature of this design question has arisen from a conscious need to closely consider our representation techniques as fundamental to how we see and produce architecture. In the contemporary architecture discipline, as technology drives our profession forward, this study sought to implement a way of consciously designing through linear perspective to engage with it further. In thinking of linear perspective in a new way, outside of the computer, it was sought to control its parameters and be more critical about it as a representational tool. Responding to this and critical to this study, has been the design of the apparatus, which was the result of a strong understanding of perspective. It led to a greater engagement with perspective. Specifically a greater engagement with the fundamentals that encompass linear perspective through shifting two of these; the viewing point and vanishing points. Furthermore, it addressed their effect on the other components to linear perspective; the picture plane, horizon line and ground plane. That finding was key to addressing the analysis of Mies' drawings and thus informing the apparatus. Advancing further from this could be another prototype of this apparatus that doesn't confine the extent of the projections as much, and which informs the design further, rather than relying on interpretations. And while these interpretations were important to the way in which they meant linear perspective could then be engaged with, they allowed a level of uncertainty in. 


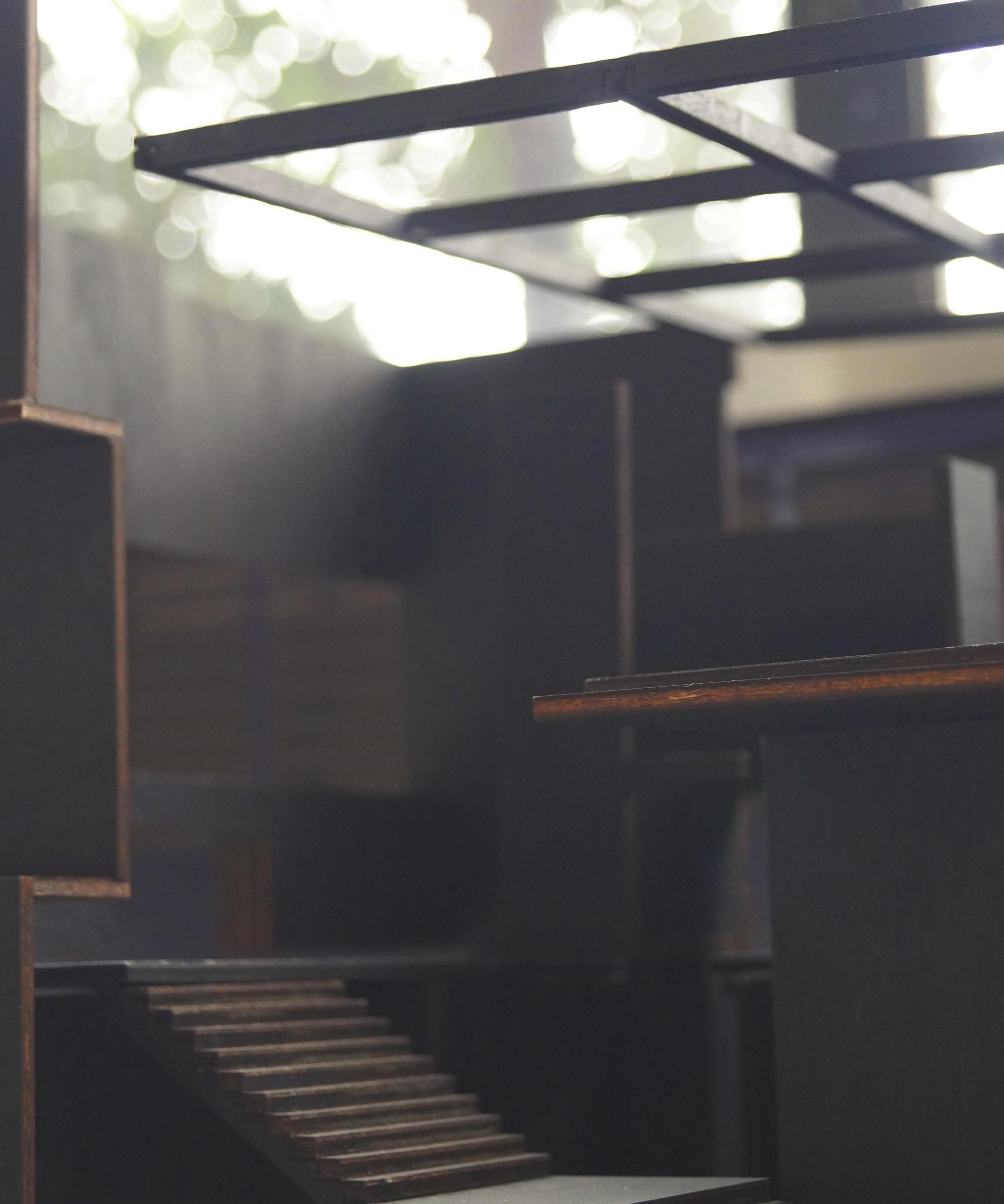




\section{THESIS CONCLUSION}

The previous design chapters discussed the design in regard to the research aims and objectives. I wish to discuss to what extent these addressed the research question; What if the representation of conventional architecture could benefit from a new way of drawing linear perspective? Regarding narrative, Mies and Schinkel have provided a 'screen for projection'. Narrative enabled a basis onto which translation from drawing to building could be discussed through the interpretation of their perspective drawings. Linear perspective's impact in the role of architectural representation has been tested through the use of a custom drawing apparatus. The design qualities that recognised a sensory role through the architecture have been addressed in the previous chapter.

Through challenging what we know about the canon of linear perspective, calls into question the nature of architecture as it has been understood since perspective's foundation during the Renaissance. What lay behind this as driving the study has been outlined in the previous chapter as a reflection of the design of an apparatus, and the outcome of such is a strong methodological approach to apply the research to design. Reflecting on the research, what the apparatus has achieved is a closer regard to what the drawings, as representational 'vessels' for translation, can embody, and the potential for abstraction through the translation process. The inherent intuitive readings of the two-dimensional projections to three-dimensional form release a potential for a translation of perspectives that would otherwise be projected without such responsiveness. The relationships between elements, within the perspectival components of the apparatus, and the formal elements, have been considered in terms of their quantitative control of space. 
This reflection acknowledges the value in embodying a closer consideration of the viewer in the space. In translating this through both plan to perspective, perspective to plan, and to three-dimensional frames, there is a richer value than would otherwise be considered in the translation of projections through unambiguous slick processes.

The study provokes the nature of 'frame', evident in the partial projections. It is architecture's obligation here to set up a formal framework as proof of reconstructing the partial projections into a 'built' form. Understood, through the questioning of the instruments of architectural drawing and designing, is that in designing through the relationship between the spectator and the elements, the very nature of perspective as upholding that exact relationship, is extrapolated.

If we understand these other parts of the question, the answer to the research question is 'yes'. From founding the core of the research on questioning what is at the very core of architectural representation, a more sophisticated understanding of architecture is obtained. 

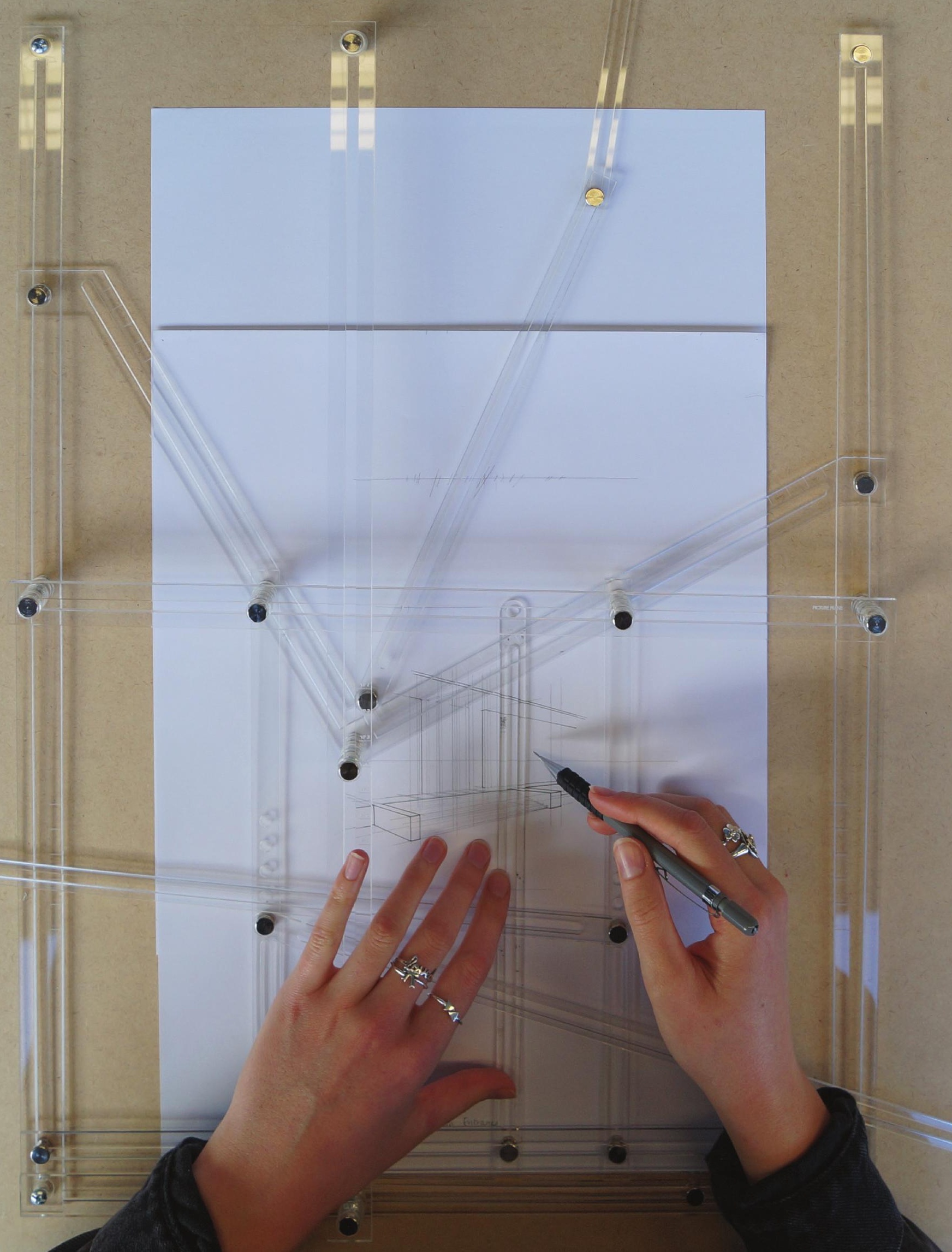



\section{REFERENCES}

Amaldi, Paolo, and Annelle Curulla. "Chairs, Posture, and Points of View: For an Exact Restitution of the Barcelona Pavilion." Future Anterior: Journal of Historic Preservation, History, Theory, and Criticism, vol.2, no.2, 2005, 16-23. Print.

Ansari, Iman, and Peter Eisenman. "Architecture \& Representation: "With Drawings I'm Not Trying to Represent Something. I'm Trying to Make It Real"." Architectural Review, vol.233, no.1395, 2013, 80-89. Web.

Benjamin, Walter. "The Work of Art in the Age of Its Technological Reproducibility (First Version)." Grey Room, no.39, 2010, 10-37. Web.

Bonta, Juan Pablo. "an Anatomy of Architectural Interpretation : A Semiotic Review of the Criticism of Mies Van Der Rohe's Barcelona Pavilion / Juan Pablo Bonta". Barcelona: Gustavo Gili, Barcelona, 1975. Print.

Borden, Gail Peter. "Process : Material and Representation in Architecture / Gail Peter Borden." Ed. Ebooks, Corporation: Abingdon, Oxon New York : Routledge, 2014. Print.

Carter, Peter James. "Mies Van Der Rohe at Work". New York, Praeger, New York, 1974. Print.

Clark, Justine. "The Origin of Drawing: Event, Embodiment and Desire in Architectural Drawing." SAHANZ (2002). Web.

Colquhoun, Alan. "Modern Architecture / Alan Colquhoun". Series Editor ProQuest, Oxford: Oxford University Press, Oxford; New York, 2002. Print.

Damisch, Hubert. "Noah's Ark : Essays on Architecture / Hubert Damisch"

Edited and Introduction by Anthony Vidler, Translated by Julie Rose." Editors Vidler, Anthony, Julie Rose and Ebscohost, The MIT Press, Cambridge, Massachusetts, 2016. Print.

Derrida, Jacques. "Edmund Husserl's Origin of Geometry, an Introduction / Jacques Derrida". Translated, with a Pref., by John P. Leavey, Jr., David B. Allison, Editor. Ed. Husserl, Edmund, Stony Brook, N.Y. : N. Hays, Stony Brook, N.Y, 1978. Print.

---. "Of Grammatology / by Jacques Derrida". Translated by Gayatri Chakravorty Spivak. 1st American ed., Johns Hopkins University Press, Baltimore, 1976. Print.

Dodds, George. "Building Desire on the Barcelona Pavilion". Routledge, New York, 2005. Print. 
Duttlinger, Carolin. "Between Contemplation and Distraction: Configurations of Attention in Walter Benjamin." German Studies Review, vol.30, no.1, 2007, 33-54. Print.

Evans, Robin. "Translations from Drawing to Building and Other Essays". Janet Evans and Architectural Association Publications, London, 2003. Print.

Filler, Martin. "Mies Van Der Rohe: Drawings. (Max Protetch Gallery, New York)." The New York Review of Books, vol.33, 1986, 26E. Print.

Frascari, Marco, Jonathan Hale, and Bradley Starkey. "From Models to Drawings : Imagination and Representation in Architecture / Edited by Marco Frascari, Jonathan Hale, and Bradley Starkey". Routledge, London ; New York, 2007. Print.

Gargiani, Roberto. "Rem Koolhaas/Oma : The Construction of Merveilles / Roberto Gargiani". Translated from the Italian by Stephen Piccolo, EPFL Press, Lausanne, Switzerland, 2008. Print.

Haralambidou, Penelope. "Marcel Duchamp and the Architecture of Desire." PhD Research. Ashgate Publishing Limited, 2013. Print.

Hilberseimer, Ludwig. "Mies Van Der Rohe". Theobald, Chicago, 1956. Print.

Ingraham, Catherine. "Architecture and the Burdens of Linearity". BookCrafters, Chelsea, Michigan USA, 1998. Print.

Jencks, Charles. "An Anatomy of Architectural Interpretations: A Semiotic Review of the Criticism of Mies Van Der Rohe's Barcelona Pavilion Juan Pablo Bonta." Journal of the Society of Architectural Historians, Vol.35, no.3, 1976, 226-27. Print.

Johnson, Philip. "Mies Van Der Rohe / by Philip C. Johnson". Editor Mies van der Rohe, Ludwig, 3rd ed., rev.. ed., London : Secker \& Warburg, 1978. Print.

Jones, Peter Blundell. "Hugo Häring - the Secret of Form." Hugo Häring - the Secret of Form, 04 September 2001, Web, 26 March 2017.

Kipnis, Jeffrey, and Sylvia Lavin. "Talk-Show: A Conversation on "the Piranesi Variations"." Taubman College. Ed. McMorrough, John: Vimeo, 2013.

Latham, Alan. "The Power of Distraction: Distraction, Tactility, and Habit in the Work of Walter Benjamin." Environment and Planning. D. Society and Space, vol. 17, no.4, 1999, 451. Print.

Lawlor, Leonard. "Derrida and Husserl : The Basic Problem of Phenomenology / Leonard Lawlor". Ed. ebrary, Inc., Indiana University Press, Bloomington, 2002. Print.

Leach, Andrew. "Tafuri and the Age of Historical Representation." Architectural Theory Review, vol. 10, no.1, 2005, 1-18. Print. 
Lubow, Arthur. "Architects, in Theory." The New York Times, The New York Times, 15 Feb. 2003, www.nytimes.com/2003/02/16/magazine/architectsin-theory.html.

Luscombe, Desley. "Drawing the Barcelona Pavilion: Mies Van Der Rohe and the Implications of Perspectival Space." The Journal of Architecture, vol.21, no.2, 2016, 210-43. Print.

Mertins, Detlef. "Mies's Event Space." Grey Room, vol.20, 2005, 60-73. Print.

---. "Modernity Unbound: Other Histories of Architectural Modernity / Detlef Mertins". London : Architectural Association, London, 2011. Print.

---. "The Presence of Mies / Detlef Mertins, Editor

George Baird ... [E† Al., Contributors]." Editors. Baird, George and ProQuest, New York: Princeton Architectural Press, New York, 1994. Print.

Mies van der Rohe, Ludwig. "Ludwig Mies Van Der Rohe

Drawings in the Collection of the Museum of Modern Art / Introduction and Notes to the Plates by Ludwig Glaeser". Editors Glaeser, Ludwig and Art Museum of Modern, New York: Museum of Modern Art, New York, 1969. Print.

---. "The Mies Van Der Rohe Archive / Edited by Arthur Drexler with Introductory Notes by Arthur Drexler and Franz Schulze". Editors Drexler, Arthur, Franz Schulze and Archive Mies van der Rohe, New York: Garland Pub., New York, 1986. Print.

Neumeyer, Fritz. "The Artless Word / Mies van der Rohe on the Building Art". MIT Press, Cambridge, Massachusetts, 1991, Web.

Newman, Michael. "Derrida and the Scene of Drawing." Research in Phenomenology, vol.24, no.1, 1994, 218-34. Print.

Panofsky, Erwin. "Perspective as Symbolic Form / Erwin Panofsky". Translated by Christopher S. Wood. 1st ed.. ed. New York : Cambridge, Mass.: New York : Zone Books, Distributed by the MIT Press, 1991. Print.

Papapetros, Spyros. "Smoke Screen." Vol. 236, Emap Limited, London, 2014, 83-89. Print.

Perez-Gomez, Alberto. "Built Upon Love: Towards Beauty and Justice in Architecture.(Essay)." Mosaic (Winnipeg), vol.44, no.3, 2011, 43. Print.

--.. "Questions of Representation: The Poetic Origin of Architecture." Arq, vol.9, no.3-4, 2005, 217-25. Print.

Pérez Gómez, Alberto. "Architectural Representation and the Perspective Hinge / Alberto Perez-Gomez, Louise Pelletier". Editor Pelletier, Louise, Cambridge, Mass. : MIT Press, 1997. Print. 
Pundt, Hermann G. "K. F. Schinkel's Environmental Planning of Central Berlin." The Journal of the Society of Architectural Historians, vol.26, no.2, 1967, 114-30. Print.

Quetglas, Josep. "Fear of Glass : Mies Van Der Rohe's Pavilion in Barcelona / Josep Quetglas". Introduction by Rafael Moneo, Drawings by Ricardo Daza, Marguerita Gonzalez, Toni Sanchez, Basel : Birkhauser, Basel, 2001. Print.

Rapp, Joanna Barbara. "A Geometrical Analysis of Multiple Viewpoint Perspective in the Work of Giovanni Battista Piranesi: An Application of Geometric Restitution of Perspective." The Journal of Architecture, vol.13, no.6, 2008, 701-36. Print.

Robbers, Lutz. "Modern Architecture in the Age of Cinema: Mies Van Der Rohe and the Moving Image." Faculty of Princeton University, 2012. Print.

Rosenfield, Karissa. "Venice Biennale 2012: The Piranesi Variations / Peter Eisenman." 2012. Web, https://www.archdaily.com/268507/venicebiennale-2012-the-piranesi-variations-peter-eisenman

Schulze, Franz. "Mies Van Der Rohe : A Critical Biography / Franz Schulze and Edward Windhorst". Editor Windhorst, Edward, London : The University of Chicago Press, London: Chicago, 2012. Print.

Smithson, Alison. "Without Rhetoric / an Architectural Aesthetic, 1955-1972 / [by] Alison \& Peter Smithson". Editor Smithson, Peter, London Latimer New Dimensions, London, 1973. Print.

Tafuri, Manfredo. "The Sphere and the Labyrinth : Avant-Gardes and Architecture from Piranesi to the 1970s / Manfredo Tafuri". Translated by Pellegrino D'acierno and Robert Connolly, Cambridge, Mass. : MIT Press, 1987. Print.

Tegethoff, Wolf. "Mies Van Der Rohe: The Villas and Country Houses / Wolf Tegethoff". Translated by Russell M. Stockman ; Edited by William Dyckes, Editors Mies van der Rohe, Ludwig and William Dyckes, New York: Museum of Modern Art ; Cambridge, Mass., Distributed by the MIT Press, 1985. Print.

Ulmer, Gregory L. "Applied Grammatology : Post(E)-Pedagogy from Jacques Derrida to Joseph Beuys / Gregory L. Ulmer". Baltimore : Johns Hopkins University Press, 1985. Print.

Vandenberg, Maritz. "New National Gallery, Berlin : Ludwig Mies Van Der Rohe / Maritz Vandenberg". Editor Mies van der Rohe, Ludwig, London : Phaidon Press, 1998. Print. 


\section{SOURCES OF FIGURES}

All figures not attributed are author's own.

Figure 0.01

Figure 0.04

Figure 1.01

Figure 1.02

Figure 1.03

Figure 1.04

Figure 1.05

Figure 1.06

Figure 1.07

Figure 1.12
Luscombe, Desley. "Drawing the Barcelona Pavilion: Mies Van Der Rohe and the Implications of Perspectival Space." The Journal of Architecture, vol.21, no.2, 2016, 210-43. Web. (MOMA, Ludwig Mies van der Rohe Collection, Cat. No., MR14.1).

Quetglas, Josep. "Fear of Glass : Mies Van Der Rohe's Pavilion in Barcelona / Josep Quetglas". Introduction by Rafael Moneo. Drawings by Ricardo Daza, Marguerita Gonzalez, Toni Sanchez, Basel : Birkhauser, 2001. Print.

Dodds, George. "Building Desire on the Barcelona Pavilion". Routledge, New York, 2005. Print.

Quetglas, Josep. "Fear of Glass : Mies Van Der Rohe's Pavilion in Barcelona / Josep Quetglas". Introduction by Rafael Moneo. Drawings by Ricardo Daza, Marguerita Gonzalez, Toni Sanchez, Basel : Birkhauser, 2001. Print.

lbid.

Dodds, George. "Building Desire on the Barcelona Pavilion". Routledge, New York, 2005. Print.

Rohe, Ludwig Mies van der. "Ludwig Mies Van Der Rohe. Row House with Interior Court, project (Interior perspective) after 1938" The Museum of Modern Art, www.moma.org/collection/works/725.

Rohe, Ludwig Mies van der. "Ludwig Mies Van Der Rohe. Resor House project, Jackson Hole, Wyoming (Interior perspective of living room and south glass wall) 1939" The Museum of Modern Art, 1 Dec. 2013, www.moma.org/ collection/works/749.

Rapp, Joanna Barbara. "A Geometrical Analysis of Multiple Viewpoint Perspective in the Work of Giovanni Battista Piranesi: An Application of Geometric Restitution of Perspective." The Journal of Architecture, vol.13, no.6, 2008, 701-36. Web.

Luscombe, Desley. "Drawing the Barcelona Pavilion: Mies Van Der Rohe and the Implications of Perspectival Space." The Journal of Architecture, vol.21, no.2, 2016, 210-43. Web. (MOMA, Ludwig Mies van der Rohe Collection, Cat. No., MR14.1). 
Figure 1.14 Ibid.

Figure 1.15 Ibid.

Figure $1.18 \quad$ Ibid.

Figure 1.19

lbid.

Figure 2.01

Berger, Ursel, Thomas Pavel, and Berlin Georg-Kolbe-Museum. "Barcelona Pavilion : Mies Van Der Rohe \& Kolbe : Architecture \& Sculpture". Barcelona Pavilion, Berlin : Jovis, 2006, Print.

Figure 2.20

Schinkel, Karl Friedrich. "Altes Museum Treppe Schinkel." Wikimedia Commons, 4 Mar. 2008, commons.wikimedia.org/wiki/File:Altes_Museum Treppe_Schinkel.jpg.

Figure 2.21

Rohe, Ludwig Mies van der. "Ludwig Mies Van Der Rohe. House with Three Courts project (Interior perspective) c. 1938" The Museum of Modern Art, www.moma.org/collection/works/716. (C) 2018 Artists Rights Society (ARS), New York / VG Bild-Kunst, Bonn

Figure 2.22

Barba, Jose Juan, and Branly Ernesto Perez. "Tugendhat House by Ludwig Mies Van Der Rohe." METALOCUS, 7 Oct. 2016, www.metalocus.es/en/ news/tugendhat-house-ludwig-mies-van-der-rohe.

Figure 2.23 Rohe, Ludwig Mies van der. "Ludwig Mies Van Der Rohe. Ulrich Lange House Project, Krefeld, Germany, Perspective Sketch. 1935" The Museum of Modern Art, www.moma.org/collection/works/87658. (C) 2018 Artists Rights Society (ARS), New York / VG Bild-Kunst, Bonn

Rohe, Ludwig Mies van der. "Ludwig Mies Van Der Rohe. Gericke House Project, Berlin-Wannsee, Germany, Interior Perspective, 1932" The Museum of Modern Art, www.moma.org/collection/works/736. (c) 2018 Artists Rights Society (ARS), New York / VG Bild-Kunst, Bonn

Figure 2.25 Rohe, Ludwig Mies van der. "Ludwig Mies Van Der Rohe. Ulrich Lange House Project, Krefeld, Germany, Perspective sketch, 1935" The Museum of Modern Art, www.moma.org/collection/works/87660. (c) 2018 Artists Rights Society (ARS), New York / VG Bild-Kunst, Bonn

Figure 2.26 Dodds, George. "Building Desire on the Barcelona Pavilion". Routledge, New York, 2005. Print. 
Figure 2.30

Figure 2.33

Figure 2.34

Figure 2.35

Figure 2.36

Figure 2.37

Figure 2.38

Figure 2.39

Figure 2.40

Figure 2.41

Figure 2.42

Figure 2.43

Figure 3.03

Figure 3.05

Figure 3.06

Figure 3.07
Schinkel, Karl Friedrich. "Stairhall, from King Yngord, Act I." The Morgan Library \& Museum, 11 Oct. 2017, www.themorgan.org/drawings/ item/187431.

Diller, Liz. "The Slow House Drawing Apparatus." Journal of Architectural 72 Education (2016). Print.

Dean, Michael, and Lawrence Lek. "Unit 03 - Metamorphosis." Slow House - Diller Scofidio, 1 Jan. 1970, unit03-metamorphosis.blogspot. co.nz/2012/12/slow-house-diller-scofidio.html.

lbid.

Hess, Peter Alfred. "Slow House Final Film Model." Flickr, 19 July 2008, www. 74 flickr.com/photos/peterhess/2687299096/in/photolist-56oW8z-56t7Dm56oVNv-56oVED-56+7i9-56+7p3.

Diller, Liz, and Ricardo Scofidio. "Slow House." https://dsrny.com/project/ slow-house

OMA. "Casa Palestra." OMA, 1985, oma.eu/projects/casa-palestra.

Ibid.

lbid.

Eisenman Architects. "EISENMAN ARCHITECTS." PIRANESI VARIATIONS, 2012, www.eisenmanarchitects.com/piranesi-variations.html\#images.

lbid.

lbid.

Schinkel, Karl Friedrich. "Altes Museum Treppe Schinkel." Wikimedia 110 Commons, 4 Mar. 2008, commons.wikimedia.org/wiki/File:Altes_Museum_ Treppe_Schinkel.jpg.

"Altes Museum (Berlin)." Wikimedia Commons, 19 Sept. 2017, commons. 112,113 wikimedia.org/wiki/Category:Altes_Museum_(Berlin).

Thiele, Friedrich Alexander. "Berlin Altes Museum Friedrich Thiele 1830." Wikimedia Commons, 13 Jan. 2006, commons.wikimedia.org/wiki/ File:Berlin_Altes_Museum_Friedrich_Thiele_1830.jpg.

Pundt, Hermann G. "K. F. Schinkel's Environmental Planning of Central 117 Berlin." The Journal of the Society of Architectural Historians, vol.26, no.2, 1967, 1 14-30. Print. 
Figure 4.03

Figure 4.41
Evans, Robin. "Translations from Drawing to Building and Other Essays".

127 Janet Evans and Architectural Association Publications, London, 2003. Print.

Dodds, George. "Building Desire on the Barcelona Pavilion". Routledge, New York, 2005. Print. 
